\title{
The Determination Of The Concrete Tensile Creep At Early Age Using The Ring Test
}

\author{
Tadamon Mohammed \\ tm0008@mix.wvu.edu
}

Follow this and additional works at: https://researchrepository.wvu.edu/etd

Part of the Civil Engineering Commons, and the Structural Engineering Commons

\section{Recommended Citation}

Mohammed, Tadamon, "The Determination Of The Concrete Tensile Creep At Early Age Using The Ring Test" (2018). Graduate Theses, Dissertations, and Problem Reports. 3736.

https://researchrepository.wvu.edu/etd/3736

This Thesis is protected by copyright and/or related rights. It has been brought to you by the The Research Repository @ WVU with permission from the rights-holder(s). You are free to use this Thesis in any way that is permitted by the copyright and related rights legislation that applies to your use. For other uses you must obtain permission from the rights-holder(s) directly, unless additional rights are indicated by a Creative Commons license in the record and/ or on the work itself. This Thesis has been accepted for inclusion in WVU Graduate Theses, Dissertations, and Problem Reports collection by an authorized administrator of The Research Repository @ WVU. For more information, please contact researchrepository@mail.wvu.edu. 


\title{
THE DETERMINATION OF THE CONCRETE TENSILE CREEP AT EARLY AGE USING THE RING TEST
}

TADAMON MOHAMMED

THESIS SUBMITTED TO THE

Benjamin M. Statler College of Engineering and Mineral Resources

at West Virginia University

\author{
IN PARTIAL FULFILLMENT OF THE REQUIREMENTS \\ FOR THE DEGREE OF \\ MASTER OF SCIENCE \\ IN \\ CIVIL ENGINEERING
}

Roger H. L. Chen, Ph.D, Chair

Yoojung Yoon, Ph.D

Fei Dai, Ph.D

Hailin Li, Ph.D

Department of Civil and Environmental Engineering

Morgantown, West Virginia

2018

Keywords: tensile creep, early age, shrinkage, degree of hydration, relative humidity, moisture loss.

Copyright 2018 Tadamon Mohammed 


\section{Abstract}

\section{THE DETERMINATION OF THE CONCRETE TENSILE CREEP AT EARLY AGE USING THE RING TEST}

Tadamon Mohammed

In this study, the modified double power law (MDPL) model is used to determine the tensile creep of concrete at an early age based on the ASTM C1581 restrained shrinkage ring test. Three concrete mixes using Ordinary Portland Cement (OPC) were tested. The three concrete mixes were cast, and each underwent the ring tests up to cracking. Mechanical properties of concrete at the age of $1,3,7,14$, and 28 days were tested to find the compressive strength, tensile strength and Young's Modulus of concrete. The strength tests results were obtained from both $4 \times 8$ inch and $6 \times 12$ inch cylinders. The moisture distribution of the concrete inside the ring was simulated and solved theoretically by solving Fick's law of diffusion equation. On the other hand, humidity sensors (SHT-21) were used at different depths to verify the theoretical solution. The interfacial compressive stress generated on the steel ring, caused by autogenous and drying shrinkages of concrete, is calculated using the experimentally measured steel strains during the restrained shrinkage ring testing. Meanwhile, the theoretical value of the interfacial compressive stress is calculated by a model with a known value of autogenous shrinkage and drying shrinkage of concrete. The tensile creep of the concrete at early age was then determined by comparing the theoretical interfacial compressive stress with the interfacial compressive stresses obtained from the strain gage measurements.

Finite Element Model (FEM) simulation was performed using ABAQUS to analyze the shrinkage and creep behavior in the concrete under the Restrained Shrinkage Ring Test. The calculated humidity was used as an input in the FEM to calculate the shrinkage in concrete for a 5-layer concrete ring model through a user-defined subroutine. Concrete tensile creep was also calculated from the subroutine using the shrinkage induced stress. The predicted creep behavior was verified by comparing the steel strain obtained from the experiment with what was solved using FEM. Furthermore, a stress analysis was performed to predict the critical time when the concrete is at risk of cracking in the concrete ring. Using this method, creep relaxation parameters were obtained for the concrete mix under different environmental temperatures and humidity, thus, can be used under any other ambient environment. The determined tensile creep, as a result, can be used in shrinkage-induced stress analyses, and further, be used for cracking control of concrete structures at early age. 


\section{Acknowledgment}

Now that I have reached the end of my university life, I would like to extend my thanks and gratitude to all those who contributed in guiding me as well as preparing me to be a good builder for this world. To all those who helped me in this humble work, thank you.

I would like to express the deepest appreciation to my advisor Dr. Roger Chen, who continually supported me through every step of this journey; without his guidance, encouragement, advice and persistent help, this thesis would not have been possible.

I would also like to thank my Thesis Committee, Dr. Yoojung Yoon, Dr. Fei Dai, and Dr. Hailin Li. for their time and effort.

To the joyous and idealistic spirit of my life for whom I can only bow with respect and reverence, my Family.

To whom I spent the most beautiful days of my lives, my Friends.

I would like to acknowledge WVDOT, whose funding provided the materials and equipment necessary to conduct this research. I would like to thank the entire research team, for assistance with all concrete castings necessary to complete this research study.

Especially, Guadalupe Leon, Seyed Navid Mardmomen. 


\section{Table of Contents}

Acknowledgment __ iii

List of Figures __ vi vi v v vili

List of Tables __ viii

Chapter 1 Introduction 1

Chapter 2 Literature Review ___ 4

Moisture Distribution at Early-Age_______ 4

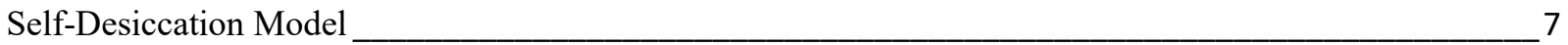

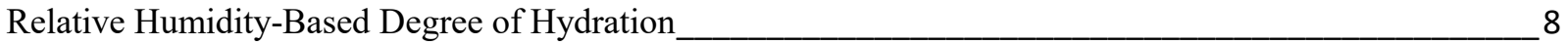

Elastic Modulus-Based Degree of Hydration ___

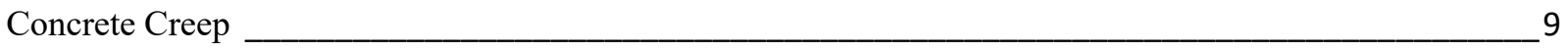

Double Power Law for Basic Creep of Concrete ___ 11

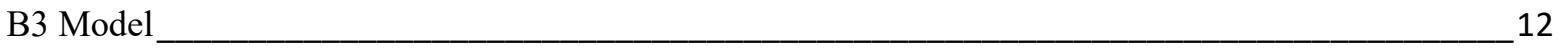

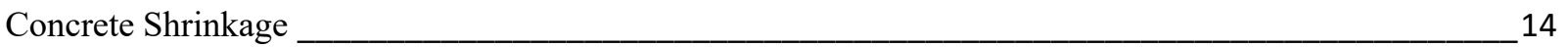

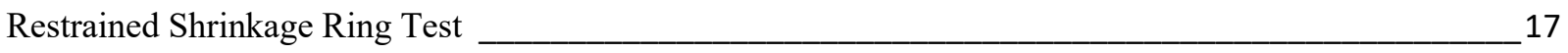

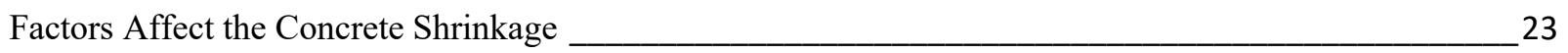

Air Content ___ 25

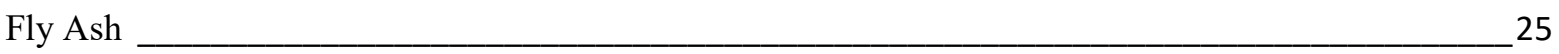

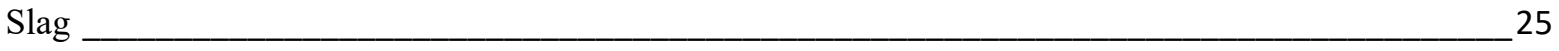

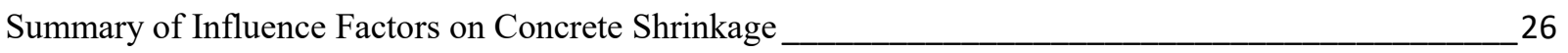

Chapter 3 Laboratory Experimental Procedures \& Results___ 27

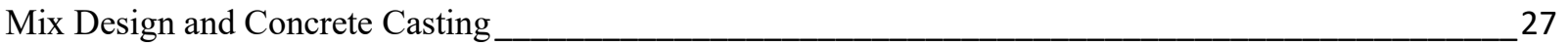

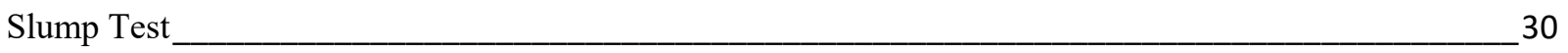

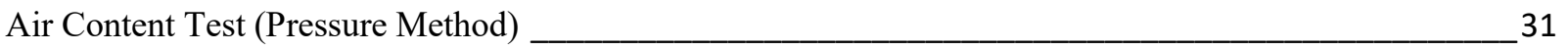

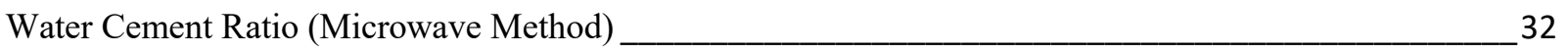

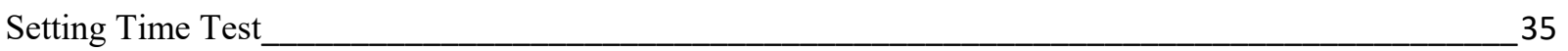

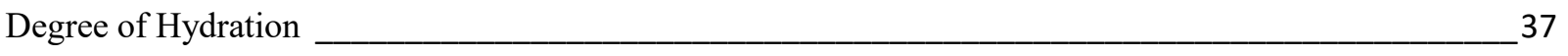

Elastic Modulus Testing _________________________________ 39

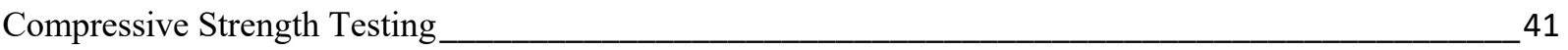

Tensile Strength Test______ 44

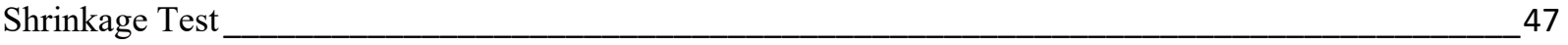

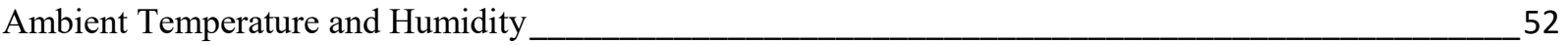


Internal Humidity-Temperature Sensor and Measurement System

Restrained Shrinkage Ring Test

Direct Tensile Test (Dog-Bone)

Chapter 4 Analysis and Interpretation of Results

Humidity Analysis

Simulating Half-Wrapped Specimens 72

Simulating No-Wrapped Specimens 73

Moisture Transport Model 74

Moisture Distribution 79

Shrinkage Modeling 83

Shrinkage Distributions 85

Shrinkage Model Vs Shrinkage Experiments 93

Tensile Creep Analysis 96

Interfacial Compressive Stress Analysis 96

Strength Analysis 103

Effect of size of test specimen on the compressive and tensile strength of concrete. 103

Air Content Effects 105

Finite Element Model 108

Modified Double Power Law 110

B3 Model 115 Summary of Procedures 123

Chapter 5 Conclusions and Recommendations 125

Recommendations for Future Study 128

References 129 


\section{List of Figures}

Figure 1 Schematic description of stress relaxation due to creep in concrete slab (Weiss, 2006) 3

Figure 2 Two stages of humidity development inside of concrete (Jun Zhang; Kun Qi; and Yu Huang, 2009) _ 5

Figure 3 Decomposing of the concrete-steel composite ring (Yuan Gao, Jun Zhang, Po Han 2013) __ 17

Figure 4 Procedures of creep correction on the effective shrinkage strain. (Yuan Gao, Jun Zhang, Po Han 2013 ) 20

Figure 5 Influence of water/cement ratio and aggregate content on shrinkage (J. J. Brooks 1989) 24

Figure 6 The pattern of shrinkage as a function of cement content, water content, and water/cement ratio; concrete moist-cured for 28 days, thereafter dried for 450 days. (J. J. Brooks 1989) __ 24

Figure 7 Standard Slump Cone Mold (ASTM C143, 2010). ___ 30

Figure 8 Type B Air Content Apparatus (ASTM C231, 2003). 31

Figure 9 Water Cement ratio (Microwave method) ___ 33

Figure 10 Setting Time Test___ 35

Figure 11 Setting Time Test results ___ 36

Figure 12 Relationship of cement hydration degree and age.__ 38

Figure 13 Elastic modulus-based degree of hydration model VS actual experiment results OPC 2

Figure 14 Elastic modulus-based degree of hydration model VS actual experiment results OPC $3 \_40$

Figure 15 Compressive Strength development curves for concrete cylinders OPC 1

Figure 16 Compressive Strength development curves for concrete cylinders OPC 2

Figure 17 Compressive Strength development curves for concrete cylinders OPC 3

Figure 18 Tensile Strength development curves for concrete cylinders OPC 2

Figure 19 Tensile Strength development curves for concrete cylinders OPC 3

Figure 20 comparator to measure the length change ___ 47

Figure 21 Shrinkage specimens (2) No-Wrap (3) Half-Wrapped ___ 48

Figure 22 Average Shrinkage (micro-strain) Experiments OPC 1

Figure 23 Average Shrinkage (micro-strain) Experiments OPC 2

Figure 24 Average Shrinkage (micro-strain) Experiments OPC 3

Figure 25 Average No-Wrap Shrinkage (micro-strain) Experiments ___ 51

Figure 26 Average Half-Wrap Shrinkage (micro-strain) Experiments___ 51

Figure 27 Ambient temperature and humidity for OPC 1

Figure 28 Ambient temperature and humidity for OPC 2

Figure 29 Ambient temperature and humidity for OPC 3

Figure 30 The difference between the partial and the saturation pressure __ 55

Figure 31 The integration of the difference between the partial and the saturation pressure __ 56

Figure 32 Overview of RH-Temp measurement system. David A Lange (2004) __ 57

Figure 33 Data collector box.___ 58

Figure 34 Proposed design End-tube covered with the Gore-Tex fabric __ 59

Figure 35 Waterproof - Gore-Tex fabric ___ 59

Figure 36 Designed box to measure the humidity at different depth__ 60

Figure 37 Humidity measurements at a different depth from the uncovered box OPC 1_ 60

Figure 38 Humidity measurements at a different depth from the sealed box OPC 1

Figure 39 Geometry of the ring specimen. (Yuan Gao, Jun Zhang, Po Han 2013) __ 63

Figure 40 Ring specimens____ 66

Figure 41 Steel Strain from the ring experiment OPC 1

Figure 42 Average Steel Strain OPC 1 _ 67

Figure 43 Steel Strain from the ring experiment OPC 2 
Figure 44 Average Steel Strain OPC 2

Figure 45 Steel Strain from the ring experiment OPC 3

Figure 46 Average Steel Strain OPC $3 \_69$

Figure 47 Cracked Ring (OPC 2)_ 70

Figure 48 Schematic of the dog bone specimen__ 71

Figure 49 Simulating the half-wrapped shrinkage_ 72

Figure 50 Simulating the drying shrinkage __ 73

Figure 51 Comparison between the coded model result and other researches results__ 77

Figure 52 The development of interior humidity with time in (a) C30 and (b) C80 concrete 78

Figure 53 The development of interior humidity with time in (a) C30 and (b) C80 concrete using the theoretical solution of the moisture development inside the concrete __ 78

Figure 54 Moisture at the inner and the outer surface no-wrap $\left(O P C 1,73^{\circ} \mathrm{F}\right) \_79$

Figure 55 Moisture at the inner and the outer surface half-wrapped $\left(O P C 1,73^{\circ} \mathrm{F}\right) \_80$

Figure 56 Moisture distribution at different age half-wrapped along the depth of the ring $\left(O P C 1,73^{\circ} \mathrm{F}\right) \_80$

Figure 57 the moisture content without and with considering the partial and the saturation pressure for (OPC 2) 82

Figure 58 The linear relationship between the shrinkage and $\mathrm{RH} \% \mathrm{OPC} 1 \_83$

Figure 59 The linear relationship between the shrinkage and $\mathrm{RH} \% \mathrm{OPC} 2 \_84$

Figure 60 The linear relationship between the shrinkage and $\mathrm{RH} \% \mathrm{OPC} 3 \_84$

Figure 61 Shrinkage (micro-strain) at the inner and the outer surface No Wrap OPC $1 \_86$

Figure 62 Shrinkage (micro-strain) distribution at different age No Wrap OPC $1 \_86$

Figure 63 Shrinkage (micro-strain) at the inner and the outer surface half-Wrap OPC $1 \_87$

Figure 64 Shrinkage (micro-strain) distribution at different age half-Wrap OPC $1 \_87$

Figure 65 Shrinkage (micro-strain) at the inner and the outer surface No Wrap OPC 2

Figure 66 Shrinkage (micro-strain) distribution at different age No Wrap OPC $2 \_88$

Figure 67 Shrinkage (micro-strain) at the inner and the outer surface half-Wrap OPC $2 \_89$

Figure 68 Shrinkage (micro-strain) distribution at different age half-Wrap OPC $2 \_89$

Figure 69 Shrinkage (micro-strain) at the inner and the outer surface No Wrap OPC $3 \_90$

Figure 70 Shrinkage (micro-strain) distribution at different age No Wrap OPC $3 \_90$

Figure 71 Shrinkage (micro-strain) at the inner and the outer surface half-Wrap OPC $3 \_91$

Figure 72 Shrinkage (micro-strain) distribution at different age half-Wrap OPC $3 \_91$

Figure 73 Shrinkage (micro-strain) Model prediction vs Shrinkage experiment OPC $1 \_93$

Figure 74 Shrinkage (micro-strain) Model prediction vs Shrinkage experiment OPC $1 \_93$

Figure 75 Shrinkage (micro-strain) Model prediction vs Shrinkage experiment OPC $2 \_94$

Figure 76 Shrinkage (micro-strain) Model prediction vs Shrinkage experiment OPC 2_ 94

Figure 77 Shrinkage (micro-strain) Model prediction vs Shrinkage experiment OPC $3 \_95$

Figure 78 Shrinkage (micro-strain) Model prediction vs Shrinkage experiment OPC $3 \_95$

Figure 79 Development of interfacial compressive stress vs. time with and without creep OPC 1__ 97

Figure 80 Development of interfacial compressive stress vs. time with and without creep OPC 2_ 97

Figure 81 Development of interfacial compressive stress vs. time with and without creep OPC $3 \_98$

Figure $82 \mathrm{MDBL}$ at different loading age OPC 1 __ 99

Figure 83 MDBL at different loading age OPC $2 \_100$

Figure $84 M D B L$ at different loading age OPC $3 \ldots 100$

Figure 85 comparison between the Dog-bone and MDBL_L 101

Figure 86 comparison between the Dog-bone OPC 1 and MDBL_ 102

Figure 87 The relationship between using 4' $x 8$ "' and 6" $x 12$ ' cylinders for measuring the compressive strength 103 Figure 88 The relationship between using 4' $x 8$ "' and 6' 'x12' cylinders for measuring the Tensile Strength _ 104

Figure 89 Compressive Strength development curves for concrete cylinders 4'x8' for three different mixes __ 105 
Figure 90 the relationship that represents the effect of the air content on the compressive strength at different ages

Figure 91 Tensile Strength development curves for concrete cylinders 4' $x 8$ ' for different mixes 106 106

Figure 92 the relationship that represents the effect of the air content on the compressive strength at different ages

Figure 93 FEM model - Simulating the Ring Experiments

107

Figure 94 Comparison the strain between FEM and Ring test result OPC 1 108

Figure 95 Comparison the strain between FEM and Ring test result OPC 2 110

Figure 96 Comparison the strain between FEM and Ring test result OPC 3

111

Figure 97 Comparison the stress between FEM and Tensile strength experiments result in OPC 1

111

Figure 98 Comparison the stress between FEM and Tensile strength experiments result in OPC 2

113

Figure 99 Comparison the stress between FEM and Tensile strength experiments result in OPC 3

Figure 100, Fitted B3 Model using the original MDBL

114

Figure 101 Comparison the strain between FEM and Ring test result OPC 1 using B3 Model

115

Figure 102 Comparison the strain between FEM and Ring test result OPC 2 using B3 Model

Figure 103 Comparison the strain between FEM and Ring test result OPC 3 using B3 Model

Figure 104 Comparison the stress between FEM and Tensile strength experiments result in OPC 1 using the B3

model

Figure 105 Comparison the stress between FEM and Tensile strength experiments result in OPC 2 using the B3

model

Figure 106 Comparison the stress between FEM and Tensile strength experiments result in OPC 3 using the B3 model

Figure 107 Stress distribution along the ring specimens Hossain, A.B.; Weiss (2006)

Figure 108 Stress distribution along the ring specimens $O P C 2$

Figure 109 The location of the crack OPC 3

Figure 110 Comparison the stress between FEM and Tensile strength experiments result OPC 2 considering the actual environment temperature

\section{List of Tables}

Table 1 Water/Cement and Aggregate/Cement ratio effects on the concrete shrinkage (J. J. Brooks 1989) 23

Table 2 Summary of influence factors on concrete shrinkage (Peter Taylor and Xuhao Wang, 2014) ___ 26

Table 3 Mix Designs for Concrete Mixtures per yd3 _ 29

Table 4 Mechanical Properties of the Mixes __ 33

Table 5 Setting Time Test results__ 36

Table 6 Elastic modulus measurements for Concrete Batches OPC 2 _ 39

Table 7 Elastic modulus measurements for Concrete Batches OPC 3 _ 40

Table 8 Compressive Strength measurements for Concrete Batches OPC 1 _ 42

Table 9 Compressive Strength measurements for Concrete Batches OPC $2 \_42$

Table 10 Compressive Strength measurements for Concrete Batches OPC $3 \_43$

Table 11 Tensile Strength measurements for Concrete Batches OPC 2 _ 45

Table 12 Tensile Strength measurements for Concrete Batches OPC 3 _ 46

Table 13 MDBL model parameters _ـ 101

Table 14 B3 model parameters__ 115

Table 15 Comparison between the predicted and the actual cracks__ 121 


\section{Chapter 1 Introduction}

Shrinkage in concrete is one of the main characteristics of concrete that causes initial cracks in structures to form. Shrinkage is affected by the amount of water lost from the surface of the concrete, which is influenced by temperature, ambient relative humidity, and wind velocity. In general, shrinkage associated with moisture loss of the concrete follows this rule: the more loss of moisture, the higher shrinkage expected in the concrete. There are two main causes for the moisture loss: moisture loss due to the environment, and self-desiccation (DOH). The moisture loss due the environment happens when the environmental humidity is lower than the humidity inside the concrete, as a result, the water in the concrete evaporates. Experimentally, more water losses will happen at the surface due to the ambient humidity, causing more shrinkage to arise at the surface.

According to (Merima Šahinagić-Isović, Goran Markovski, Marko Ćećez, 2012) Shrinkage in concrete can be classified by

1. Autogenous shrinkage or hydration shrinkage: it is closely connected to chemical shrinkage, and it is a consequence of self-desiccation in pores of cement paste in the process of hydrating non-hydrated cement.

2. Chemical shrinkage: it is a consequence of chemical binding (i.e. using of water in concrete in the cement hydration process).

3. Plastic shrinkage: it develops on the surface of fresh concrete exposed to drying.

4. Hardened concrete drying shrinkage: when the concrete is exposed to an environment that causes water to evaporate from capillaries. 
5. Carbonation shrinkage: carbon dioxide from the environment causes chemical reactions in cement stone.

6. Thermal shrinkage: A result of temperature changes in concrete in the process of hydration.

As the concrete shrinks, tensile stresses will be developed in structure due to restraints from adjacent materials or connected members.

Creep is formally defined as "the time-dependent increase in strain in a solid resulting from force" (ASTM E 6-07 Standard terminology relating to methods of mechanical testing). By this definition, any material will undergo creep at some condition of loading. Concrete can exhibit substantial creep and stress relaxation at early ages. Creep can be defined as the increase in strain under a sustained stress; because this increase can be several times as large as the strain on loading, creep is of considerable importance in structures. "The beneficial role of creep is shown diagrammatically in Figure 1.

Consider a freshly laid concrete slab (a) with given initial length. Under ideal conditions, without any interference from the surrounding environment, unrestrained drying shrinkage will occur, giving the net reduction in length shown in (b). This occurrence is unrealistic in practice because slab movement will invariably be constrained to some degree, if only by the friction of the underlying substrate. Consequently, we suppose the hypothetical case of perfect restrains, which exactly preserves the initial dimensions of the slab. Achieving this situation requires imposing a fictitious load on the concrete to counteract the shrinkage stress (c). However, because of the applied load, the length of the slab will increase due to concrete creep (d). To maintain the condition of perfect, restrain an opposing load is necessary (e), with the net result being a reduction in shrinkage stress experienced by the slab (f)" Lee NP. 2007. 


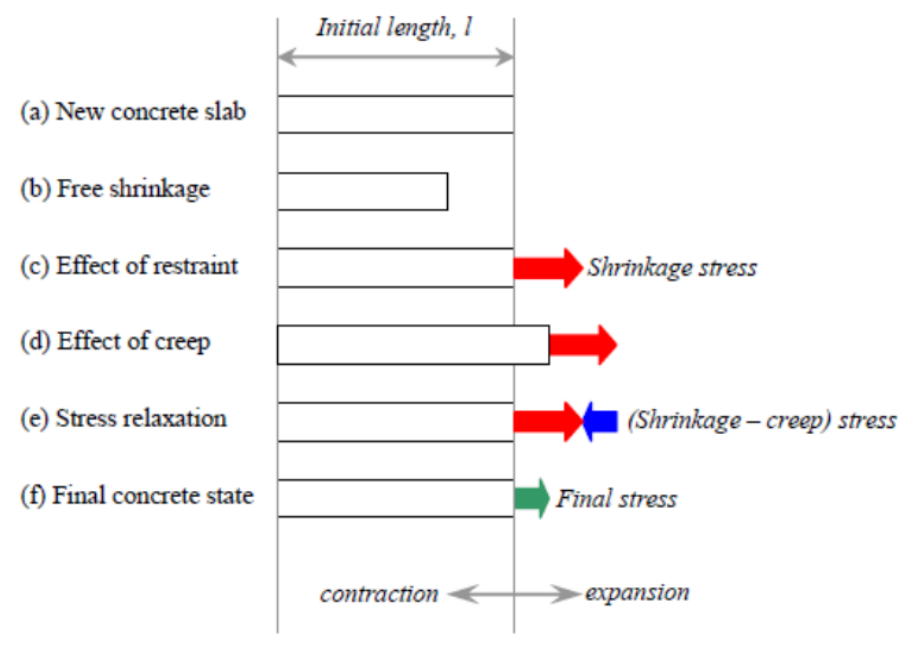

Figure 1 Schematic description of stress relaxation due to creep in a concrete slab (Weiss, 2006)

When these stresses exceed the allowable tensile strength of the concrete, cracks will occur. Cracking in concrete members may reduce the load carrying capacity of the structure, because it allows water and other chemicals to go through the cover layer and meet the reinforcements, leading to reinforcement corrosion and rupture in steel reinforced concrete. 


\section{Chapter 2 Literature Review}

\section{Moisture Distribution at Early-Age}

Several references are found in the literature on the investigation of moisture content and its variations with time in concrete. The moisture content in the concrete is a critical factor for the processes in the concrete (e.g., concrete shrinkage and shrinkage-related cracks). As mentioned before concrete shrinks as moisture is lost to the environment or by self-desiccation. The magnitude of shrinkage strain is normally proportional to the amount of moisture lost, (Bissonnette et al. 1999; Baroghel-Bouny et al. 1999; Wittmann et al. 2002; Zhang and Zhang 2006.)

Recently, Zhang et al. 2007 experimentally investigated the development of humidity inside of concrete at an early age by measuring the interior humidity and temperature of concrete immediately after specimen casting until 28 days. The model is built based on the consideration that the moisture variations in early age concrete results from both cement hydration (selfdesiccation) and water diffusion from concrete to environment due to low environmental humidity.

The variation law of the interior relative humidity of concrete with age can be described by a water-vapor-saturated stage with $100 \%$ relative humidity (Stage I) followed by a stage that relative humidity gradually decreases (Stage II). Shown in Figure 2. 


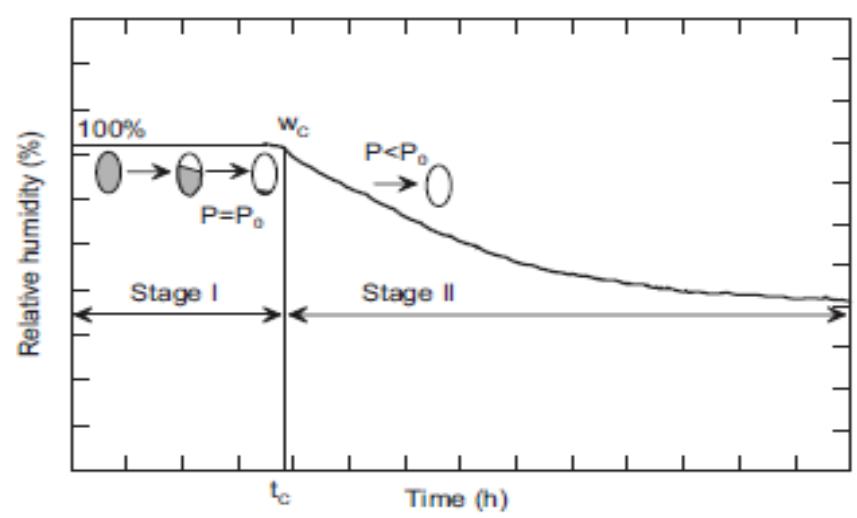

Figure 2 Two stages of humidity development inside of concrete ( Jun Zhang; Kun Qi; and Yu Huang, 2009 )

With continuous drying and cement hydration, the water content in concrete gradually reduces. When the water content in concrete pores decreases to a critical value, at which the vapor pressure becomes lower than the saturated value, the relative humidity in concrete starts to decrease from $100 \%$ value. Starting from this moment where $t_{c}$ is shown in figure 2 , the development of internal humidity goes into stage II, in which the interior humidity decreases with concrete age.

Bazant and Najjar (Bazant and Najjar 1972) developed a nonlinear water diffusion model, which can accurately simulate the moisture transport inside concrete, and their model was improved to treat two parameters, diffusivity, and moisture capacity separately (Xi and Bazant 1994), to consider water-cement ratio, curing time, temperature and cement type.

According to Fick's second law, the moisture variation with time and position can be expressed as:

$$
\frac{\partial\left(\mathrm{W}-W_{S}\right)}{\partial t}=\frac{\partial}{\partial x}\left(D \frac{\partial\left(\mathrm{W}-W_{S}\right)}{\partial x}\right)+2 \frac{\partial}{\partial y}\left(D \frac{\partial\left(\mathrm{W}-W_{S}\right)}{\partial y}\right)++2 \frac{\partial}{\partial z}\left(D \frac{\partial\left(\mathrm{W}-W_{S}\right)}{\partial z}\right)+k \frac{\partial T}{\partial t}
$$

Eq. 1 Fick's second law 
Since the relationship between humidity, $H$, and water content, $W$, can be related by the well-known desorption or sorption isotherms, the humidity, $H$, is a linear function of water content, $W$. Thus, Eq. 1 can be rewritten as:

$$
\frac{\partial\left(\mathrm{H}-H_{S}\right)}{\partial t}=\frac{\partial}{\partial x}\left(D \frac{\partial\left(\mathrm{H}-H_{S}\right)}{\partial x}\right)+2 \frac{\partial}{\partial y}\left(D \frac{\partial\left(\mathrm{H}-H_{S}\right)}{\partial y}\right)++2 \frac{\partial}{\partial z}\left(D \frac{\partial\left(\mathrm{H}-H_{S}\right)}{\partial z}\right)+k \frac{\partial T}{\partial t} \quad \text { Eq. } 2
$$

Where $H_{s}$ is the humidity reduction due to cement hydration. $k$ is the change in $H$ due to a one-degree change in temperature, $T$, at constant $W$ and a fixed degree of cement hydration. $D$ is the moisture diffusion coefficient. Experimental results have indicated that change in $H$ due to temperature variation inside concrete is rather small and can be neglected (I. V. AmirkhanovE. Pavlušová, 2008). If one-dimensional water diffusion is considered along the coordinate direction $\mathrm{x}$, the Eq. 2 becomes:

$$
\frac{\partial\left(\mathrm{H}-H_{S}\right)}{\partial t}=\frac{\partial}{\partial x}\left(D \frac{\partial\left(\mathrm{H}-H_{S}\right)}{\partial x}\right) \quad \text { Eq. } 3
$$

The diffusivity coefficient is a key material parameter determining moisture transport speed. Diffusivity is dependent on multiple factors including material properties, pore structure, PCC material constituent (i.e., w/c ratio), and moisture content. The literature review by Banzant and Najjar showed that diffusivity falls in a range of $0.144 \mathrm{~cm}^{2} /$ day to $1.93 \mathrm{~cm}^{2} /$ day. Different empirical models were studied in terms of laboratory experimental tests. The first model proposed by Bazant and Najjar.

$$
D(H)=D_{r}\left[\alpha_{0}+\frac{1-\alpha_{0}}{1+\left(\frac{1-H}{1-H_{c}}\right)^{n}}\right] \quad \text { Eq. } 4
$$

Where:

$D_{\mathrm{r}}$ : maximum diffusivity coefficient, $\alpha_{0}$ : constant (0.05), $H_{c}$ : moisture at the ultimate degree of hydration, and $n$ : integer constant. 


\section{Self-Desiccation Model}

The reduction of water content due to the chemical reaction between cement and water is called self-desiccation and can be presented as a function of the hydration degree.

A cement hydration degree-based model describing the humidity reduction due to cement hydration was proposed by Oh and Cha (2003). A modified cement hydration degree-based model, which takes the initial liquid-water saturated stage (Stage I) into account, is used to describe the humidity reduction due to cement hydration was proposed by Zhang J, Qi K, Huang Y. (2009).

$$
H_{s}=\left\{\begin{array}{l}
0 \text { for } \alpha \leqslant \alpha_{c} \\
\left(1-H_{s, u}\right)\left(\frac{\alpha-\alpha_{c}}{\alpha_{u}-\alpha_{c}}\right)^{\beta} \text { for } \alpha>\alpha_{c}
\end{array}\right.
$$

Where $H_{s, u}$ is the relative humidity considering self-desiccation at ultimate degree hydration, which is a function of the water-cement ratio $(w / c)$ and can be determined from experiments. $\alpha_{c}$ is a hydration parameter called critical hydration degree at which the humidity inside of concrete starts to decrease from $100 \%$ level, which can be calculated by applying the experimental determined critical time $t_{c}$ and the parameter :

$\beta$ which is a constant.

$\alpha_{u}$ is the ultimate degree hydration, which is a function of w/c. 


\section{Relative Humidity-Based Degree of Hydration}

Under drying condition, the moisture content in concrete may be less than that under sealed state and this moisture reduction reduces the cement hydration degree. The effect of moisture content on cement hydration is taken into consideration in the model. Through isothermal tests and interior humidity measurements, the relationship between cement hydration degree and interior humidity can be obtained. Based on experimental results, the relationship of cement hydration rate and interior relative humidity can be expressed as (Yuan Gao 2012) :

$$
\frac{\mathrm{d} \alpha}{\mathrm{d} t_{e}}=k_{\alpha}(R H)^{n}+P_{E q .6}
$$

$\mathrm{k} \alpha$ : is a function of the hydration degree, when $\mathrm{RH}=1, \alpha=\alpha_{\mathrm{c}}$, we have:

$$
k_{\alpha}=\alpha_{c} \cdot \frac{B}{A}\left(\ln \left(\frac{\alpha_{u}}{\alpha_{c}}\right)\right)^{\frac{B+1}{B}}-P_{E q .7}
$$

where $\alpha_{c}$ is cement hydration degree when the interior humidity starts to decrease from an initial value of $100 \%$.

When $\alpha>\alpha_{c}$ we obtain the relationship between cement hydration rate and interior relative humidity as:

$$
\frac{\mathrm{d} \alpha}{\mathrm{d} t_{e}}=\left(\alpha_{c} \cdot \frac{B}{A}\left(\ln \left(\frac{\alpha_{u}}{\alpha}\right)\right)^{\frac{B+1}{B}}-P\right)(R H)^{n}+P \quad E q .8
$$

where $n$ and $P$ are constants that can be determined from interior humidity measurements and isothermal tests.

$\mathrm{A}$ and $\mathrm{B}$ are two empirical constants. 


\section{Elastic Modulus-Based Degree of Hydration}

Elastic modulus of concrete is also an important parameter for shrinkage calculation. After setting the modulus of concrete starts to grow from zero. Based on the equivalent age, the development of elastic modulus of concrete with age under varied temperature and drying status can be estimated by:

$$
E(\alpha)=1.05 E_{28}\left(\frac{\alpha-\alpha_{0}}{\alpha_{u}-\alpha_{0}}\right)^{b} \quad E q .9
$$

where $\alpha_{0}$ is the hydration degree at concrete setting and $b$ is a constant.

\section{Concrete Creep}

Creep occurs in concrete under applied loads as a slow increase of inelastic deformations after the instantaneous deformation which happens when the dead load is applied to the concrete member. And it can be defined as the increase in strain under a sustained stress (Lam, 2002). For a long service life of a concrete structure, the increase of inelastic deflection could be several times as the elastic deflection (Nawy, 2009).

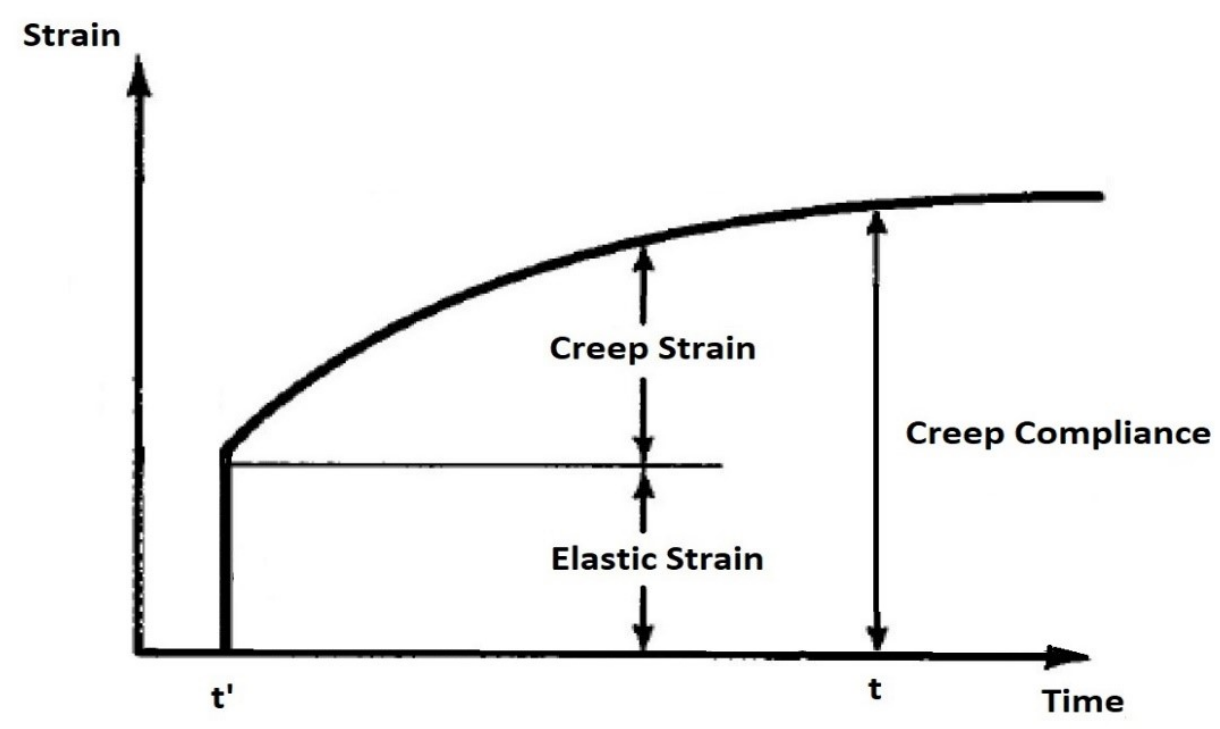




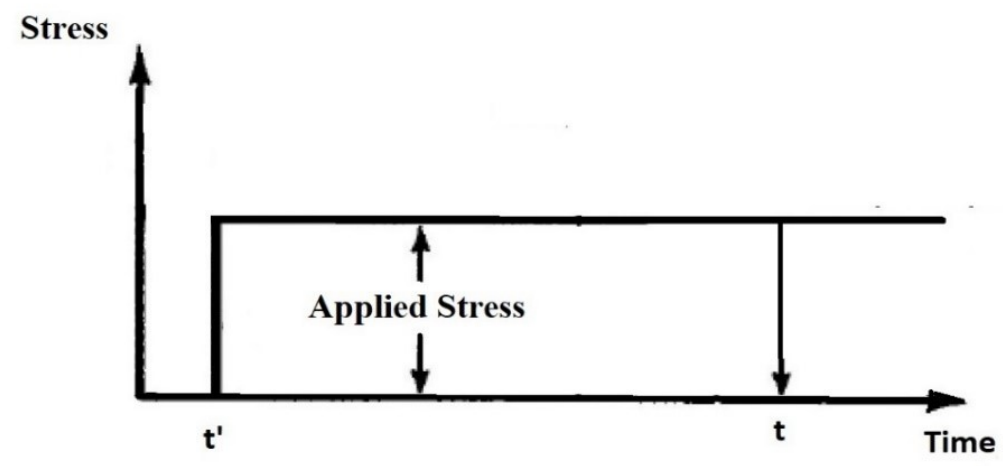

Figure 4 Development of the Creep-Strain under sustained load.

Many terms are used to describe the types of the Creep according to (ACI 209, 2008)

- Basic Creep is a time-dependent increase in strain under sustained constant load without any moisture change.

- Creep Coefficient is defined as the ratio of the creep strain to its instantaneous strain.

- Creep is the total load-dependent strain (including both elastic and creep strain) at age t per unit stress produced by the sustained load that has been applying since loading age $t_{0}$.

According to (Hassoun 2014) For the same loading duration the creep increase with higher stress level. Creep increase with sustained loading period and higher loading rates. Creep tends to decrease with bigger size concrete specimen. Cement creeps approximately 15 times as much as concrete, not only the amount of cement but the type and fineness of cement could greatly influence the final creep of concrete.

According to (Lam, 2002) Creep increases with increasing w/c ratio as a change in w/c ratio directly impact on changes in cement content and concrete strength. Also, the aggregates act as a restraint to reduce the creep as the potential creep could be reduced by well-graded aggregates. 


\section{Double Power Law for Basic Creep of Concrete}

Many creep models have been used to find the creep of the concrete such as B3, B4, and the Double Power Law (DPL) model. The Double Power Law was first proposed by Bazant (1975), which is a creep compliance function to express basic creep of concrete. The equation is:

$$
J\left(t, t^{\prime}\right)=\frac{1}{E_{0}}+\frac{\varphi_{1}}{E_{0}} t^{\prime-d}\left(t-t^{\prime}\right)^{p} \quad \text { Eq. } 10
$$

where:

t: Concrete age

t': Concrete age at loading

$\mathrm{J}\left(\mathrm{t}, \mathrm{t}^{\prime}\right)$ : Compliance function

$E_{0}$ : Asymptotic modulus of elasticity

$\varphi_{1}, \mathrm{~d}$, and $\mathrm{p}$ : Creep model parameters

The original DPL was found to fit well with early age creep but may overestimate creep strains after long duration (Zdenek P. Bazant and Chern 1985; Atrushi 2003). A modified version by Atrushi that is simpler and more convenient for young concrete was expressed as (Atrushi 2003) MDPL:

$$
J\left(t, t^{\prime}\right)=\frac{1}{E_{c}\left(t^{\prime}\right)}\left[1+\varphi_{1}\left(t^{\prime}\right)^{-d}\left(t-t^{\prime}\right)^{p}\right] \quad \text { Eq. } 11
$$

In equation 11 ,

$E_{c}\left(t^{\prime}\right)$ is the modulus of elasticity at the time of loading.

Where $\varphi_{1}, d$ and $p$ are material parameters, which should be determined directly or indirectly from experiments. 
For this research, the modified double power law is been used since it can fit the creep all the way up to the cracking, including the non-linear behavior of the concrete before cracking.

\section{B3 Model}

Bazant's B3 model (Bažant 1988) can be used for both Tensile and compressive creep and was developed from compressive creep test data on hardened concrete. since then it has been used for studying the concrete creep behavior widely. A study by østergaard et al. (2001) showed that concrete exhibits high tensile creep strain if loaded at ages less than or equal to 1 day, and a modification to $\mathrm{q}_{2}$ in $\mathrm{B} 3$ model to seize the very early-age high viscoelastic and he improved the B3 model on the early age creep behavior by adjusting the "aging" term, another modification has been made by Wei and Hansen (2013) on the later ages by modifying the "flow" term of B3 model.

The temperature has a big effect on early-age concrete creep behavior, temperature effect can be solved using the equivalent age to consider the temperature proposed by Bažant and Baweja (2000). The B3 model was found to agree better with the experimental data.

The creep compliance function can be expressed by :

$$
J\left(t, t^{\prime}\right)=\frac{\varepsilon(t)}{\sigma}=q_{1}+q_{2} Q\left(t, t^{\prime}\right)+q_{3} \ln \left[1+\left(t-t^{\prime}\right)^{0.1}\right]+q_{4} \ln \frac{t}{t^{\prime}}
$$

$\mathrm{q}_{1}$ is the Instantaneous Compliance,

$\mathrm{q}_{2}$ is the Aging Viscoelastic Compliance,

$\mathrm{q}_{3}$ Nonaging Aging Compliance,

$\mathrm{q}_{4}$ is the Flow Compliance.

The individual terms $\mathrm{q}_{1}, \mathrm{q}_{2}, \mathrm{q}_{3}$, and $\mathrm{q}_{4}$ are the empirical material constitutive parameters based on concrete strength and composition. 


$$
\begin{aligned}
Q\left(t, t^{\prime}\right) & =Q_{f}\left(t^{\prime}\right)\left[1+\left(\frac{Q_{f}}{Z\left(t, t^{\prime}\right)}\right)^{r}\right]^{-1 / r} \quad \text { Eq. } 13 \\
Q_{f}\left(t^{\prime}\right) & =\left[0.086\left(t^{\prime}\right)^{\frac{2}{9}}+1.21\left(t^{\prime}\right)^{\frac{4}{9}}\right]^{-1} \text { Eq. } 14 \\
Z\left(t, t^{\prime}\right) & =\left(t^{\prime}\right)^{-1 / 2} \ln \left[1+\left(t-t^{\prime}\right)^{0.1}\right] \quad \text { Eq. } 15 \\
r & =1.7\left(t^{\prime}\right)^{0.12}+8.0 \quad \text { Eq. } 16
\end{aligned}
$$

t': Loading age in days

$\mathrm{q}_{1}, \mathrm{q}_{2}, \mathrm{q}_{3}$, and $\mathrm{q}_{4}$ : Empirical constant

t: Current age in days

Temperature has two different effects on the creep behavior of early-age concrete. From the maturity point of view, higher curing temperature will accelerate the hydration process and increase the concrete maturity, therefore, decrease the creep (Lin and Chen, 2014). However, the creep deformation at early-age increases significantly as the temperature increases. Atrushi (2003) stated that the increasing effect is much greater than the decreasing effect. To account for the effect of the temperature, the equivalent age was used by Bažant and Baweja (2000) and Atrushi (2003) to replace the regular age in the place of the loading age and the loading duration, where he found better agreements between the theoretical and experimental results. the modified B3 model can be expressed as

$$
J\left(t_{e}, t_{e}^{\prime}\right)=\frac{\varepsilon\left(t_{e}\right)}{\sigma}=q_{1}+q_{2} \frac{t_{e}^{\prime}}{t_{e}^{\prime}-q_{5}} Q\left(t_{e}, t_{e}^{\prime}\right)+q_{3} \ln \left[1+\left(t_{e}-t_{e}^{\prime}\right)^{0.1}\right]+q_{4} \ln \frac{t_{e}}{t_{e}^{\prime}} \quad E q .17
$$




\section{Concrete Shrinkage}

Many shrinkage models have been developed to predict concrete shrinkage behavior. These models are based on empirical data and predict shrinkage using concrete properties, environmental conditions, and geometry of concrete structures. The model is based on the capillary tension created in the capillary pores of concrete and uses the interior humidity (RH) that can relate to the moisture loss in concrete directly as a driving parameter for shrinkage predictions. This model is powerful because it can be used for shrinkage prediction of concrete whether the shrinkage is caused by self-desiccation or by drying. In addition, because the model can reflect the effect on moisture loss of age and position from one parameter, $\mathrm{RH}$, the model can predict shrinkage strain in concrete structures not only for different time but also for different positions. A similar model was developed and is being used by Japanese researchers.

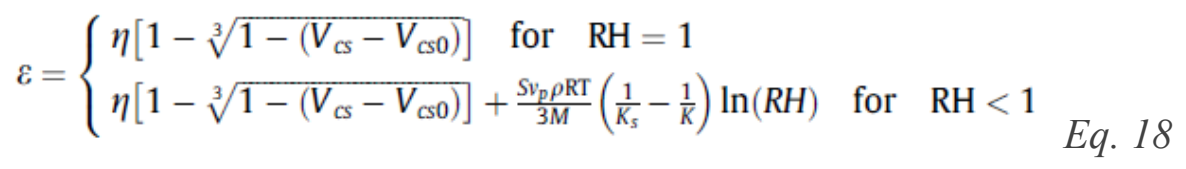

$\eta_{: \text {is the influencing factor of stiffness. }}$

$V_{c s}$ and $V_{c s 0}$ : are the chemical shrinkage (in volume) at a given cement hydration degree.

$M$ : is molar weight of water $(0.01802 \mathrm{~kg} / \mathrm{mol})$.

$\rho:$ is the density of water.

$R:$ is ideal gas constant $(8.314 \mathrm{~J} / \mathrm{mol} \mathrm{K})$.

$K$ : is the bulk modulus of the whole porous body.

$$
K=E / 3(1-2 v) E q .19
$$


$v$ : is poison's ratio.

$E$ : the elastic modulus of the concrete:

$K_{s}:$ is the bulk modulus of the solid material.

$v_{p}:$ is the pore structure influencing factor, where :

$$
v_{\mathrm{p}}=1-\exp \left(-k_{0} \beta r_{p}\right) \text { Eq. } 20
$$

$r_{p}$ : is the radius of the capillary pore.

$\mathrm{k}_{0}$ : Parameter is obtained by comparing model and experimental results.

$\beta$ : is a parameter reflecting the influence of concrete age.

$$
\beta=\alpha_{0} e^{\lambda \alpha} \text { Eq. } 21
$$

Where:

$\alpha_{0}$ and $\lambda$ are experimentally determined constants.

$\alpha$ : is cement hydration degree.

T: Is the absolute temperature.

$$
S=\frac{p-0.7(1-p) \alpha}{p-0.5(1-p) \alpha} \quad \text { Eq. } 22
$$

The above equation is called the saturation fraction and can be estimated through Powers' volumetric models Grzybowski M, Shah SP, 1990, Where:

$$
\boldsymbol{\rho}=\frac{w / c}{w / c+\rho_{w} / \rho_{c}} \quad E q .23
$$

$\boldsymbol{\rho}_{\mathrm{w}}$ and $\boldsymbol{\rho}_{\mathrm{c}}$ are the density of water and cement respectively. 
$\mathrm{RH}$ : is relative humidity in the concrete.

The ACI has an empirical equation to calculate the shrinkage of the concrete, but it's biased and overestimates the actual shrinkage in the concrete.

$$
\left(\varepsilon_{\mathrm{sh}}\right)_{\mathrm{u}}=\frac{\left(\varepsilon_{\mathrm{sh}}\right)_{\mathrm{t}}(35+t)}{\mathrm{t}} \text { Eq. } 24
$$

Where,

$\left(\varepsilon_{\mathrm{sh}}\right)_{\mathrm{u}}$ : Ultimate shrinkage.

$\left(\varepsilon_{\text {sh }}\right)$ : Shrinkage Measured at time $t$.

$t$. Time of shrinkage measurement days of drying.

Prediction of the development of shrinkage by the above equation is subject to considerable variability, but the equation can be used to estimate the ultimate shrinkage of a wide range of moist-cured concretes. One-half of the ultimate shrinkage is expected to occur after 35 days drying. For steam-cured concrete, the value of 35 in the denominator is replaced by 55, and time $t$ is reckoned from the end of steam curing at 1 to 3 days.

According to J. Zhang*, H. Dongwei* and S. Wei† (2010) a linear relationship between free shrinkage strain and humidity reduction exists:

$$
\varepsilon_{\mathrm{w}}=\varepsilon_{0}+k(100-\mathrm{RH}) \quad \text { for } \mathrm{RH}<100 \% \quad E q .25
$$

where $\varepsilon_{0}$ is the shrinkage occurring during the humidity developed in stage $1,(\mathrm{RH}=$ 100), which should principally be governed by the water-cement ratio (w/c), and $k$ is the shrinkage strain generated by a one-unit humidity reduction. The relationship of free shrinkage strain and (RH) may be used to calculate the free shrinkage strain field and further to calculate the shrinkage-induced stresses in structures as well. and this relationship has been used in this research 


\section{Restrained Shrinkage Ring Test}

We know that during the Restrained Shrinkage Ring experiment (ASTM C1581M - 16) a pressure is created on the inner surface of the steel, see Figure 3.
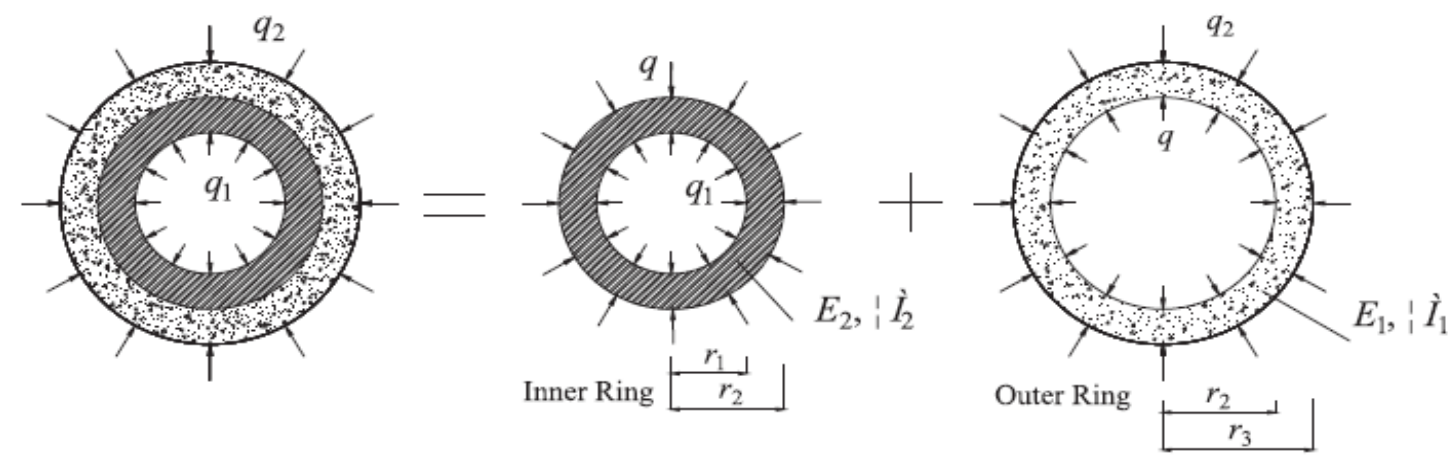

Figure 3 Decomposing of the concrete-steel composite ring (Yuan Gao, Jun Zhang, Po Han 2013)

The interfacial compressive stress generated on the steel ring, caused by autogenous and drying shrinkages of concrete, can be measured experimentally using

$$
q=-\left[1-\left(\frac{r_{1}}{r_{2}}\right)^{2}\right] E_{2} \varepsilon_{\theta} \quad E q .26
$$

The compressive strain $\varepsilon_{\theta}$ can be measured from experiments, $E_{2}$ is the elastic modulus of the steel ring, $r_{1}$ is the inner radius of the steel ring, $r_{2}$ is the outer radius of the steel ring. Meanwhile, the theoretical value of the interfacial compressive stress is precisely calculated by a model for given autogenous and drying shrinkages of concrete. Based on the stress analysis of the restrained ring. 
The derivation of the model is explained step by step in the following pages, where $\mathrm{E}$ and $\mu$ are the elastic modulus and Poisson's ratio of the material. $a$ and $b$ are the inner and outer radius of the ring.

The stress-strain relations for radial stress and circumferential stress can be expressed as:

$$
\begin{aligned}
& \sigma_{r}=\frac{E}{1-\mu^{2}}\left[\varepsilon_{r}+\mu \varepsilon_{\theta}-(1+\mu) \varepsilon_{\mathrm{sh}}\right] \\
& \sigma_{\theta}=\frac{E}{1-\mu^{2}}\left[\varepsilon_{\theta}+\mu \varepsilon_{\mathrm{r}}-(1+\mu) \varepsilon_{\mathrm{sh}}\right]
\end{aligned}
$$

In addition, $\sigma_{\mathrm{r}}$ and $\sigma_{\theta}$ satisfy the equation of equilibrium:

$$
\frac{\mathrm{d} \sigma_{\mathrm{r}}}{\mathrm{d} r}+\frac{\sigma_{\mathrm{r}}-\sigma_{\theta}}{r}=0
$$

Eq. 29

If $u$ is radial displacement, we have:

$$
\varepsilon_{\mathrm{r}}=\frac{\mathrm{d} u}{\mathrm{~d} r}, \quad \varepsilon_{\theta}=\frac{u}{r} \quad \text { Eq. } 30
$$

Using Eqs. (27), (28) and (30) in Eq. (29), we get:

$$
\frac{\mathrm{d}}{\mathrm{d} r}\left[\frac{1}{r} \frac{\mathrm{d}}{\mathrm{d} r}(r u)\right]=(1+\mu) \frac{\mathrm{d}}{\mathrm{d} r} \varepsilon_{\mathrm{sh}}
$$

Integrating this equation:

$$
u(r)=(1+\mu) \frac{1}{r} \int_{a}^{r} \varepsilon_{s h} r \mathrm{~d} r+\frac{C_{1}}{2} r+\frac{C_{2}}{r}
$$

Eq. 32

where $C_{1}$ and $C_{2}$ are constants that can be determined by the boundary conditions.

$$
\sigma_{\mathrm{r}}=-\frac{E}{r^{2}} \int_{a}^{r} \varepsilon_{\mathrm{sh}} r \mathrm{~d} r+\frac{E C_{1}}{2(1-\mu)}-\frac{E C_{2}}{1+\mu} \frac{1}{r^{2}}
$$




$$
\sigma_{\theta}=\frac{E}{r^{2}} \int_{a}^{r} \varepsilon_{\mathrm{sh}} r \mathrm{~d} r-E \varepsilon_{\mathrm{sh}}+\frac{E C_{1}}{2(1-\mu)}+\frac{E C_{2}}{1+\mu} \frac{1}{r^{2}} \quad E q .34
$$

From the boundary conditions that $\sigma_{\mathrm{r}}=q_{1}$ at $r=a$ and $\sigma_{\mathrm{r}}=q_{2}$ at $r=b$, we obtain:

$$
\begin{aligned}
& C_{1}=\frac{2(1-\mu)}{E} \frac{1}{b^{2}-a^{2}}\left(b^{2} q_{2}-a^{2} q_{1}+E \int_{a}^{b} \varepsilon_{\mathrm{sh}} r d r\right) \\
& C_{2}=\frac{1+\mu}{E} \frac{a^{2} b^{2}}{b^{2}-a^{2}}\left(q_{2}-q_{1}+\frac{E}{b^{2}} \int_{a}^{b} \varepsilon_{\mathrm{sh}} r d r\right)
\end{aligned}
$$

Eq. 35

For the concrete ring, we have $q_{2}=0$ and $q_{1}=q$. For steel ring, we have $q_{2}=q, q_{1}=0$ and $\varepsilon_{s h}=0$. Using above conditions in Eq.35 and noting the displacement (u) at the interface of concrete and steel calculated from concrete and steel rings respectively are equal, we obtain the constants of $\mathrm{C} 1$ and $\mathrm{C} 2$ for concrete and steel rings respectively as:

$$
\begin{aligned}
& C_{11}=\frac{2\left(1-\mu_{1}\right)}{E_{1}} \frac{1}{r_{3}^{2}-r_{2}^{2}}\left(r_{2}^{2} q+E_{1} \int_{r_{2}}^{r_{3}} \varepsilon_{s h} r d r\right) \\
& C_{12}=\frac{1+\mu_{1}}{E_{1}} \frac{r_{2}^{2} r_{3}^{2}}{r_{3}^{2}-r_{2}^{2}}\left(q+\frac{E_{1}}{r_{2}^{2}} \int_{r_{2}}^{r_{3}} \varepsilon_{s h} r d r\right)
\end{aligned}
$$

and

$$
\begin{aligned}
& C_{21}=-\frac{2\left(1-\mu_{2}\right)}{E_{2}} \frac{r_{2}^{2} q}{r_{2}^{2}-r_{1}^{2}} \\
& C_{22}=-\frac{1+\mu_{2}}{E_{2}} \frac{r_{1}^{2} r_{2}^{2}}{r_{2}^{2}-r_{1}^{2}} q
\end{aligned}
$$

Then, the interfacial stress $q$ can be expressed as:

$$
q=\frac{-\frac{2}{r_{3}^{2}-r_{2}^{2}} \int_{r_{2}}^{r_{3}} \varepsilon_{s h} r d r}{\frac{1}{E_{1}} \frac{\left(1-\mu_{1}\right) r_{2}^{2}+\left(1+\mu_{1}\right) r_{3}^{2}}{r_{3}^{2}-r_{2}^{2}}+\frac{1}{E_{2}} \frac{\left(1-\mu_{2}\right) r_{1}^{2}+\left(1+\mu_{2}\right) r_{2}^{2}}{r_{2}^{2}-r_{1}^{2}}}
$$

Eq. 36 
Creep consideration starts here :
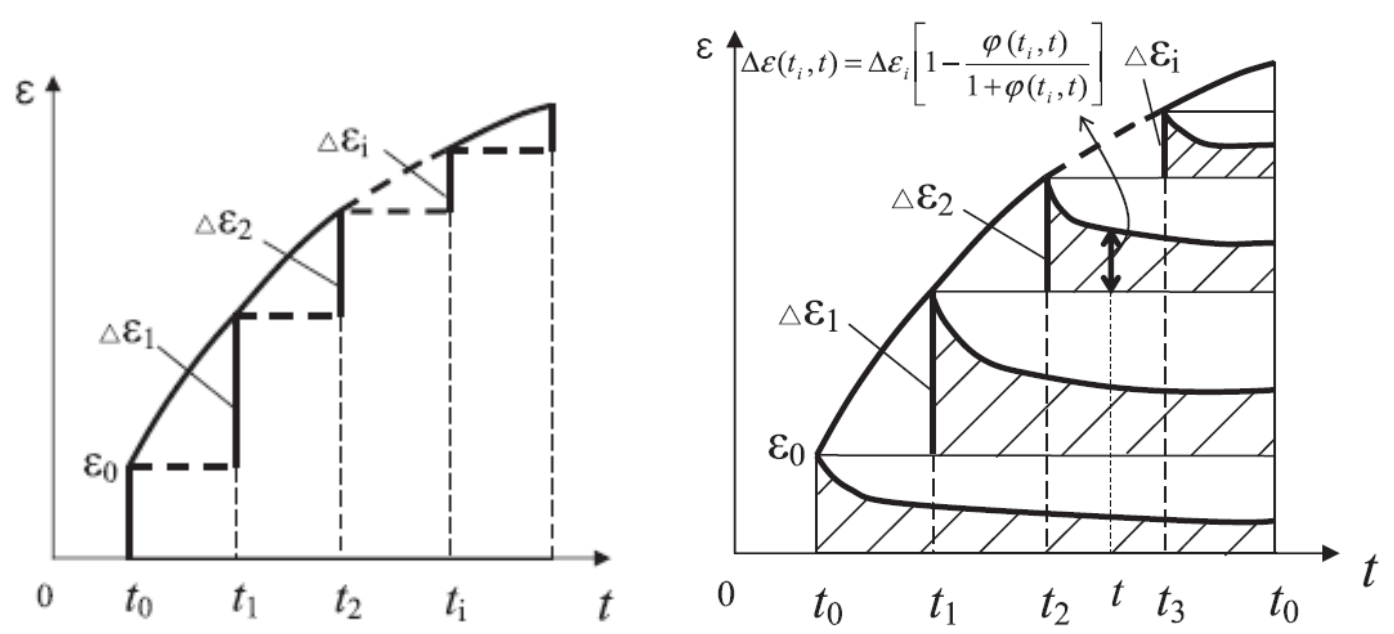

Figure 4 Procedures of creep correction on the effective shrinkage strain. (Yuan Gao, Jun Zhang, Po Han 2013 )

Clearly, the interfacial pressure is generated from the volume change of concrete layer and is a function of $\varepsilon_{s h}$ as displayed in Eq. 36. Using Eq. 36 in both Eq.33. and Eq. 34, we can obtain the stresses of $\sigma_{\mathrm{rr}}$ and $\sigma_{\theta}$ in concrete and steel rings respectively as concrete undergoes shrinkage. In the ring test, shrinkage of concrete is restraint by steel ring and tensile stress is created in the concrete ring. Creep of concrete then immediately takes place as concrete ring is loaded in tension. Then part of the shrinkage strain is counteracted by the creep strain, behaving as the shrinkage tress decreasing with age.

Such stress relation also reflects as the reduction of the interfacial stress with age in the ring test. If we define an effective shrinkage strain that been used for generation of shrinkage stress in the concrete ring as $\varepsilon_{s h-e}$, then we have:

$$
\varepsilon_{\text {sh-e }}(t)=\varepsilon_{\text {sh }}(t)-\varepsilon_{\text {creep }}\left(t, t_{0}\right) \quad E q .37
$$


Based on the effective shrinkage, the relaxation parameter can be easily back-calculated by comparing both the theoretical and experiment shrinkage models, as displayed in Figure 4. Note that $t$ and $t_{0}$ are loading end and load start time, respectively. $\varepsilon_{\text {creep }}$ is the creep strain after loading period of $\left(t-t_{0}\right)$. The creep strain may relate with the effective shrinkage strain by creep coefficient factor $\varphi$ as:

$$
\varphi\left(t, t_{0}\right)=\frac{\varepsilon_{\text {creep }}\left(t, t_{0}\right)}{\varepsilon_{\text {sh-e }}\left(t, t_{0}\right)} E q .38
$$

The equation is a function of load time and loading period also and can be simulated by :

$$
\varphi\left(t, t_{0}\right)=\varphi_{1} t_{0}^{-d}\left(t-t_{0}\right)^{p} \quad E q .39
$$

Where $\varphi_{1}, d$ and $p$ are material parameters, which should be determined directly or indirectly from experiments.

Many numbers of references can be found in the literature regarding the magnitude of creep relaxation parameters. Through analyzing these references, it is suggested that the range of $\varphi_{1}, p$ and $d$ are normally within $0.13-3.7,0.10-0.90$ and $0.05-0.6$ for various concrete types and loading conditions.

$$
\varepsilon_{\mathrm{sh}-e}(t)=\varepsilon_{\mathrm{sh}}(t)\left[1-\frac{\varphi\left(t, t_{0}\right)}{1+\varphi\left(t, t_{0}\right)}\right]
$$

After taking the creep of concrete into account, we obtain the interfacial pressure stress:

$$
q=\frac{-\frac{2}{r_{3}^{2}-r_{2}^{2}}\left[1-\frac{\varphi\left(t, t_{0}\right)}{1+\varphi\left(t, t_{0}\right)}\right] \int_{r_{2}}^{r_{3}} \varepsilon_{s h} r d r}{\frac{1}{E_{1}} \frac{\left(1-\mu_{1}\right) r_{2}^{2}+\left(1+\mu_{1}\right) r_{3}^{2}}{r_{3}^{2}-r_{2}^{2}}+\frac{1}{E_{2}} \frac{\left(1-\mu_{2}\right) r_{1}^{2}+\left(1+\mu_{2}\right) r_{2}^{2}}{r_{2}^{2}-r_{1}^{2}}} \text { Eq. } 41
$$


The above discussion may well suit for the situation where the strain or deformation is fixed. However, shrinkage of concrete is normally growth with age from the initial value of zero in early age concrete. To deal with the stress relaxation under varied restrained strain, a method used for the prediction of stress relaxation under varied loading stress was used in the present paper Zhu BF, 1999. The effective strain at the time $t_{1}$ can then be given by:

$$
\begin{aligned}
\varepsilon_{\text {sh }-e}\left(t, t_{i}\right)= & \varepsilon_{\text {sh }-0}\left(t_{0}\right)\left[1-\frac{\varphi\left(t, t_{0}\right)}{1+\varphi\left(t, t_{0}\right)}\right] \\
& +\sum_{i=1}^{n} \Delta \varepsilon_{\text {sh-i }}\left(t_{i}\right)\left[1-\frac{\varphi\left(t, t_{i}\right)}{1+\varphi\left(t, t_{i}\right)}\right] \quad \text { Eq. } 42
\end{aligned}
$$

The interfacial pressure stress after considering creep relaxation for varied loading history presented as:

$$
q=\frac{-\frac{2}{r_{3}^{2}-r_{2}^{2}} \sum_{i=1}^{n}\left[1-\frac{\varphi\left(t, t_{i}\right)}{1+\varphi\left(t, t_{i}\right)}\right] \int_{r_{2}}^{r_{3}} \Delta \varepsilon_{s h i} r d r}{\frac{1}{E_{1}} \frac{\left(1-\mu_{1}\right) r_{2}^{2}+\left(1+\mu_{1}\right) r_{3}^{2}}{r_{3}^{2}-r_{2}^{2}}+\frac{1}{E_{2}} \frac{\left(1-\mu_{2}\right) r_{1}^{2}+\left(1+\mu_{2}\right) r_{2}^{2}}{r_{2}^{2}-r_{1}^{2}} E q .43}
$$

It should be noted that the time $t$ in the above equations should be transferred into the corresponded equivalent time if varied temperature history is experienced which is the case in this research. Comparing Eq.43 with Eq. 26 the relaxation parameters of concrete in tension then can be calculated. The comparison between calculated and tested interfacial compressive stresses is carried out within the stress calculation.

$\mathrm{E}_{1}$ and $\mu_{1}$ are the elastic modulus and Poisson's ratio of the concrete.

$\mathrm{E}_{2}$ and $\mu_{2}$ are the elastic modulus and Poisson's ratio of the steel.

$r_{1}$ is the inner radius of the steel ring, $r_{2}$ is the outer radius of the steel ring/ inner radius of the concrete ring, $r_{3}$ is the outer radius of the concrete ring. 


\section{Factors Affect the Concrete Shrinkage}

As far as shrinkage of the hydrated cement paste itself is concerned, shrinkage increases with higher water/cement ratio (w/c) because the latter determines the amount of evaporable water in the cement paste and the rate at which water can move towards the surface of the specimen. Brooks demonstrated that shrinkage of hydrated cement paste is directly proportional to the w/c ratio between the values of about 0.4 and 0.7 . At higher w/c ratios, the additional water is removed upon drying without resulting in shrinkage (J. Brooks 1989), shown in Table 1.

\begin{tabular}{llrrr}
\hline \multirow{2}{*}{$\begin{array}{l}\text { Aggregate/cement } \\
\text { ratio }\end{array}$} & \multicolumn{4}{l}{$\begin{array}{l}\text { Shrinkage after six months }\left(10^{-6}\right) \\
\text { for water/cement ratio of: }\end{array}$} \\
\cline { 2 - 5 } & 0.4 & 0.5 & 0.6 & 0.7 \\
\hline 3 & 800 & 1200 & - & - \\
4 & 550 & 850 & 1050 & - \\
5 & 400 & 600 & 750 & 850 \\
6 & 300 & 400 & 550 & 650 \\
7 & 200 & 300 & 400 & 500 \\
\hline
\end{tabular}

Table 1 Water/Cement and Aggregate/Cement ratio effects on the concrete shrinkage (J. J. Brooks 1989 )

The second factor which affects the shrinkage is both the aggregate content and the w/c ratio as shown in Figure 5. One of the most important factors to reduce shrinkage in the concrete is to increase the aggregate content in the concrete mix. It's interesting to notice that using lower w/c ratio for the same amount of the aggregate will also reduce the shrinkage of the concrete. 


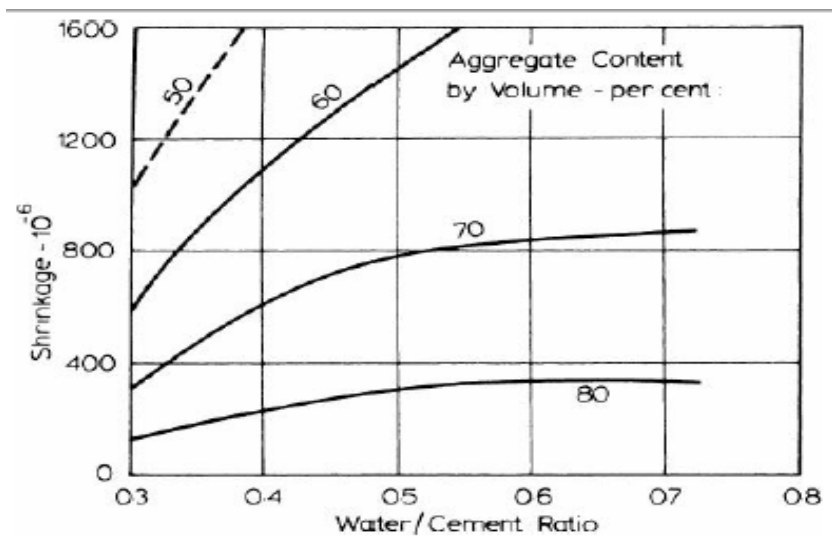

Figure 5 Influence of water/cement ratio and aggregate content on shrinkage (J. J. Brooks 1989)

At a constant w/c ratio, shrinkage increases with an increase in the cement content because increasing cement content results in a larger volume of hydrated cement paste which is able to shrink. However, at a given workability, which means an approximately constant water content, shrinkage is unaffected by an increase in the cement content, or may even decrease, because the $\mathrm{w} / \mathrm{c}$ ratio is reduced, and the concrete is, therefore, better able to resist shrinkage as shown in Figure 6.

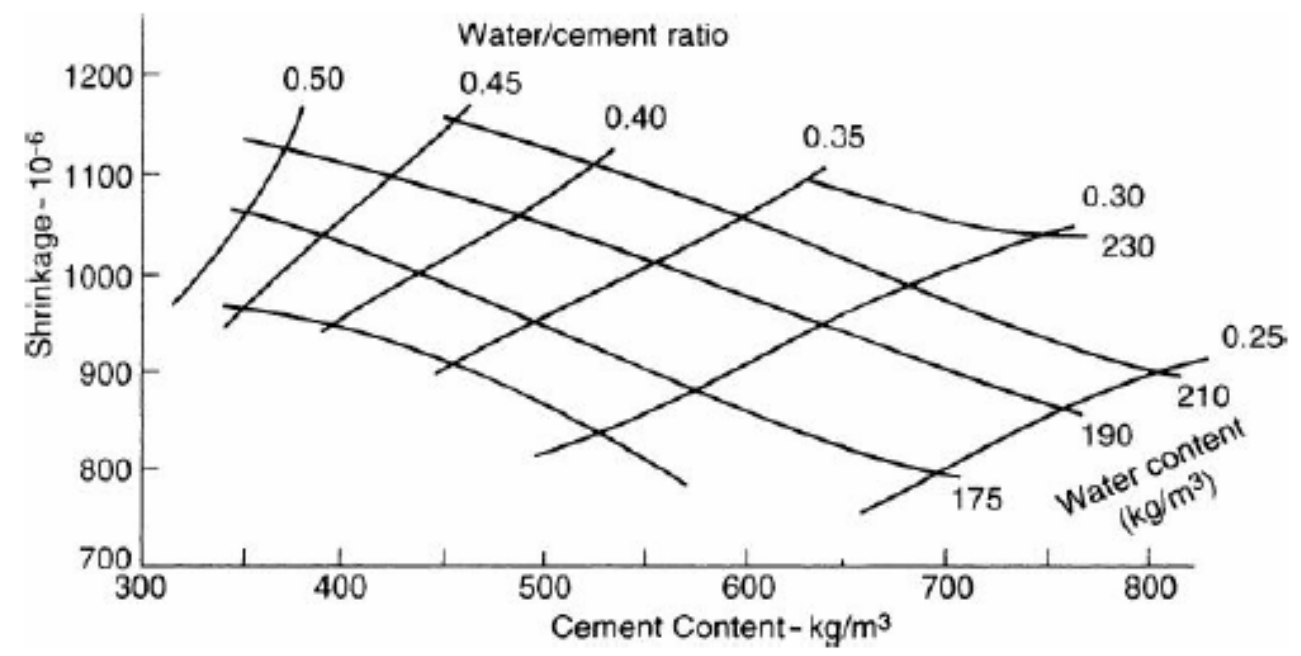

Figure 6 The pattern of shrinkage as a function of cement content, water content, and water/cement ratio; concrete moist-cured for 28 days, thereafter dried for 450 days. (J. J. Brooks 1989 ) 


\section{$\underline{\text { Air Content }}$}

If the air content is less than $8 \%$, there is no significant effect on the magnitude of drying shrinkage (Davis and Troxell 1954).

Fly Ash

ACI Committee 232 (2005) on the use of fly ash in concrete reported that shrinkage may be increased slightly with the addition of fly ash with a constant water content. This finding is attributed to the increased paste volume in a concrete mix. Meanwhile, if the water content is reduced, shrinkage should be about comparable to concrete without fly ash.

$\underline{\text { Slag }}$

Cement ACI Committee 233 (2000) on the use of slag cement in concrete and mortars reported that shrinkage is reduced when lower paste contents are used with slag mixes. The committee stated that published data on the effects of slag on shrinkage indicated conflicting results, and, overall, drying shrinkage was comparable in Portland cement concrete and concrete mixtures containing slag cement. 
Summary of Influence Factors on Concrete Shrinkage

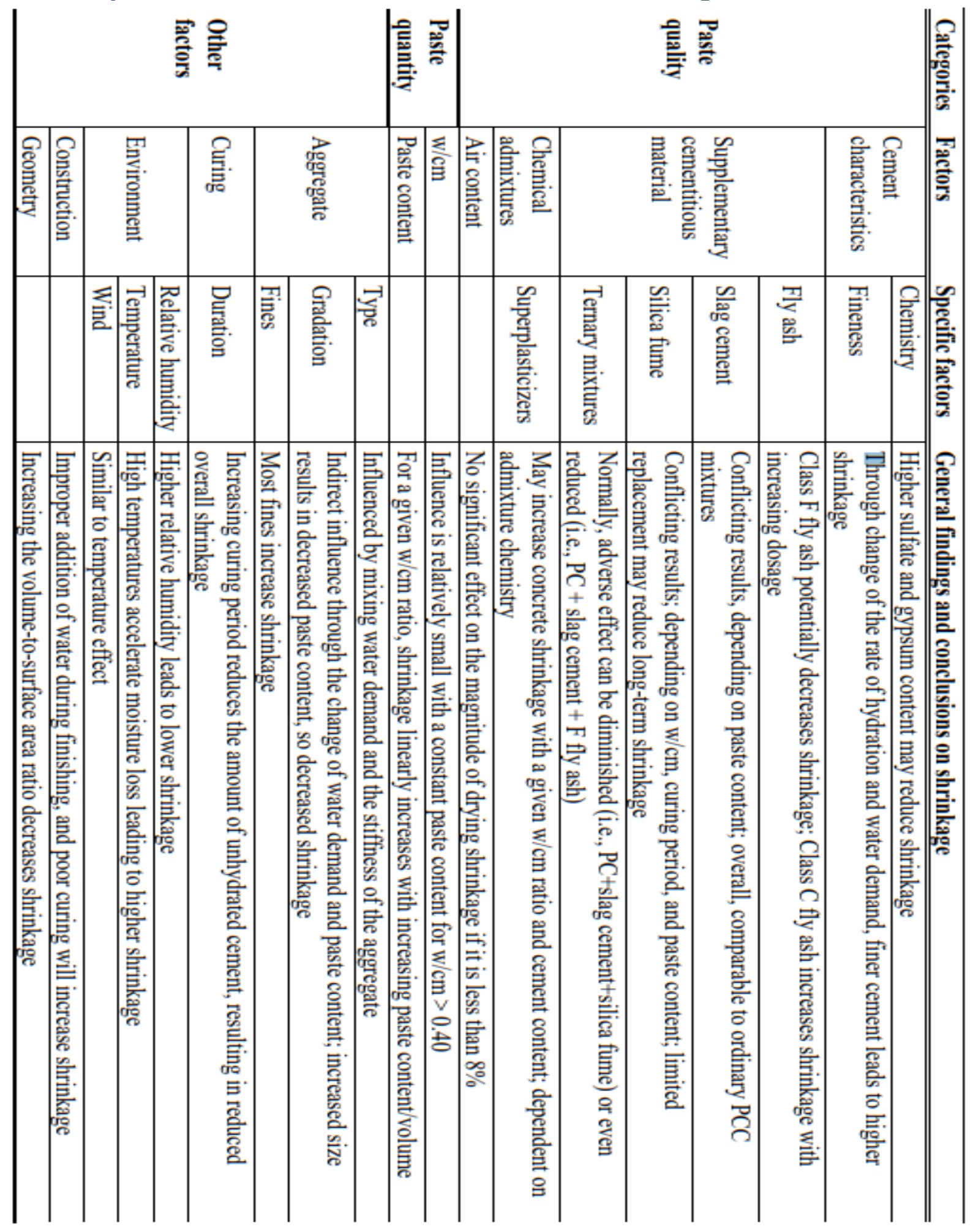

Table 2 Summary of influence factors on concrete shrinkage (Peter Taylor and Xuhao Wang, 2014) 


\section{Chapter 3 Laboratory Experimental Procedures \& Results}

\section{Mix Design and Concrete Casting}

The ASTM standard for making and curing concrete test specimens in the laboratory was followed to develop each of the different concrete batches and form the appropriate specimens for each (ASTM C192/C 192M, 2006). A standard laboratory drum mixer with a capacity of $3 \mathrm{ft}^{3}$ was used in accordance with ASTM for all samples. The materials used in each of the castings were ordered from Central Supply Company, a local concrete production company in the Morgantown, WV. These materials consisted of cement, sand and large aggregate.

After the concrete was produced in the drum mixer air content, slump, and water/cement $(w / c)$ ratio for each concrete batch were determined. The concrete was placed into the respective molds/forms with appropriate rodding and consolidating techniques outline by ASTM (ASTM C192/C 192M, 2006). After the molds were filled, damp burlap was placed over the top of each of the specimens for a 24-hour period.

24 hours after castings, each of the concrete specimens was removed from their respective molds and placed into curing tanks filled with water and a lime additive. The temperature of the curing tanks was monitored with temperature loggers to ensure that the temperature was a constant $72^{\circ} \mathrm{F}$ for each of the samples. 


\section{OPC 1}

The first concrete batch that was cast was an Ordinary Portland Cement (OPC) concrete batch, cast on April 12, 2018, at approximately 5:00 P.M. A total of 2.5 $\mathrm{ft}^{3}$ were produced during this casting. The specimens that were formed are as follows:

- 7 - 4" x 8" Cylinders

- 6 - 3" x 3" x 12" Rectangular Steel Mold Prims

The 4" x 8" cylinders were used to measure the compressive strengths. The rectangular prisms were used for the shrinkage under three different drying conditions: fully wrapped, half-wrapped, and no wrap.

\section{OPC 2}

The Second concrete batch that was cast was an Ordinary Portland Cement (OPC) concrete batch, cast on June 6, 2018, at approximately 9:30 A.M. A total of $4 \mathrm{yd}^{3}$ was produced during this casting. The specimens that were formed are as follows:

- $24-4 " x$ 8" Cylinders

- $26-6 " \times 12 "$ Cylinders

- $6-3$ - x 3" x 12” Rectangular Steel Mold Prims

Both 4" x 8" and 6" x 12" cylinders were used to measure the compressive and tensile strengths. The rectangular prisms were used for the shrinkage under three different drying conditions: fully wrapped, half-wrapped, and no wrap. 


\section{OPC 3}

The third concrete batch that was cast was the Ordinary Portland Cement (OPC) concrete batch, cast on July 12, 2018, at approximately 11:30 A.M. The specimens that were formed are as follows:

- $24-4$ " x 8" Cylinders

- $26-6 " x 12 "$ Cylinders

- 6-3” x 3" x 12" Rectangular Steel Mold Prims

Both 4" $\mathrm{x} 8$ " and 6" $\mathrm{x} 12$ " cylinders were used to measure the compressive and tensile strengths. The rectangular prisms were used for the shrinkage under three different drying conditions: fully wrapped, half-wrapped, and no wrap.

Slump test and air content test were measured for each concrete mix. The water to cement ratio was also measured to confirm that it was the same as the design. After all, materials were thoroughly mixed in the drum. Mixes are shown in Table 3.

\begin{tabular}{|c|c|c|c|}
\hline \multicolumn{3}{|c|}{ Mix Design } \\
\hline Material & OPC 1 & OPC 2 / OPC 3 & Weight \\
\hline Cement & 564 & 564 & $\mathrm{Lb} / \mathrm{yd}^{3}$ \\
\hline Sand & 276.5 & 276.5 & $\mathrm{Lb} . / \mathrm{yd}^{3}$ \\
\hline Water & 1633 & 1633 & $\mathrm{Lb} . \mathrm{yd}^{3}$ \\
\hline
\end{tabular}

Table 3 Mix Designs for Concrete Mixtures per yd3 


\section{Slump Test}

The concrete slump test measures the consistency of fresh concrete before it sets. It is performed to check the workability of freshly made concrete, and therefore the ease with which concrete flows. It can also be used as an indicator of an improperly mixed batch. The test is popular due to the simplicity of apparatus use and procedure.

For each of the concrete batches, the ASTM Standard for Slump Test was followed (ASTM C143, 2010). The freshly mixed concrete is compacted into the standard slump cone. The cone is then removed slowly (5-7 seconds should elapse) and the difference in height is immediately measured to determine the slump value.

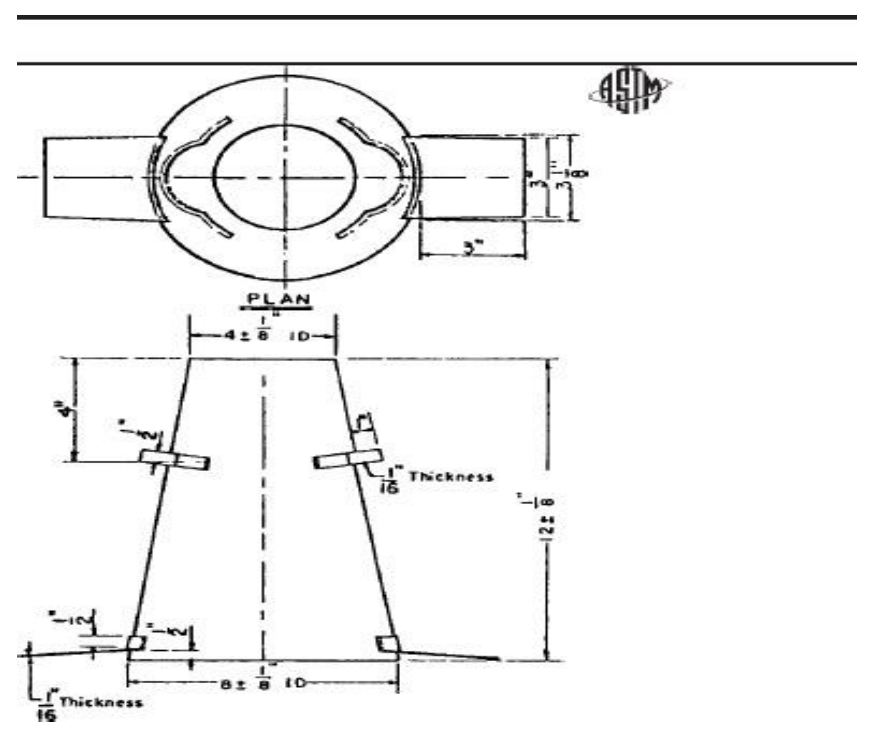

Figure 7 Standard Slump Cone Mold (ASTM C143, 2010).

The Slump values for each of the three applicable concrete batches can be seen in Table 4 Mechanical Properties of the Mixes. The common range for slump measurement is anywhere from 2 in. to 7 in., with the lower end of the range resulting in less workability, and the higher range resulting in greater workability. 


\section{Air Content Test (Pressure Method)}

The purpose of the air content test is to determine the percentage of air that is contained in the freshly mixed concrete, excluding any air that may exist inside voids of aggregate. The measured air content can be a factor of consolidation techniques, exposure, uniformity of air bubbles, amongst other variables (ASTM C231, 2003). Air content is important as it can be directly related to the strength and freeze-thaw durability of the concrete. Typically, concrete with lower air content results in a higher strength concrete, and vice-versa.

There are two types of air content apparatuses commonly used to determine air content in freshly mixed concrete: Type A and Type B meters. For this research project, a Type B Meter was used. A schematic of this apparatus can be seen in Figure 8 below, and the actual apparatus used in each of the castings can be seen in Figure 8.

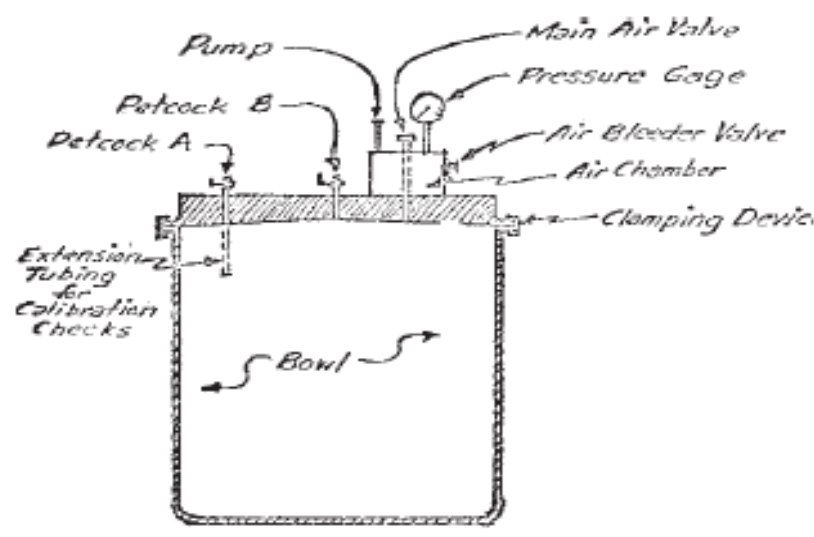

Figure 8 Type B Air Content Apparatus (ASTM C231, 2003).

The air content apparatus was calibrated appropriately according to the ASTM C231 Standards (ASTM C231, 2003). The freshly mixed concrete was then placed into the apparatus bowl, rodded, and finished accordingly. The air content for each of the different concrete batches can be seen in Table 4 Mechanical Properties of the Mixes. 


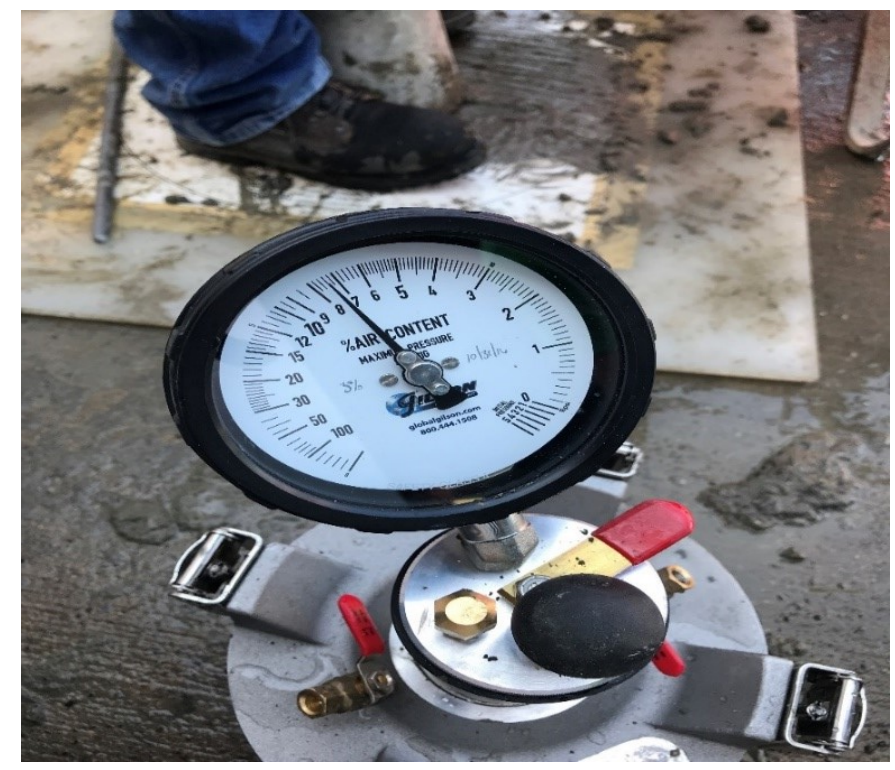

Figure 10 Type B Air Content Apparatus (ASTM C231, 2003).

\section{Water Cement Ratio (Microwave Method)}

The water-cement $(\mathrm{w} / \mathrm{c})$ ratio has a significant effect on the strength and permeability of the concrete. The microwave method can be used to obtain $\mathrm{w} / \mathrm{c}$ ratio results within hours, rather than waiting days for the strength results. Monitoring the test results may provide an early flag of potentially low-strength concrete, allowing the contractor to adjust operations sooner than conventional strength testing might indicate.

Concrete strength varies inversely with the amount of water in the mixture. In simplest terms, for a given cement content, less water leads to higher strength. Other factors such as consolidation, curing, aggregate quality, air content, and aggregate shape affect strength as well. For a given mixture with a constant amount of cement, the w/c ratio has the greatest impact on strength. 
The total water in a concrete mixture comes from the following sources:

- Moisture absorbed in the aggregate.

- Free water on the aggregate.

- Water added in the batching process.

The mass of water removed from a fresh mixture by drying in a microwave can be used to calculate the $\mathrm{w} / \mathrm{c}$ ratio of the mixture. This test is described in AASHTO T 318 , and the total water content of the concrete sample can be expressed as a percentage:

Total water content $\%(\mathrm{~W})=($ wet sample mass - dry sample mass $) /$ wet sample mass.

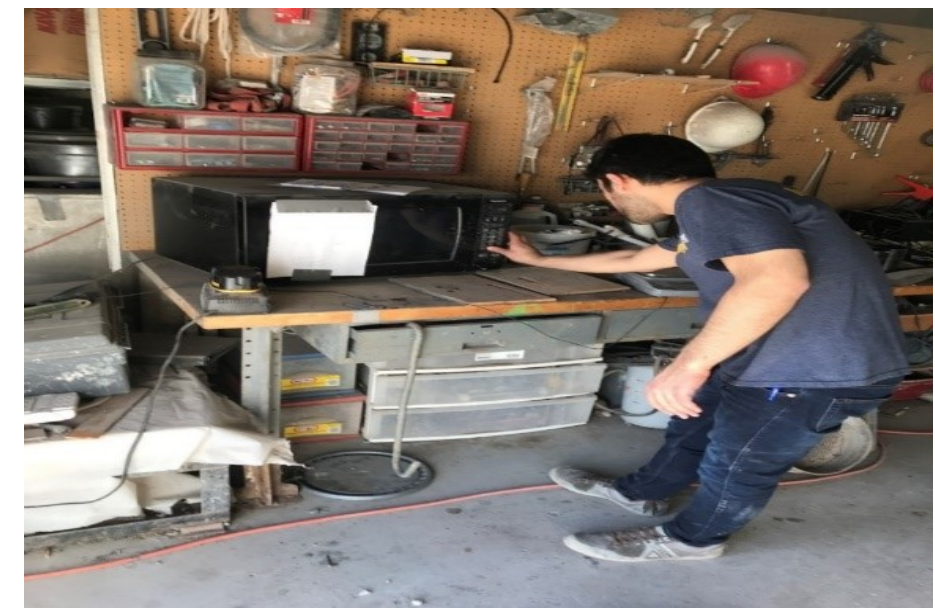

Figure 9 Water Cement ratio (Microwave method)

Mix Properties are shown in Table 4

\begin{tabular}{|c|c|c|c|}
\hline Concrete Type & Slump Measurements & Air Content (\%) & Measured (W/C) Ratio \\
\hline OPC 1 & 7.87 & 5.5 & 0.49 \\
\hline OPC 2 & 5.75 & 6.4 & 0.5 \\
\hline OPC 3 & 5 & 7.5 & 0.5 \\
\hline
\end{tabular}

Table 4 Mechanical Properties of the Mixes 
For this research study, concrete specimens from each concrete batch were tested under several different ASTM experimental procedures at different ages. The concrete specimens were tested at $0.5,1,3,7,14$, and 28 days for the following:

1- Setting Time

2- Hydration degree

3- Elastic modulus

4- Compressive Strength

5- Tensile Strength

6- Relative Humidity Analysis

7- Shrinkage Analysis

8- Ring Test

9 -Interfacial Compressive Stress Analysis

Each of the concrete specimens remained in the same curing tank at a constant temperature of $73^{\circ} \mathrm{F}$ during the entire 28-day span when they were not undergoing testing. 


\section{Setting Time Test}

Setting of concrete is identified as the transition of fresh concrete from the liquid phase to the solid phase. It is important to identify this phase change to plan transporting and placing of concrete. According to ASTM C 403, initial setting time is identified based on the penetration resistance measured on mortar sieved from a concrete mixture and it is defined as the time taken to achieve a penetration resistance of $500 \mathrm{psi}$.

A mortar sample was cast separately by using the mix design ratio. Tow cylinders with dimensions of 6 in. in height and 6 in. in diameter were filled with sieved mortar mix, then the containers with mortar were left for several minutes in an inclined position and bleed water accumulated at the surface of each specimen was removed using napkins. A needle of appropriate size was then inserted into the mortar, depending on the degree of the setting of the mortar. At the start, a needle with the largest diameter was used and subsequently needles of smaller diameters were used with the stiffening of mortar. The test started $3-4 \mathrm{hr}$. after mixing with subsequent tests made at 1/2- to 1-hr Intervals. Penetration needles with the following bearing areas $\left(\mathrm{in}^{2}\right): 1.00,0.50,0.25,0.05,0.025$, were used.

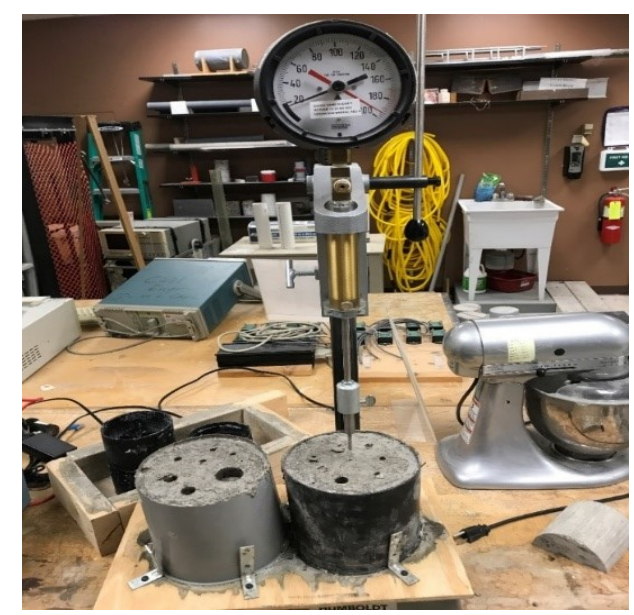

Figure 10 Setting Time Test 
The penetration resistance was calculated by dividing the force by the penetration area. The initial and the final setting time can be calculated by solving the fitting equation, at 500 and 4000 psi respectively as shown in Table 5. The penetration resistant is shown in Figure 11.

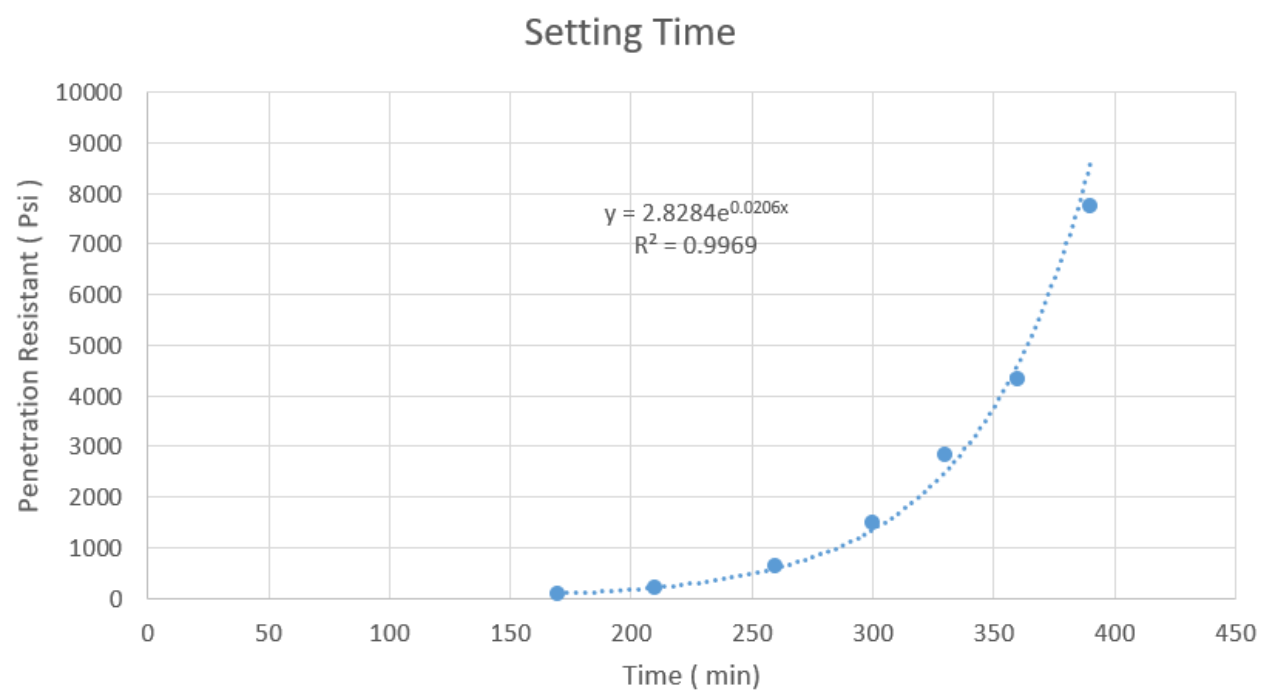

Figure 11 Setting Time Test results

\begin{tabular}{|c|c|c|c|}
\hline & Required $(\mathrm{P})$ & Time $(\mathrm{min})$ & Time $($ hrs.) \\
\hline Initial Setting & 500 & 251.21 & 4.19 \\
\hline Final Setting & 4000 & 352.15 & 5.87 \\
\hline
\end{tabular}

Table 5 Setting Time Test results 


\section{Degree of Hydration}

The hydration degree is defined as the extent of the reactions between the cementitious materials and the water and is the ratio between the quantity of the hydrated cementitious material and the original quantity of the cementitious material. The chemical reaction between the cement particle and the water occurs over time, as a result, the hydration degree is a function of time and can change from $0 \%$ to $100 \%$ once the reaction is complete. However, in reality, the cement does not reach full hydration, so $100 \%$ may never occur.

It's important to consider the curing temperature effects on the hydration process, where the higher temperature curing the faster chemical reaction which causes the higher degree of hydration in terms of actual time compared to the lower temperature curing. The maturity method can be applied on the calculation of concrete degree of hydration which makes the degree of hydration a function of equivalent age ( $t_{e}$ ) (Freiesleben and Pedersen 1993, Yikicci and Chen, 2015).

An indirect method was used to estimate the hydration degree based on the heat development that occurs during the hydration, by measuring the adiabatic temperature rise of concrete at a different time, the cement hydration degree is estimated by:

$$
\alpha(t)=\frac{H(t)}{H_{T}} \quad E q .44
$$

$\alpha(t)$ : Degree of hydration at time t.

$H(t)$ : The cumulative heat of hydration released at time $t,\left(\mathrm{~J} / \mathrm{m}^{3}\right)$.

$H_{T}$ : The ultimate heat of hydration of the concrete $\left(\mathrm{J} / \mathrm{m}^{3}\right)$. 
Once the released heat is measured the degree of hydration can be represented by the exponential formulation and it has been shown accurately represent the s-shape of the hydration development ( Lin and Chen, 2015)

$$
\alpha\left(t_{e}\right)=\alpha_{u} \exp \left(-\left[\frac{\tau}{t_{e}}\right]^{\beta}\right) \text { Eq. } 45
$$

Where: $\zeta$ and $\beta$ are two empirical constants which can be determined by fitting isothermal experimental results.

$\alpha_{u}$ is the ultimate degree of hydration and is a function of water to cement ratio.

Numerous tests that were used to determine the ultimate degree of hydration were performed by Mills, 1966. He measured the amount of chemically bound water after hydration is complete. He found a numerical equation can be used to find the ultimate degree of hydration based on the water/cement ratio given below :

$$
\alpha_{\mathrm{u}}=\frac{1.031 \cdot \mathrm{w} / \mathrm{c}}{0.194+\mathrm{w} / \mathrm{c}} \text { Eq. } 46
$$

\section{1- OPC Mixes}

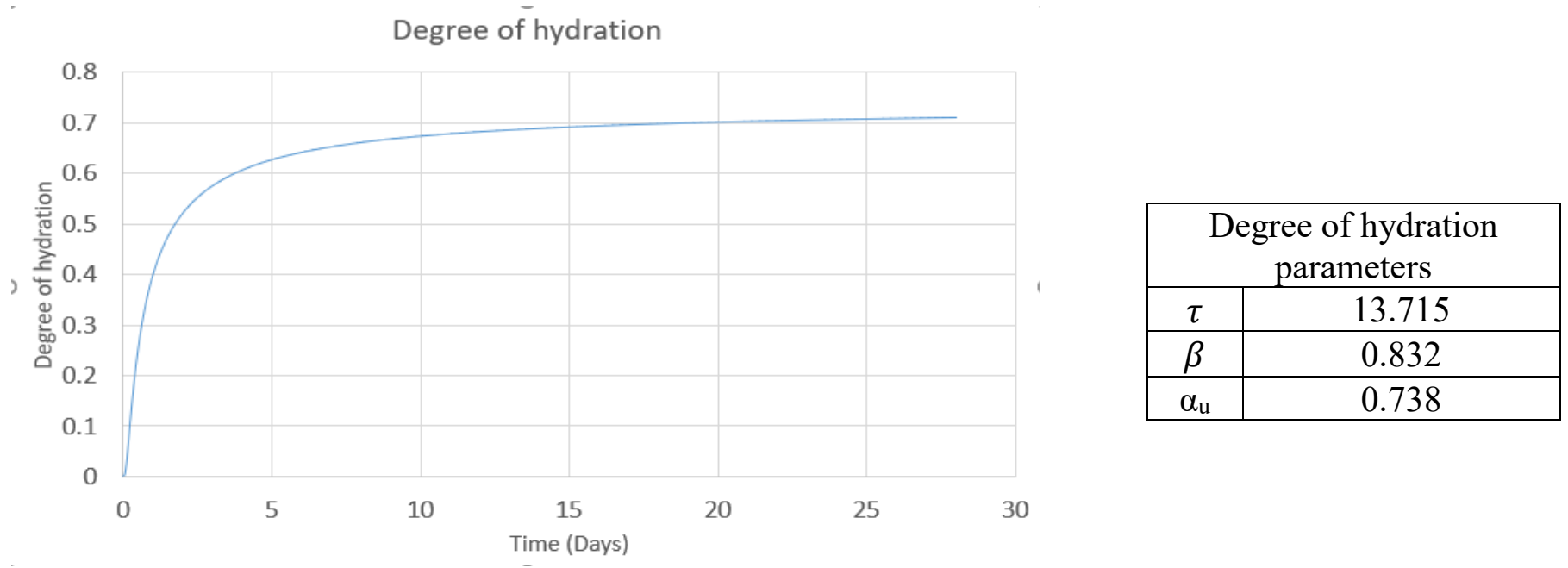

Figure 12 Relationship of cement hydration degree and age. 


\section{Elastic Modulus Testing}

For each of the concrete batches, two 6" x 12" cylindrical concrete specimens were tested at $1,3,7,14$, and 28 days using the "Standard Test Method for Static Modulus of Elasticity and Poisson's Ratio of Concrete in Compression" (ASTM C469, 2002). Results are shown in Figure 13 and Figure 14, Tests results are shown in Table 6 and Table 7.

\section{OPC 2}

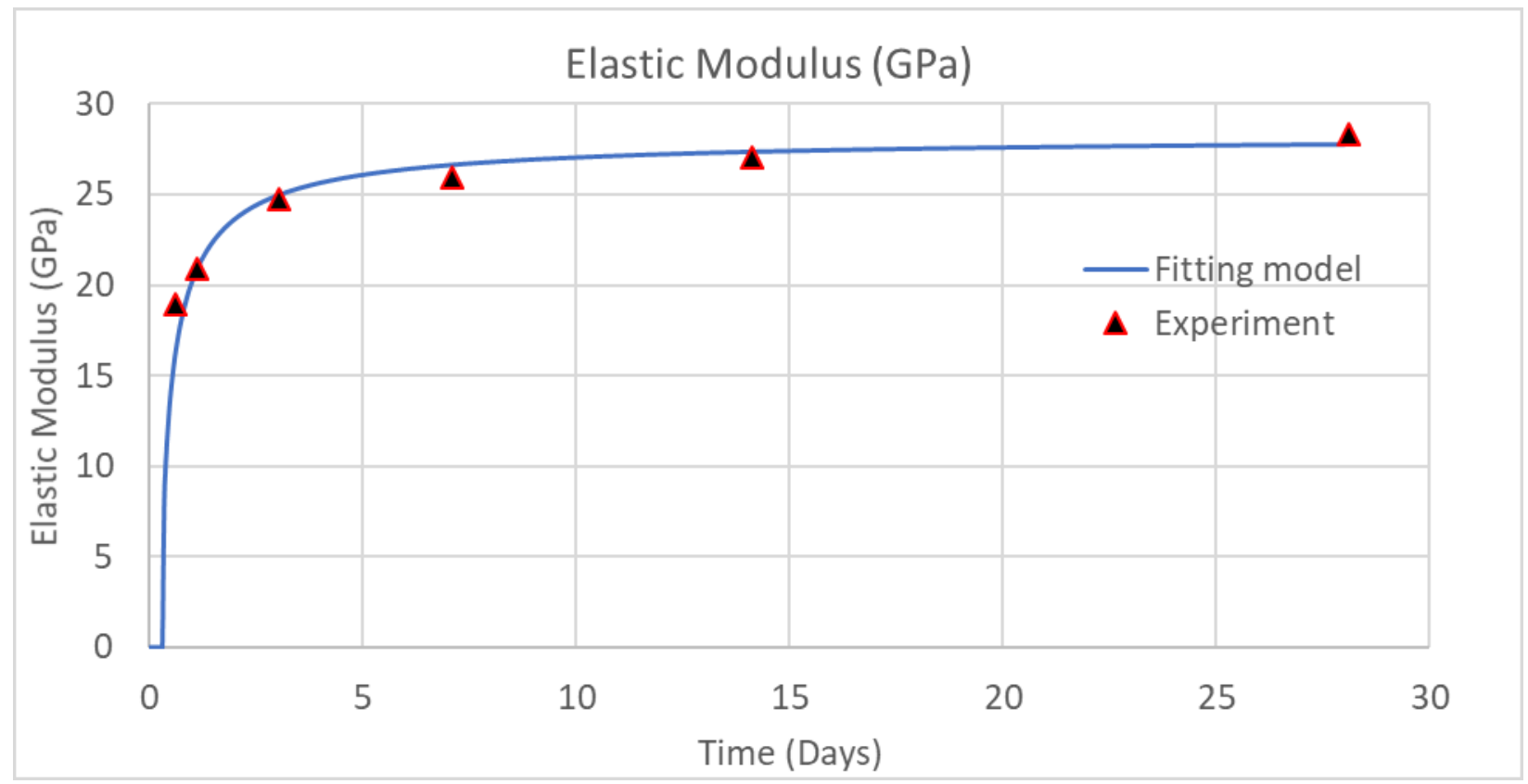

Figure 13 Elastic modulus-based degree of hydration model VS actual experiment results OPC 2

\begin{tabular}{|c|c|}
\hline Time (Day) & Elastic Modulus (GPa) \\
\hline 0 & 0 \\
\hline 0.6 & 18.98 \\
\hline 1.125 & 20.88 \\
\hline 3 & 24.73 \\
\hline 7 & 25.94 \\
\hline 14 & 27.07 \\
\hline 28 & 28.32 \\
\hline
\end{tabular}

\begin{tabular}{|c|c|}
\hline \multicolumn{2}{|c|}{ Young Modulus model parameters } \\
\hline E (28) GPA & 28 \\
\hline b & 0.4 \\
\hline
\end{tabular}

Table 6 Elastic modulus measurements for Concrete Batches OPC 2 


\section{OPC 3}

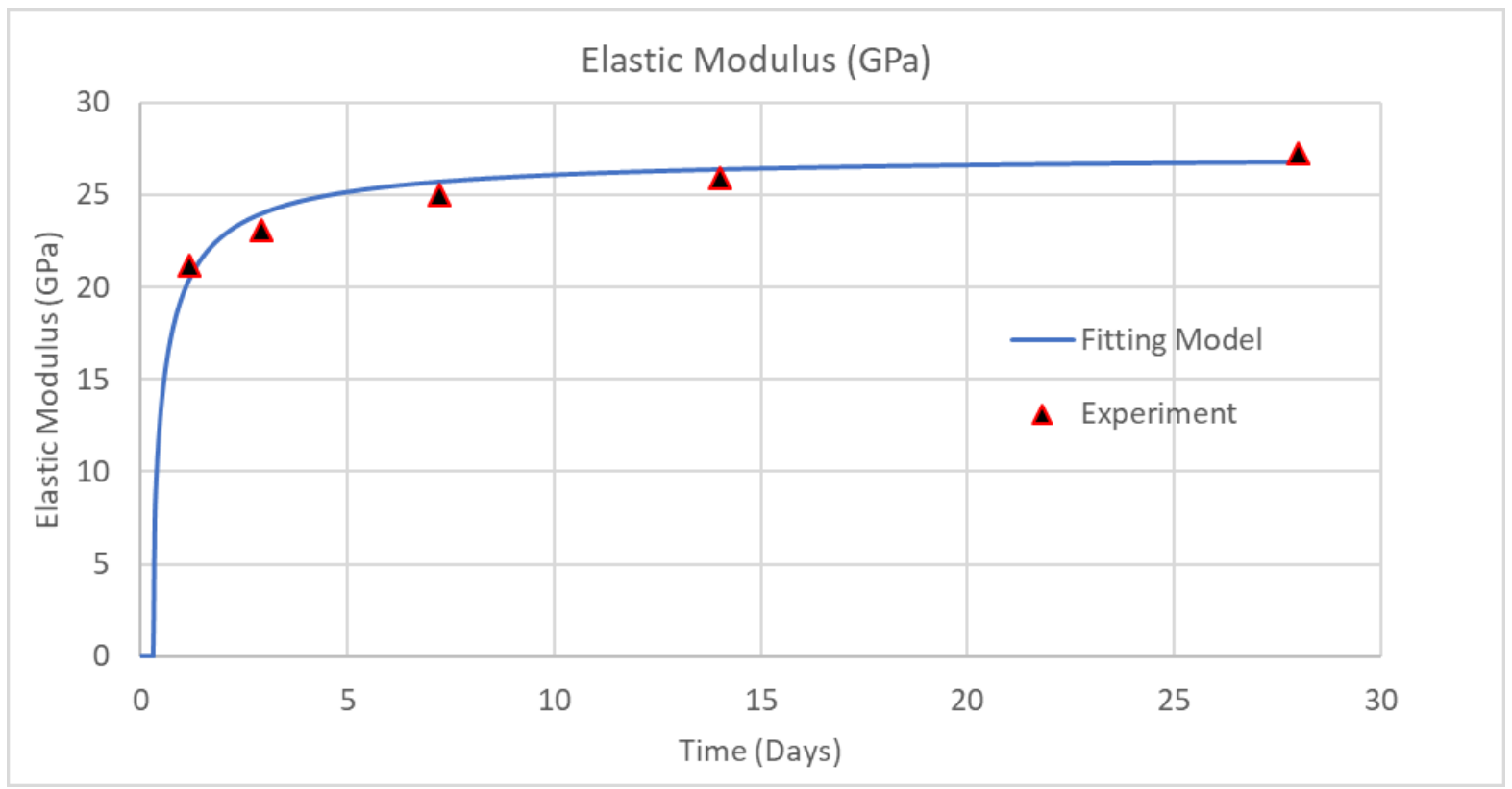

Figure 14 Elastic modulus-based degree of hydration model VS actual experiment results OPC 3

\begin{tabular}{|c|c|}
\hline Time (Day) & Elastic Modulus (GPa) \\
\hline 0 & 0 \\
\hline 1.167 & 21.15 \\
\hline 2.92 & 23 \\
\hline 7.2 & 25 \\
\hline 14 & 25.87 \\
\hline 28 & 27.12 \\
\hline
\end{tabular}

\begin{tabular}{|c|c|}
\hline \multicolumn{2}{|c|}{ Young Modulus model parameters } \\
\hline E (28) GPA & 26 \\
\hline b & 0.4 \\
\hline
\end{tabular}

Table 7 Elastic modulus measurements for Concrete Batches OPC 3 


\section{Compressive Strength Testing}

For each concrete batch, at least two 4" x 8" cylindrical specimens were tested at each of the above-mentioned days for compressive strength at the Concrete Materials Laboratory at West Virginia University. The ASTM Standard for Compressive Strength of Cylindrical Concrete Specimens (ASTM C39) was followed for each testing (ASTM C39, 2003). Each specimen was loaded under a Uni-axial load under a constant loading rate until failure. Results are shown in

Figure 15, Figure 16 and Figure 17. And Table 8 Table 9 and Table 10.

\section{1- OPC 1}

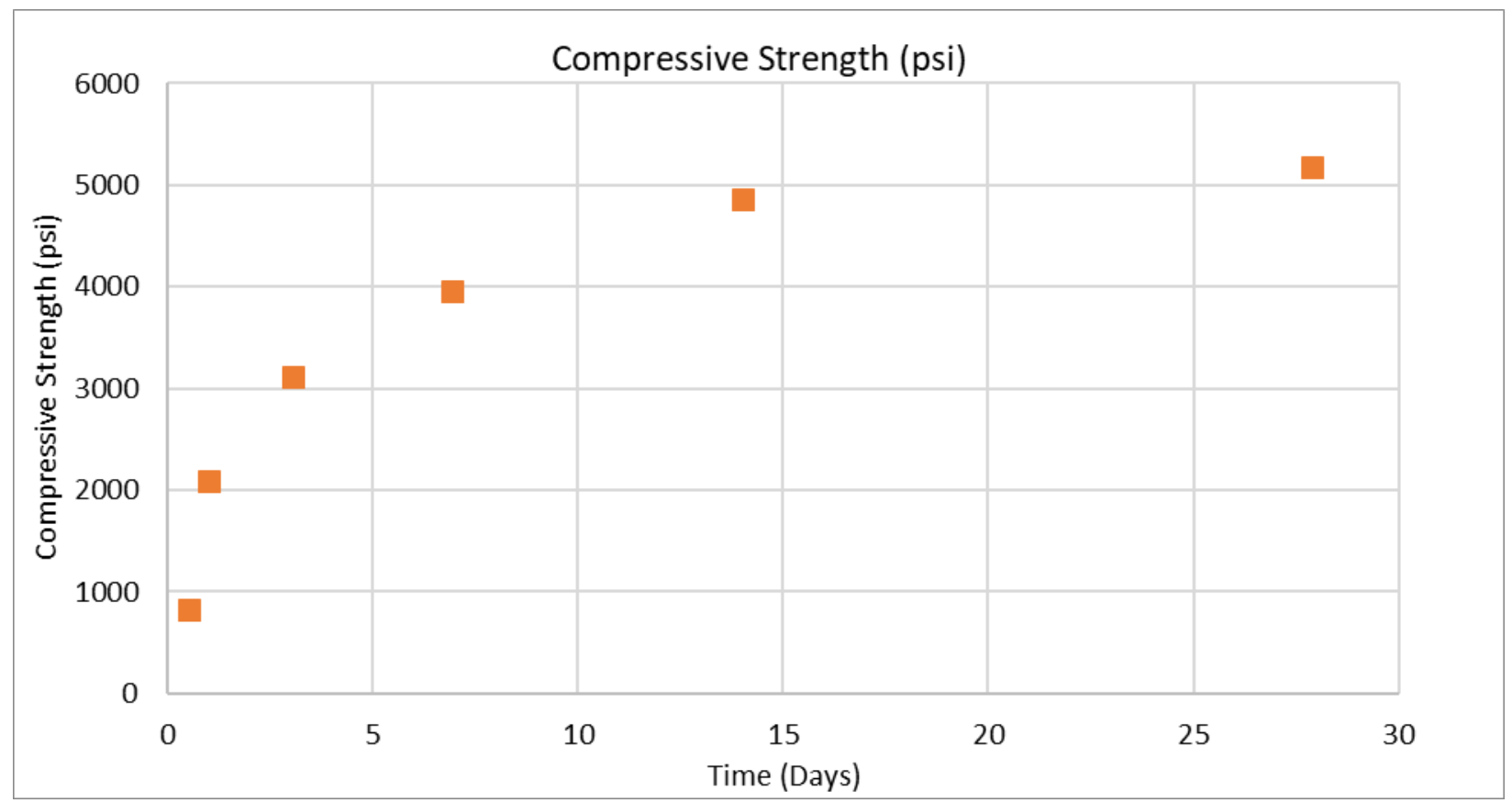

Figure 15 Compressive Strength development curves for concrete cylinders OPC 1 


\begin{tabular}{|c|c|}
\hline Time (Day) & Compressive Strength (psi) \\
\hline 0 & 0 \\
\hline 0.5 & 819.65 \\
\hline 1 & 2084.93 \\
\hline 3 & 3103.52 \\
\hline 7 & 3947.1 \\
\hline 14. & 4854.23 \\
\hline 27.92 & 5172.54 \\
\hline
\end{tabular}

Table 8 Compressive Strength measurements for Concrete Batches OPC 1

\section{2- OPC 2}

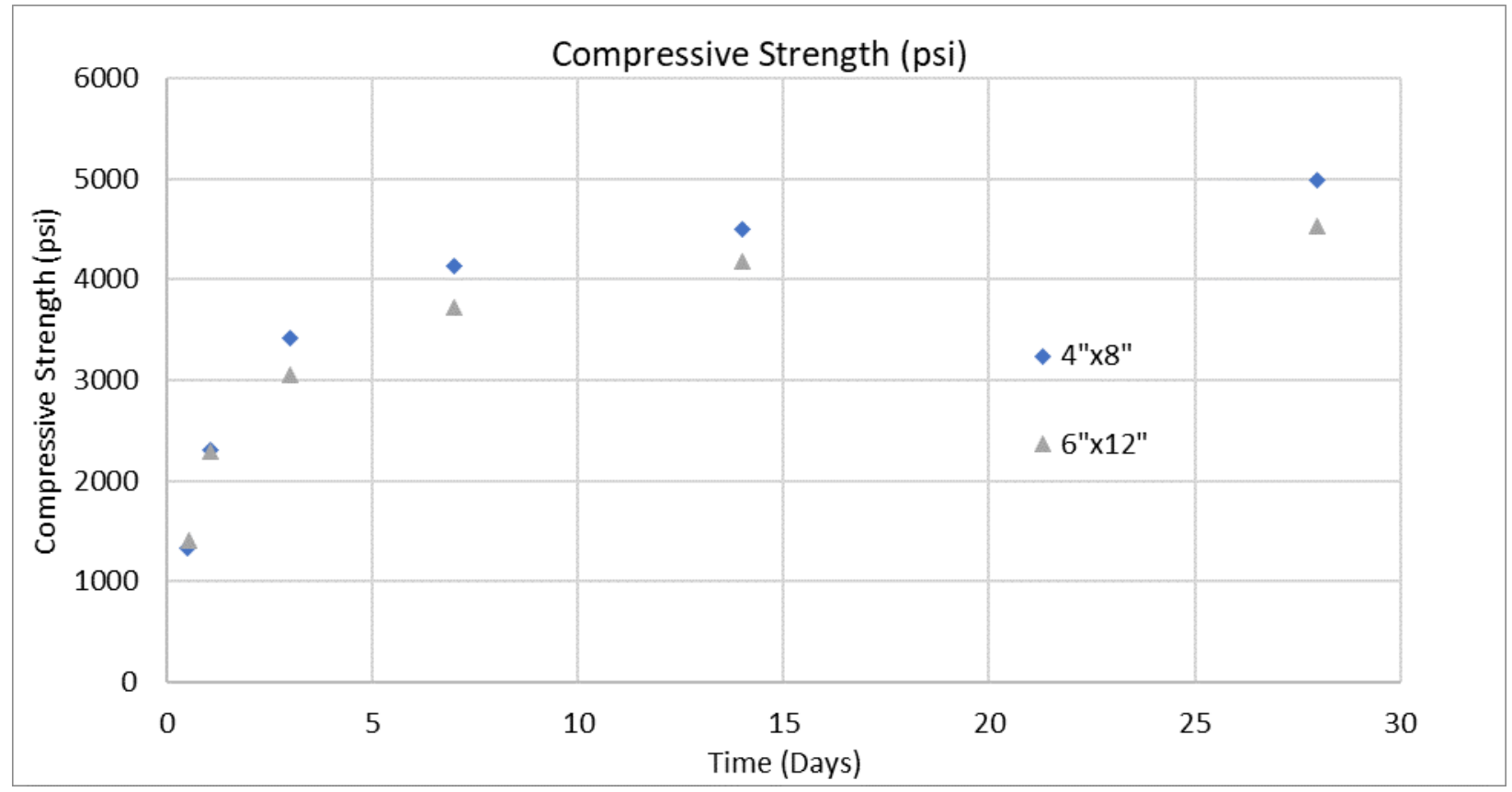

Figure 16 Compressive Strength development curves for concrete cylinders OPC 2

\begin{tabular}{|c|c|c|}
\hline \multicolumn{3}{|c|}{ Measured Compressive Strength $(\mathrm{psi})$} \\
\hline Test Day & OPC2 $(6 \times 12)$ & OPC2 $(4 \times 8)$ \\
\hline 0.5 & 1404.1 & 1332.92 \\
\hline 1 & 2287.12 & 2303.78 \\
\hline 3 & 3059.31 & 3411.22 \\
\hline 7 & 3725.4 & 4138.03 \\
\hline 14 & 4173.39 & 4496.13 \\
\hline 28 & 4532.97 & 4986.85 \\
\hline
\end{tabular}

Table 9 Compressive Strength measurements for Concrete Batches OPC 2 


\section{3- OPC 3}

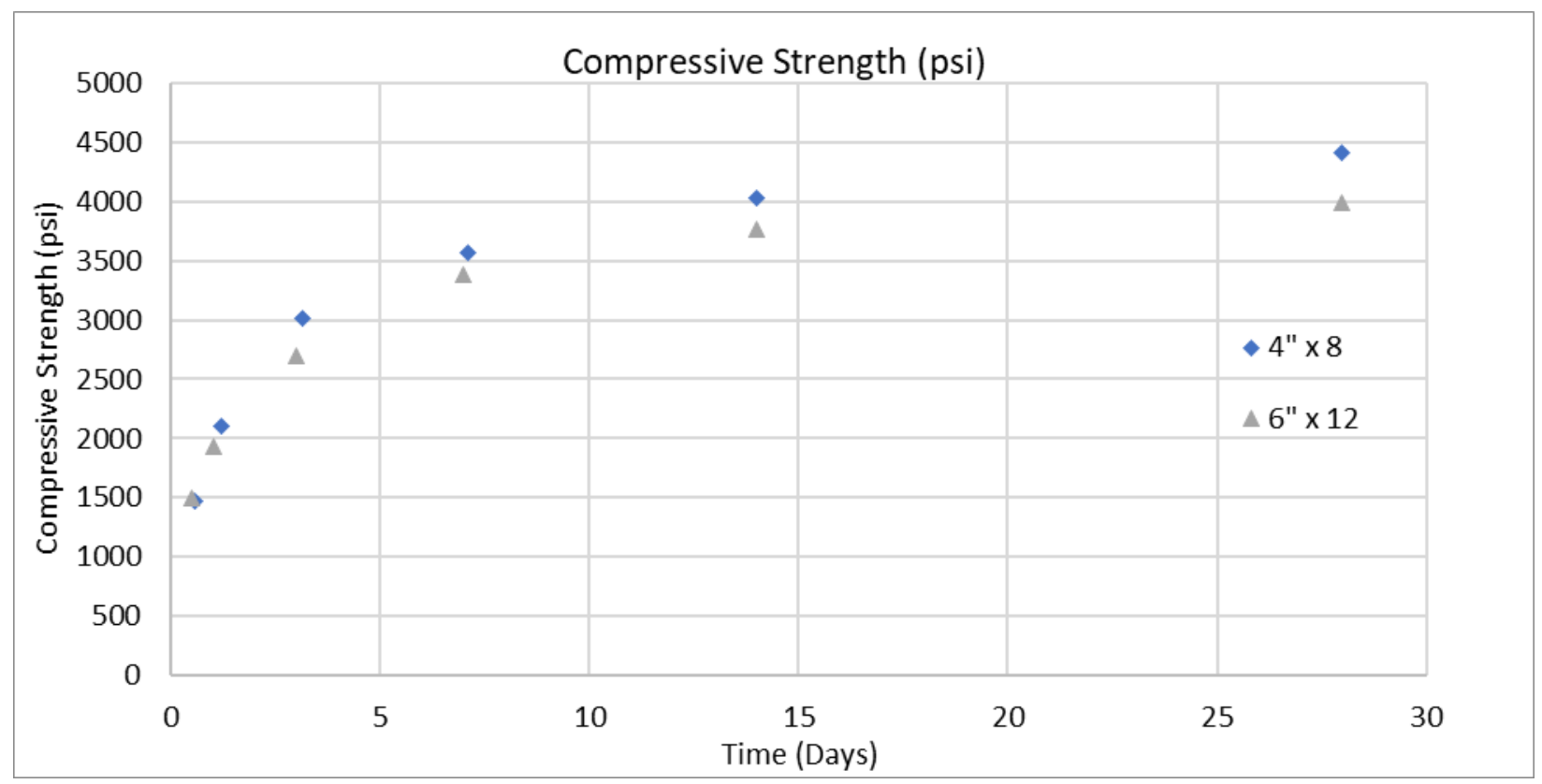

Figure 17 Compressive Strength development curves for concrete cylinders OPC 3

\begin{tabular}{|c|c|c|}
\hline \multicolumn{3}{|c|}{ Measured Compressive Strength (psi) } \\
\hline Test Day & OPC3 $(6 \times 12)$ & OPC3 $(4 \times 8)$ \\
\hline 0.5 & 1497.24 & 1472.18 \\
\hline 1 & 1927.54 & 2108.8 \\
\hline 3 & 2695.85 & 3010.68 \\
\hline 7 & 3389.41 & 3573 \\
\hline 14 & 3772.56 & 4031.93 \\
\hline 28 & 3987.71 & 4416.55 \\
\hline
\end{tabular}

Table 10 Compressive Strength measurements for Concrete Batches OPC 3 


\section{Tensile Strength Test}

The tensile strength of concrete is one of the basic and important properties. Splitting tensile strength test on concrete cylinder is a method to determine the tensile strength of concrete.

The concrete is very weak in tension due to its brittle nature and is not expected to resist the direct tension. The concrete develops cracks when subjected to tensile forces. Thus, it is necessary to determine the tensile strength of concrete to determine the load at which the concrete members may crack.

Two 4"x 8" and 6"x 12" cylindrical specimens were tested at each of the abovementioned days for tensile strength at the Concrete Materials Laboratory at West Virginia University. Standard Test Method for Splitting Tensile Strength of Cylindrical Concrete Specimens. Results are shown in Figure 18, Figure 19, Table 11 and Table 12 Calculate the splitting tensile strength of the specimen as follows:

$$
T=2 P / \pi l d
$$

Eq. 47

$P$ : applied load

$D$ :diameter of the specimen

$L$ : length of the specimen 


\section{1- OPC 2}

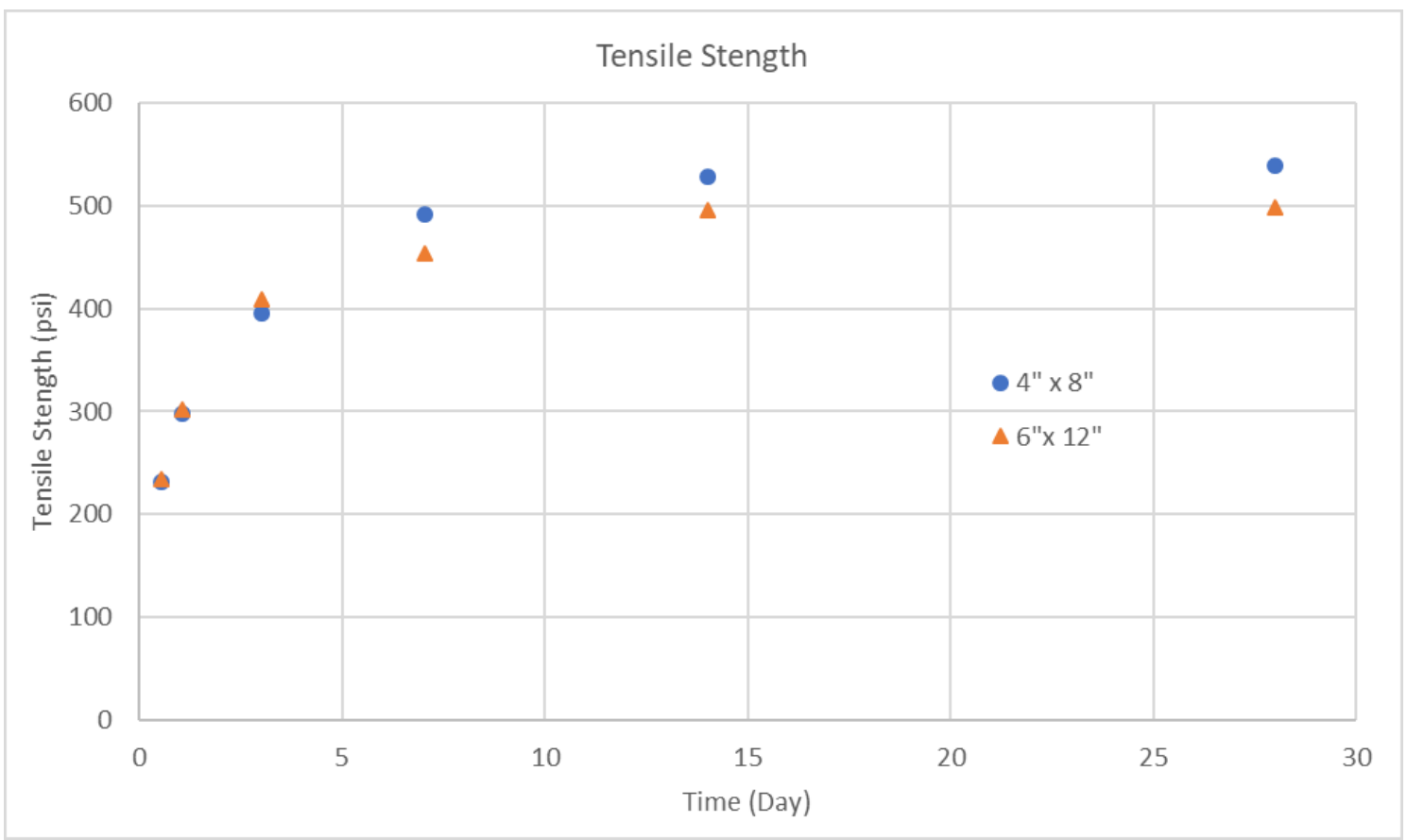

Figure 18 Tensile Strength development curves for concrete cylinders OPC 2

\begin{tabular}{|c|c|c|}
\hline \multicolumn{3}{|c|}{ Measured Tensile Strength $(\mathrm{psi})$} \\
\hline Test Day & OPC2 $(6 \times 12)$ & OPC2 $(4 \times 8)$ \\
\hline 0.5 & 233.7 & 231.07 \\
\hline 1 & 301.51 & 297.62 \\
\hline 3 & 409.06 & 395.5 \\
\hline 7 & 453.3 & 492.29 \\
\hline 14 & 496.07 & 528.5 \\
\hline 28 & 497.8 & 539.44 \\
\hline
\end{tabular}

Table 11 Tensile Strength measurements for Concrete Batches OPC 2 


\section{2- OPC 3}

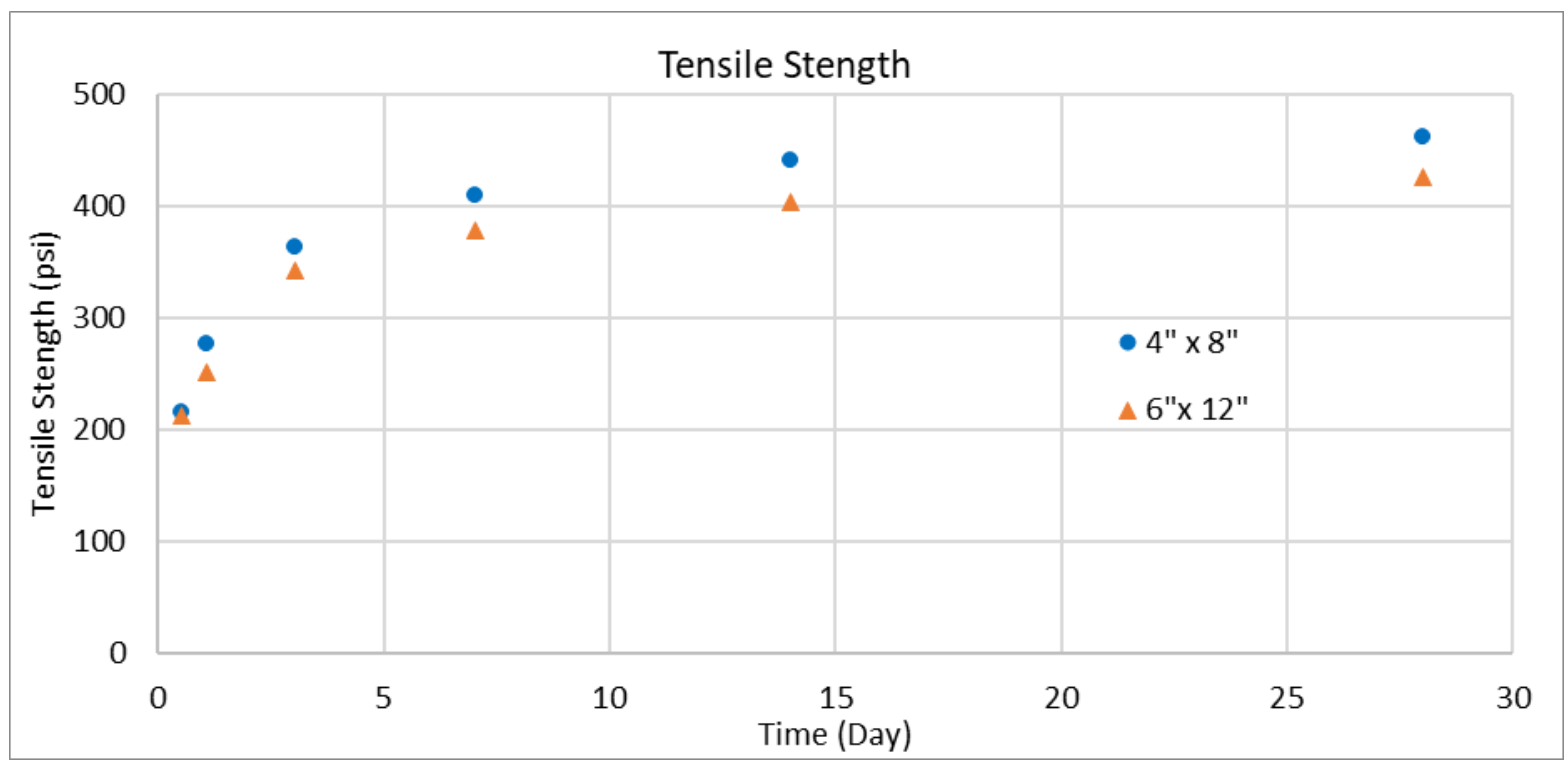

Figure 19 Tensile Strength development curves for concrete cylinders OPC 3

\begin{tabular}{|c|c|c|}
\hline \multicolumn{3}{|c|}{ Measured Tensile Strength $(\mathrm{psi})$} \\
\hline Test Day & OPC $(6 \times 12)$ & OPC $(4 \times 8)$ \\
\hline 0.5 & 211.91 & 216.05 \\
\hline 1 & 252 & 277.19 \\
\hline 3 & 343.07 & 363.87 \\
\hline 7 & 378.94 & 409.72 \\
\hline 14 & 403.5 & 440.77 \\
\hline 28 & 426.67 & 461.85 \\
\hline
\end{tabular}

Table 12 Tensile Strength measurements for Concrete Batches OPC 3 


\section{Shrinkage Test}

Six square prism specimens with dimensions of $3 \times 3 \times 12$ in. $(76 \times 76 \times 305 \mathrm{~mm})$ were used in the free shrinkage test in accordance with ASTM C157 Method. Figure 21 shows the shrinkage test specimens. Steel end plates with a hole at their centers were used to hold the contact points in place at each end of the specimen. The length change is measured with a device called a comparator. It's an LVDT on a stand.

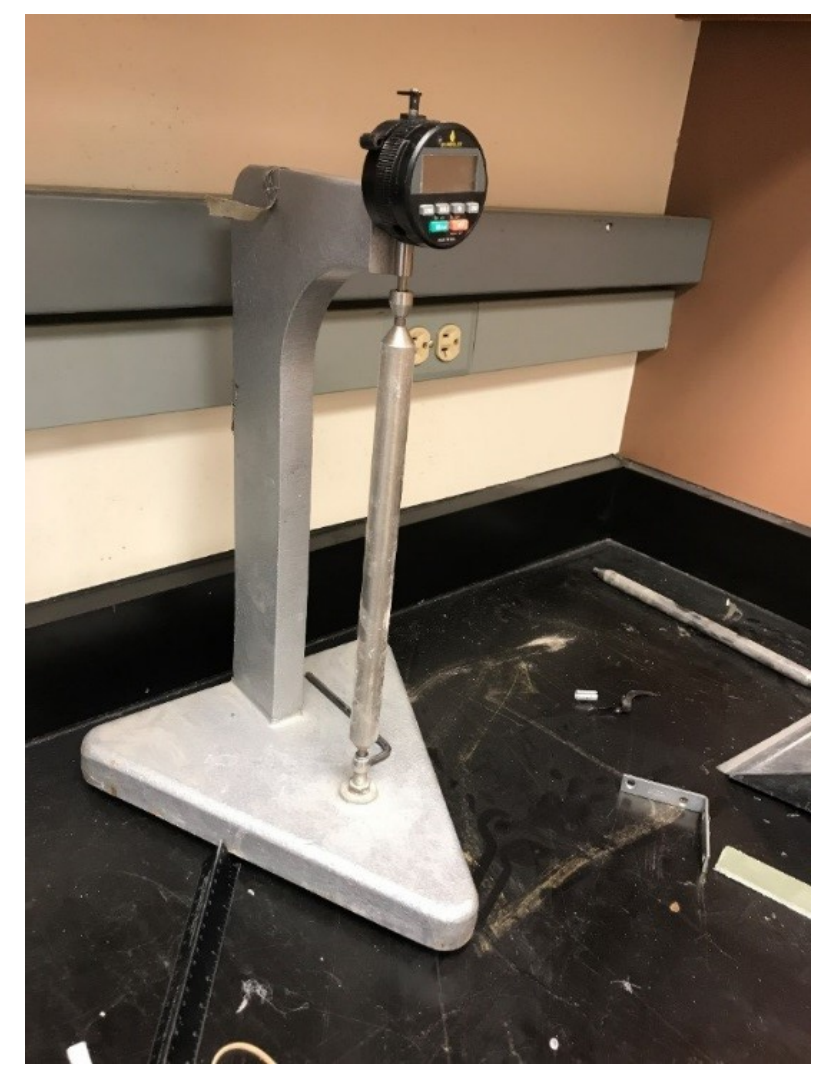

Figure 20 comparator to measure the length change

The Length Comparator, with Invar Bar and Digital Indicator, is used for measuring length changes in specimens cast with special gage studs in the ends to fit the bottom and top anvils of the Comparator. The sensitivity of the indicator is 0.0001 in $(0.002 \mathrm{~mm})$ divisions measures specimen length. The comparator is shown in Figure 20. 
Three different types of drying were performed on the specimens as follow:

1. Fully wrapped

2. Half-wrapped

3. No wrap

Full-wrap specimens were used to determine the concrete autogenous shrinkage due to the hydration only.

Half-wrap specimens were used to simulate the shrinkage in the concrete ring since the concrete rings have a 1.5-inch thickness and the shrinkage prisms also have 1.5-inch drying thickness.

No wrap specimens were used to measure the drying shrinkage of the concrete. Following the ASTM procedure

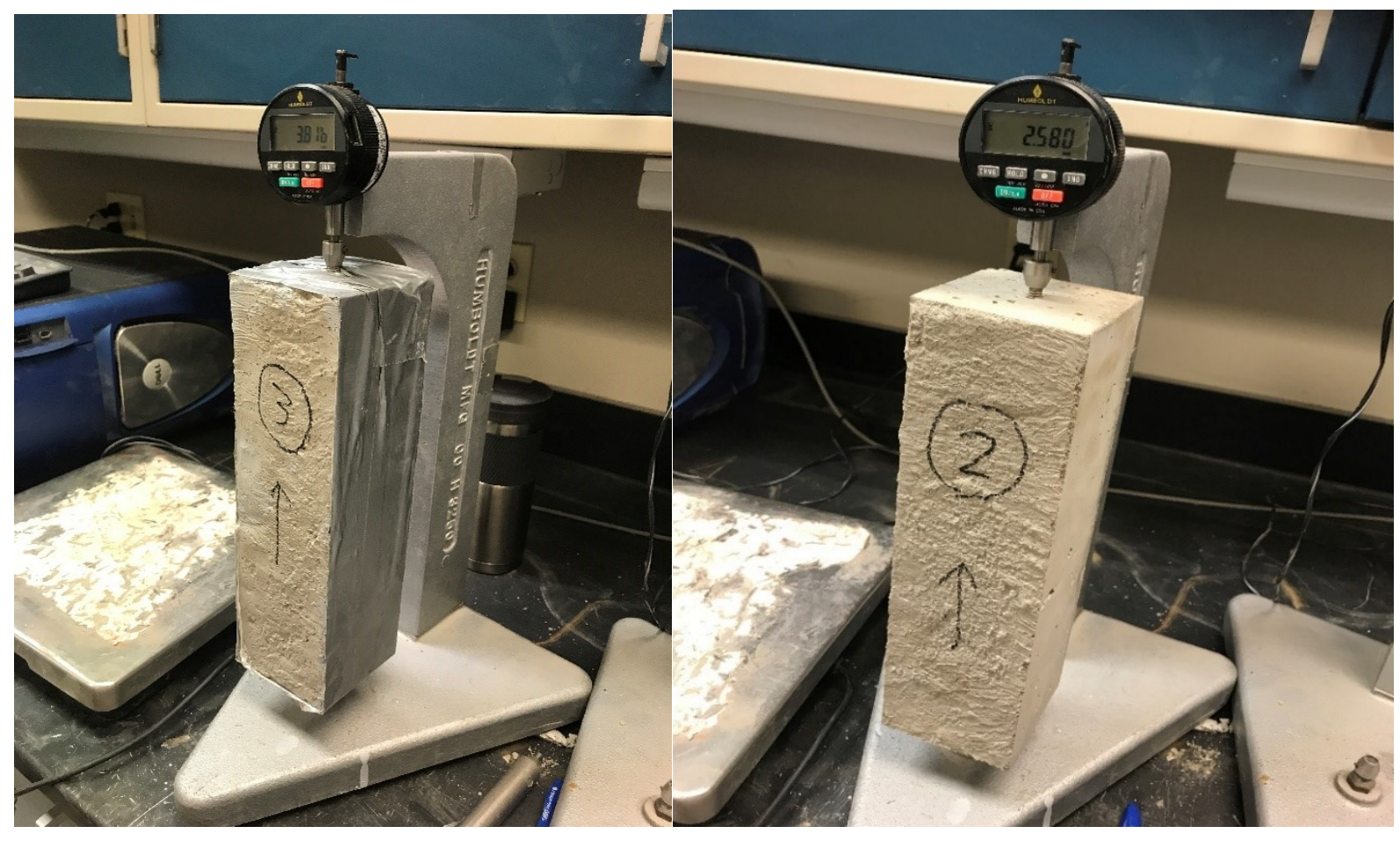

Figure 21 Shrinkage specimens (2) No-Wrap (3) Half-Wrapped 


\section{Experiments Results}

\section{1- OPC 1}

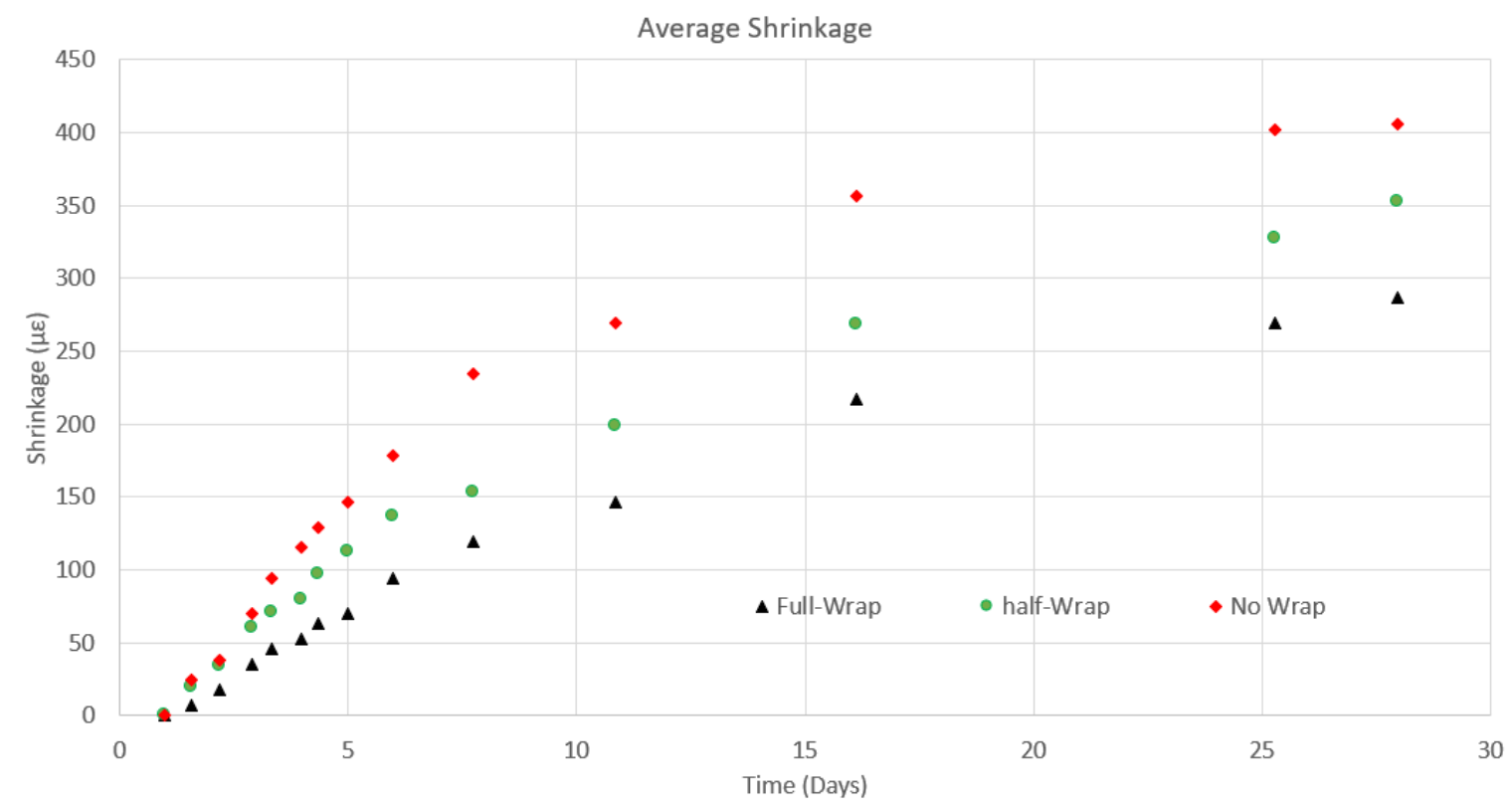

Figure 22 Average Shrinkage (micro-strain) Experiments OPC 1

\section{2- OPC 2}

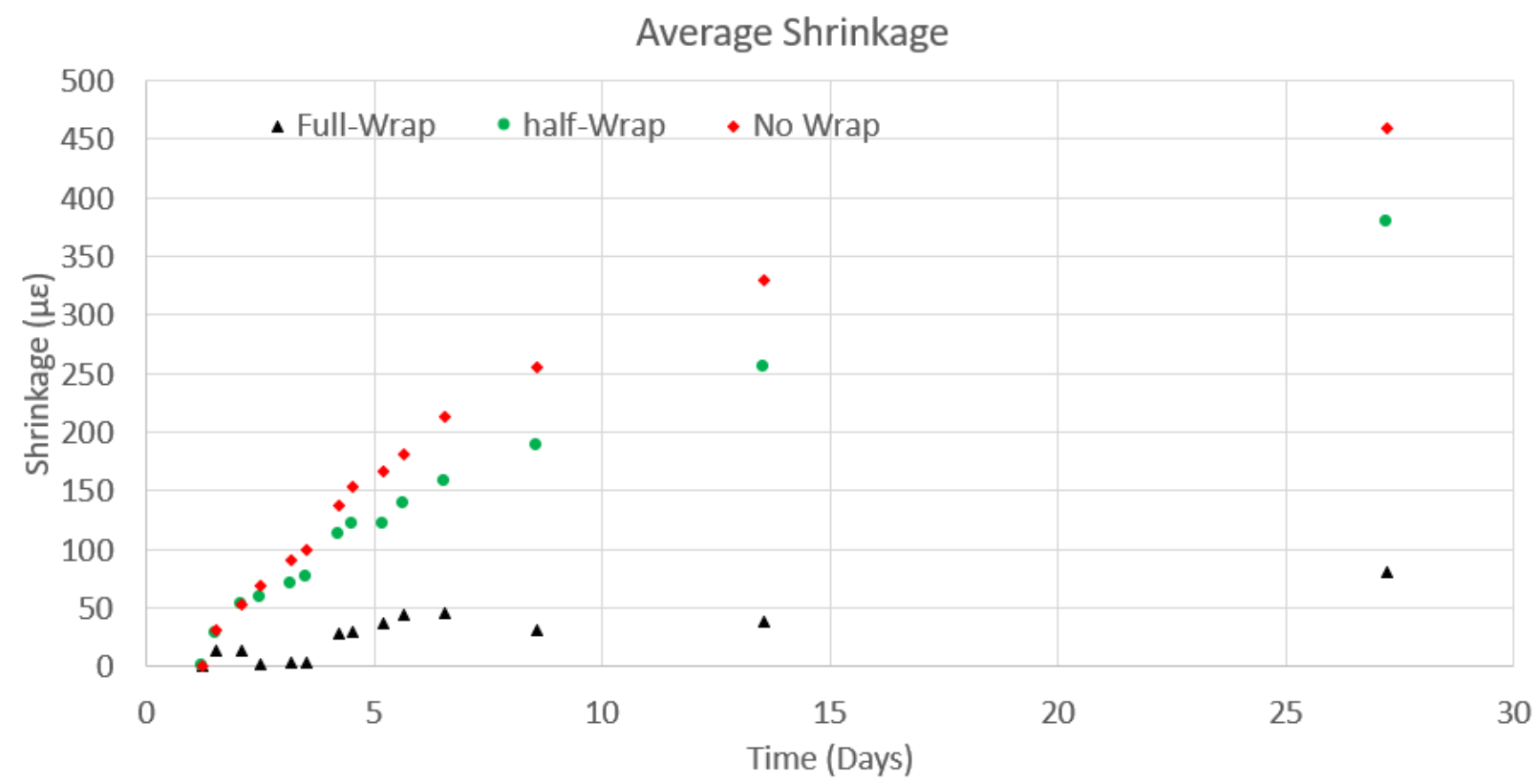

Figure 23 Average Shrinkage (micro-strain) Experiments OPC 2 


\section{3- OPC 3}

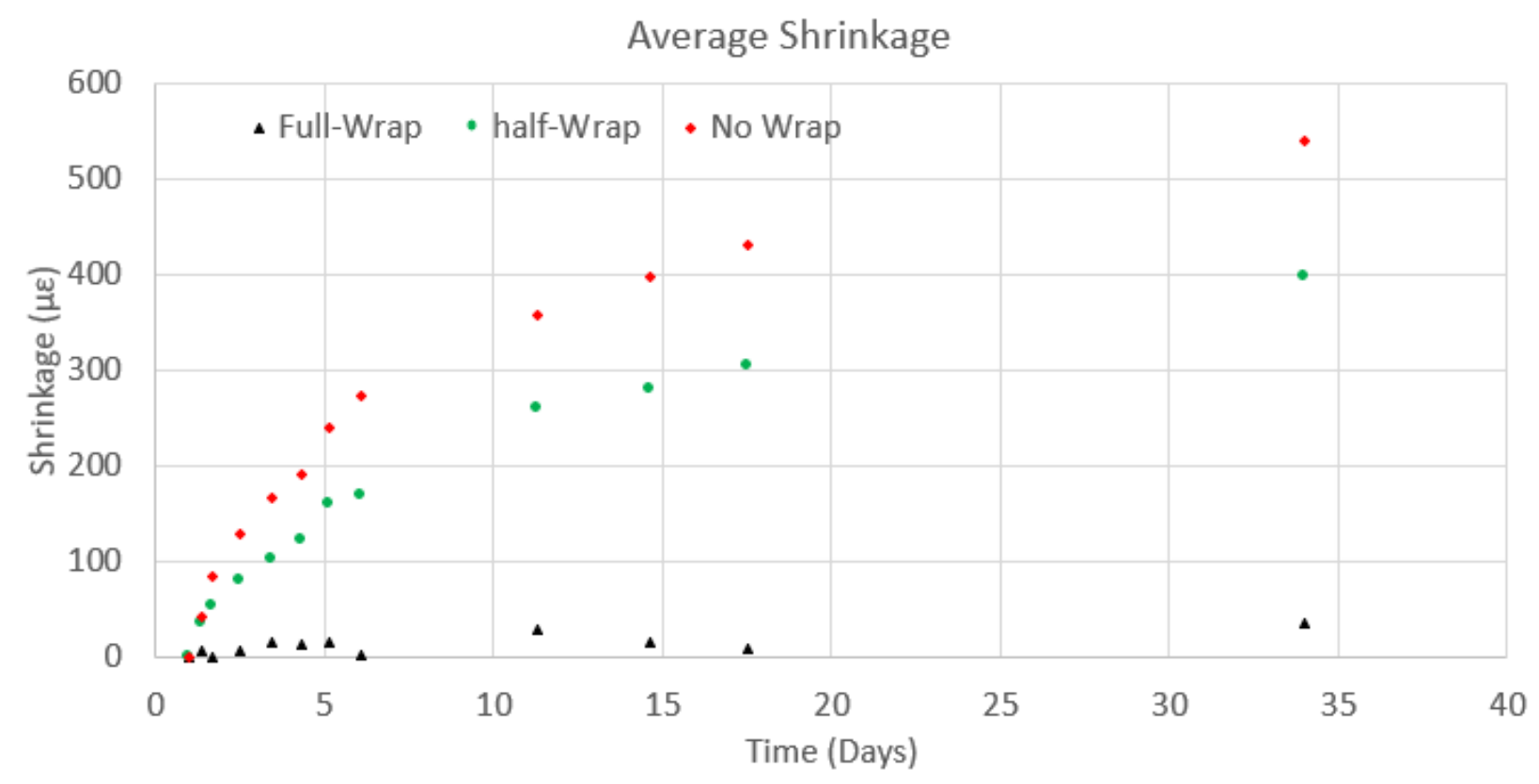

Figure 24 Average Shrinkage (micro-strain) Experiments OPC 3

The results are shown in Figure 22, Figure 23 and Figure 24 indicate that the higher the environment temperature, the higher concrete shrinkage will occur; the environmental temperature and humidity influence will be discussed in the following section.

For the fully wrap case in OPC 1 very high autogenous shrinkage which is not reasonable; the specimens must have not been fully wrapped correctly, and the concrete was undergoing drying shrinkage. The testing preparation was improved after the OPC 1 test; to ensure fully wrapped not only plastic wrap was used in OPC 2 and OPC 3, but also tape was used to ensure that no moisture loss can happen. Figures 25-26 represent all mixes together for No-Wrap and Half-Wrap. 


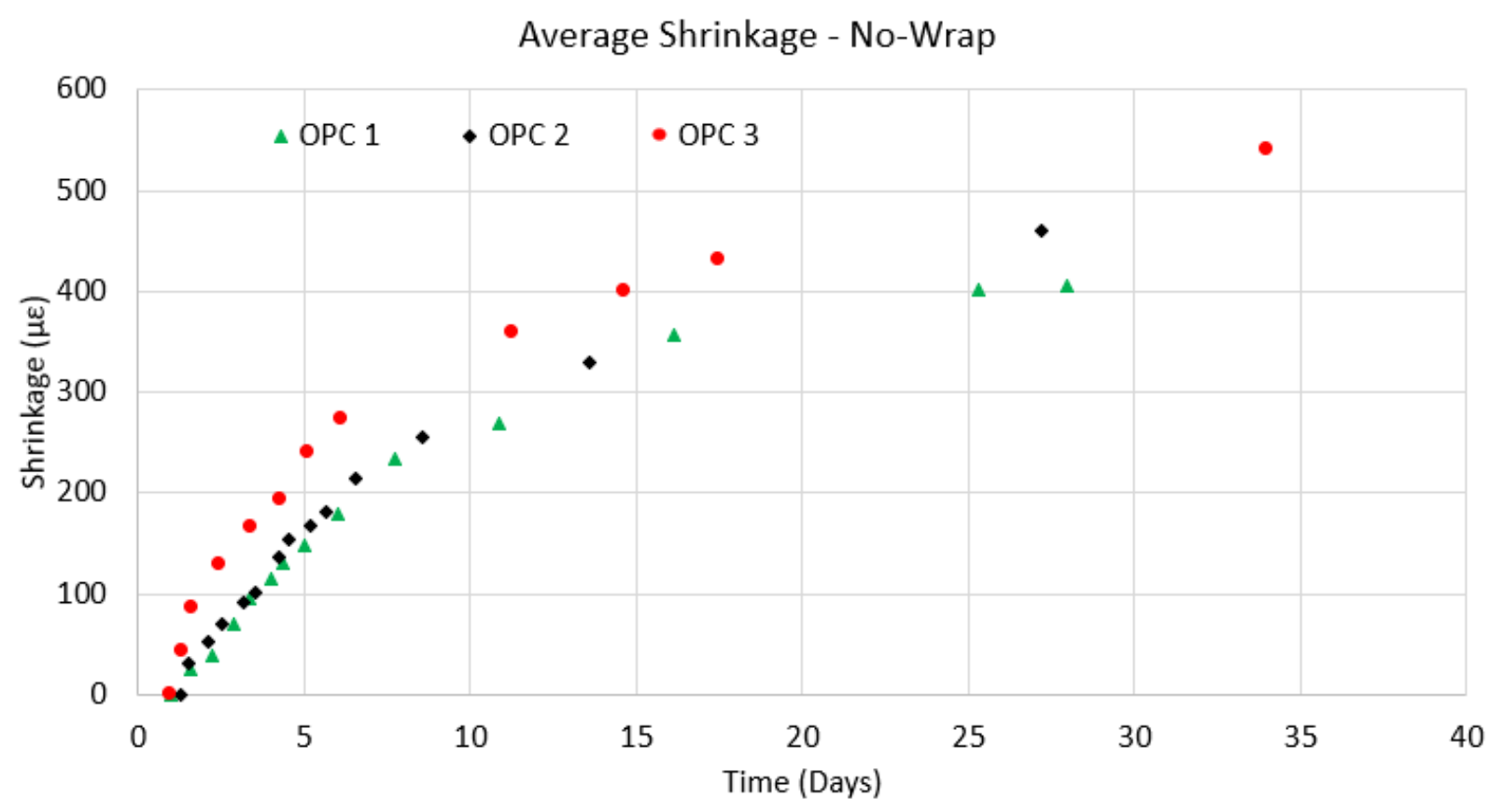

Figure 25 Average No-Wrap Shrinkage (micro-strain) Experiments

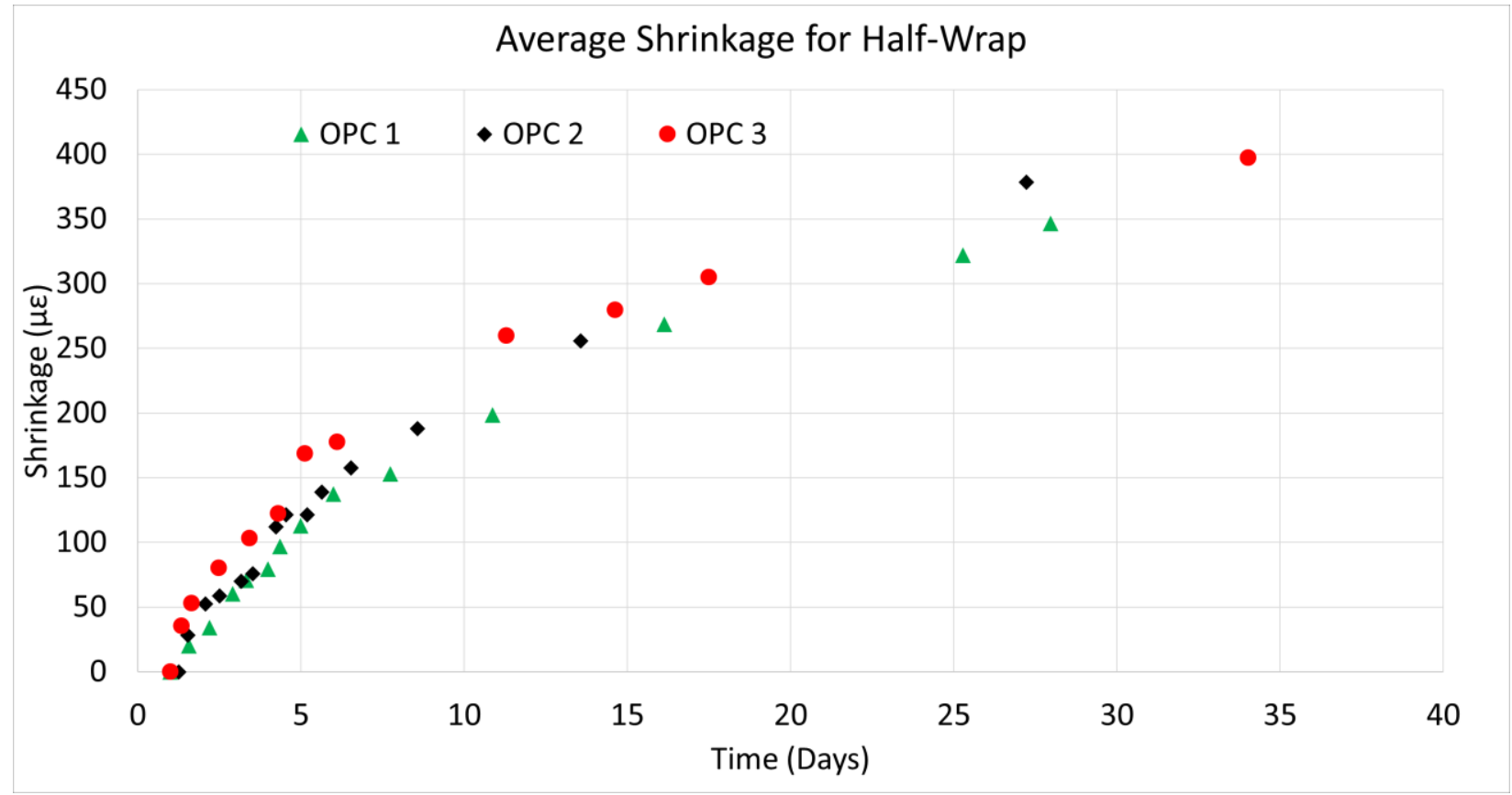

Figure 26 Average Half-Wrap Shrinkage (micro-strain) Experiments 


\section{Ambient Temperature and Humidity}

The rings and the shrinkage specimens were tested in a laboratory room where variations

of the environmental temperatures and air humidity were observed during testing, therefore there are different drying behavior. Although the same mix design was used, different drying behavior was observed due to the fact that the saturation pressure of the water is a function of the temperature and the relative humidity.

To further investigate the phenomenon, the partial vapor pressure was calculated and also the saturation pressure of the water. The difference between the partial vapor pressure and the saturation pressure of the water can explain the speed of the drying process.

The measured relative humidity explains how close the air to the saturation

$$
\mathrm{RH}=\frac{P_{i}}{P_{\text {sat }}} X 100 \% \text { Eq. } 48
$$

Where

Pi: is the partial vapor pressure

$P_{\text {sat: }}$ the saturation pressure of the water

The saturation pressure of the water is a function of the humidity and the temperature and can be calculated using the empirical equation or given tables. The empirical equations given below give a good approximation to the saturation water vapor pressure in Pascal at temperatures within the limits of the earth's climate. (Tetens, O., 1930):

$$
\mathrm{P}_{\mathrm{sat}}=610.78 \times \exp (\mathrm{T} /(\mathrm{T}+238.3) \times 17.2694) \text { Eq. } 49
$$


Where:

$\mathrm{T}$ : is the temperature in ${ }^{\circ} \mathrm{C}$.

The Absolute humidity which is (g water/g dry ) which is a gram of water over a gram of dry air at a given temperature and humidity.

$$
\text { Absolute humidity }=\frac{\mathrm{Pi} \times \mathrm{M}_{(\mathrm{h} 2 \mathrm{o})}}{\left.(\mathrm{P}-\mathrm{Pi}) \times \mathrm{M}_{(\mathrm{dry}} \text { air }\right)} \text { Eq. } 50
$$

Where:

Pi: is the partial vapor pressure.

$\mathrm{P}=$ One atmosphere of pressure at sea level is equivalent to 1 Barr or $760 \mathrm{mmHg}$ pressure.

$\mathrm{M}_{(\mathrm{h} 2 \mathrm{o})}$ is the molecular weight of the water $18 \mathrm{gr} / \mathrm{mol}$.

$\mathrm{M}_{\text {(dry air) }}$ is the molecular weight of the average dry air $29 \mathrm{gr} / \mathrm{mol}$.

In order to find the relationship between the shrinkage factor and the environmental effect, the slope value of the integration of the difference between the difference between the partial vapor pressure and the saturation pressure of the water was calculated from the accumulated integration shown in Figure 31 which again indicates the speed of the drying process under different environment situation.

As shown OPC 3 will dry faster due to the fact of higher difference between the partial vapor pressure and the saturation pressure of the water and that can be verified from the experiments. Although OPC 1, OPC 2 were tested in a different environment ( Temperature and humidity ) but as shown the drying process was close.

It should be noted that the drying for OPC 2 was started after 30 hours of the casting, and the drying for OPC 1 and OPC 3 was started after 24 hours of the casting. 


\section{1- OPC 1}

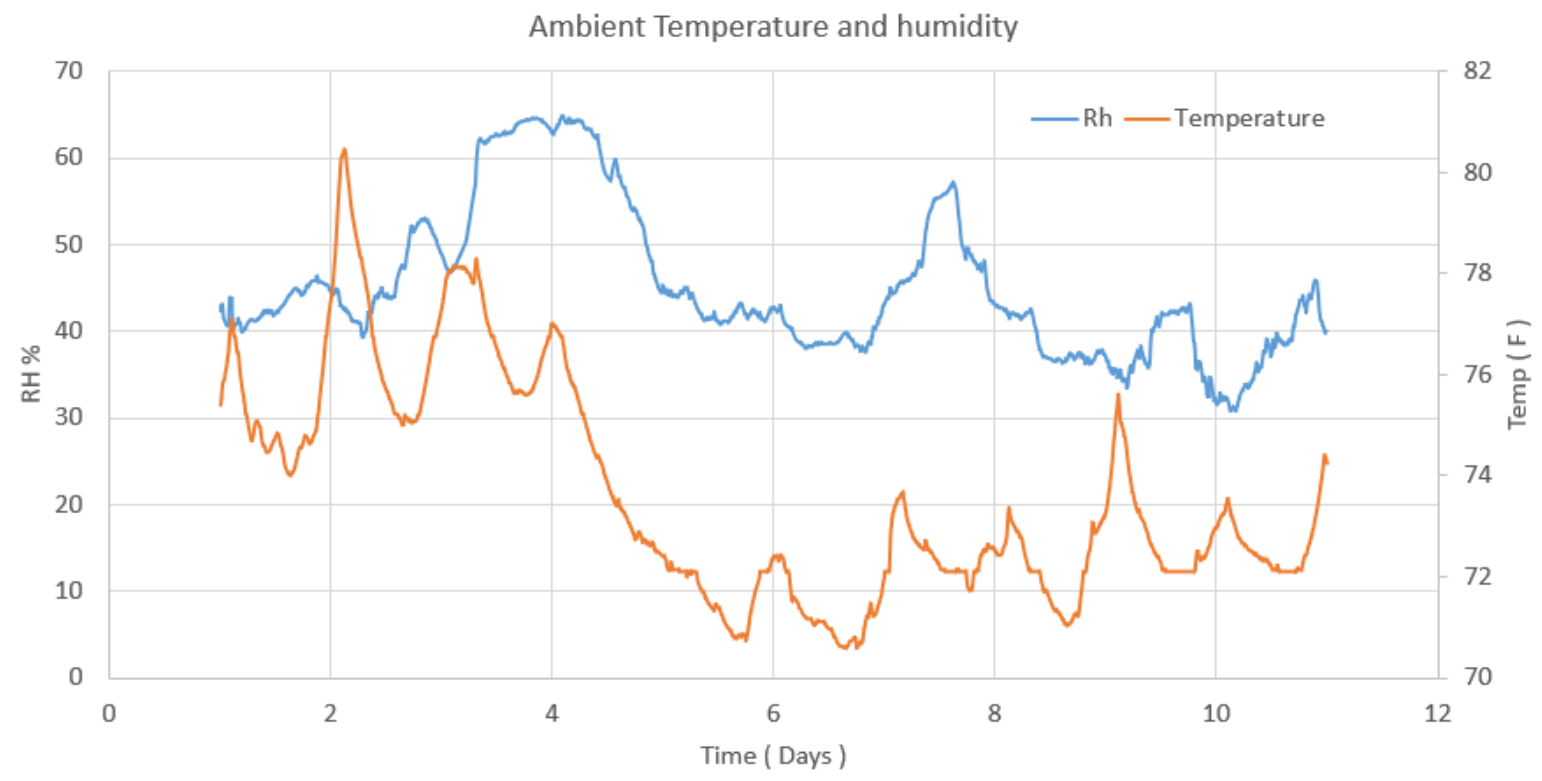

Figure 27 Ambient temperature and humidity for OPC 1

\section{2- OPC 2}

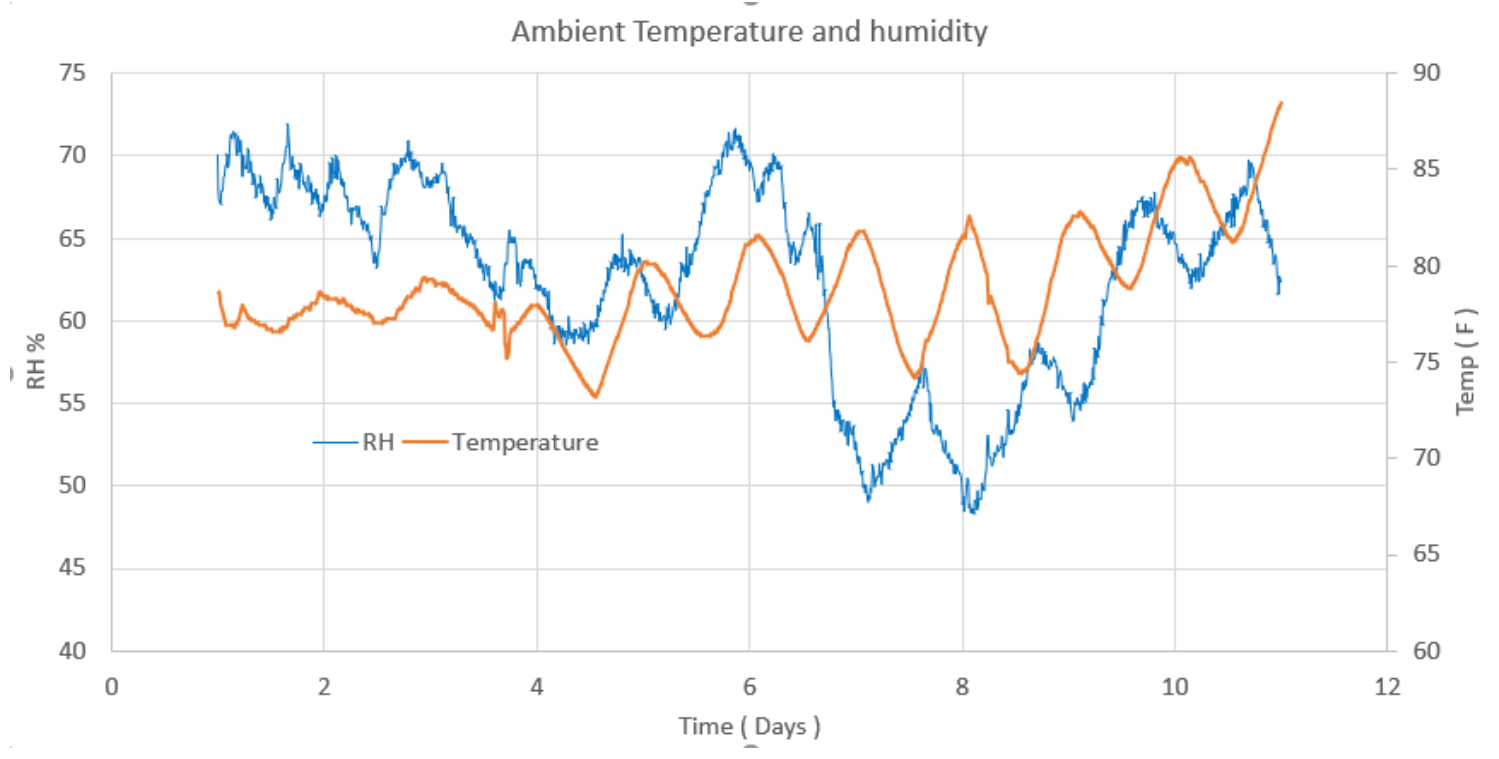

Figure 28 Ambient temperature and humidity for OPC 2 


\section{3- OPC 3}

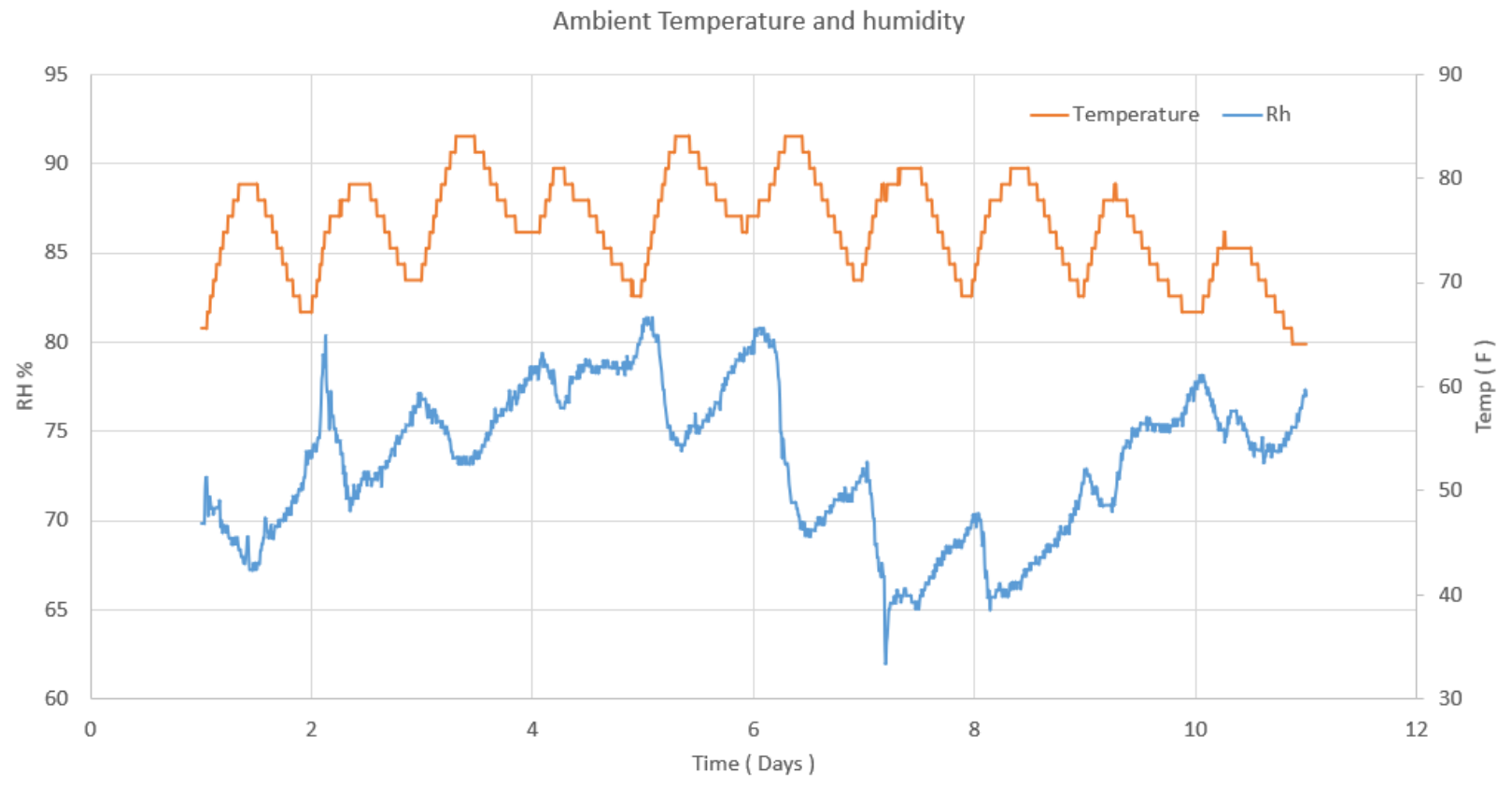

Figure 29 Ambient temperature and humidity for OPC 3

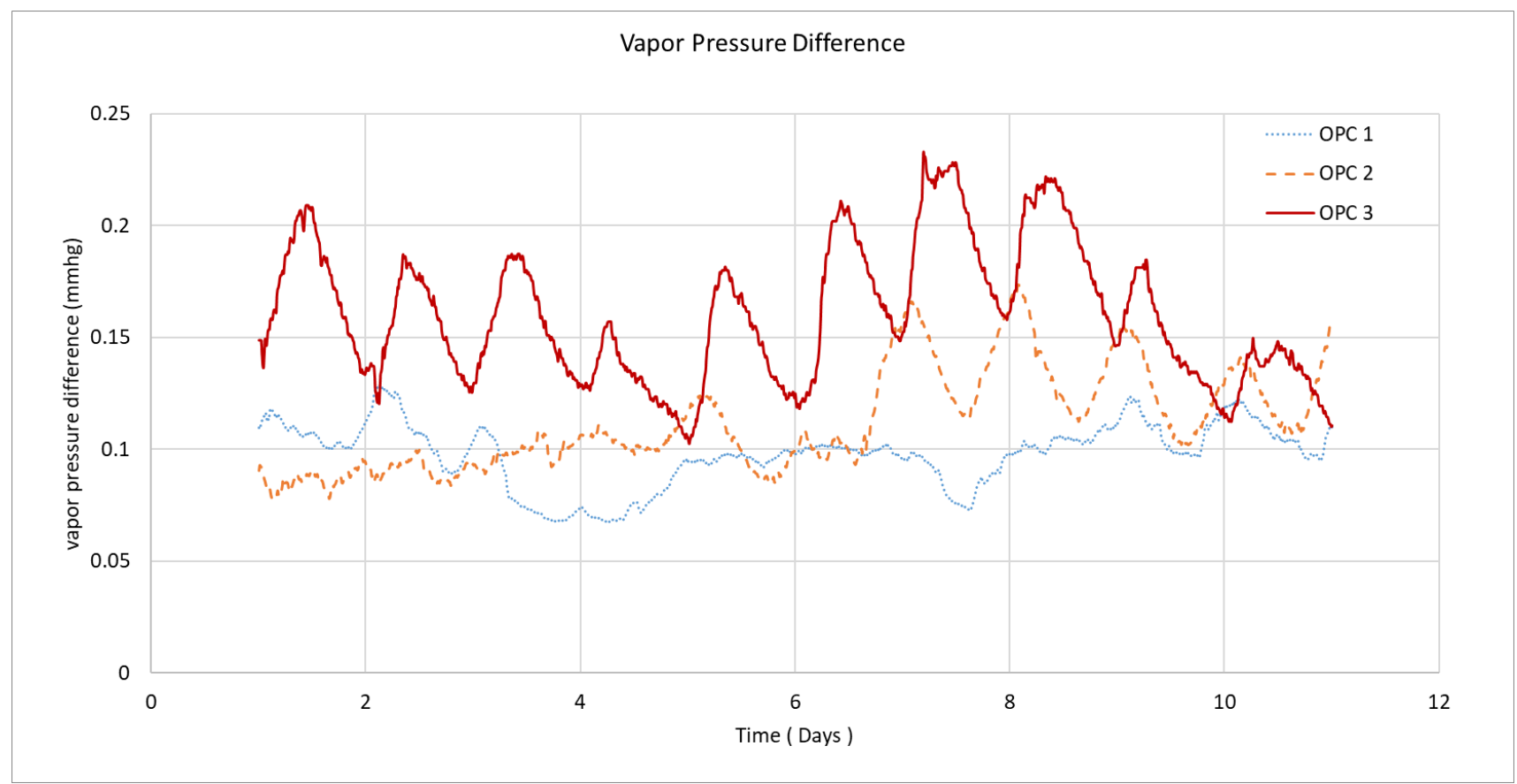

Figure 30 The difference between the partial and the saturation pressure 


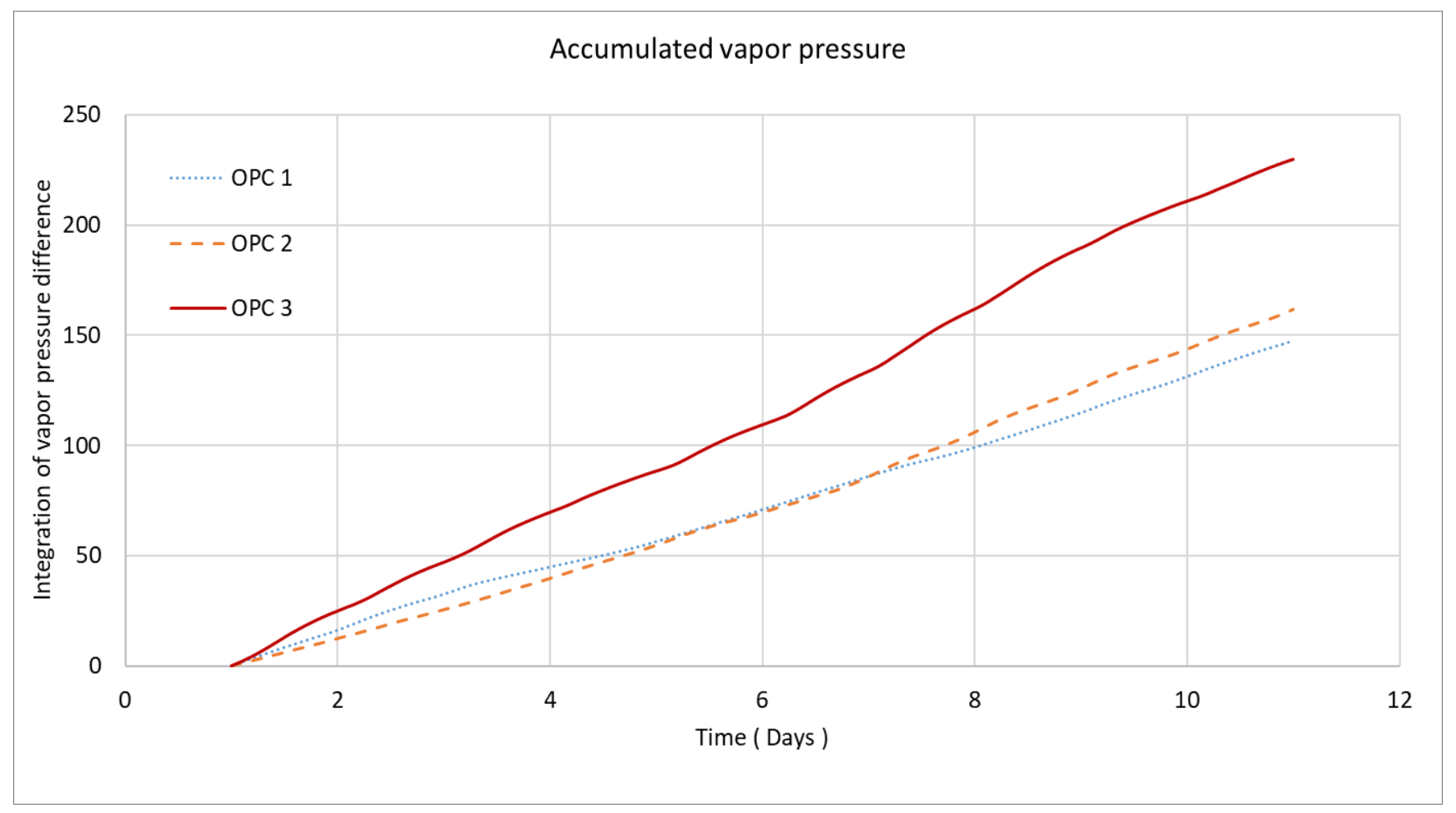

Figure 31 The integration of the difference between the partial and the saturation pressure

As shown in figure 31 , the integration of the difference between the partial and the saturation pressure can be fitted by a line, and the slop of that line indicates the drying speed of the specimen.

For OPC 1 the slop is 14.269.

For OPC 2 the slop is 16.44 .

For OPC 3 the slop is 23.302. 


\section{Internal Humidity-Temperature Sensor and Measurement System}

The Humidity-Temperature Sensor and Measurement System was designed at the University of Illinois at Urbana-Champaign (UIUC) and utilizes small, inexpensive digital RHtemperature sensors manufactured by Sensirion (part \# SHT21). Figure 32 provides an overview of the internal RH measurement system.

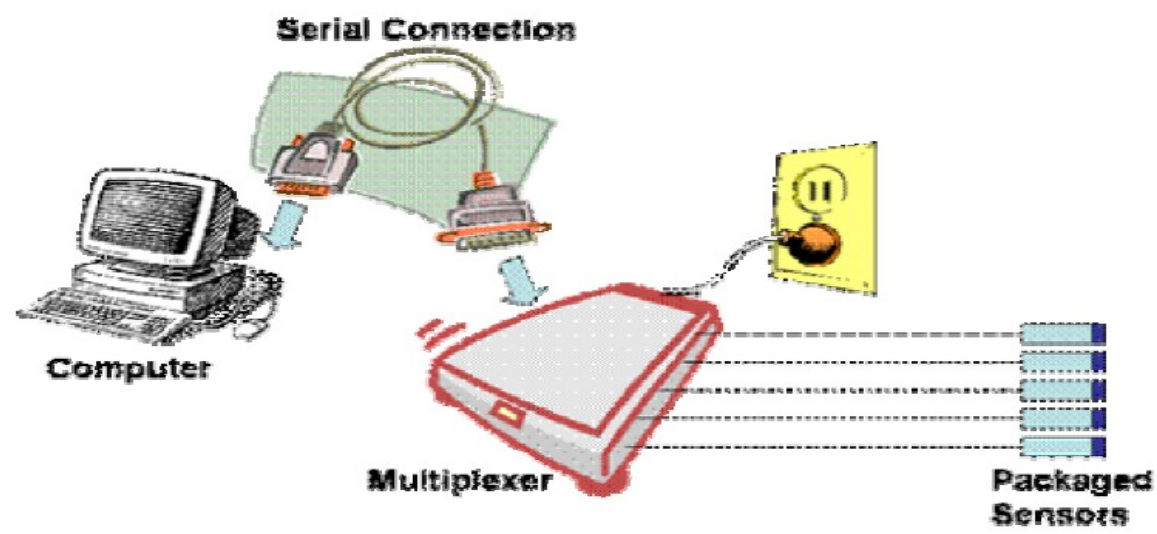

Figure 32 Overview of RH-Temp measurement system. David A Lange (2004)

A humidity-temperature sensor, Sensirion SHT21, was used to monitor the internal relative humidity $(\mathrm{RH})$ and the temperature inside the concrete. The sensor has a $\mathrm{RH}$ operating range of $0 \%$ to $100 \%$ RH with a maximum accuracy of $\pm 2 \%$ RH between $10 \%$ and $90 \% \mathrm{RH}$, and a temperature operating range of $-40^{\circ} \mathrm{F}$ to $257^{\circ} \mathrm{F}\left(-40^{\circ} \mathrm{C}\right.$ to $\left.125^{\circ} \mathrm{C}\right)$ with a maximum accuracy of $\pm 0.54{ }^{\circ} \mathrm{F}\left( \pm 0.3{ }^{\circ} \mathrm{C}\right)$ at $77^{\circ} \mathrm{F}\left(25^{\circ} \mathrm{C}\right)$. The sensor has four connector pins designated for the SCK (clock), voltage supply, ground, and serial data.

One could solder directly to the sensor tabs, but the connector allows the easy replacement of any sensors that have been damaged and prevents damage to the sensor during the soldering process. A 4-pin connector was used (JST EH/XH 2.54 MM 4 Pin connector). 
The RH and temperature data were digitally transmitted from the sensor to a small microcontroller, BasicX-24, and then collected by a personal computer (PC) through a PC COM port shown in Figure 33.

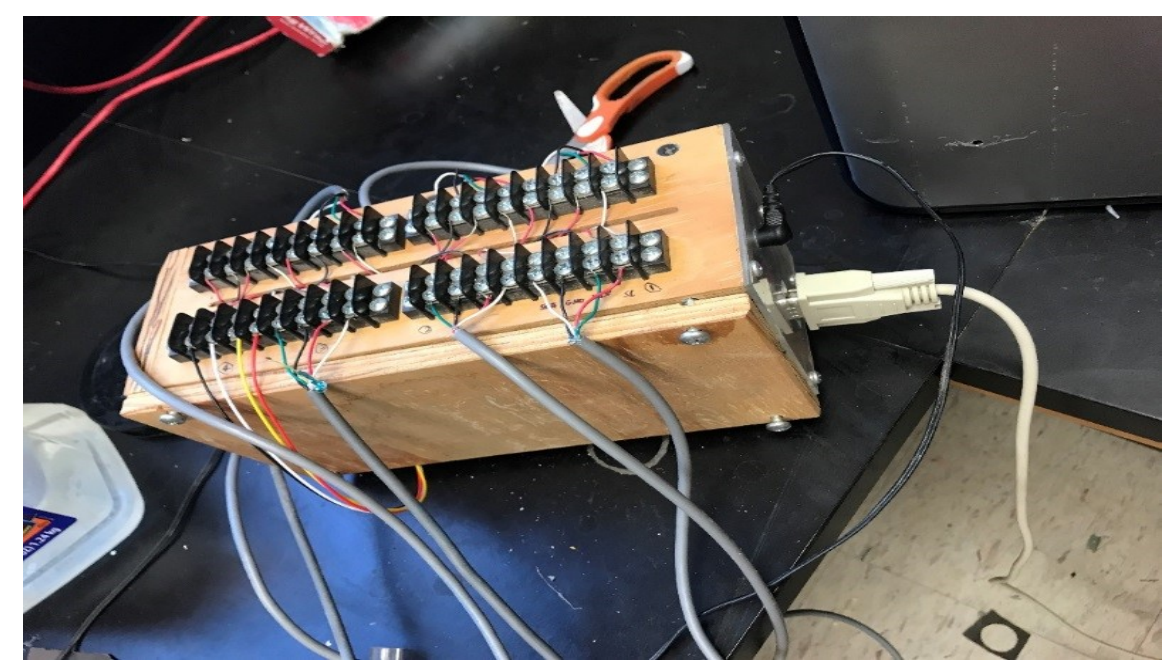

Figure 33 Data collector box.

The microcontroller can accommodate simultaneous monitoring of up to 15 sensors. Meanwhile, a data acquisition software developed by (Grasley and Lange 2004) was installed in the PC for the control of the data collection and the sensor (Choi, 2012). A data collecting interval of 30 seconds was adopted in this monitoring. The sensors were placed inside a plastic $3 / 4$ in end tube cab, as shown in Figure 34. A hole was made from the top for the wires and a plastic tube was used to protect the wires. 


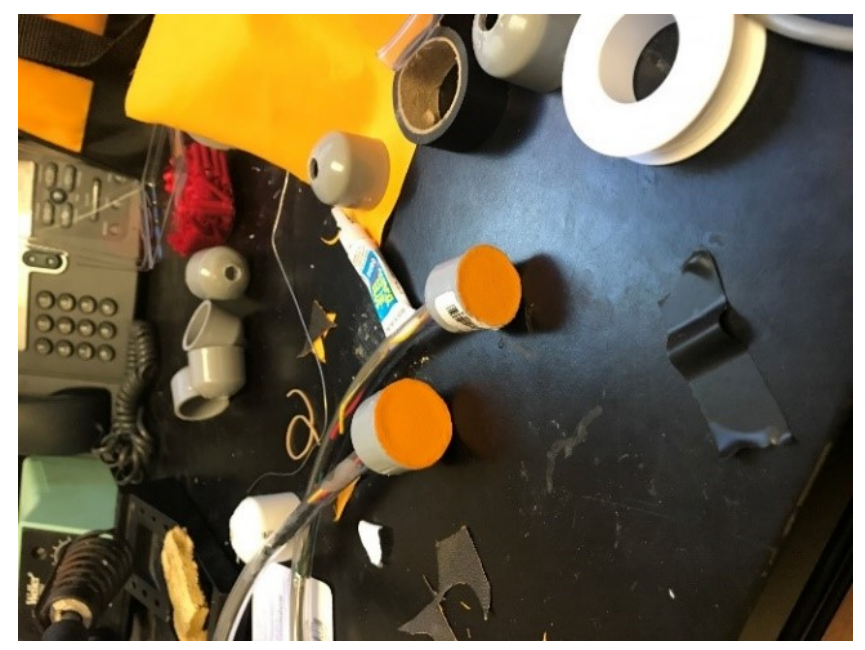

Figure 34 Proposed design End-tube covered with the Gore-Tex fabric

A waterproof, breathable and durable Gore-Tex fabric was used to cover the end tube, since it can repel liquid water while allowing water vapor to pass through, and is designed to be a lightweight, waterproof fabric for all-weather use. As shown in Figure 35.

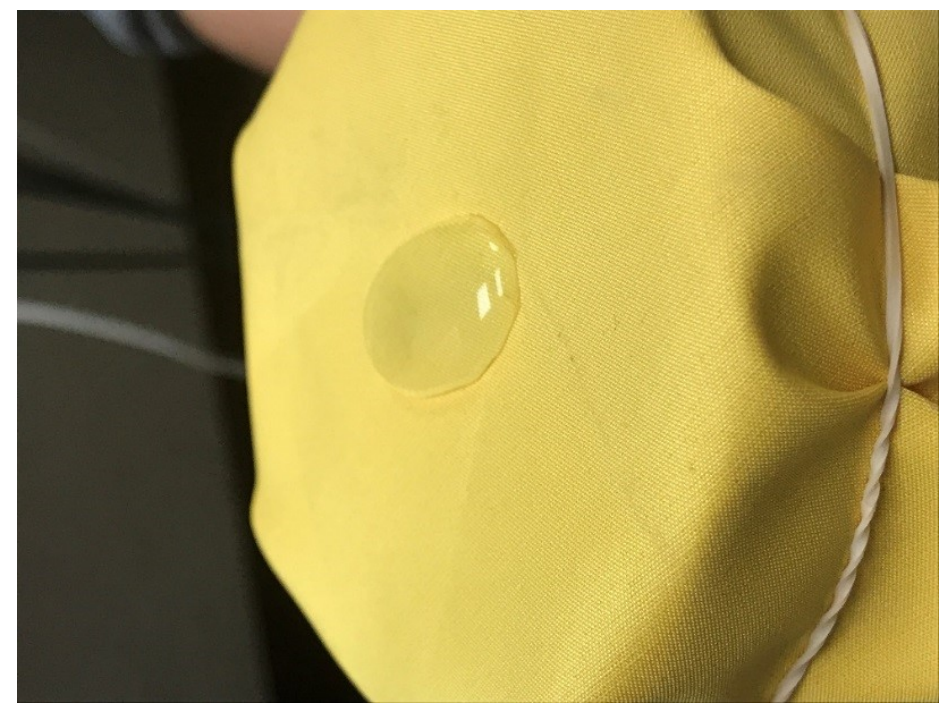

Figure 35 Waterproof - Gore-Tex fabric

To monitor and simulate the humidity inside of the concrete ring, for each experiment three sensors were used and placed at different depths $1 / 2,1$, and $1 \frac{1}{2}$ in from the drying surface. 
A mold with dimensions of $6 \times 6 \times 12$ in was sealed all the way but one side assuming that the moisture movement inside the concrete ring is from the inside to the outside and only in one direction. Another mold with the same dimensions was made but sealed entirely to measure the moisture loss due to the hydration only.

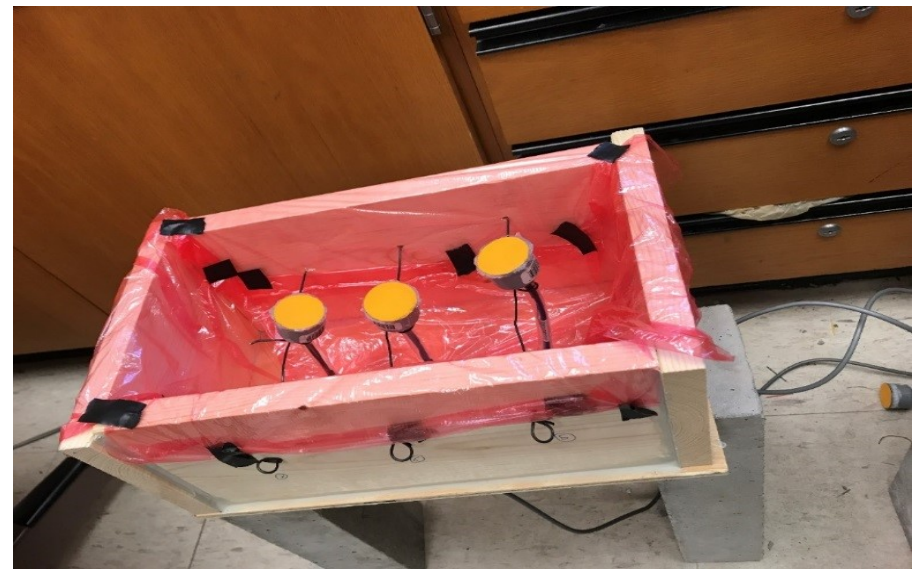

Figure 36 Designed box to measure the humidity at different depth

The collected data from both boxes is shown in Figure 37 and Figure 38, the sensors responded to the humidity change after placing the concrete inside the boxes but went over $100 \%$.

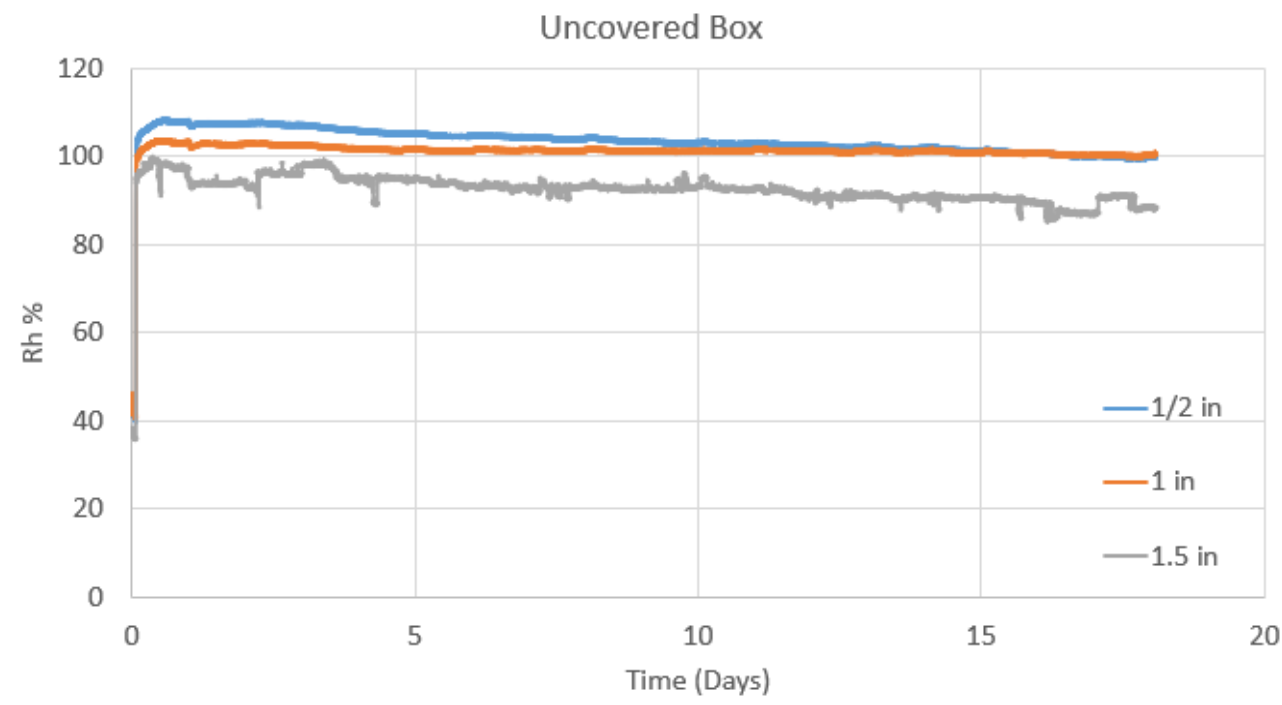

Figure 37 Humidity measurements at a different depth from the uncovered box OPC 1 


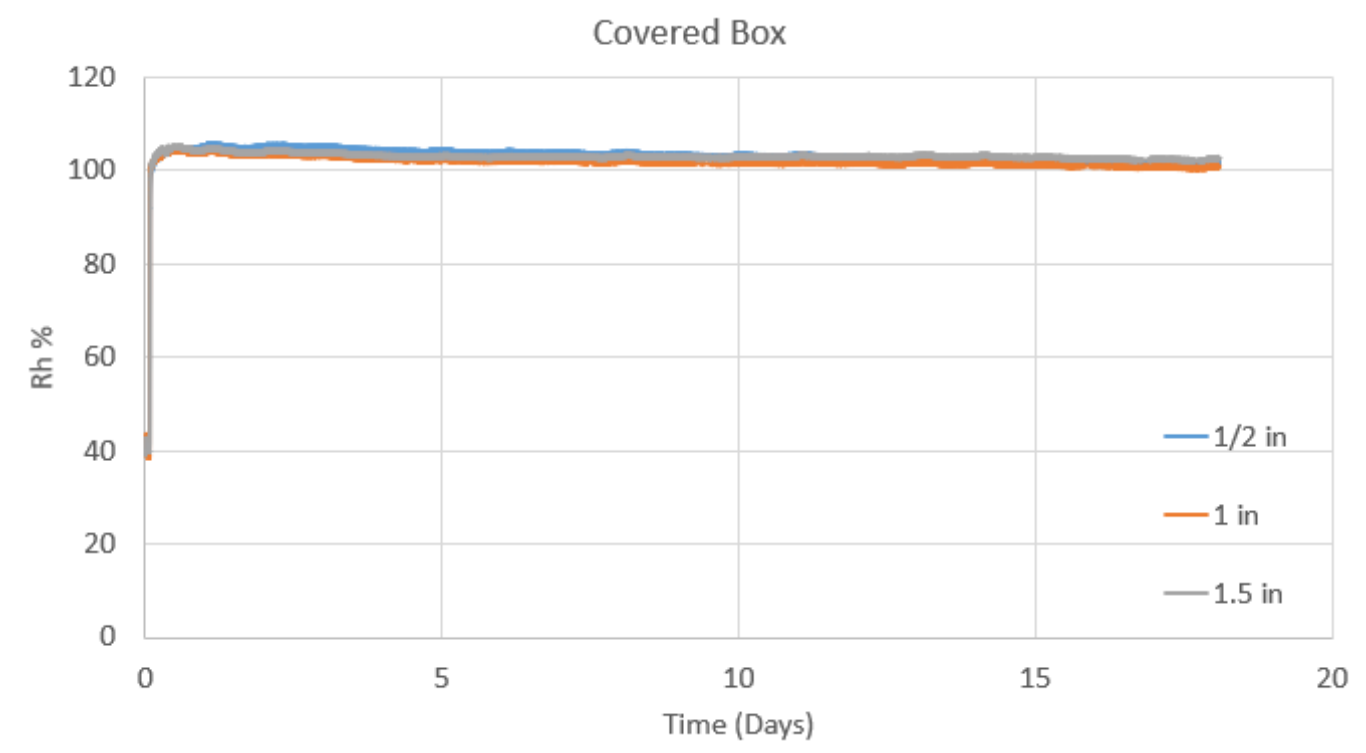

Figure 38 Humidity measurements at a different depth from the sealed box OPC 1

Unfortunately, the results were not usable due to a few possible reasons:

1 - The sensors were placed inside the box before casting, some water may have gotten into the tube-end while filling the box with concrete, and this possibility can explain the high humidity during the test.

2- The cement particles blocked the pores in the Gore-Tex from exchanging the humidity after casting.

3 - Using the humidity sensor SHT21 instead of SHT71. The original program was written for the SHT7X sensors.

Few suggestions to avoid this problem in the future:

1 -The sensors should be inserted after the setting time of the concrete where less water existed and the humidity still close to $100 \%$

2 - Measure the humidity by drilling holes on the concrete surface after one day and get readings every day. 
3 - Using better design by measuring the humidity directly without using the Gore-Tex.

As mention earlier, the moisture loss in the concrete is related directly to the drying shrinkage. To find the humidity inside the concrete, the experiment described is a good approach to measure the humidity.

Unfortunately, the theoretical analysis of the humidity distribution in the concrete has not been verified with the experiments described earlier. Instead, Finite Element analysis (Abaqus) was used, assuming that the behavior of the moisture movement inside the concrete is the exact same as the temperature change under specific boundary conditions.

As mention before the half-wrapped specimens were made to simulate the shrinkage of the concrete ring. Therefore, to find the best fit shrinkage models the humidity should be known. Two different FEM models using ABAQUS were generated to find the humidity inside the shrinkage specimens. 


\section{Restrained Shrinkage Ring Test}

ASTM C1581M - 16 "Determining Age at Cracking and Induced Tensile Stress Characteristics of Mortar and Concrete under Restrained Shrinkage" was used to measure the strain.

Some of the test specifications are Steel ring —Structural steel pipe with a wall thickness of $0.50 \pm 0.05$ in., an outside diameter of $13.0 \pm 0.12$ in. and a height of $6.0 \pm 0.25$ in. Strain gages-As a minimum, use two electrical resistance strain gauges to monitor the strain development in moisture analysis for 1-D the steel ring, in this study four electrical resistance strain gauges to monitor the strain development in each steel ring.

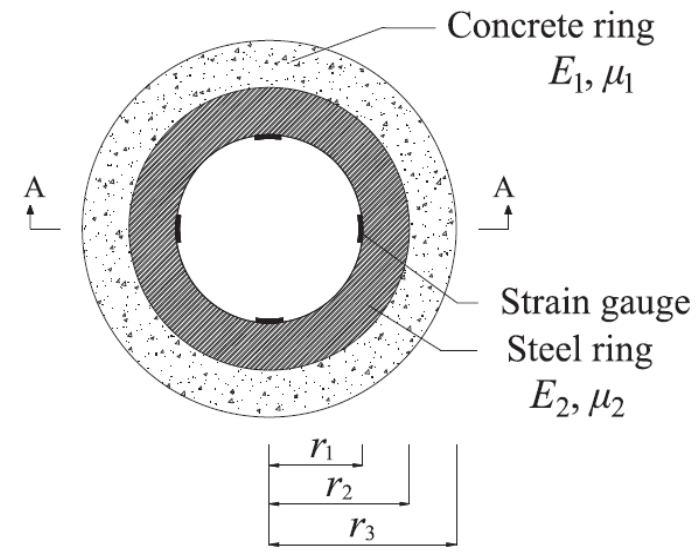

(a) top view

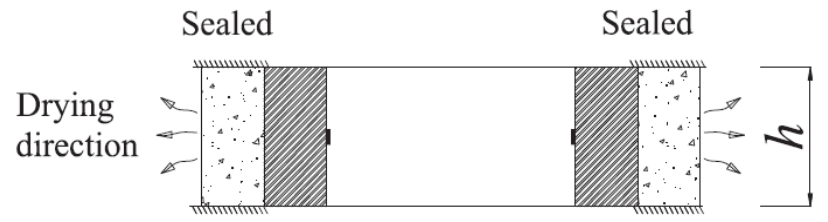

(b) cross view

Figure 39 Geometry of the ring specimen. (Yuan Gao, Jun Zhang, Po Han 2013)

A sudden decrease in compressive strain in the strain gages indicates cracking of the concrete because the maximum tensile stress was higher than the tensile strength of the concrete.

It's very important to record ambient temperature and relative humidity of the environment during the test since it affects the shrinkage of the concrete directly. If varied temperature history 
is experienced during the test, before using the data, it must be adjusted as Temperature

Compensation. To do so, the Linear Elastic Solution of the cylinder stress-strain relationship can be used. For the thick wall cylinder, the stresses are giving by:

$$
\sigma_{r}=\frac{r_{i}^{2} P_{i}-r_{o}^{2} P_{o}}{\left(r_{o}^{2}-r_{i}^{2}\right)}-\frac{\left(P_{i}-P_{o}\right) r_{i}^{2} r_{o}^{2}}{\left(r_{o}^{2}-r_{i}^{2}\right) r^{2}} \quad \sigma_{\theta}=\frac{r_{i}^{2} P_{i}-r_{o}^{2} P_{o}}{\left(r_{o}^{2}-r_{i}^{2}\right)}+\frac{\left(P_{i}-P_{o}\right) r_{i}^{2} r_{o}^{2}}{\left(r_{o}^{2}-r_{i}^{2}\right) r^{2}}
$$

Eq. 51

For a cylinder subjected to External Pressure only $(\mathrm{Pi}=0)$ :

$$
\sigma_{\theta}=\frac{-P_{o} r_{o}^{2}}{r_{o}^{2}-r_{i}^{2}}\left[1+\frac{r_{i}^{2}}{r^{2}}\right]: \sigma_{r}=\frac{-P_{o} r_{o}^{2}}{r_{o}^{2}-r_{i}^{2}}\left[1-\frac{r_{i}^{2}}{r^{2}}\right]
$$

Eq. 52

At inside surface $\left(r=r_{i}\right)$ :

$$
\sigma_{\theta}=\left[\frac{-2 P_{o} r_{o}^{2}}{r_{o}^{2}-r_{i}^{2}}\right]: \sigma_{r}=0
$$

Eq. 53

On the other hand

For a cylinder subjected to internal Pressure only $\left(P_{o}=0\right)$ :

$$
\sigma_{\theta}=\frac{P_{i} r_{i}^{2}}{r_{o}^{2}-r_{i}^{2}}\left[1-\frac{r_{o}^{2}}{r^{2}}\right]: \quad \sigma_{r}=\frac{P_{i} r_{i}^{2}}{r_{o}^{2}-r_{i}^{2}}\left[1+\frac{r_{o}^{2}}{r^{2}}\right]
$$

At inside surface $(r=r i)$ :

$$
\sigma_{\theta}=P_{i}\left[\frac{r_{o}^{2}+r_{i}^{2}}{r_{o}^{2}-r_{i}^{2}}\right]: \sigma_{r}=-P_{i}
$$


The stress-strain relationship is giving by:

$$
\varepsilon_{\theta}=\frac{u}{r}=\frac{1}{E}\left(\sigma_{\theta}-\sigma_{r}\right) \quad \varepsilon_{r}=\frac{d u}{d r}=\frac{1}{E}\left(\sigma_{r}-v \sigma_{\theta}\right)_{E q .56}
$$

Solving for $\varepsilon_{\theta}$ at $r_{i}$ :

$$
\varepsilon_{\theta}=\frac{p}{E} \times\left(\frac{r o^{2}{ }_{1}+r i^{2}}{r o^{2}{ }_{1}-r i^{2}{ }_{1}}\right)+\frac{v p}{E} \quad \text { Eq. } 57
$$

If

$$
\varepsilon_{\theta}=\Delta \alpha \times \Delta T=\left(\alpha_{S}-\alpha_{C}\right) \times \Delta T \quad \text { Eq. } 58
$$

Then:

$$
\left(\alpha_{S}-\alpha_{C}\right) \times \Delta T=\frac{p}{E} \times\left(\frac{r i^{2}+r o^{2}}{r o^{2}-r i^{2}}\right)+\frac{v p}{E} \quad \text { Eq. } 59
$$

Solving for $P$ :

$$
p=\frac{\left(\alpha_{S}-\alpha_{C}\right) \times \Delta T \times E c}{\left(\frac{r i^{2}+r o^{2}}{r r^{2}-r i^{2}}\right)+v} \quad \text { Eq. } 60
$$

Then:

$$
\varepsilon_{\theta}=\frac{2 \times r o^{2} \times \frac{E c}{E S} \times\left(\alpha_{S}-\alpha_{C}\right) \times \Delta T}{\left(r o^{2}-r i^{2}\right) \times\left(\frac{r^{2} 1+r i^{2} 1}{r o^{2} 1-r i^{2}{ }_{1}}\right)+v} \quad \text { Eq. } 61
$$

$\alpha_{C}$ : is the thermal expansion coefficient of the concrete.

$\alpha_{s}$ : is the thermal expansion coefficient of the steel.

The strain change due to temperature change can be calculated and then Temperature Compensation can be applied. 


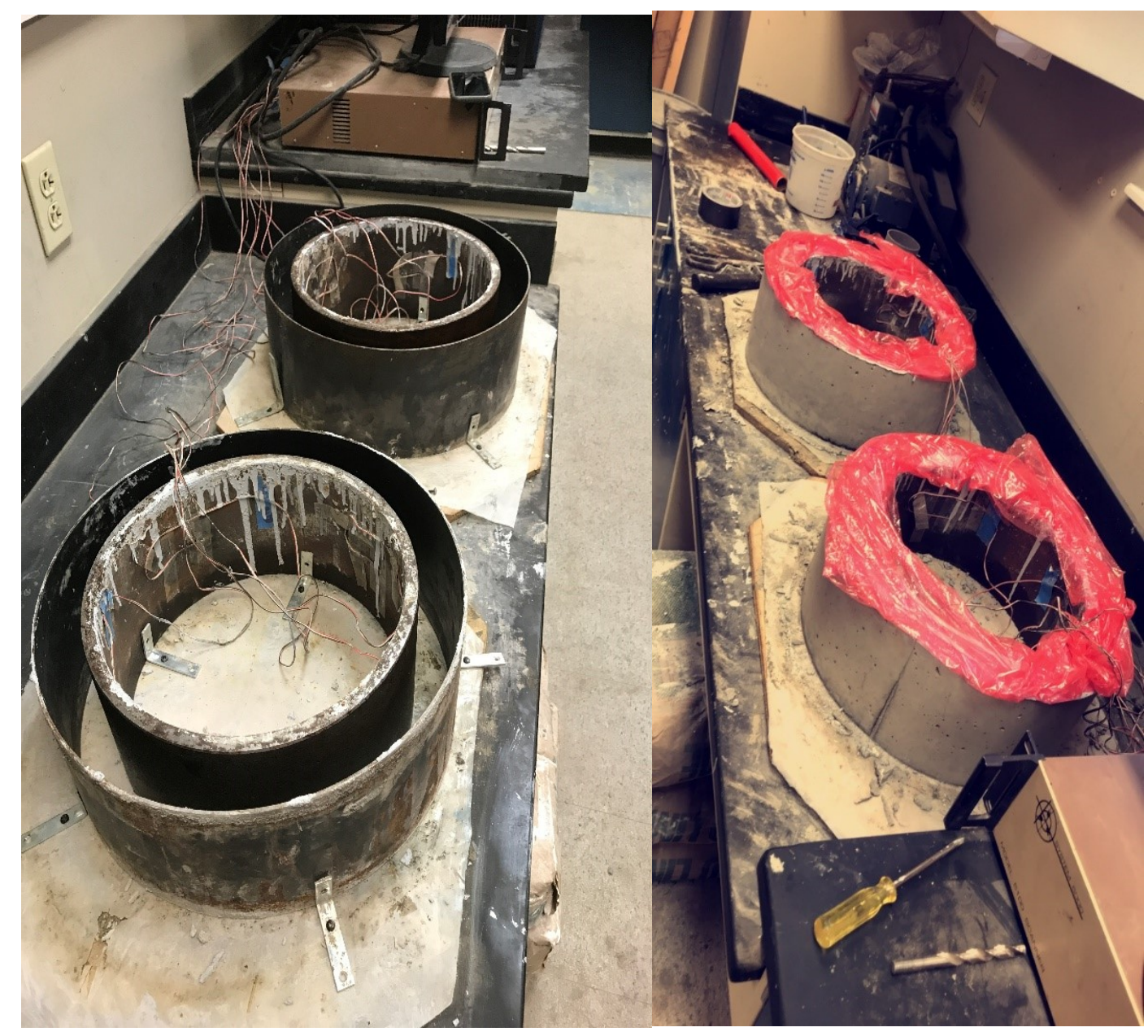

Figure 40 Ring specimens

The following experimental results in Figure 41 through Figure 46 represent the raw strain data obtained from the ring experiment on the inner steel ring and the next figure represent the average corrected strain by temperature compensation. 


\section{Experiments results:}

\section{1- OPC 1}

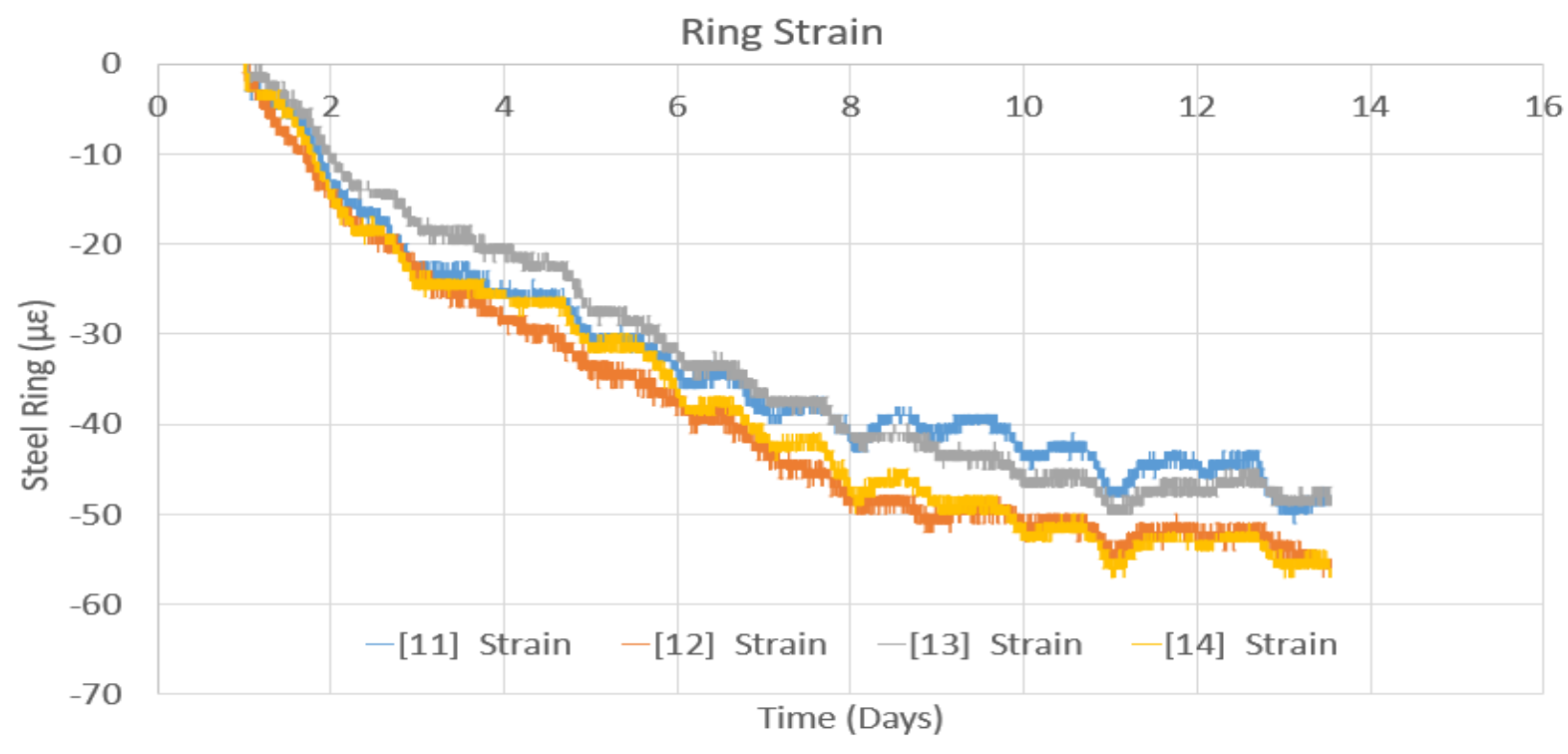

Figure 41 Steel Strain from the ring experiment OPC 1

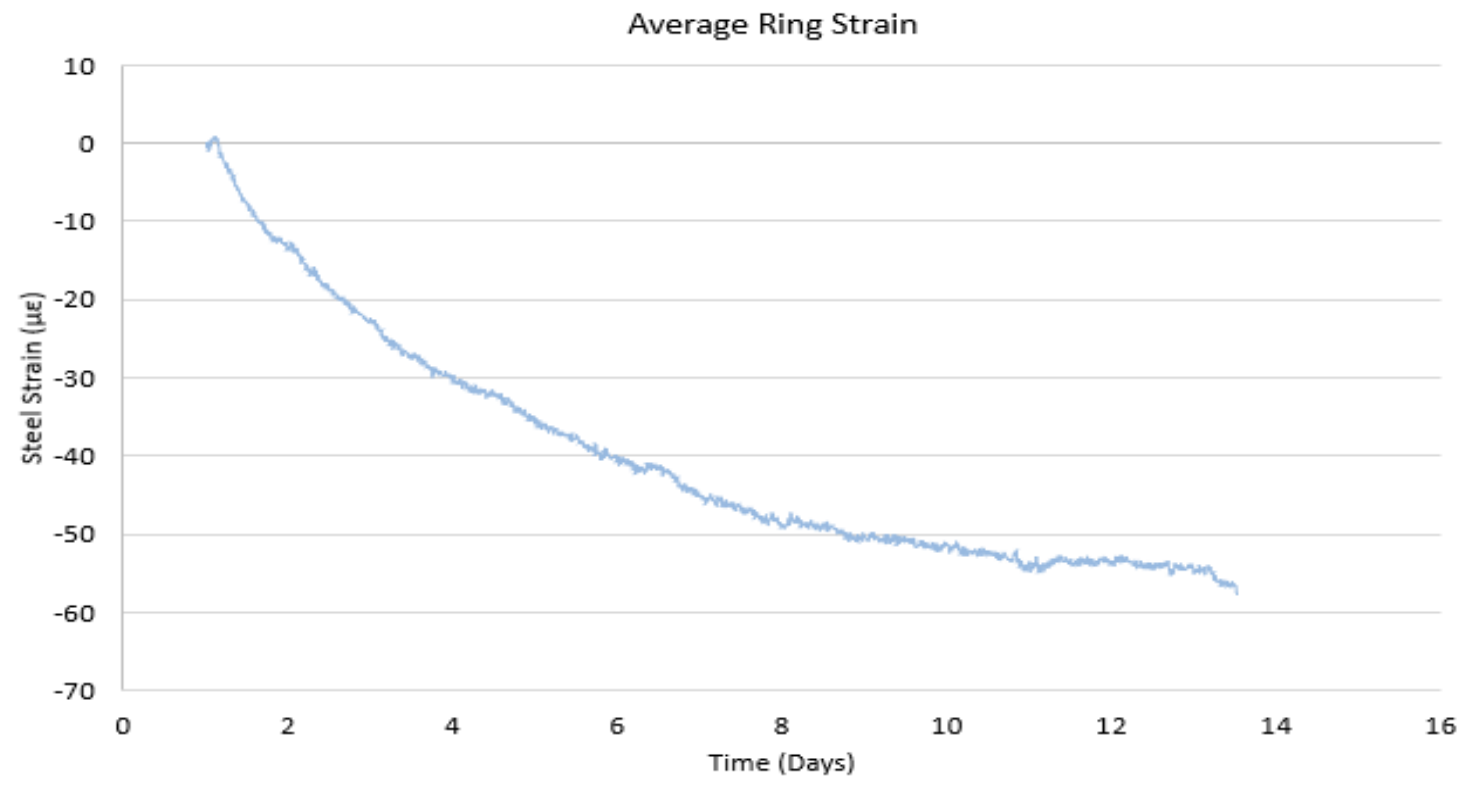

Figure 42 Average Steel Strain OPC 1 


\section{2- OPC 2}

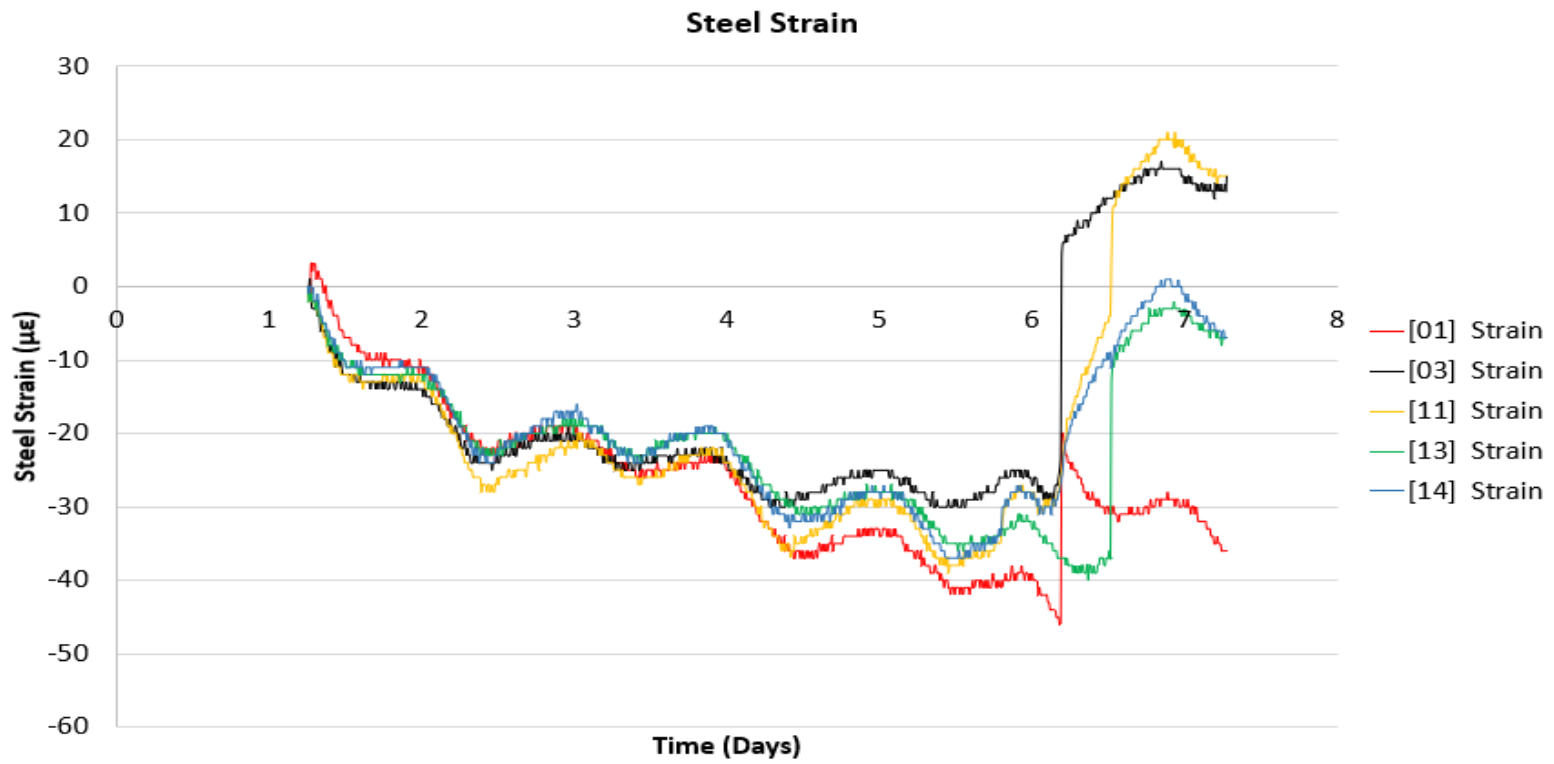

Figure 43 Steel Strain from the ring experiment OPC 2

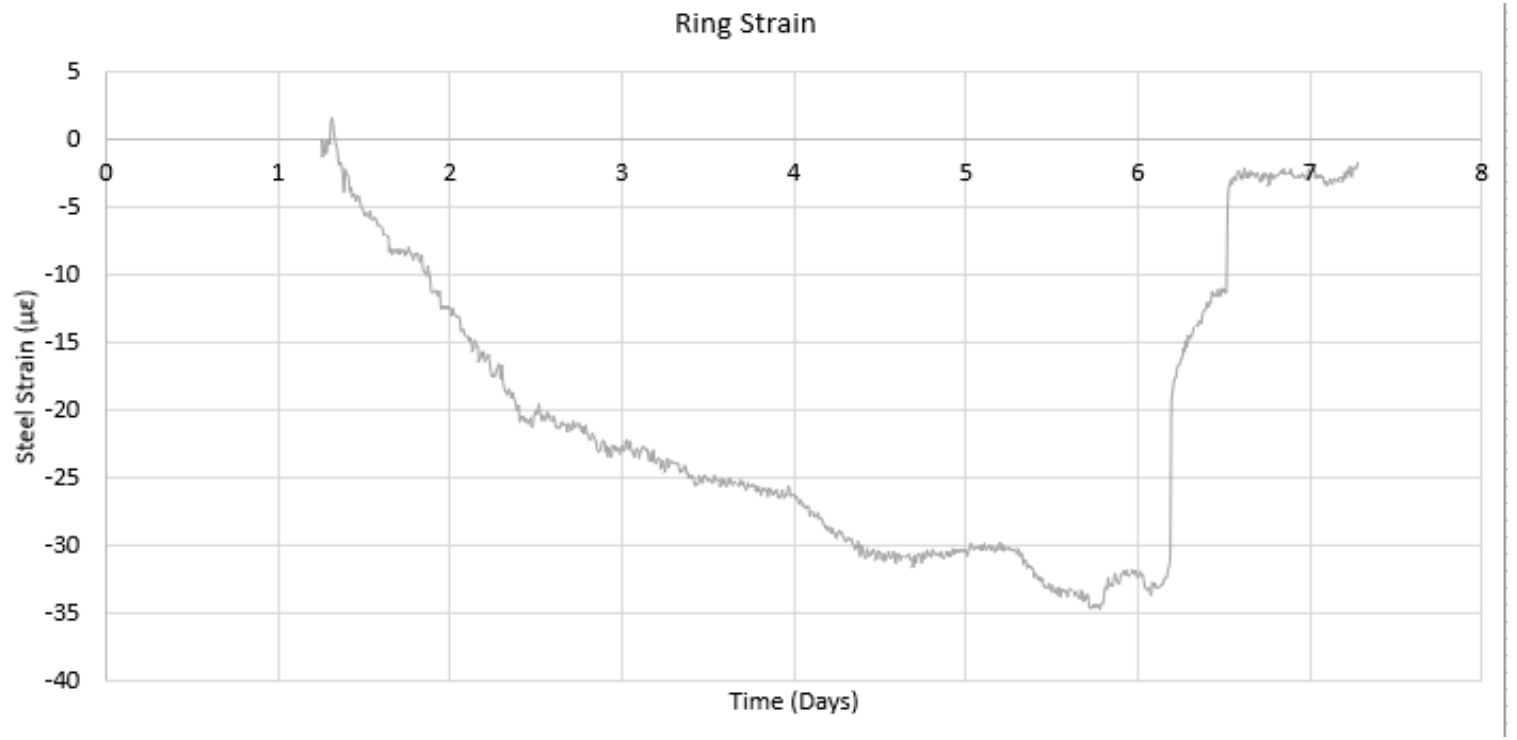

Figure 44 Average Steel Strain OPC 2 


\section{3- OPC 3}

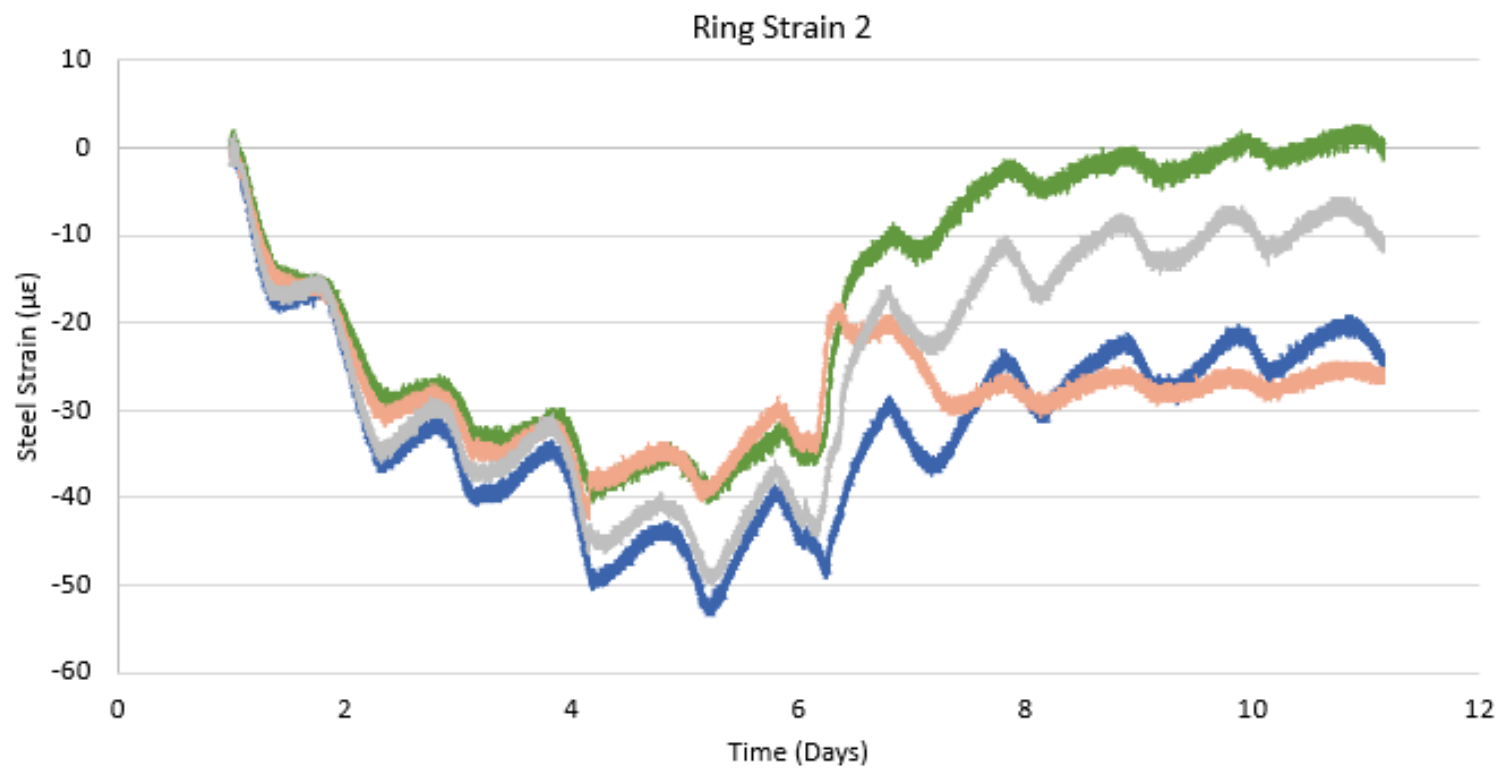

Figure 45 Steel Strain from the ring experiment OPC 3

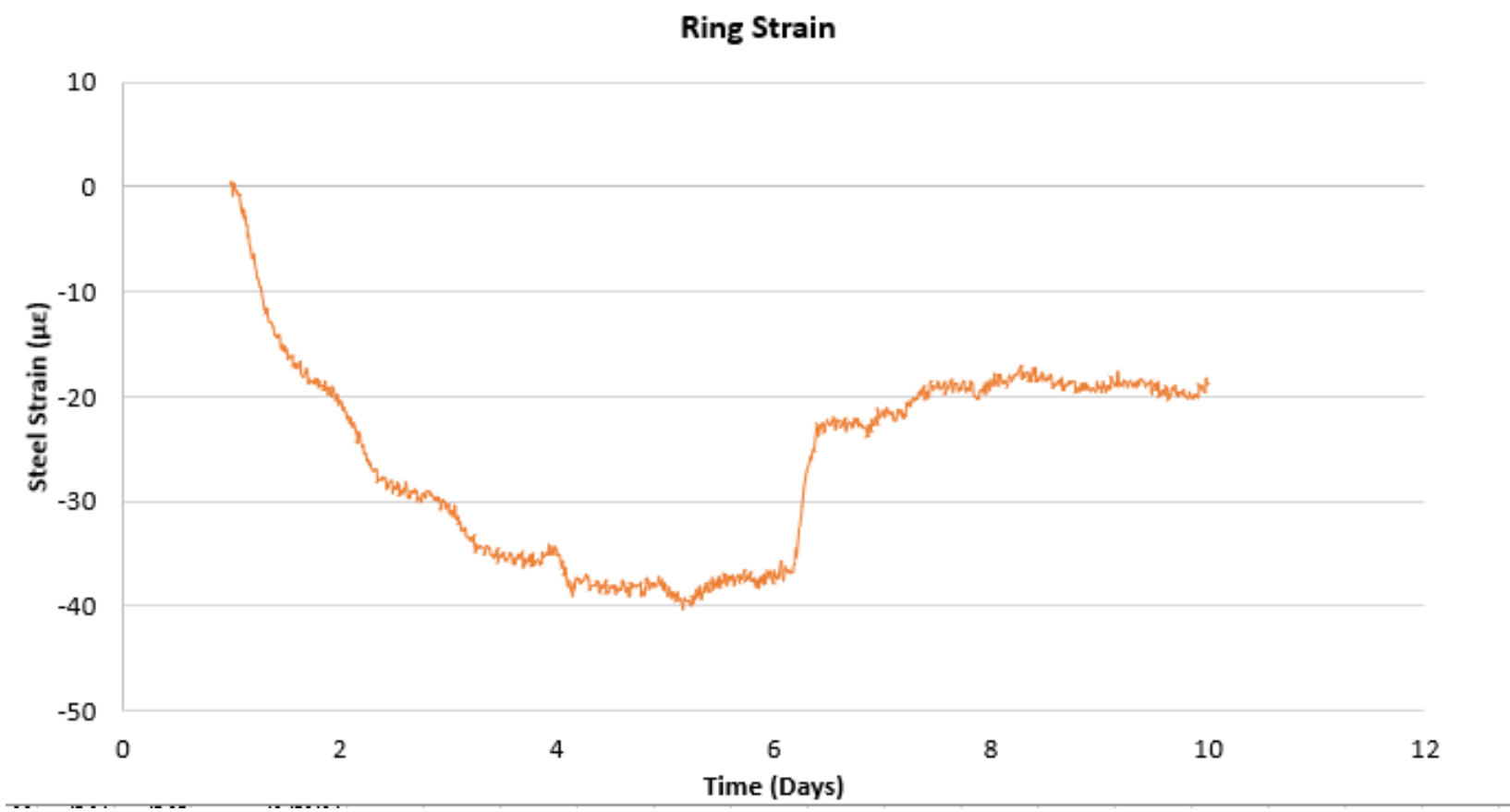

Figure 46 Average Steel Strain OPC 3 
For OPC 1, only one ring specimen was used. For OPC 2, and 3 two-ring specimens were used, and both rings behaved the same way. As the environment temperature was increased for OPC 2 and even higher for OPC 3 the measured strain increased faster in both cases, indicates that the higher the environment temperature the faster the Interfacial Compressive Stress generated, and the higher the measured strain.

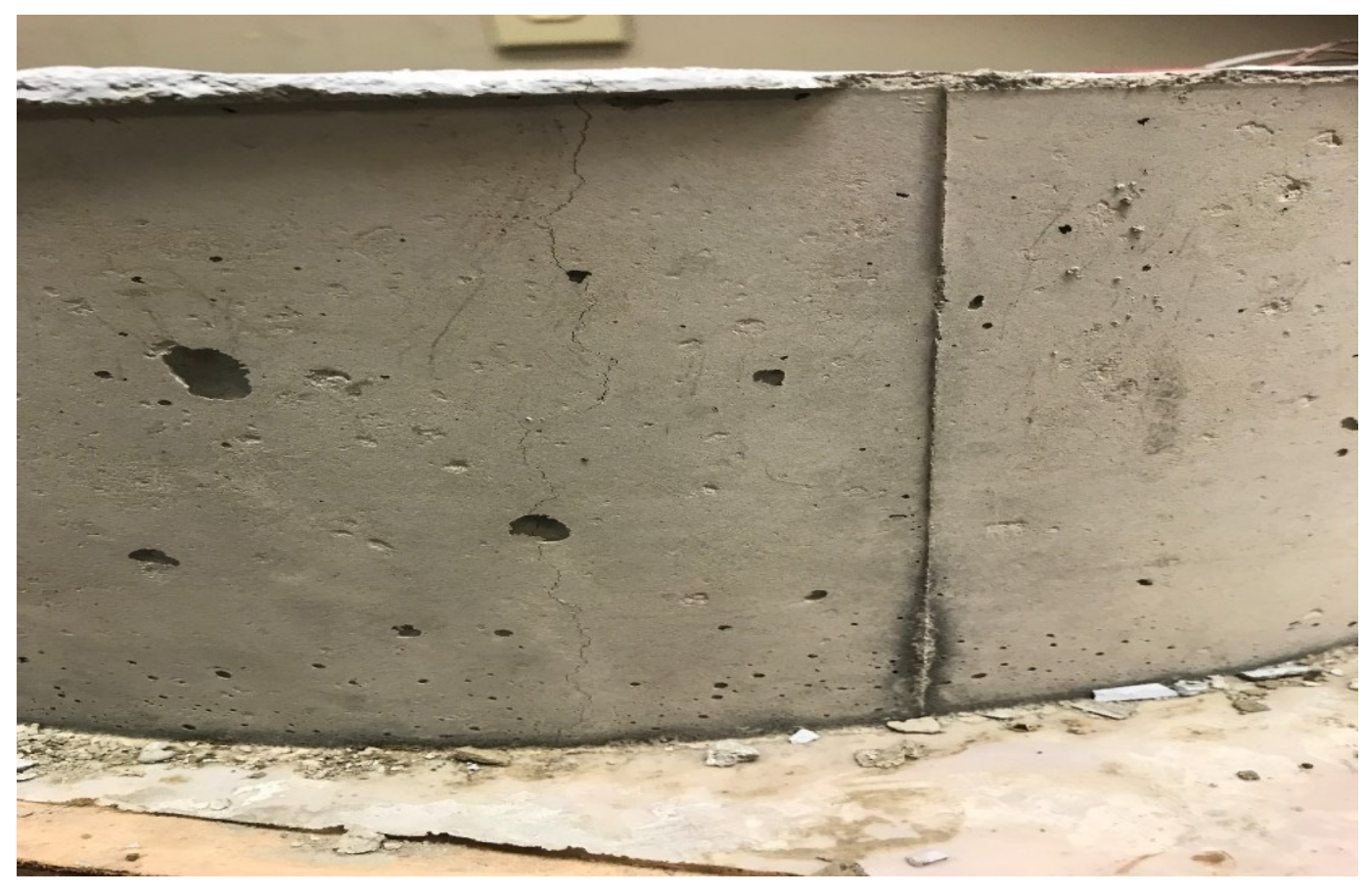

Figure 47 Cracked Ring (OPC 2) 


\section{Direct Tensile Test (Dog-Bone)}

In this research, three 3-foot dog-bone specimens with a 4"x4" center cross-section were designed to be used for tensile modulus and tensile creep testing as shown in Figure 48. A vibrating wire strain gauge embedded at the center to record the internal strain of the specimens. All the specimens were painted one day after unmolding and being wrapped using plastic wrap. One of them was used to measure the free shrinkage of the specimens, while the others were used direct tensile creep testing. For the tensile creep testing, the specimen was loaded $300 \mathrm{lbs}$. at 1 day and 12.75 days. The dog-bone specimen deformation after loading at one day was used later to verify the creep parameters obtained for the Mat-Lab model. The creep results will be discussed later in this research.
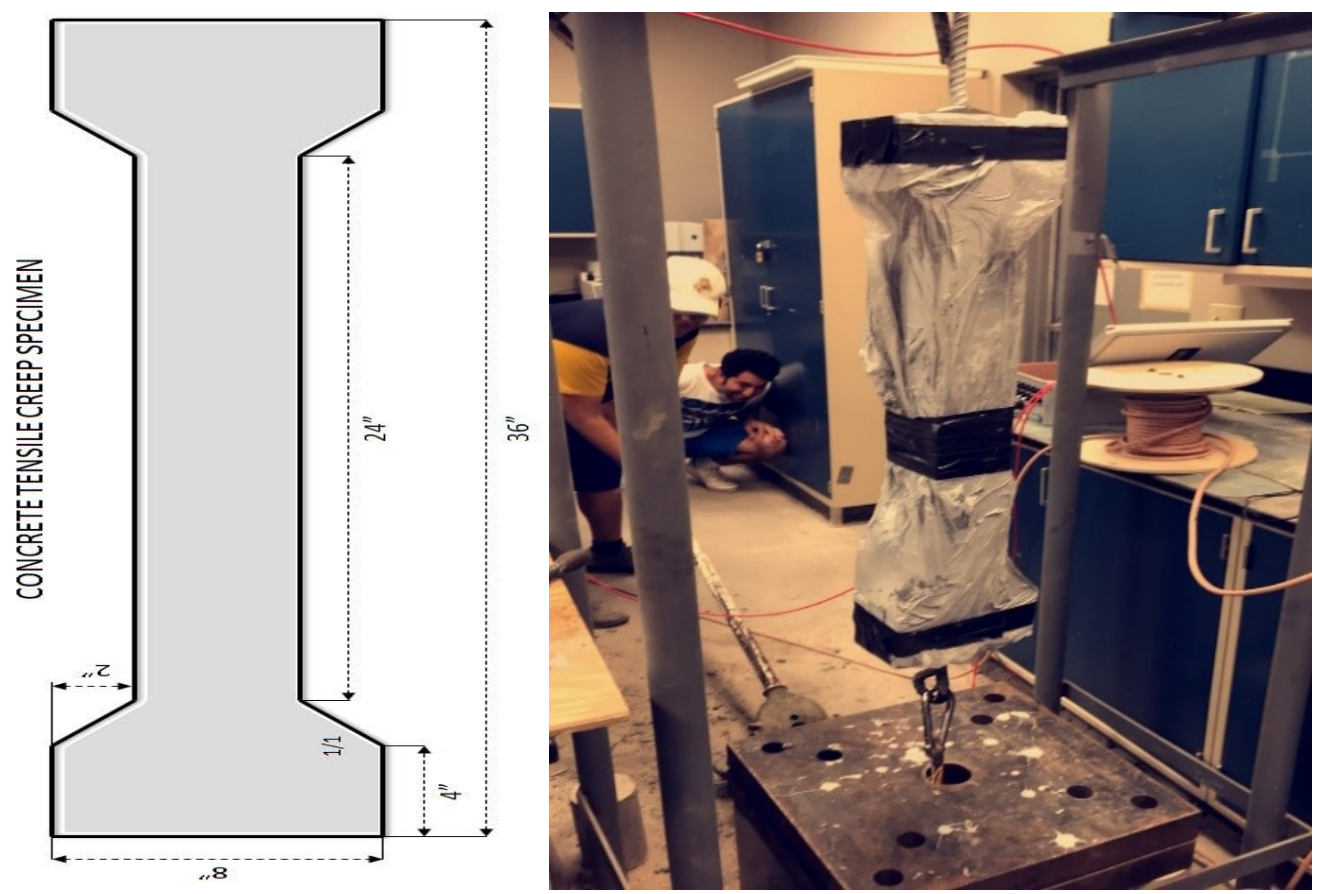

Figure 48 Schematic of the dog bone specimen 


\section{Chapter 4 Analysis and Interpretation of Results}

\section{Humidity Analysis}

\section{$\underline{\text { Simulating Half-Wrapped Specimens }}$}

The first model simulates the half-wrapped Shrinkage specimens using the ABAQUS thermal analysis since both humidity and temperature are diffusion equations. A $3 \times 3$ rectangular prism with predefined Temperature of $1000^{\circ} \mathrm{F}$, only 2 surfaces allowed for exchanging temperature with the ambient. $6 \times 1.5(\mathrm{~h} / 2)$ slab with a predefined temperature of $10000^{\circ} \mathrm{F}$ with only 1 surface allowed for exchanging temperature with the ambient. As shown in Figure 49.
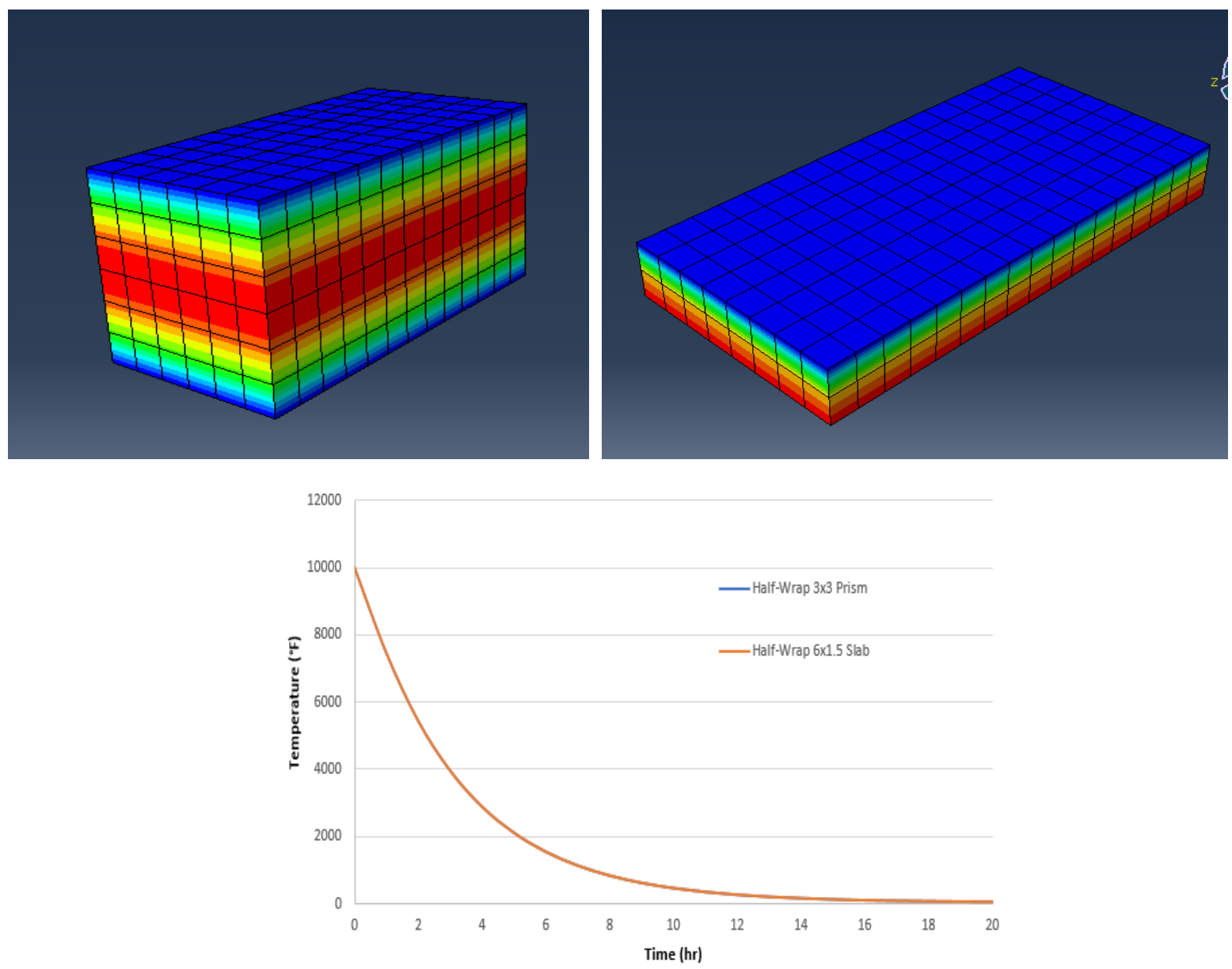

Figure 49 Simulating the half-wrapped shrinkage 
The result shows that the temperature change at the center of the prism is exact same of the temperature change at the bottom of the 1-D Slab with a height equal to half of the height of the prism. In this case 3"x 3" prism drying from two surfaces (half-wrapped shrinkage specimens) can be calculated as 1-D slab moisture humidity with a thickness of 1.5 " which is exactly the case of the concrete ring. As shown in Figure 49.

\section{$\underline{\text { Simulating No-Wrapped Specimens }}$}

The second model is to simulate the No-Wrapped Shrinkage specimens.
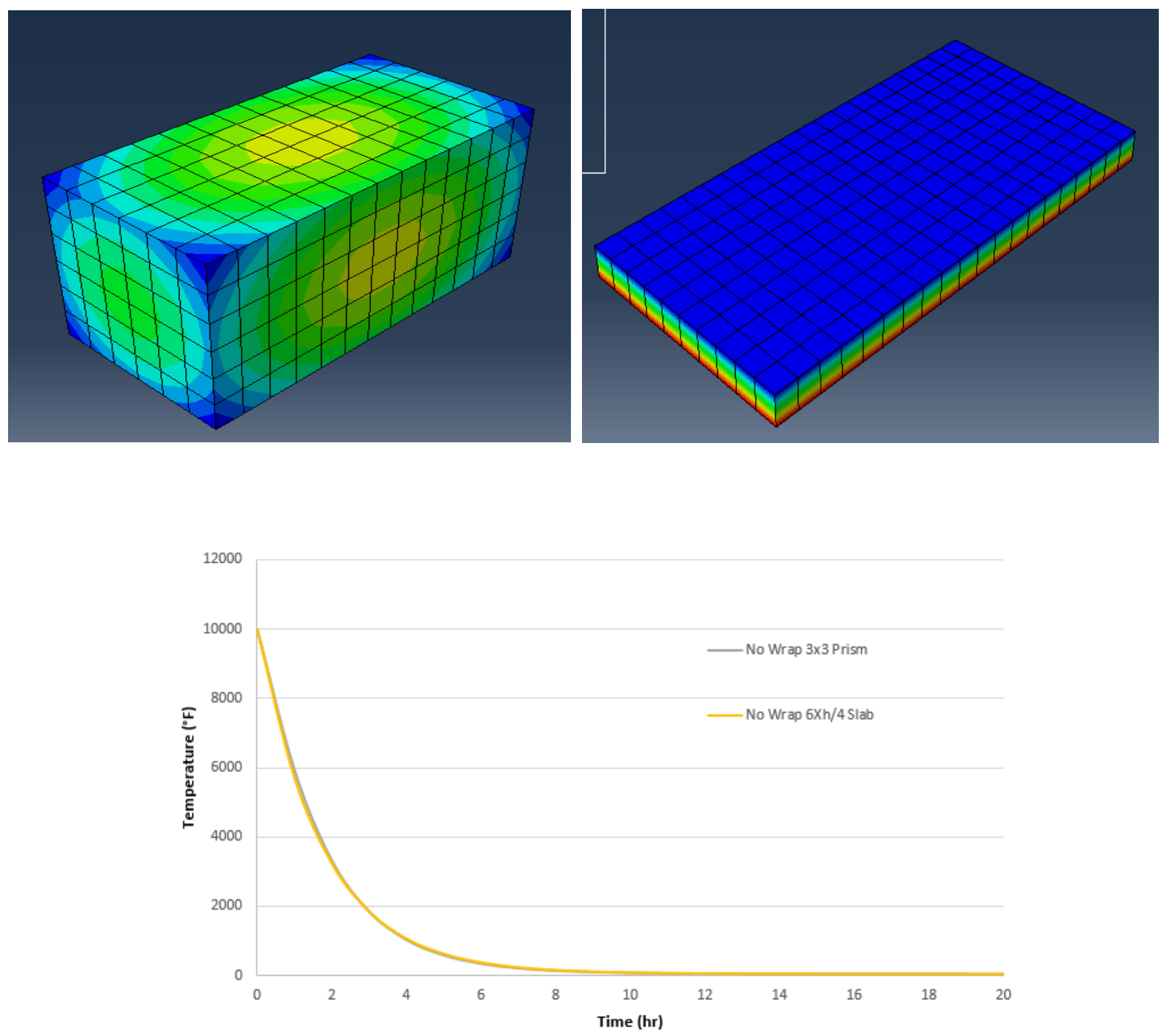

Figure 50 Simulating the drying shrinkage 
3"x3" rectangular prism with predefined Temperature of 10000, all surfaces could exchange temperature with the ambient. 6"x $0.75 "(\mathrm{~h} / 4)$ Slab with a predefined temperature of $10000^{\circ} \mathrm{F}$ with only one surface allowed for exchanging temperature with the ambient.

The result shows that the temperature change at the center of the prism is exact same of the temperature change at the bottom of the 1-D Slab with height of equal to $(1 / 4)$ of the height of the prism, in this case 3"x 3" prism drying from all surfaces (No-wrap shrinkage specimens) can be calculated as 1-D slab moisture humidity with thickness of 0.75 " which is exactly the case of the No-wrap shrinkage specimens.

\section{$\underline{\text { Moisture Transport Model }}$}

A Portland Cement Concrete Pavement (PCCP) moisture model by (Qinwu Xu, J. Mauricio Ruiz, George K. Chang, Robert O. Rasmussen, and Dan K. Rozycki, 2009) is used for the prediction of the moisture transportation. This model predicts PCCP moisture transport and moisture loss to the environment due to drying and self-desiccation.

According to Fick's second law, the reduced moisture variation with time and position 1-D can be expressed as:

$$
\frac{\partial H}{\partial t}=\frac{\partial}{\partial x}\left(D(H) \frac{\partial H}{\partial x}\right)
$$

Eq. 62

The solution for the partial differential equation (PDE) using the Crank-Nicolson method is as follows:

$$
\frac{H_{i}^{n+1}-H_{i}^{n}}{\Delta t}=\frac{1}{2}\left[D_{i+1 / 2} \frac{H_{i+1}^{n+1}-H_{i}^{n+1}+H_{i+1}^{n}-H_{i}^{n}}{\Delta h^{2}}-D_{i-1 / 2} \frac{H_{i}^{n+1}-H_{i-1}^{n+1}+H_{i}^{n}-H_{i-1}^{n}}{\Delta h^{2}}\right]
$$

Eq. 63 
$\mathrm{H}_{\mathrm{in}}$ is the relative humidity at the $\left(\mathrm{i}_{\mathrm{th}}\right)$ time step and $\left(\mathrm{n}_{\mathrm{th}}\right)$ depth step. $\Delta \mathrm{t}$ and $\Delta \mathrm{h}$ are time step length and depth step length. In this study, the time step is ( $1 \mathrm{hr}$.) increment and a total of 100 depth steps was used in the finite difference calculation. $\mathrm{D}$ is the diffusivity and it is a function of the relative humidity and given in Eq.4.

For solving the PDE using Crank-Nicolson method which is an implicit method, boundary conditions have to be applied, the surface on the concrete is the first boundary condition as the moisture may be lost or gained at the slab surface because of a moisture unbalance between the slab and ambient air, which is affected by multiple factors including curing conditions, environmental temperature, wind speed, and air properties such as vapor pressure. To maintain the moisture emission balance at the slab surface, a surface factor $\mathrm{f}$ (moisture emissivity) is used to correlate this relationship as follows:

$$
D \frac{\partial H}{\partial x}=f\left(H_{e n}-H_{\text {sur }}\right) \text { Eq. } 64
$$

Where:

$\mathrm{f}=$ surface factor of emissivity $(10-6 \mathrm{~m} / \mathrm{h})$,

$\mathrm{H}_{\mathrm{en}}=$ relative humidity of ambient.

$\mathrm{H}_{\text {sur }}=$ moisture content at concrete surface.

The surface factor of emissivity is expressed as a function of the water/cement ratio by Akita et al. in the following equation:

$$
f=\frac{50}{\frac{w}{c}+10}+2.5 \text { Eq. } 65
$$


The solution of the relative humidity at the concrete surface becomes:

$$
\left(\frac{f * \Delta h}{D_{0}}+1\right) H_{0}^{n+1}-H_{1}^{n+1}=f * \frac{\Delta h}{D_{0}} * H_{e n} E q .66
$$

On the other hand, there is no moisture loss at the inner surface of the concrete since it is attached to the steel ring, then second the boundary condition can be expressed as follows:

$$
D \frac{\partial H}{\partial x}=0 \quad E q .67
$$

The moisture transport model is coded in MATLAB and can solve the moisture distribution for 1-D concrete slab exposed to the environment drying from the top surface at different depth and different ages.

In the MATLAB code, the critical degree of hydration assumed to be 0.4 , and the moisture at the ultimate degree of hydration was calculated based on the water/cement ratio as 0.7781 , Beta with a value of 2.5 , was used. For the diffusivity calculation $\mathrm{Dr}=0.0195 \mathrm{~cm}^{2} / \mathrm{h}$, and $\mathrm{n}=6$.

The humidity model was verified by comparing its results to other researchers results because the relative humidity inside the concrete was not measured successfully during the experiments. The first comparison was from the original researchers who developed the model by solving the theoretical solution of the moisture development inside the concrete, using their parameters in the model, and assuming parameters for the hydration degree since it was not given. 
As shown in figure 51 the model can well follow the shape and predict the moisture loss development inside the concrete for different mix designs.
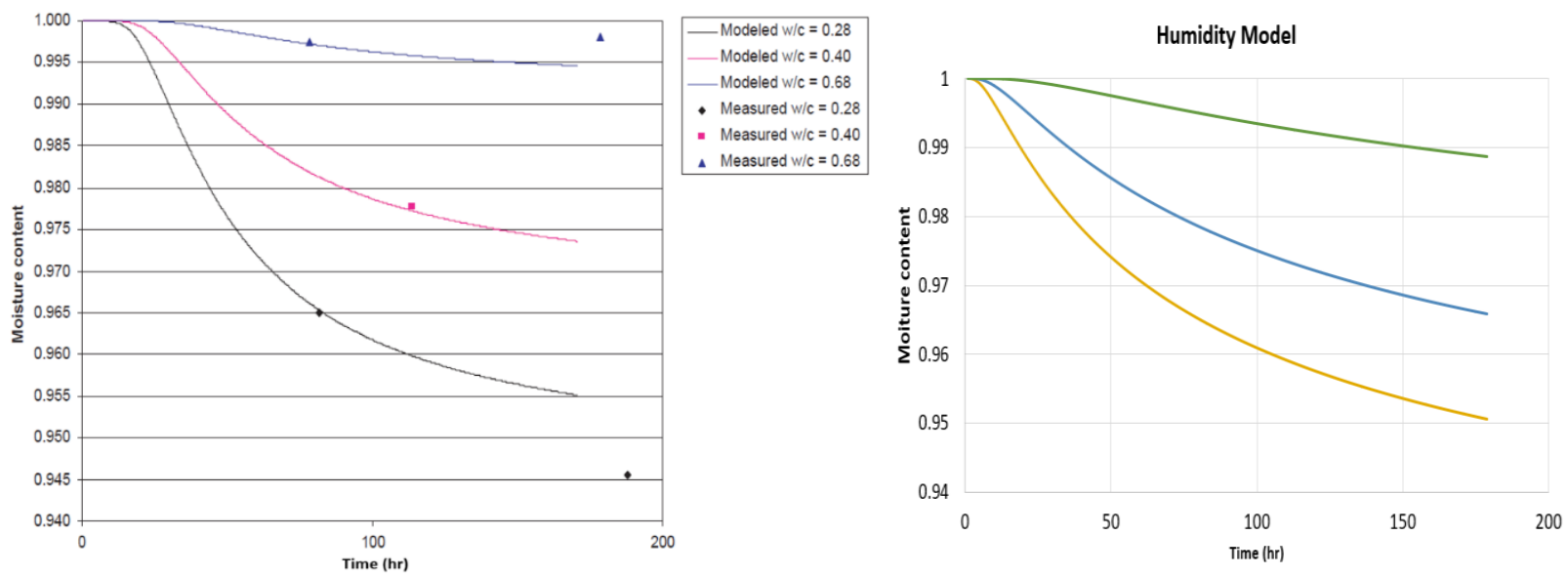

Figure 51 Comparison between the coded model result and other researches results

To further verify the accuracy and the validation of the humidity model, a second comparison was made between the theoretical solution of the moisture development inside the concrete and experimental data obtained by (Zhang 2010). Zhang experimentally measured the relative humidity inside the concrete using a humidity sensor located at the centroid of a prism with a dimension of $100 \times 100 \times 400 \mathrm{~mm}$, which means at a depth of $50 \mathrm{~mm}(1.9685 \mathrm{in})$ from the drying surface. Zhang used two concrete mixes, C30, and C80.

The theoretical solution of the moisture development inside the concrete is shown in figure 53, it should be noted that the theoretical value of the moisture was solved using parameters provided by Zhang for each mix design.

Comparing both figures 52 and 53, the theoretical solution can well predict the moisture development inside the concrete. 


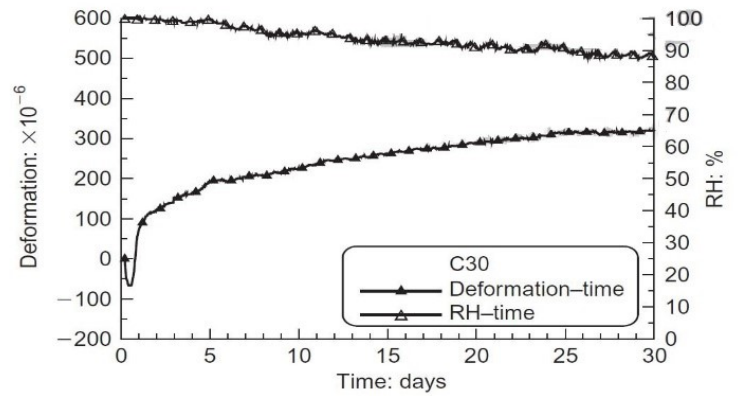

(a)

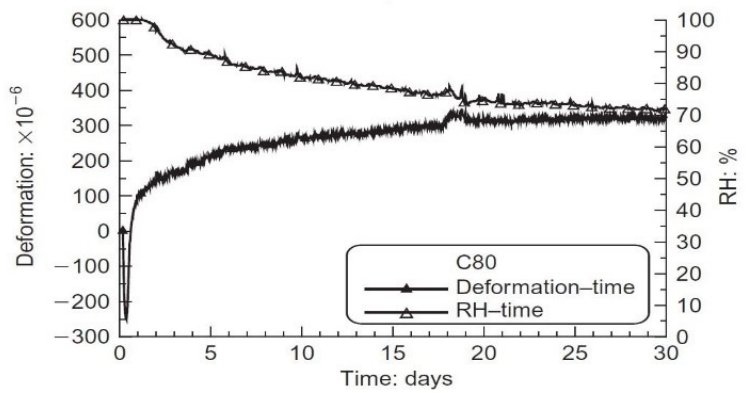

(b)

Figure 52 The development of interior humidity with time in (a) C30 and (b) C80 concrete

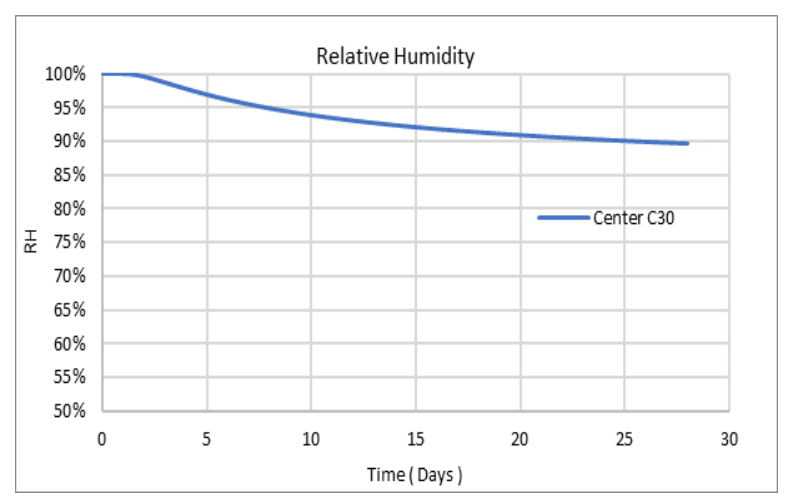

(a)

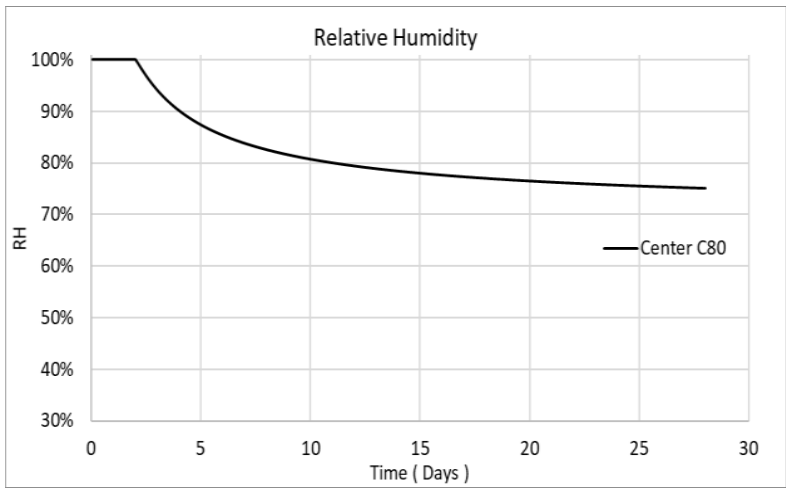

(b)

Figure 53 The development of interior humidity with time in (a) C30 and (b) C80 concrete using the theoretical solution of the moisture development inside the concrete

\section{No-Wrap case:}

Using the thickness of 0.75 " in the analysis to find the moisture loss. In this case, the inner surface which is the bottom of the slab is equal to the center of the no wrap shrinkage specimen.

\section{Half-Wrapped case:}

Using the thickness of $1.5 "$ in the analysis to find the moisture loss. In this case, the inner surface which is the bottom of the slab is equal to the center of the half-wrapped shrinkage specimen which is exactly the case of the concrete ring. 


\section{Fully-Wrapped case:}

Using the thickness of 1.5 " in the analysis to find the moisture loss due to the selfdesiccation only. In this case, both the inner surface and the outer surface must have the same moisture loss and it's equal to the center of the fully-wrapped shrinkage specimens.

\section{Moisture Distribution}

Since the moisture model does the calculation based on time and location, the humidity distribution can be calculated versus depth for a different time. Drying due the self- desiccation (hydration), is different for each mix because of the difference of the degree of hydration curve since they have been cured in the different environment temperature. Figure 54, Figure 55 and Figure 56 represent the relative humidity distribution for the normal temperature of $\left(73^{\circ} \mathrm{F}\right)$ which is the OPC 1 and similarly the distribution of the moisture can be solved for each case.

\section{$\underline{\text { OPC } 1}$}

\section{No Wrap}

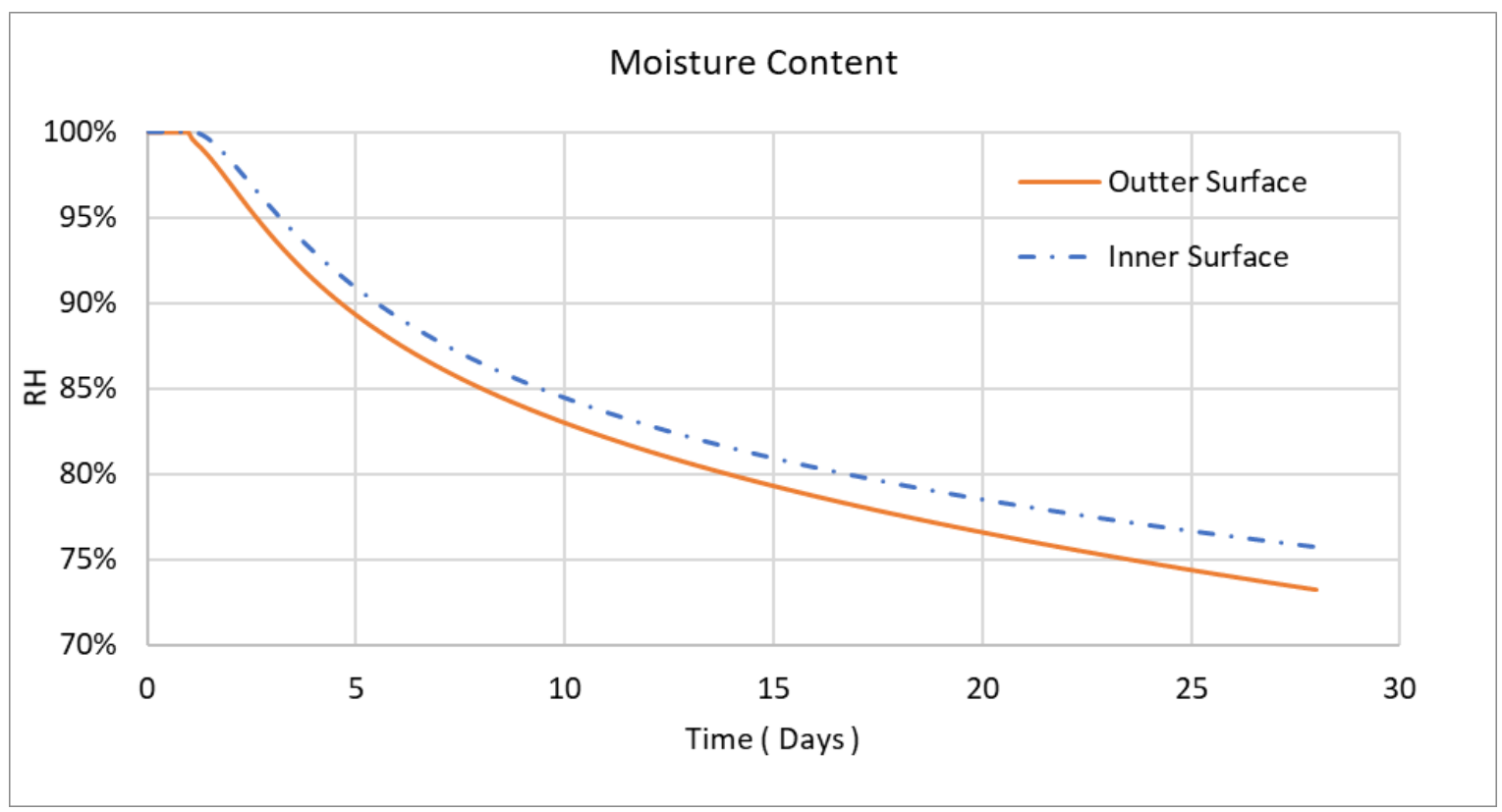

Figure 54 Moisture at the inner and the outer surface no-wrap (OPC $\left.1,73^{\circ} \mathrm{F}\right)$ 


\section{Half-Wrapped}

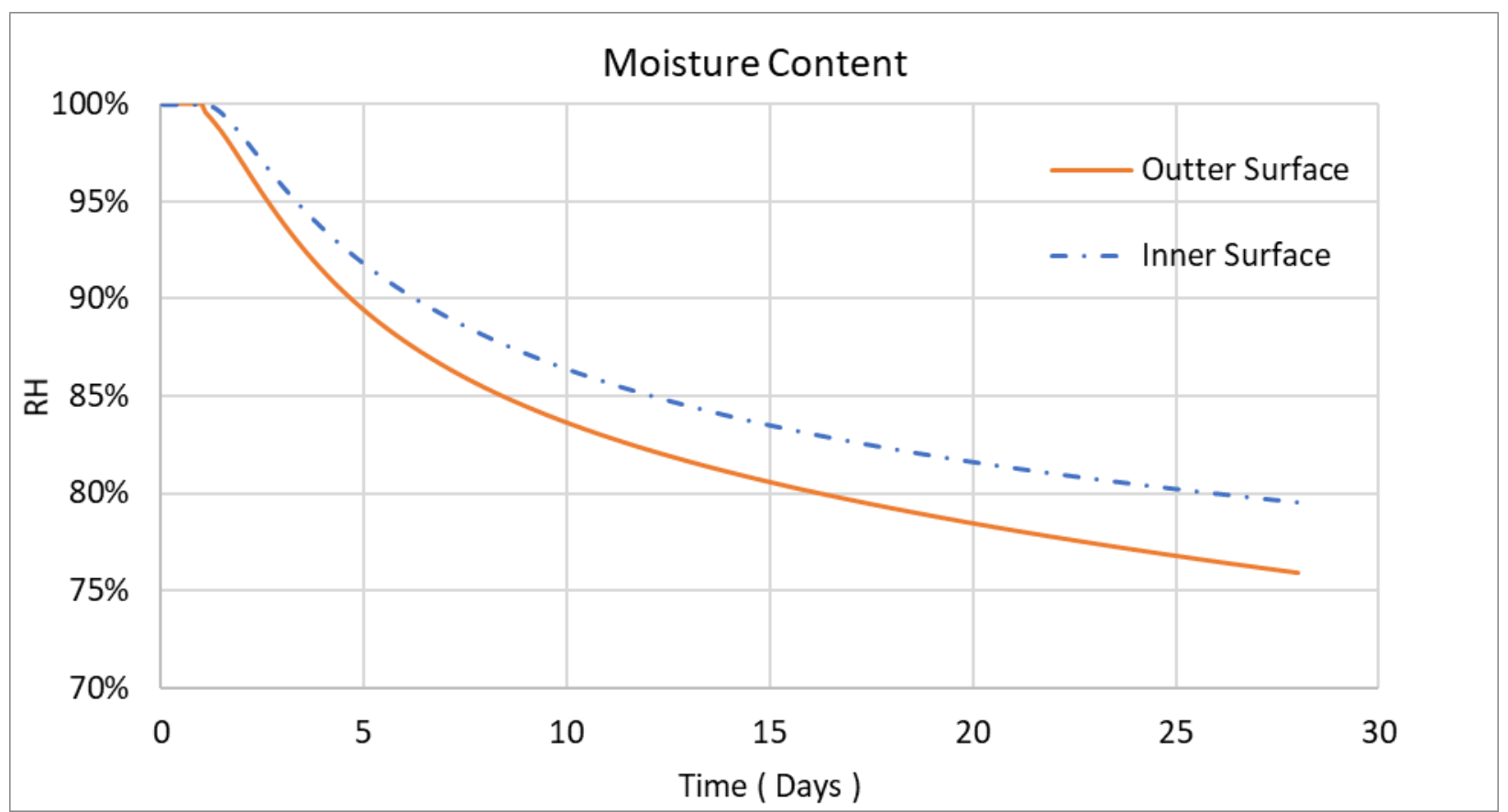

Figure 55 Moisture at the inner and the outer surface half-wrapped (OPC 1, $\left.73^{\circ} \mathrm{F}\right)$

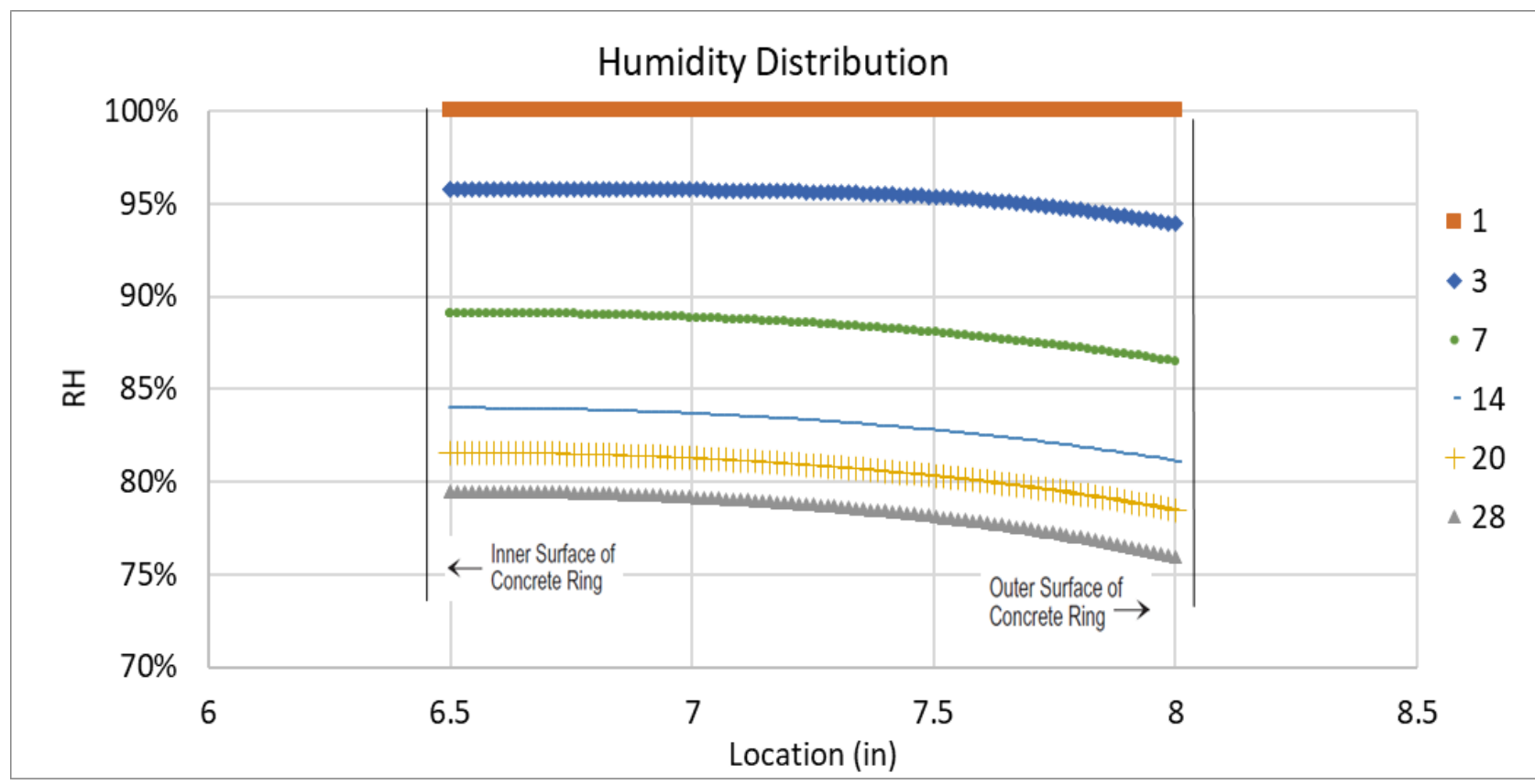

Figure 56 Moisture distribution at different age half-wrapped along the depth of the ring (OPC 1, $\left.73{ }^{\circ} \mathrm{F}\right)$ 
In order to consider the effect of the change in the ambient temperature and the humidity, an improvement for the existing theoretical solution of the moisture content inside the concrete was made. As seen previously, different shrinkage behavior was observed under different ambient temperature and humidity which means the partial and saturation pressure under different ambient temperature and humidity should be considered. Since, the drying speed of the concrete is directly related and controlled by the difference between the partial and the saturation pressure then, the moisture content inside of the concrete is also directly related and controlled by the difference between the partial and the saturation pressure since the moisture content and the shrinkage are directly related by a linear relationship in Eq 25.

Considering the OPC 1 as the ideal case, where the difference between the partial and the saturation pressure was minimum. The effect of the partial and the saturation pressure on OPC 2 can be considered by multiplying the moisture loss by the percentage of the slops.

For example, the slop percentage of OPC 2 is 16.44 divided by 14.269 which is equal to 1.15. Which means that the moisture loss for OPC 2 at a given time should be increased by $15 \%$. And this increase in the moisture loss is a result of the change ambient temperature and the humidity as result is the change of the partial and the saturation pressure. in order to make it clear here is an example using the slop percentage method for OPC 2 case.

At a given time, $\mathrm{t}=28$ days, the moisture content without considering the partial and the saturation pressure is $78 \%$ as shown in figure 57 which means that the moisture loss is equal to $100-78=22 \%$. Now considering the effect of the partial and the saturation pressure, the corrected moisture loss is equal to $22 \times 1.15=25.3 \%$ and the moisture content now equal to $74.7 \%$ instead of $77 \%$. 


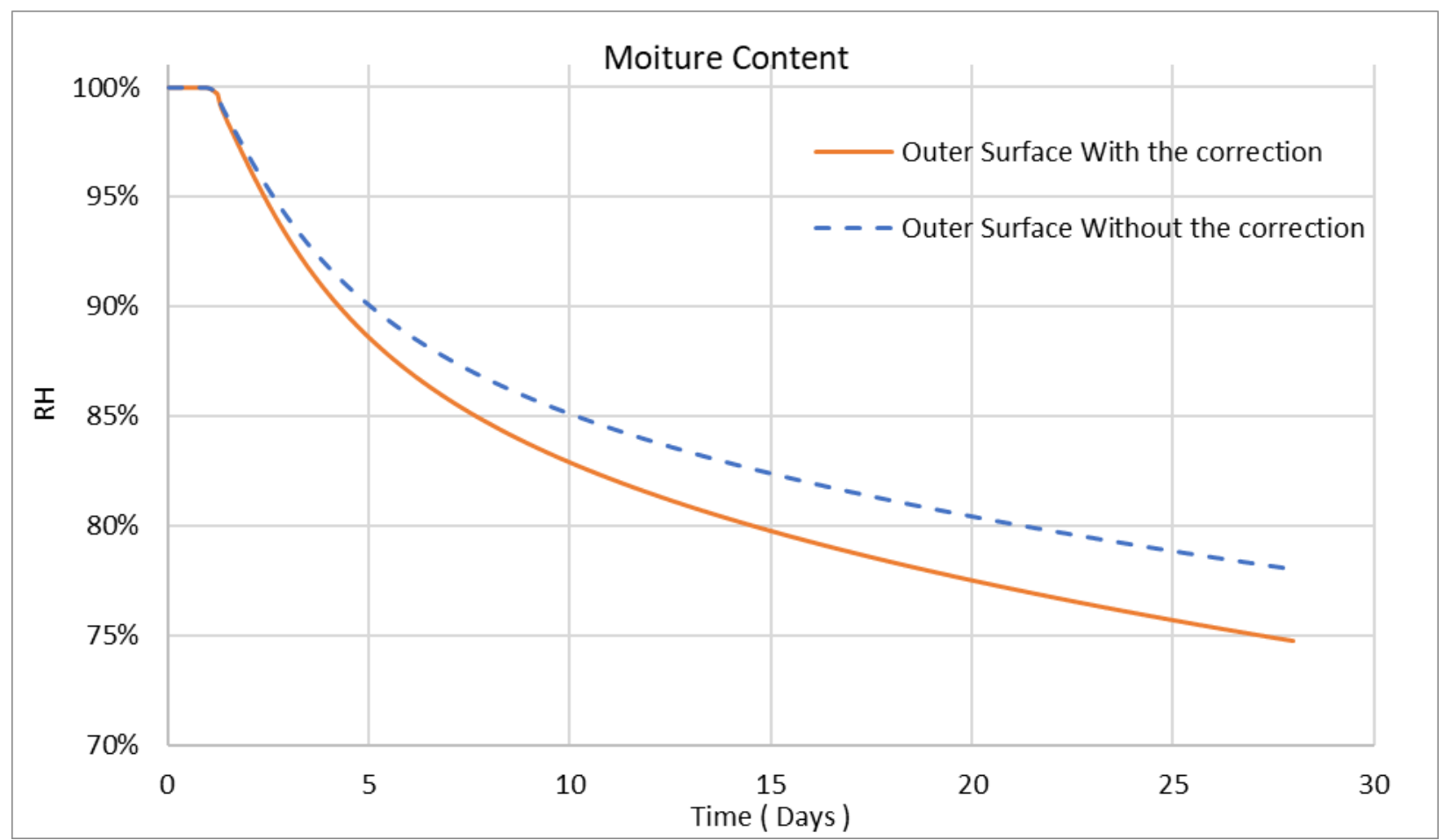

Figure 57 the moisture content without and with considering the partial and the saturation pressure for (OPC 2)

It should be noted that this method was valid in this research and the correction of the moisture content was considered for both cases OPC 2 and OPC 3 but has not been verified yet, more research needs to be done in order to verify and finalize the slop percentage method. 


\section{Shrinkage Modeling}

The linear relationship between free shrinkage, strain, and humidity reduction described earlier was used to model the shrinkage.

$$
\varepsilon_{\mathrm{W}}=\varepsilon_{0}+k(100-\mathrm{RH}) \quad \text { for } \mathrm{RH}<100 \% E q .68
$$

Where $\varepsilon_{0}$ is the shrinkage occurring during the humidity developing stage 1 when $(\mathrm{RH}=$ $100 \%$ ), which should principally be governed by w/c, and $k$ is the shrinkage strain generated by a one-unit humidity reduction. The shrinkage factor $k$ was determined by plotting the humidity analysis versus the experiment results at the same time for each measurement, then modify $k$ until getting the best fit between both the experiments and the fitting model.

\section{1- OPC 1}

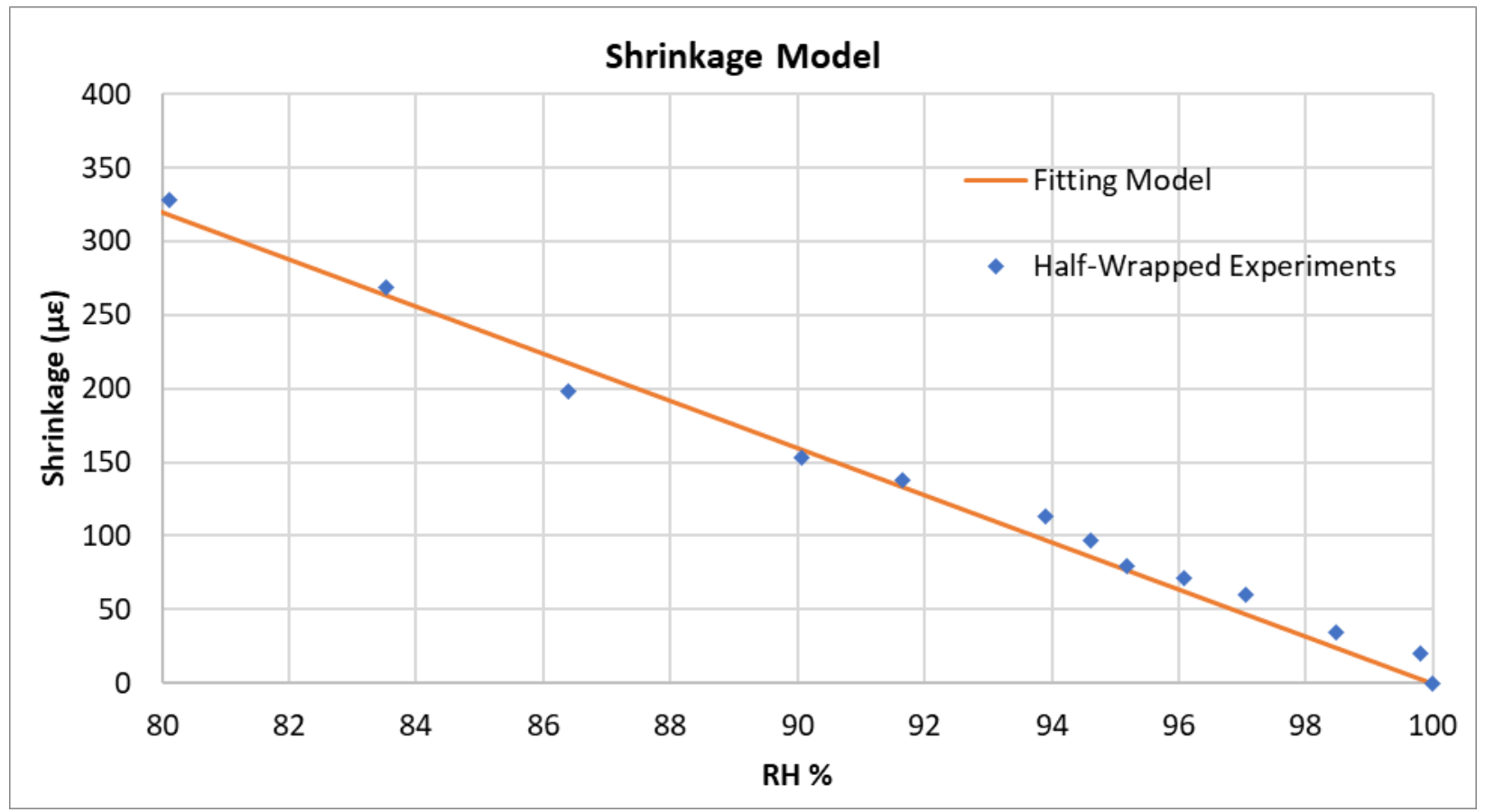

Figure 58 The linear relationship between the shrinkage and RH\% OPC 1 


\section{2- OPC 2}

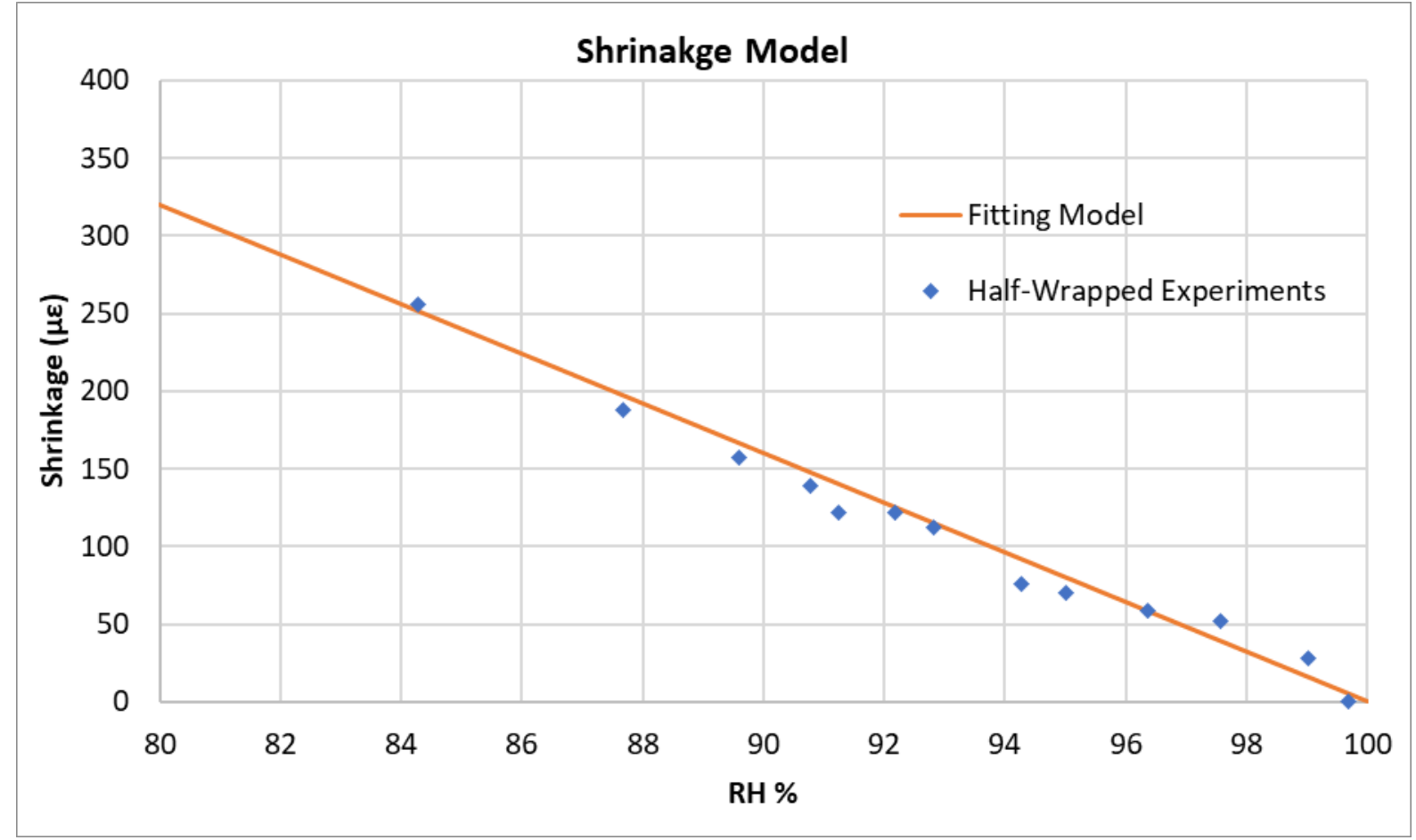

Figure 59 The linear relationship between the shrinkage and RH\% OPC 2

\section{3- OPC 3}

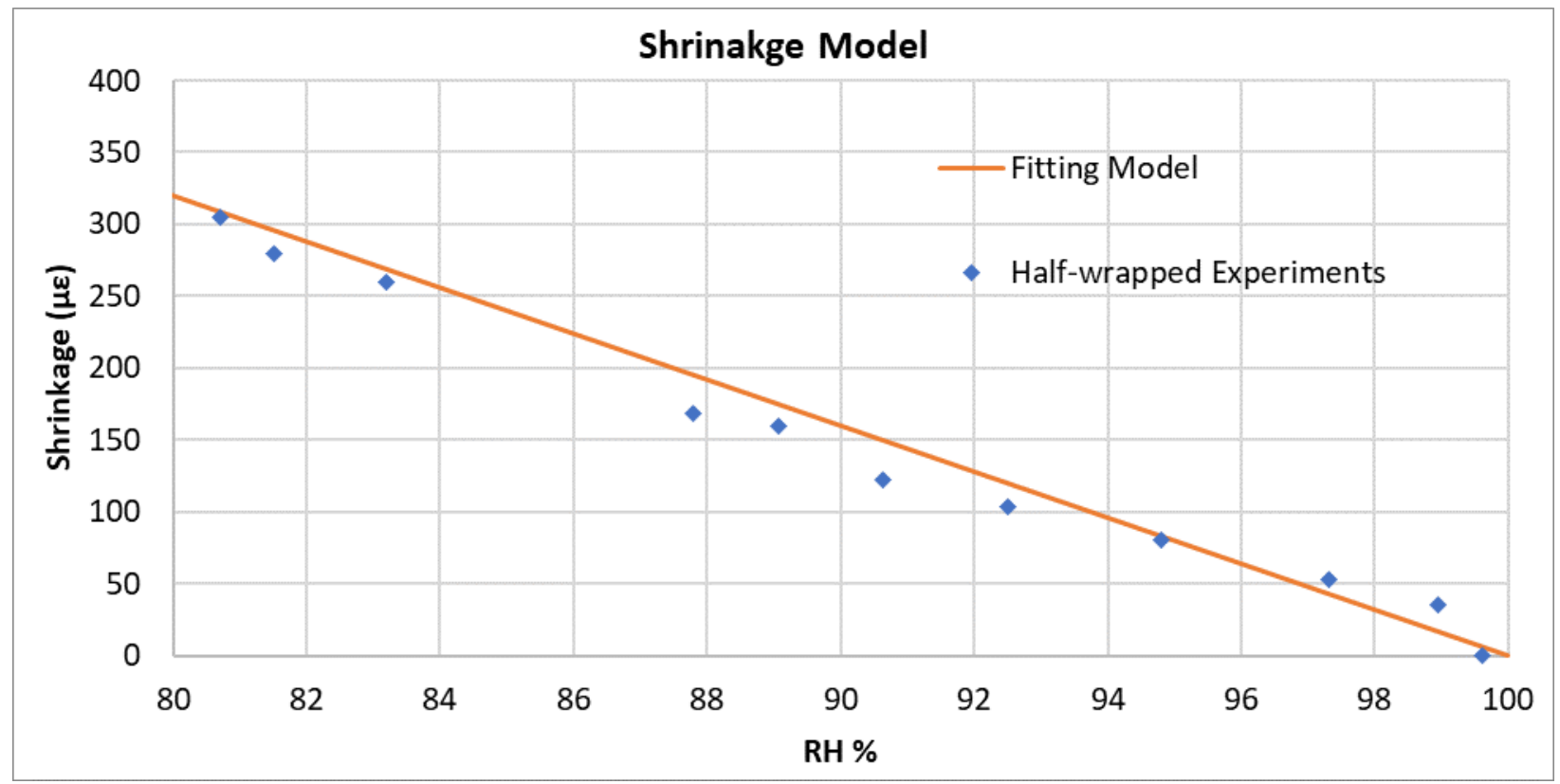

Figure 60 The linear relationship between the shrinkage and $\mathrm{RH} \%$ OPC 3 
As previously mentioned, the higher the environment temperature the higher the shrinkage in the concrete, and the faster the hydration process of the concrete. The shrinkage factor is a material property and supposed to be the same for each mix design, a unique value each mix design to be determined, the shrinkage factor of the OPC mixes used in this study is ( 16 micro-strain ). Again, $\mathrm{k}$ is the shrinkage strain generated by a one-unit humidity reduction which means if the concrete's relative humidity changed by $1 \%$, the shrinkage increases by 16 micro-strain. As shown in Figure 58, Figure 59 and Figure 60, the shrinkage factor of 16 microstrain can fit the experiment perfectly.

\section{$\underline{\text { Shrinkage Distributions }}$}

After the determination of the shrinkage factor of the concrete mix, the shrinkage analysis can be performed using Eq. 68 . Where the relative humidity $\mathrm{RH}$ was calculated previously, and $k$ was determined, shrinkage distribution analysis in the concrete under different wrapping conditions can be calculated for each concrete mix. 


\section{1- OPC 1}

\section{No Wrap}

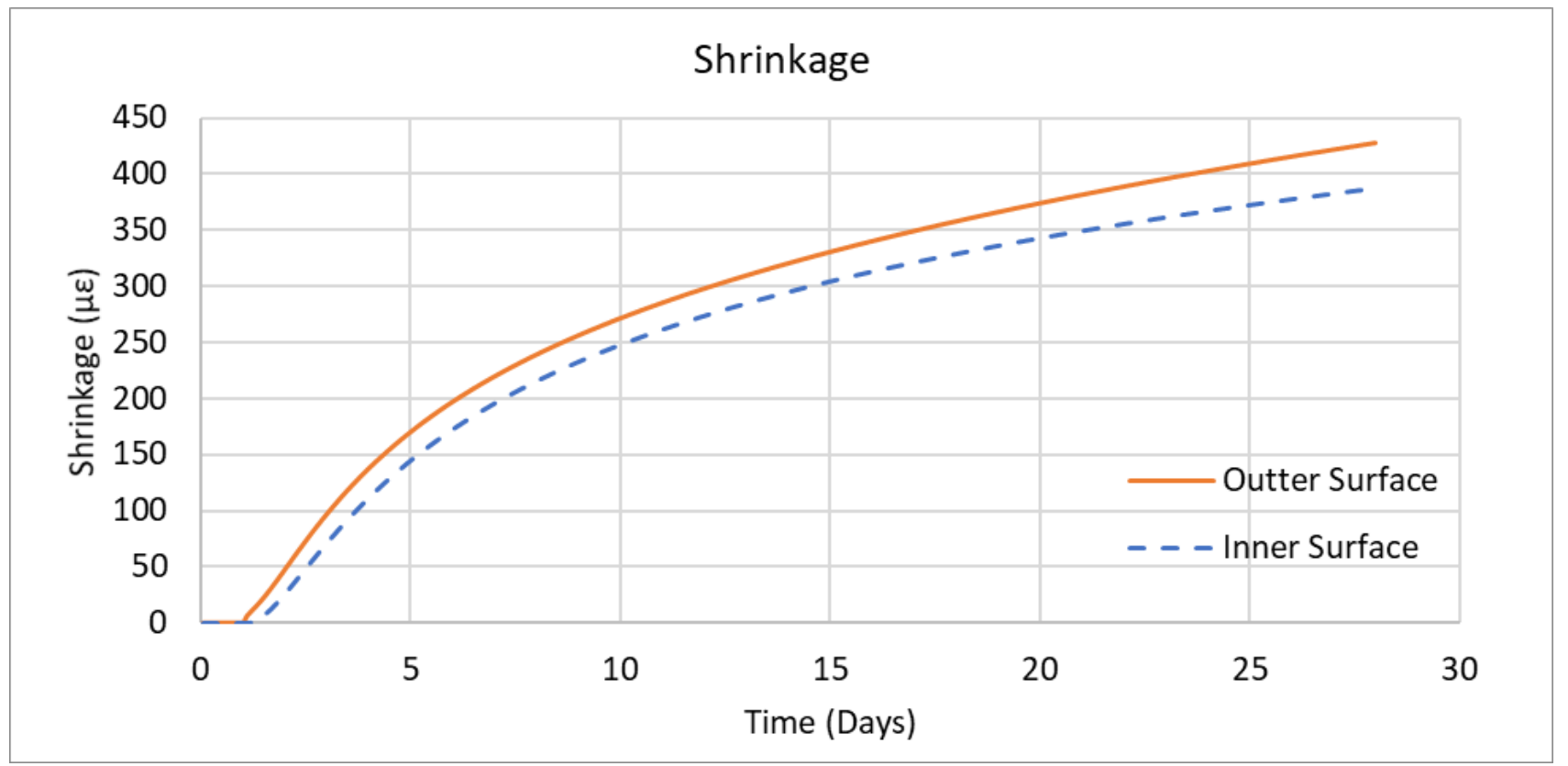

Figure 61 Shrinkage (micro-strain) at the inner and the outer surface No Wrap OPC 1

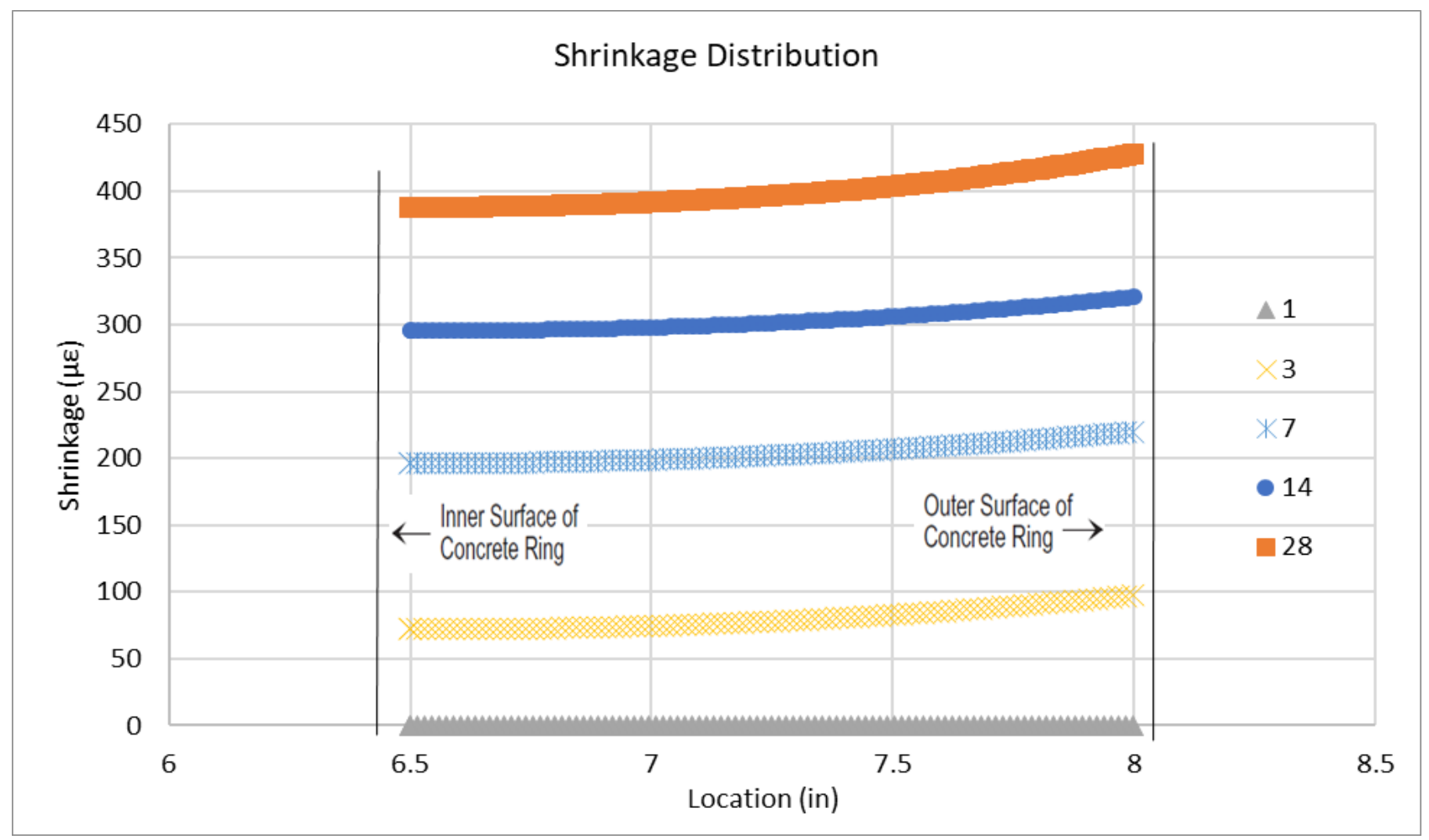

Figure 62 Shrinkage (micro-strain) distribution at different age No Wrap OPC 1 


\section{Half Wrapped}

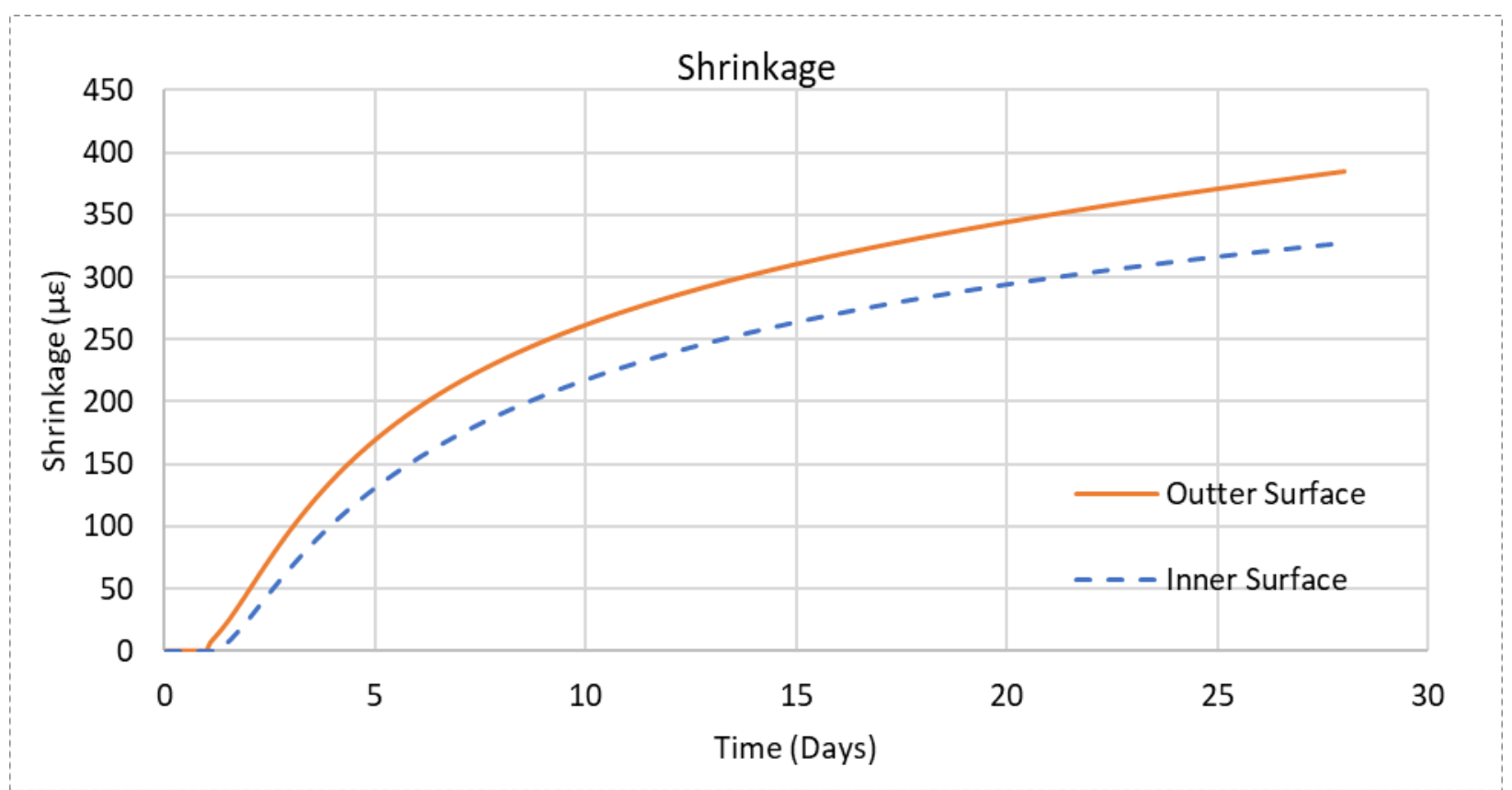

Figure 63 Shrinkage (micro-strain) at the inner and the outer surface half-Wrap OPC 1

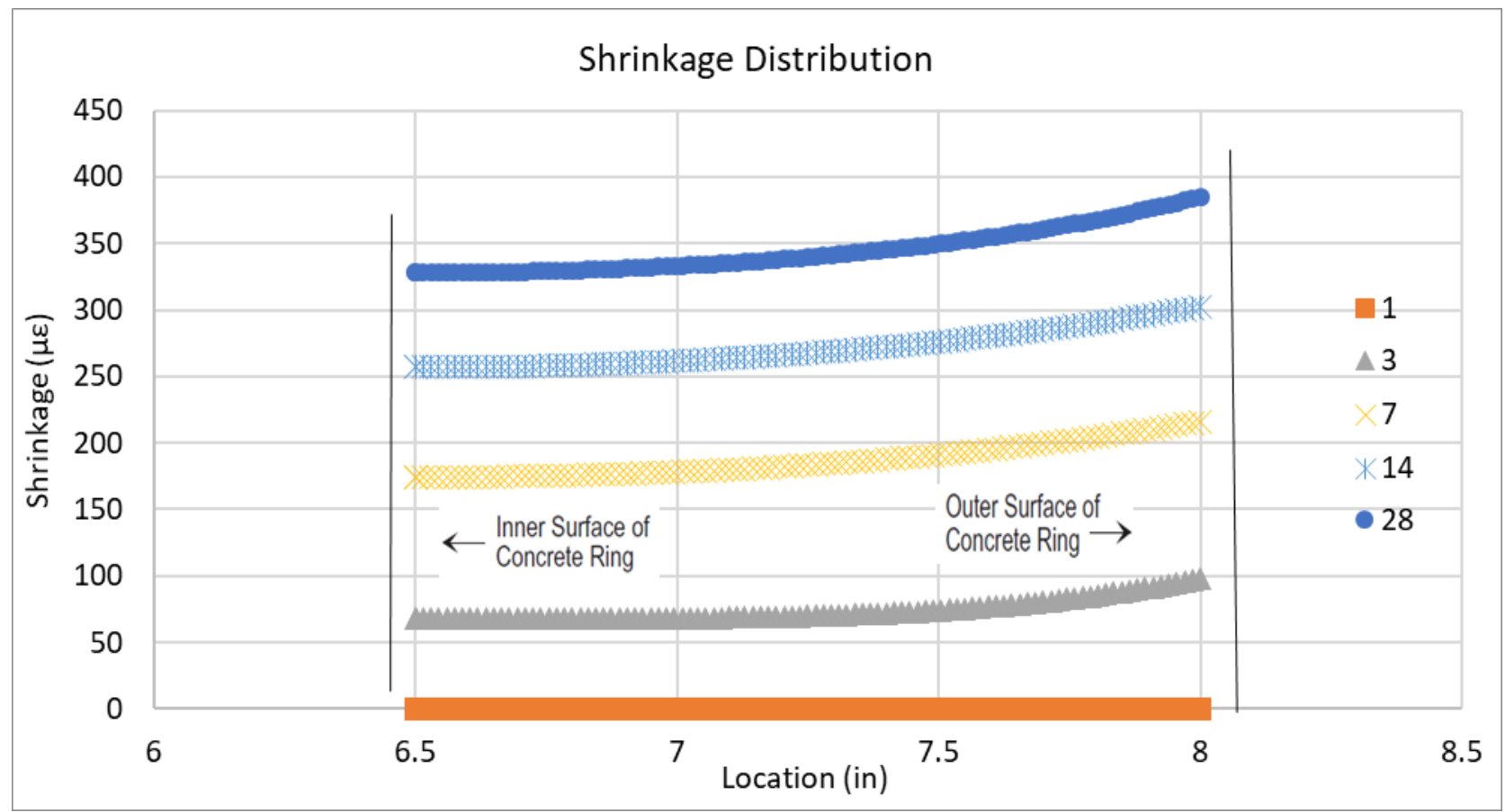

Figure 64 Shrinkage (micro-strain) distribution at different age half-Wrap OPC 1 


\section{2- OPC 2}

\section{No Wrap}

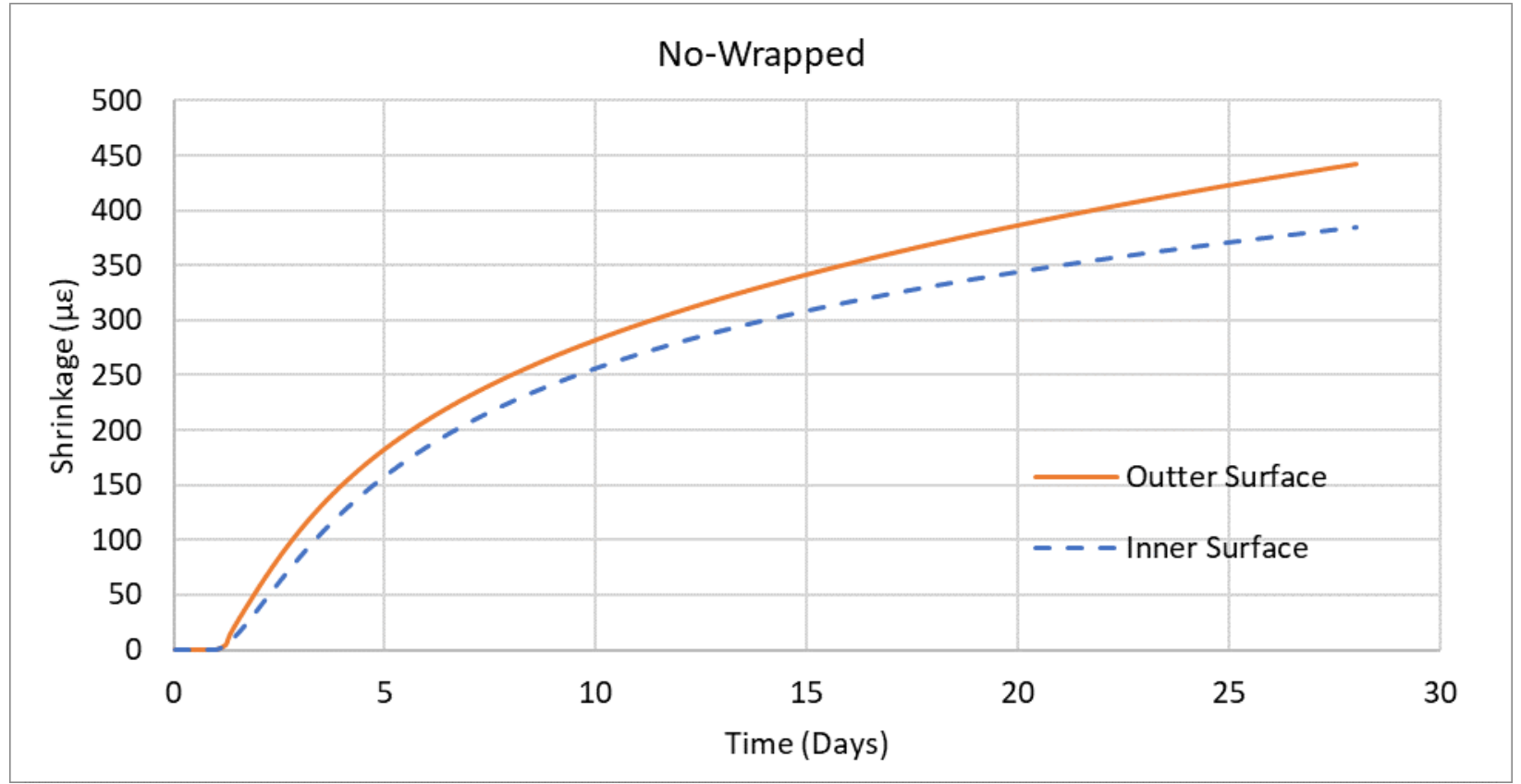

Figure 65 Shrinkage (micro-strain) at the inner and the outer surface No Wrap OPC 2

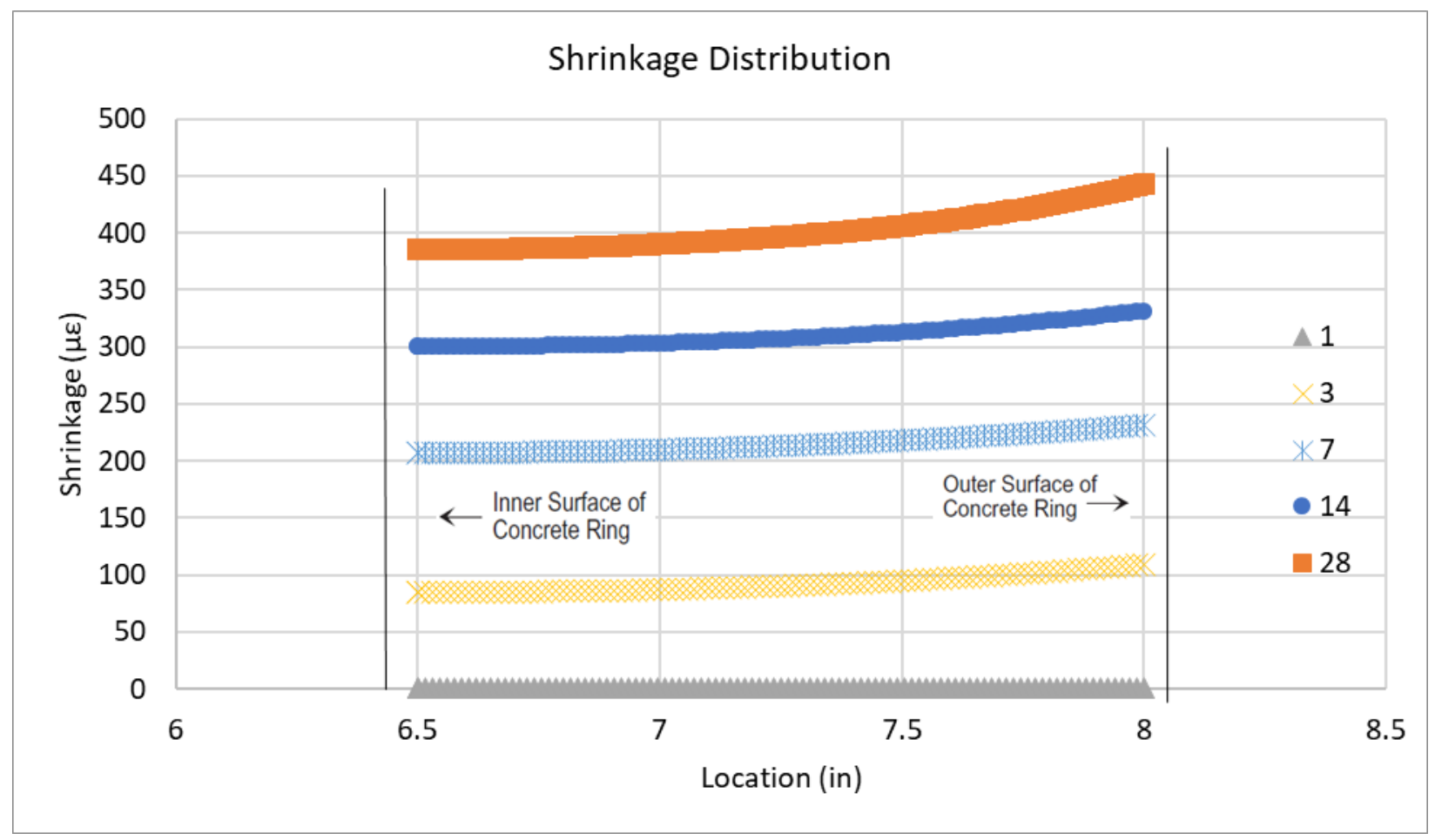

Figure 66 Shrinkage (micro-strain) distribution at different age No Wrap OPC 2 


\section{Half Wrapped}

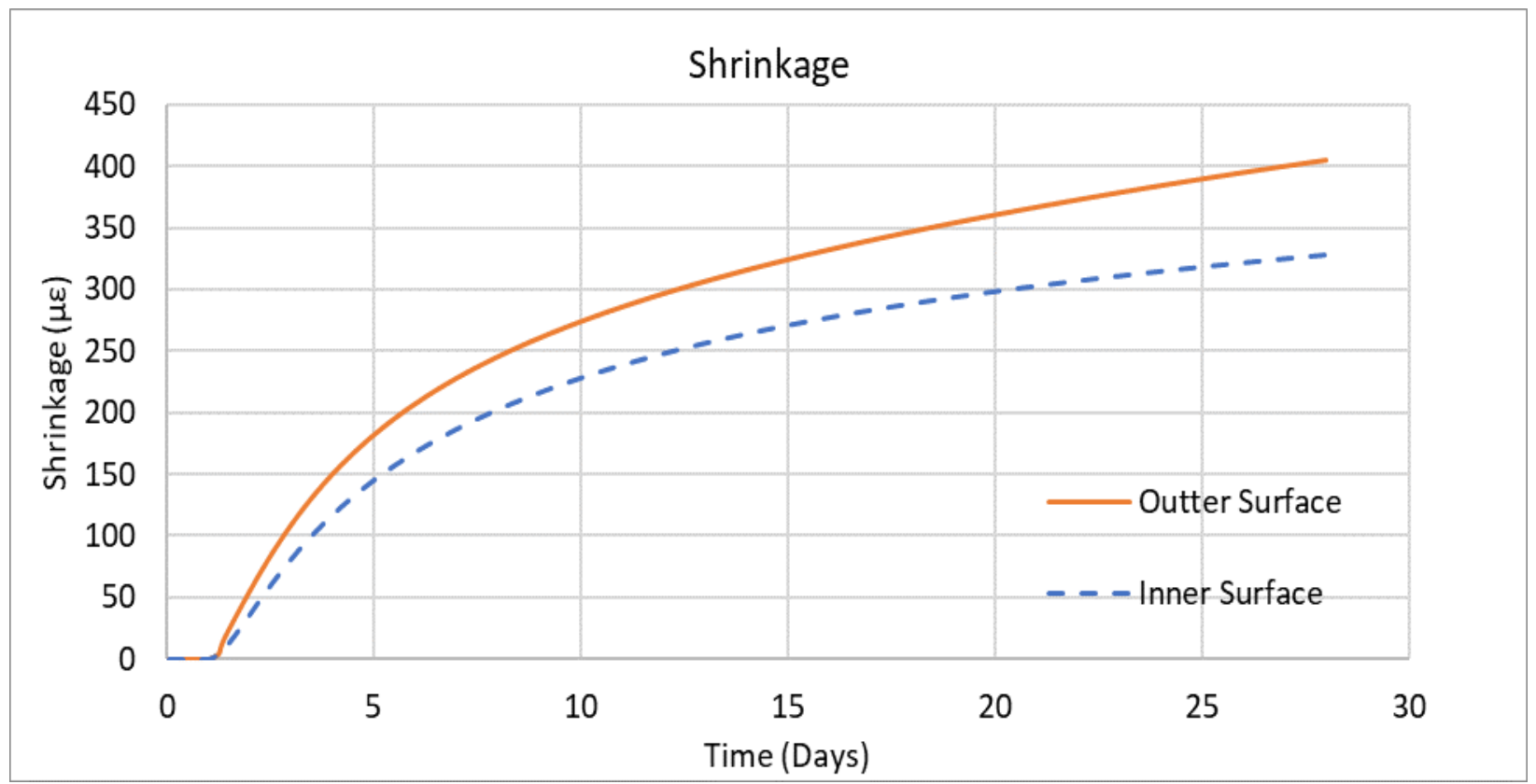

Figure 67 Shrinkage (micro-strain) at the inner and the outer surface half-Wrap OPC 2

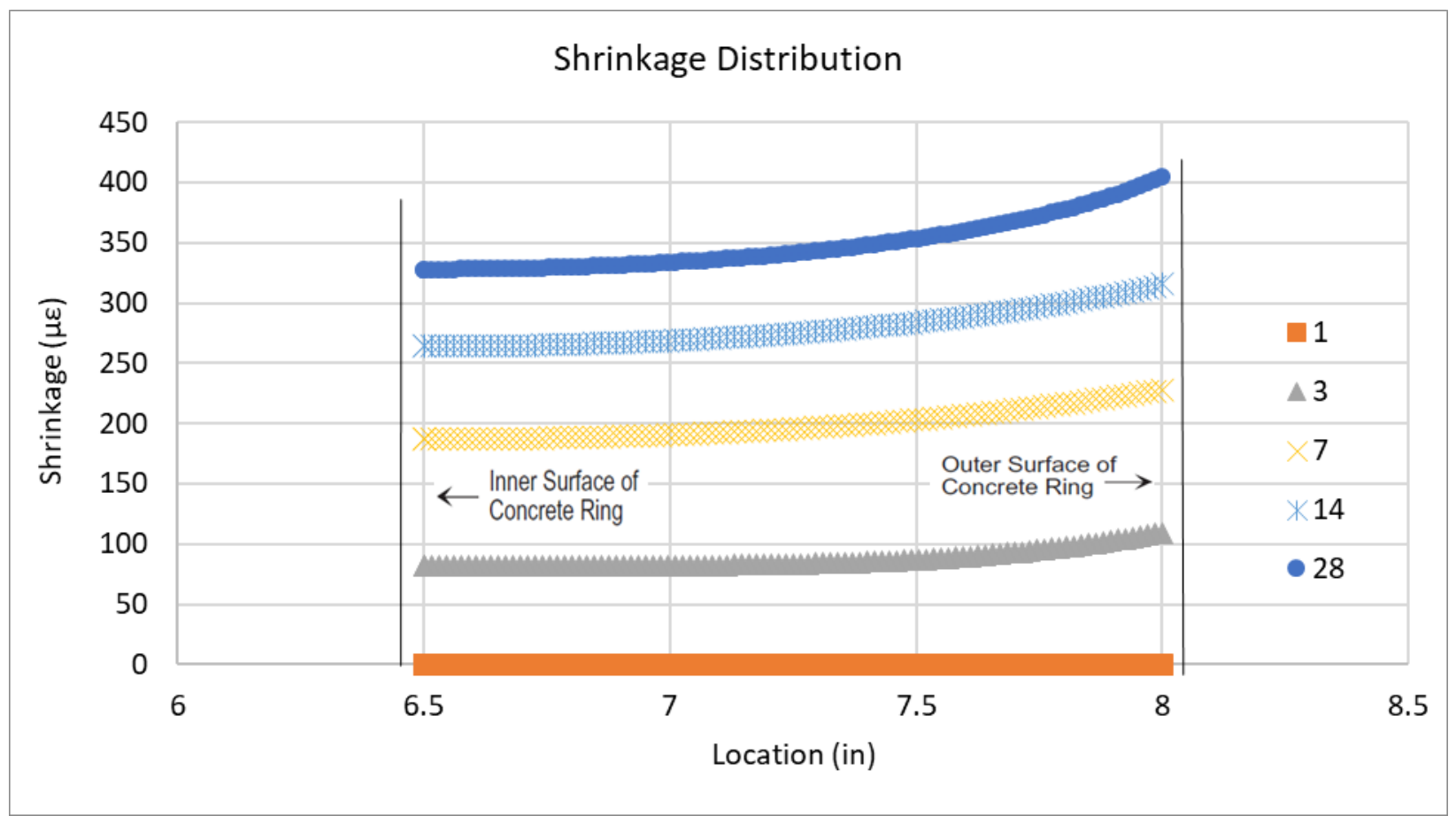

Figure 68 Shrinkage (micro-strain) distribution at different age half-Wrap OPC 2 


\section{3- OPC 3}

\section{No Wrap}

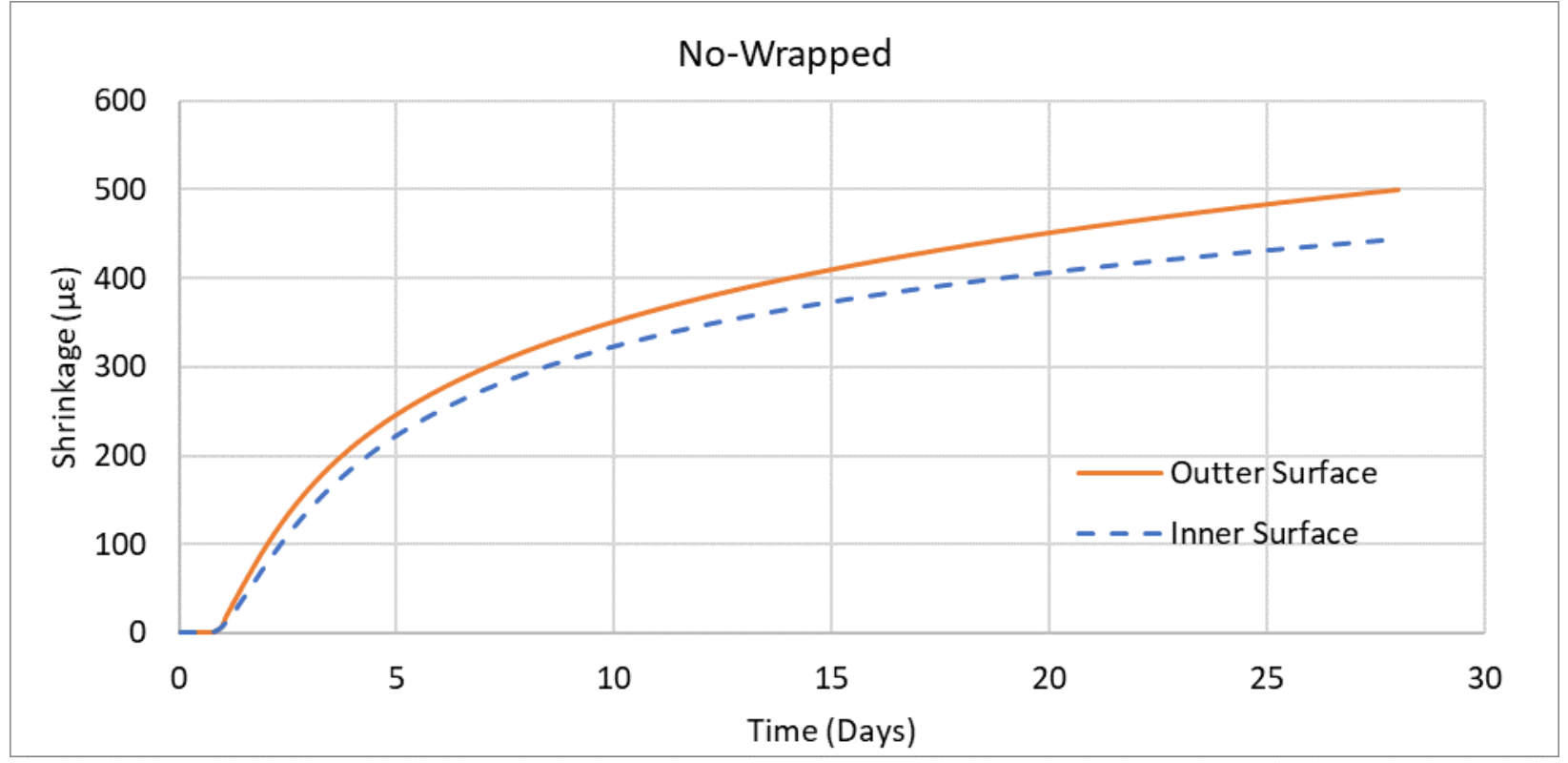

Figure 69 Shrinkage (micro-strain) at the inner and the outer surface No Wrap OPC 3

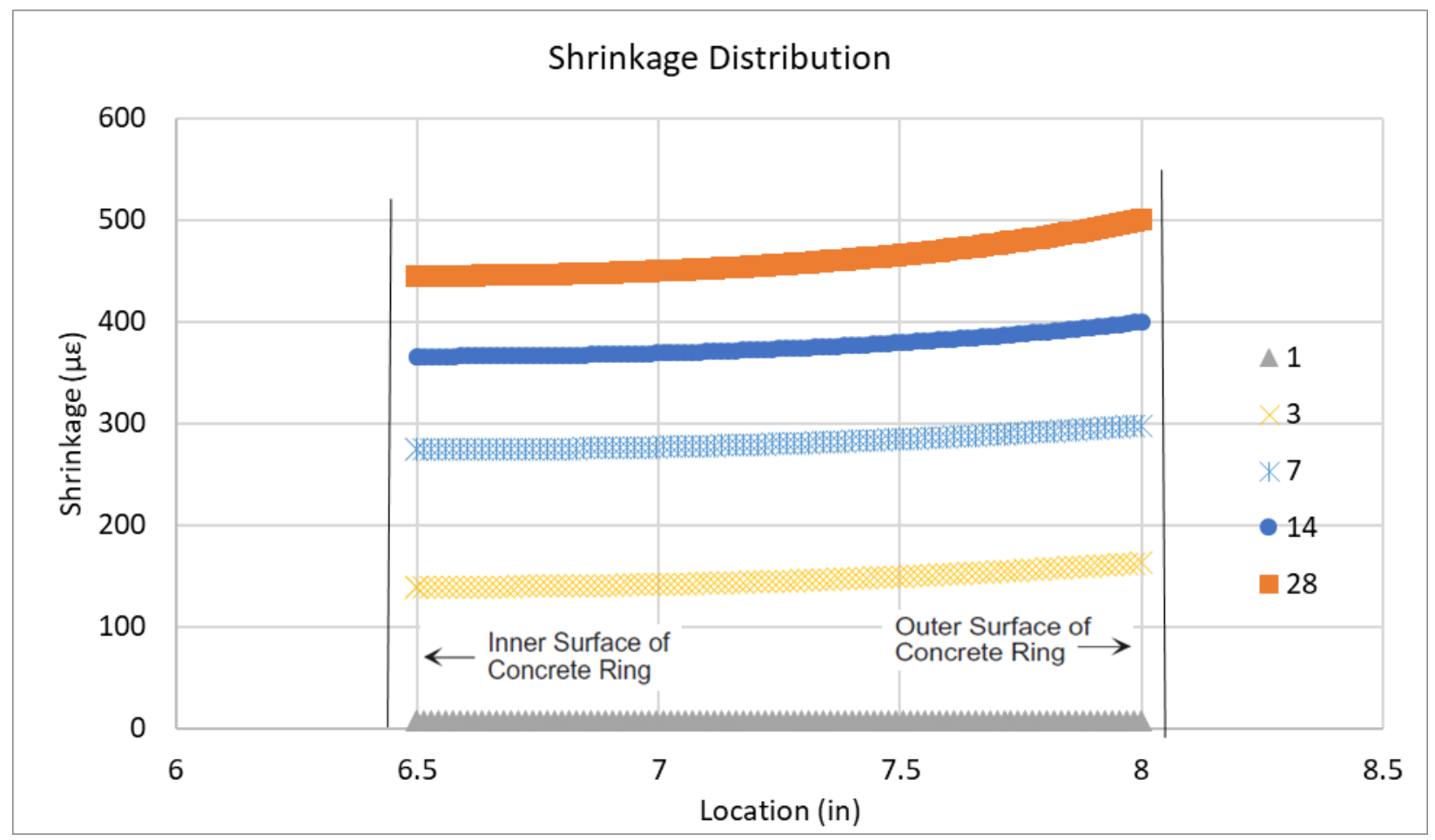

Figure 70 Shrinkage (micro-strain) distribution at different age No Wrap OPC 3 


\section{Half Wrapped}

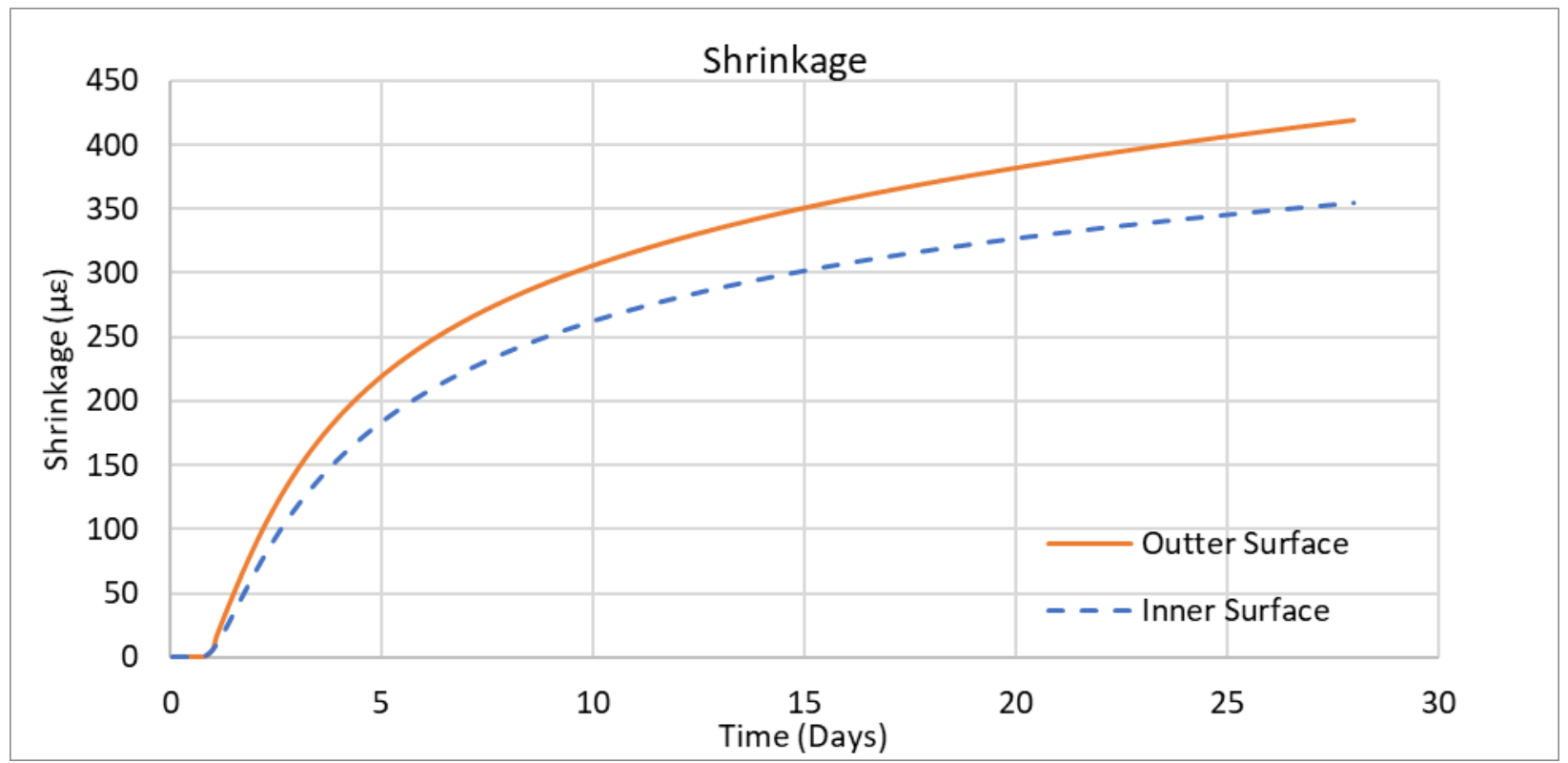

Figure 71 Shrinkage (micro-strain) at the inner and the outer surface half-Wrap OPC 3

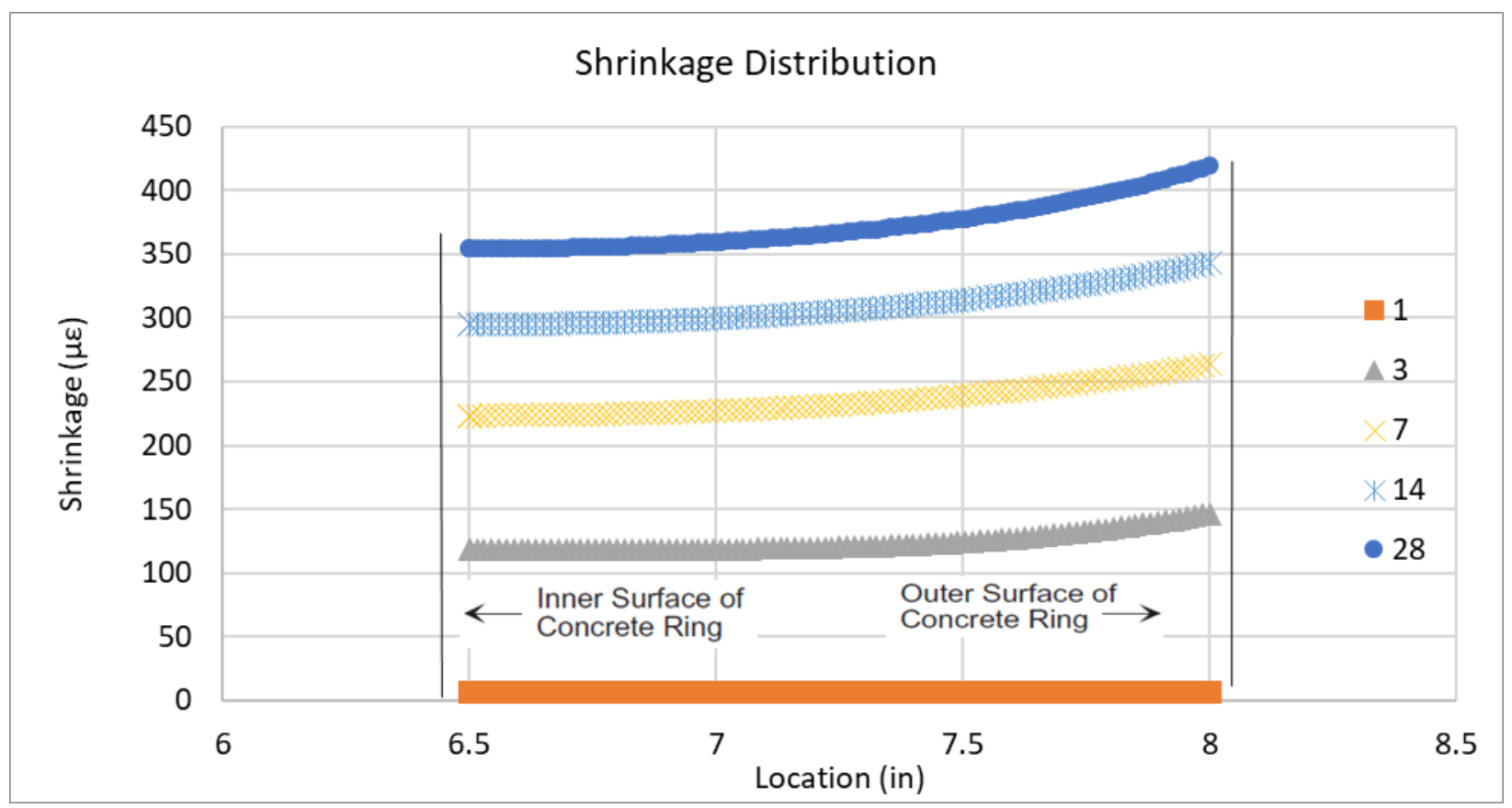

Figure 72 Shrinkage (micro-strain) distribution at different age half-Wrap OPC 3 
The shrinkage distribution along the depth for each mix design at different ages is shown in the previous Figure 61 through Figure 72. The distribution of the non-uniform shrinkage exists in both cases half-wrapped and no-wrap analysis-which is a very important concept since more stresses are developed at the surface. Thus, the non-uniform shrinkage causes a non-uniform stress along the depth.

At the outer surface, the concrete is shrinking more than the inner surface and that is a result of the outer surface being directly exposed to the environment. Additionally, specimens with no wrap will shrink more than the ones with half-wrap, which has been verified by the shrinkage experiments later in this research.

Using the humidity model, it is possible to solve for the shrinkage under different environmental temperature using the equivalent age of the concrete for each case. Using the humidity model, it is also possible to solve for the shrinkage at different times of the exposed, and it's shown in Figure 61 through Figure 72. This model can capture the time when the concrete undergoes drying shrinkage; for OPC 2 the dry shrinkage starts at $30 \mathrm{hrs}$. after casting, and for both OPC 1, OPC 3 the dry shrinkage starts at 24 hrs. 
$\underline{\text { Shrinkage Model Vs Shrinkage Experiments }}$

\section{1- OPC 1}

\section{No Wrap}

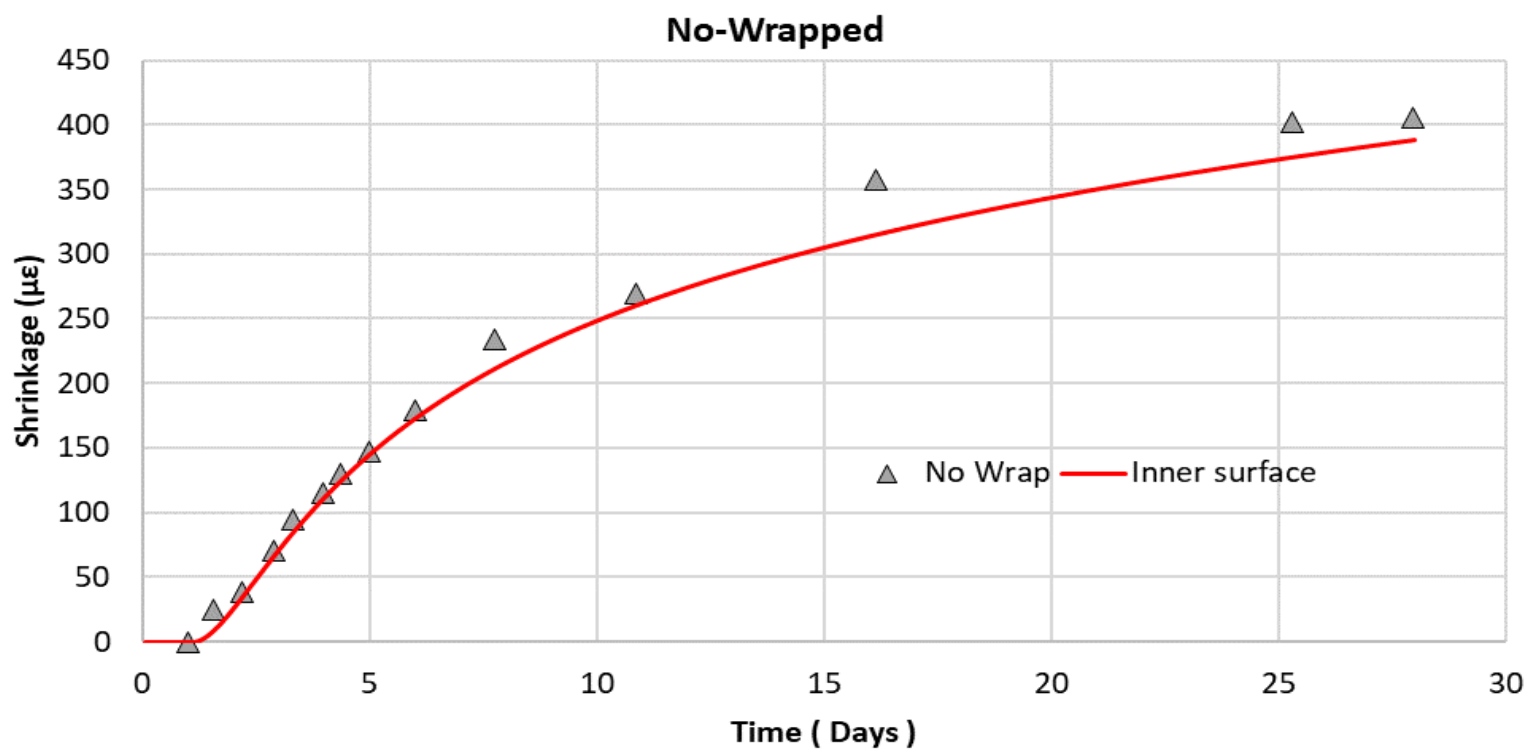

Figure 73 Shrinkage (micro-strain) Model prediction vs Shrinkage experiment OPC 1

\section{Half Wrapped}

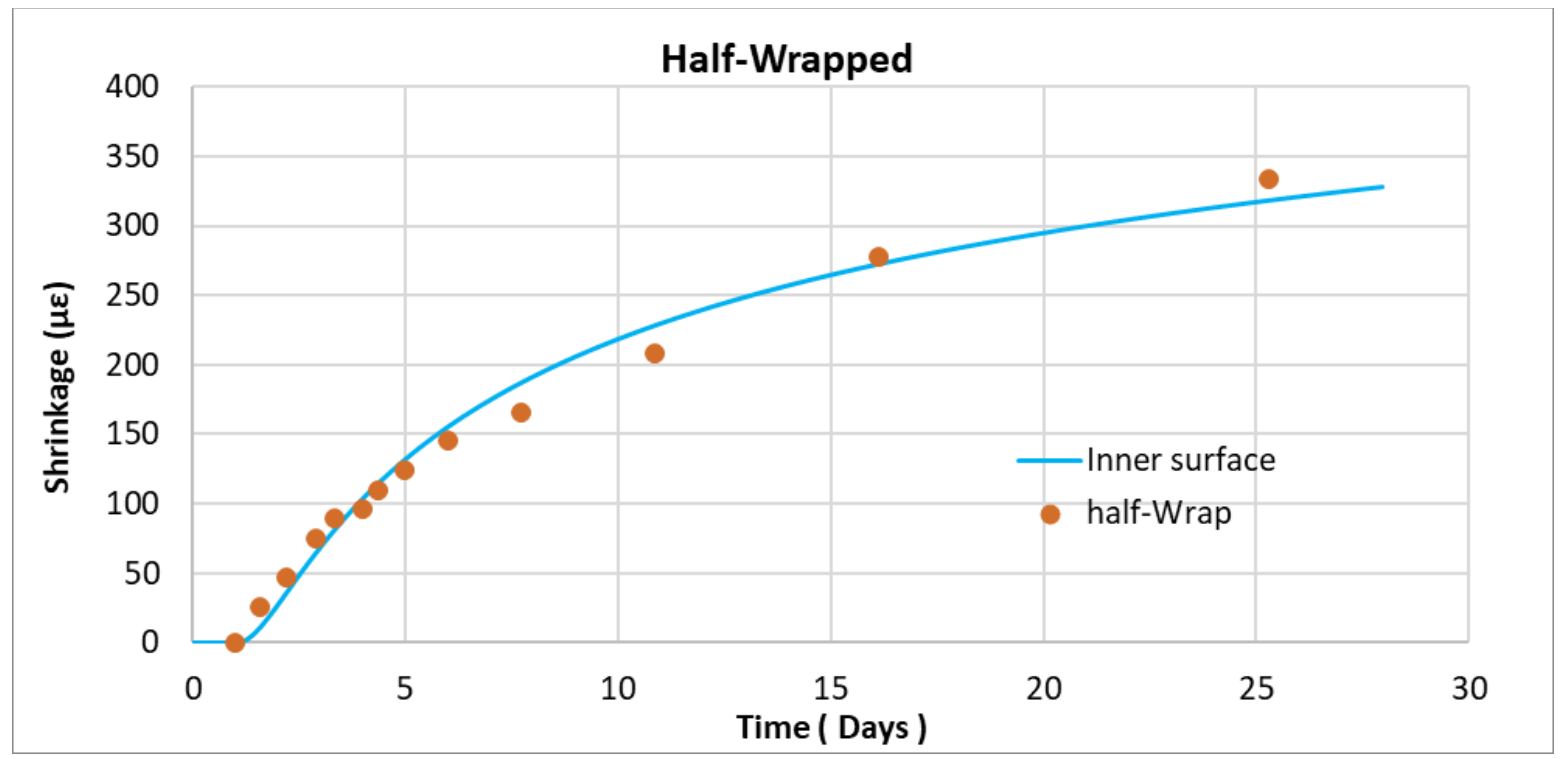

Figure 74 Shrinkage (micro-strain) Model prediction vs Shrinkage experiment OPC 1 


\section{2- OPC 2}

\section{No Wrap}

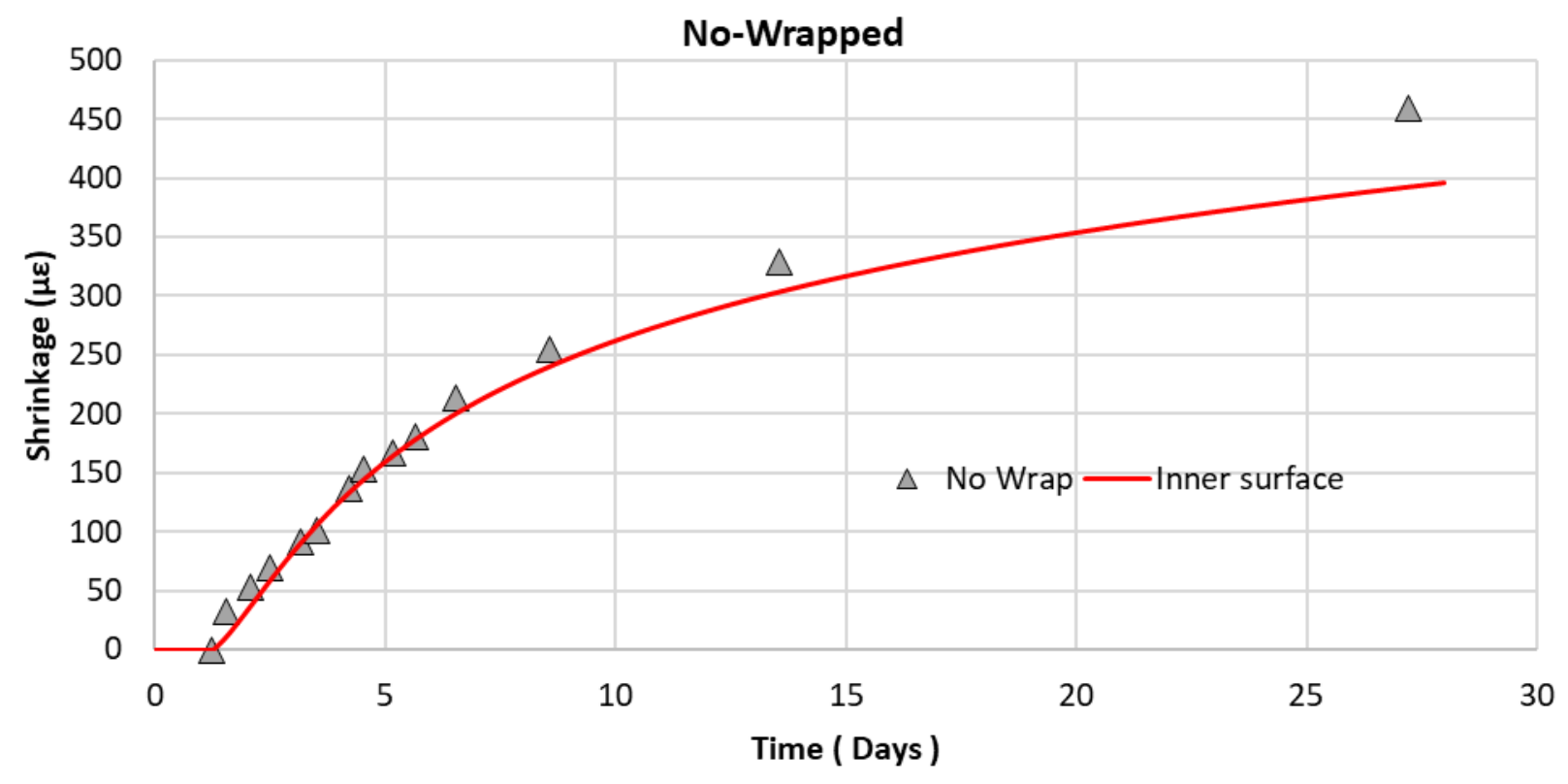

Figure 75 Shrinkage (micro-strain) Model prediction vs Shrinkage experiment OPC 2

\section{Half Wrapped}

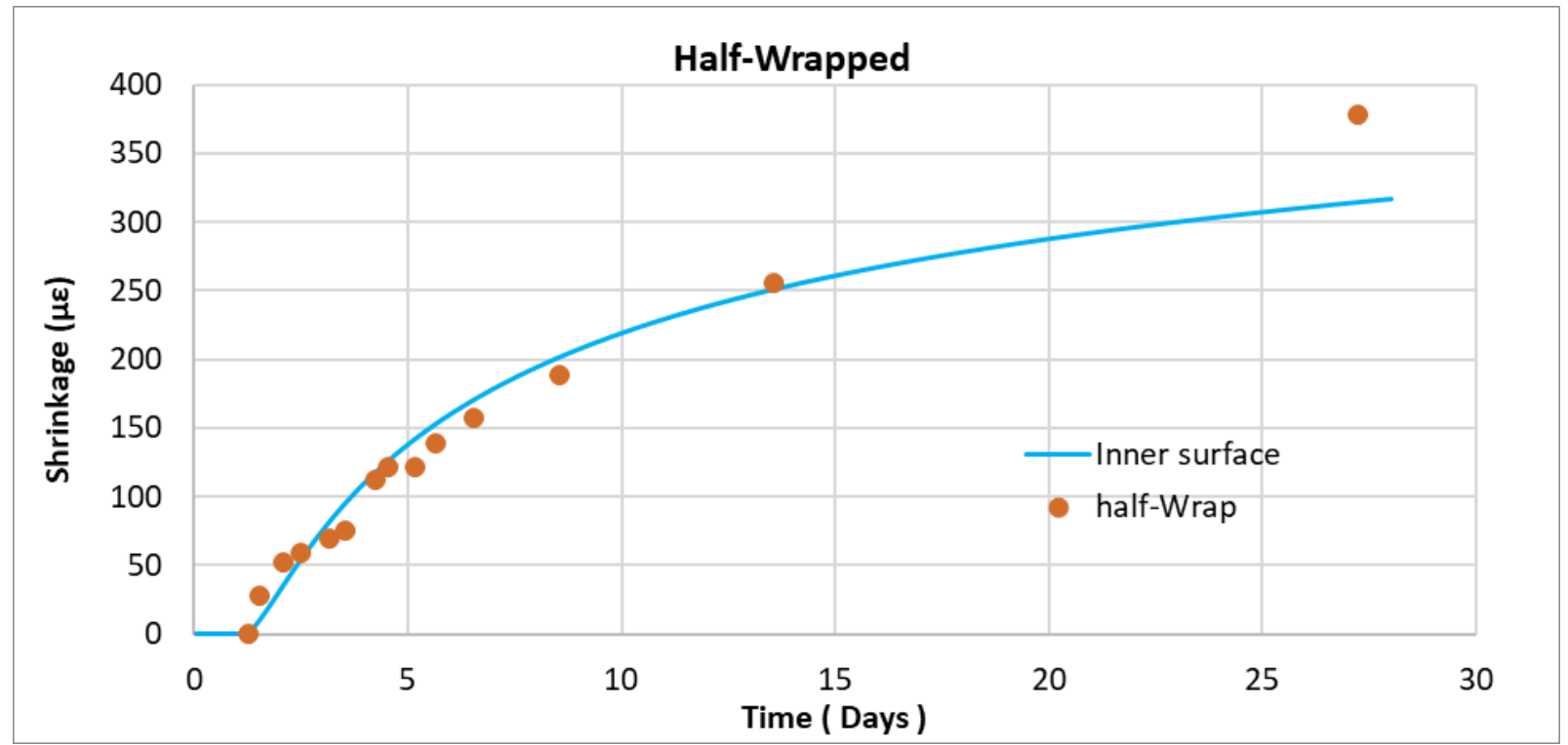

Figure 76 Shrinkage (micro-strain) Model prediction vs Shrinkage experiment OPC 2 


\section{3- OPC 3}

\section{No Wrap}

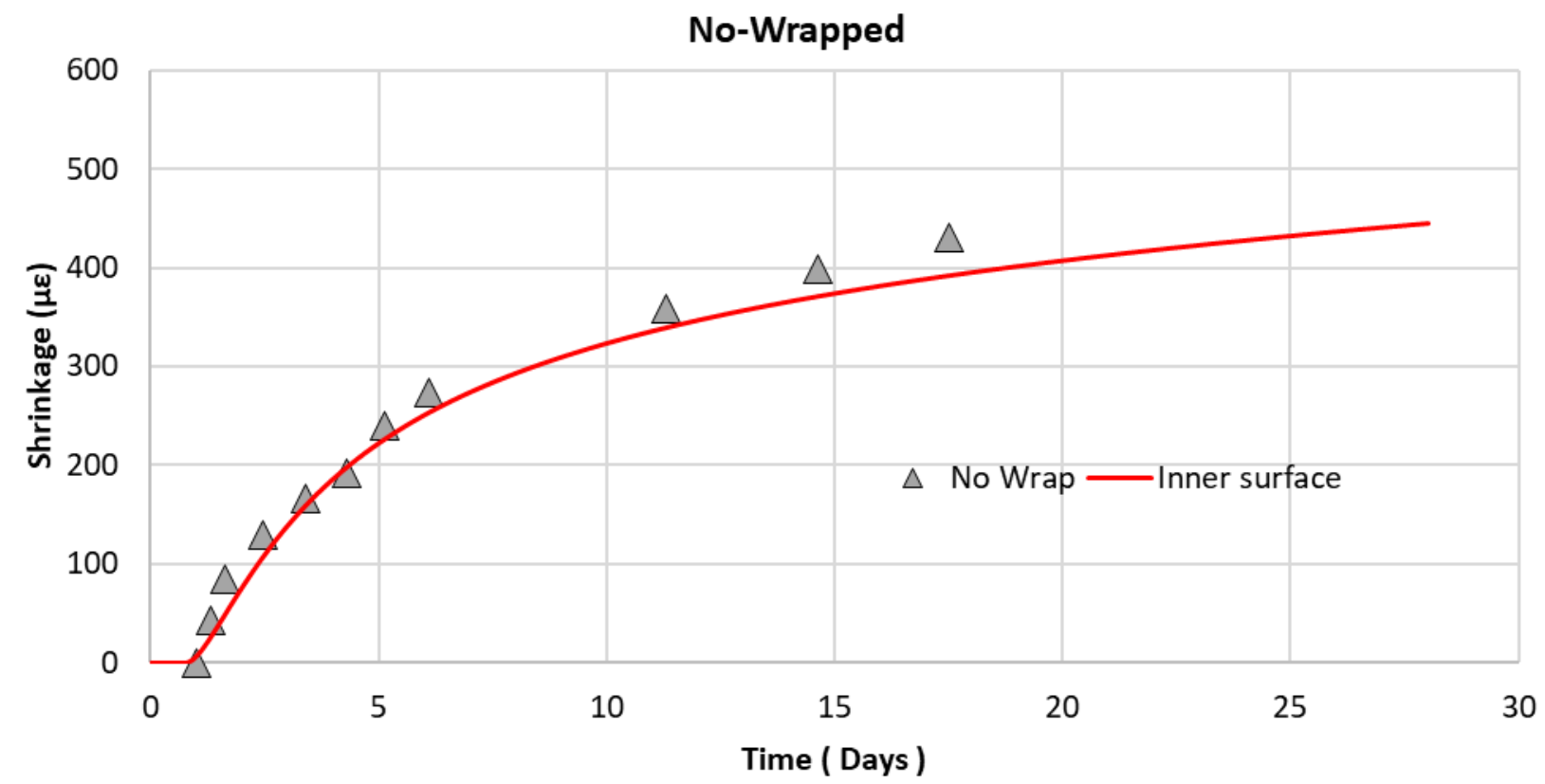

Figure 77 Shrinkage (micro-strain) Model prediction vs Shrinkage experiment OPC 3

\section{Half Wrapped}

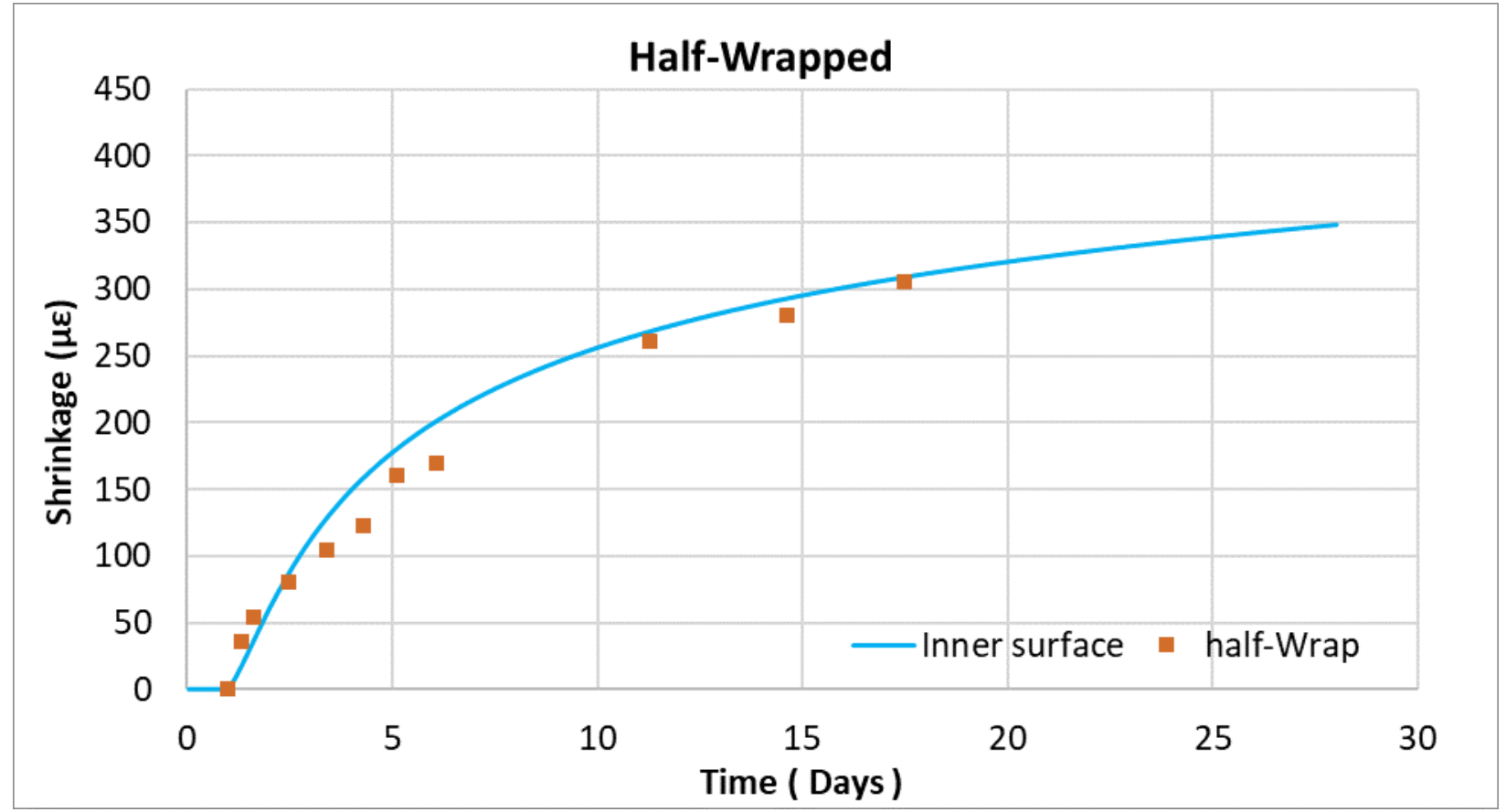

Figure 78 Shrinkage (micro-strain) Model prediction vs Shrinkage experiment OPC 3 
As shown in Figure 73 through Figure 78. The proposed shrinkage model can well predict the development of the shrinkage for both cases half-wrapped and no-wrap, and the results can be used as load induced tensile stresses in FEM.

\section{Tensile Creep Analysis}

\section{$\underline{\text { Interfacial Compressive Stress Analysis }}$}

The interfacial compressive stress generated on the steel ring, caused by autogenous and drying shrinkages of concrete, is calculated using the strain gauges measured during the restrained shrinkage ring testing. Meanwhile, the theoretical value of the interfacial compressive stress is calculated by a model for given autogenous and drying shrinkages of concrete. The expected tensile creep of the concrete at early age can then be determined with the condition that the difference between calculated and tested interfacial compressive stresses is accepted.

As derived previously :

The theoretical value of the interfacial compressive stress without Creep is shown as:

$$
q=\frac{-\frac{2}{r_{3}^{2}-r_{2}^{2}} \int_{r_{2}}^{r_{3}} \varepsilon_{\mathrm{sh}} r d r}{\frac{1}{E_{1}} \frac{\left(1-\mu_{1}\right) r_{2}^{2}+\left(1+\mu_{1}\right) r_{3}^{2}}{r_{3}^{2}-r_{2}^{2}}+\frac{1}{E_{2}} \frac{\left(1-\mu_{2}\right) r_{1}^{2}+\left(1+\mu_{2}\right) r_{2}^{2}}{r_{2}^{2}-r_{1}^{2}}}
$$

And the theoretical value of the interfacial compressive stress with Creep is shown as

$$
q=\frac{-\frac{2}{r_{3}^{2}-r_{2}^{2}} \sum_{i=1}^{n}\left[1-\frac{\varphi\left(t, t_{i}\right)}{1+\varphi\left(t, t_{i}\right)}\right] \int_{r_{2}}^{r_{3}} \Delta \varepsilon_{s h i} r d r}{\frac{1}{E_{1}} \frac{\left(1-\mu_{1}\right) r_{2}^{2}+\left(1+\mu_{1}\right) r_{3}^{2}}{r_{3}^{2}-r_{2}^{2}}+\frac{1}{E_{2}} \frac{\left(1-\mu_{2}\right) r_{1}^{2}+\left(1+\mu_{2}\right) r_{2}^{2}}{r_{2}^{2}-r_{1}^{2}}} \quad \text { Eq. } 70
$$

The above equations have been formulated using Mat-Lab, to solve for the best-fit parameters between q obtained experimentally and $\mathrm{q}$ from the theoretical solution both with and without creep. 


\section{1- OPC 1}

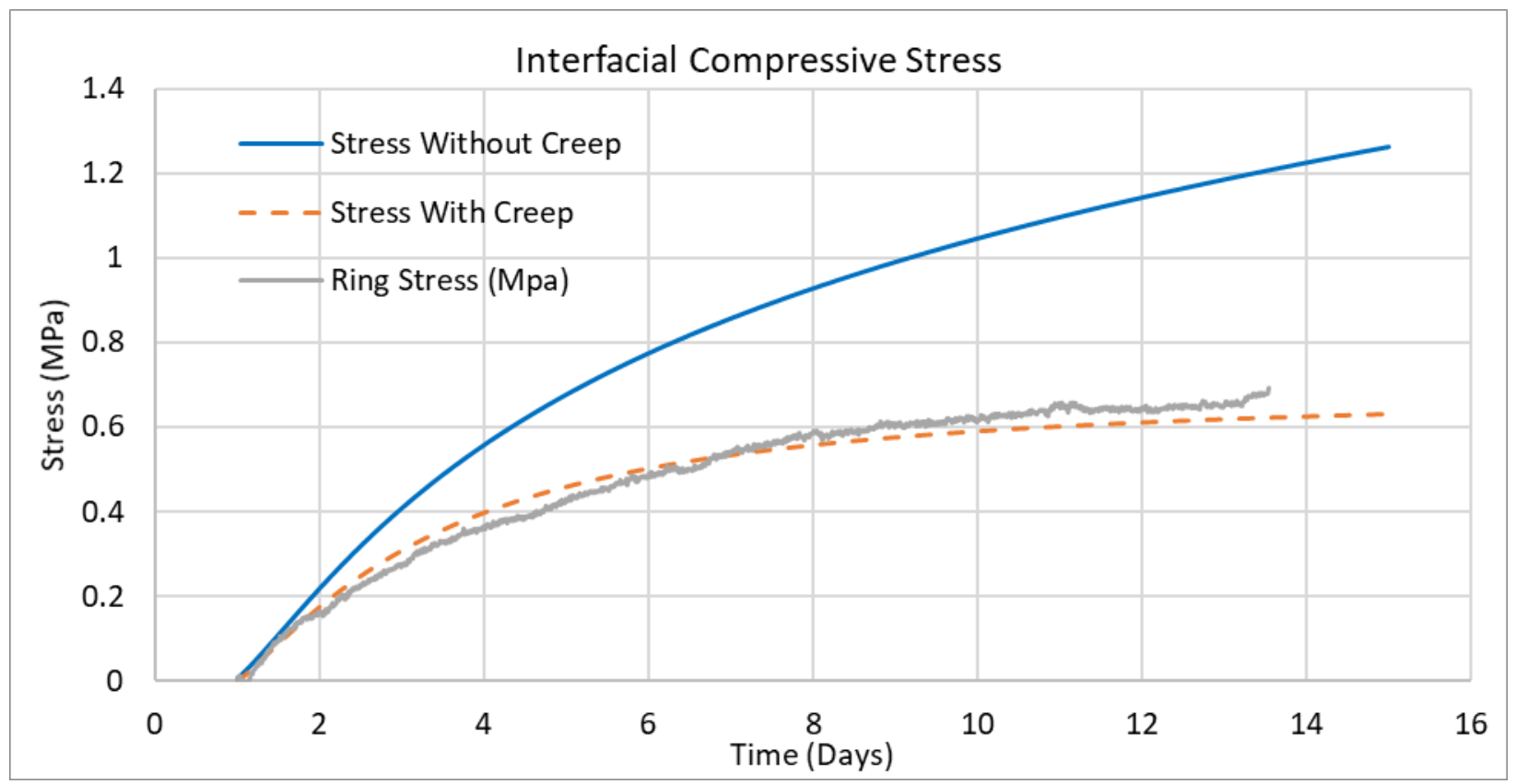

Figure 79 Development of interfacial compressive stress vs. time with and without creep OPC 1

\section{2- OPC 2}

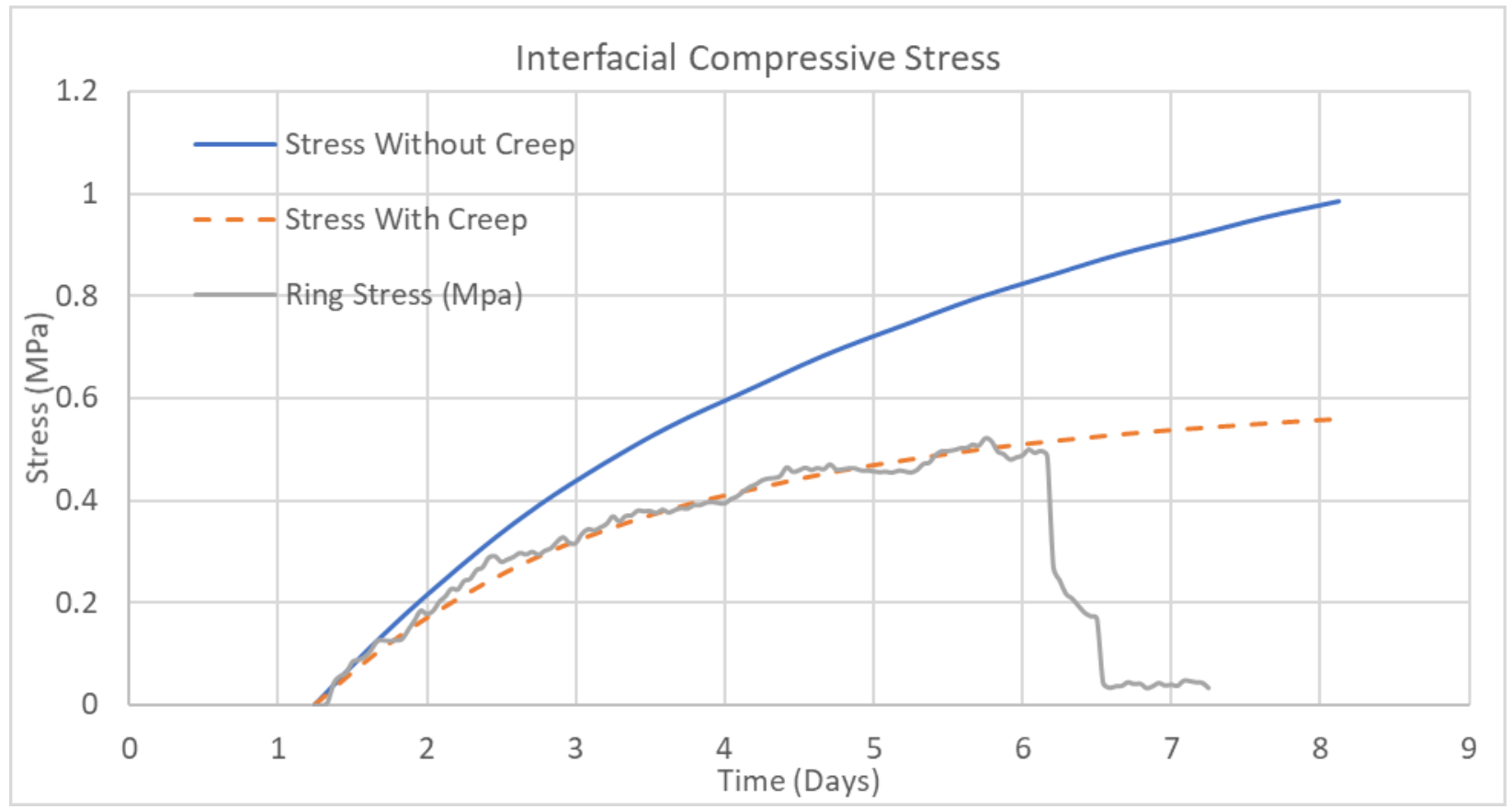

Figure 80 Development of interfacial compressive stress vs. time with and without creep OPC 2 


\section{3- OPC 3}

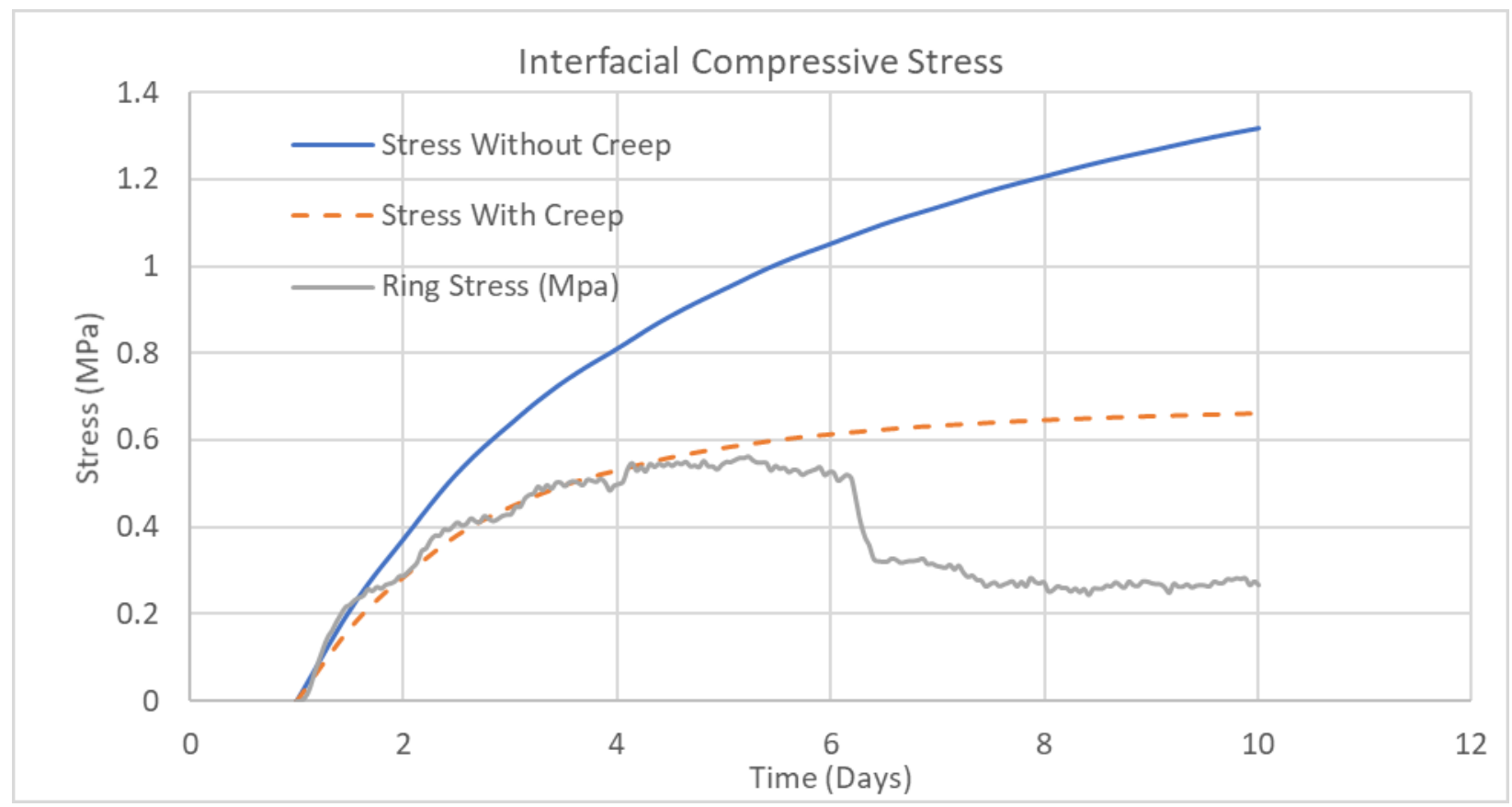

Figure 81 Development of interfacial compressive stress vs. time with and without creep OPC 3

The comparison between model predicted and experimental measured interfacial compressive stress $q$ in terms of stress versus age diagrams of OPC concrete rings are presented in Figure 79, Figure 80 and Figure 81.

From the results, first, we can observe that the model can well capture the development of interfacial compressive stress generated from shrinkage of concrete. Second, as creep of concrete is not taken into consideration, the calculated value of $q$ is much greater than the measured value for the same age. This indicates that the creep resulted from stress relaxation must be considered in the stress calculation. Third, after creep correction, the calculated interfacial stress can well follow the measured value. This means the creep correction factor in the form of Eq. 40, which was originally proposed by Bazant and Panula, can well be used for concrete under varied tensile stress state. Meanwhile, the stress relaxation parameters may be 
independent of loading ages, which should be more interesting in shrinkage stress calculation of concrete at early age.

The creep compliance is plotted versus different loading days, although the same parameters obtain the difference between the three mixes is due to the elastic modulus since for hightemperature environment the development of the elastic modulus is faster than normal environment temperature. The creep compliance was plotted again for the normal time and it's shown in Figure 82, Figure 83 and Figure 84 and was compared to the direct tensile creep test Dog-Bone specimens.

\section{1- OPC 1}

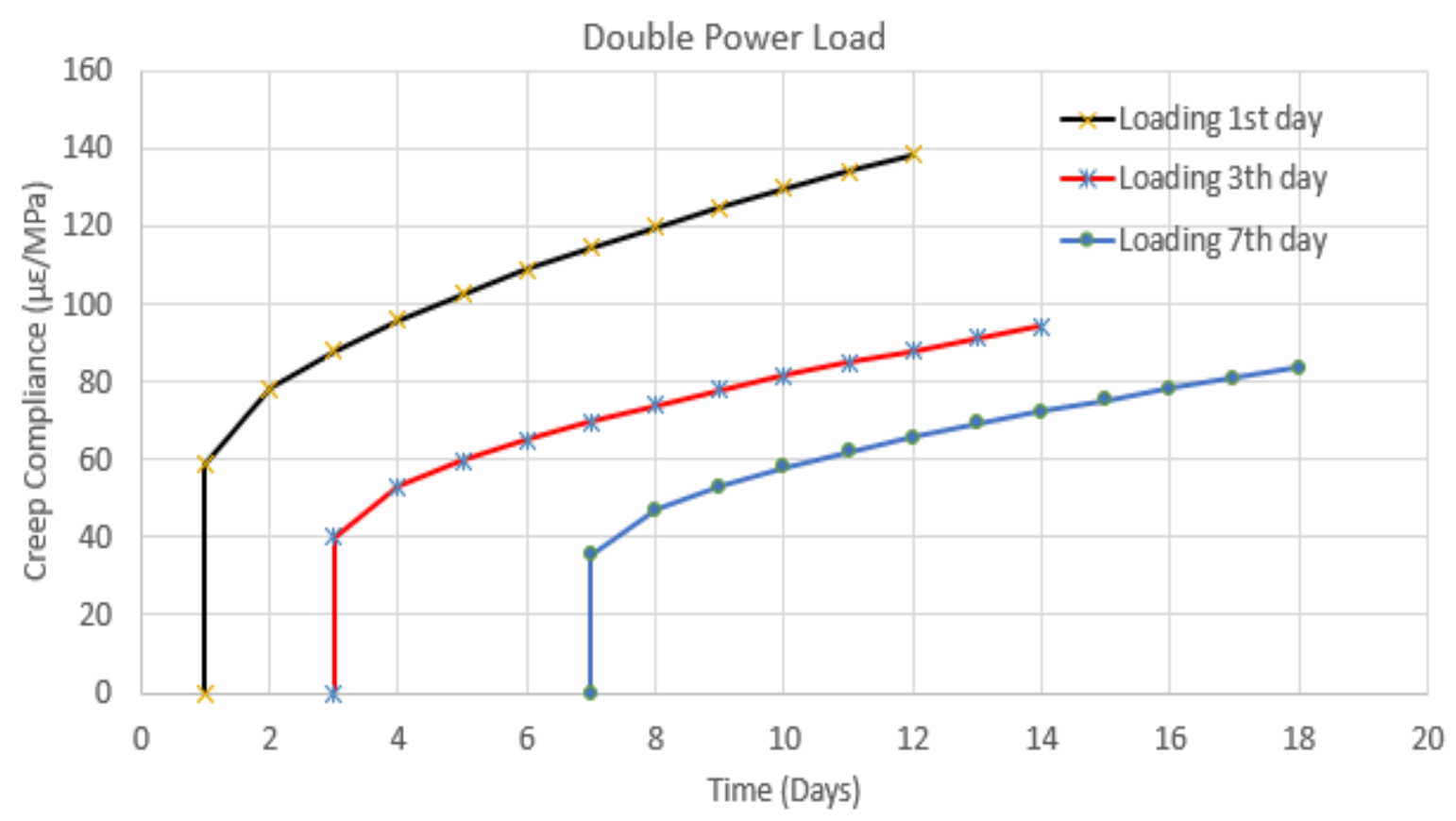

Figure $82 \mathrm{MDBL}$ at different loading age OPC 1 


\section{2- OPC 2}

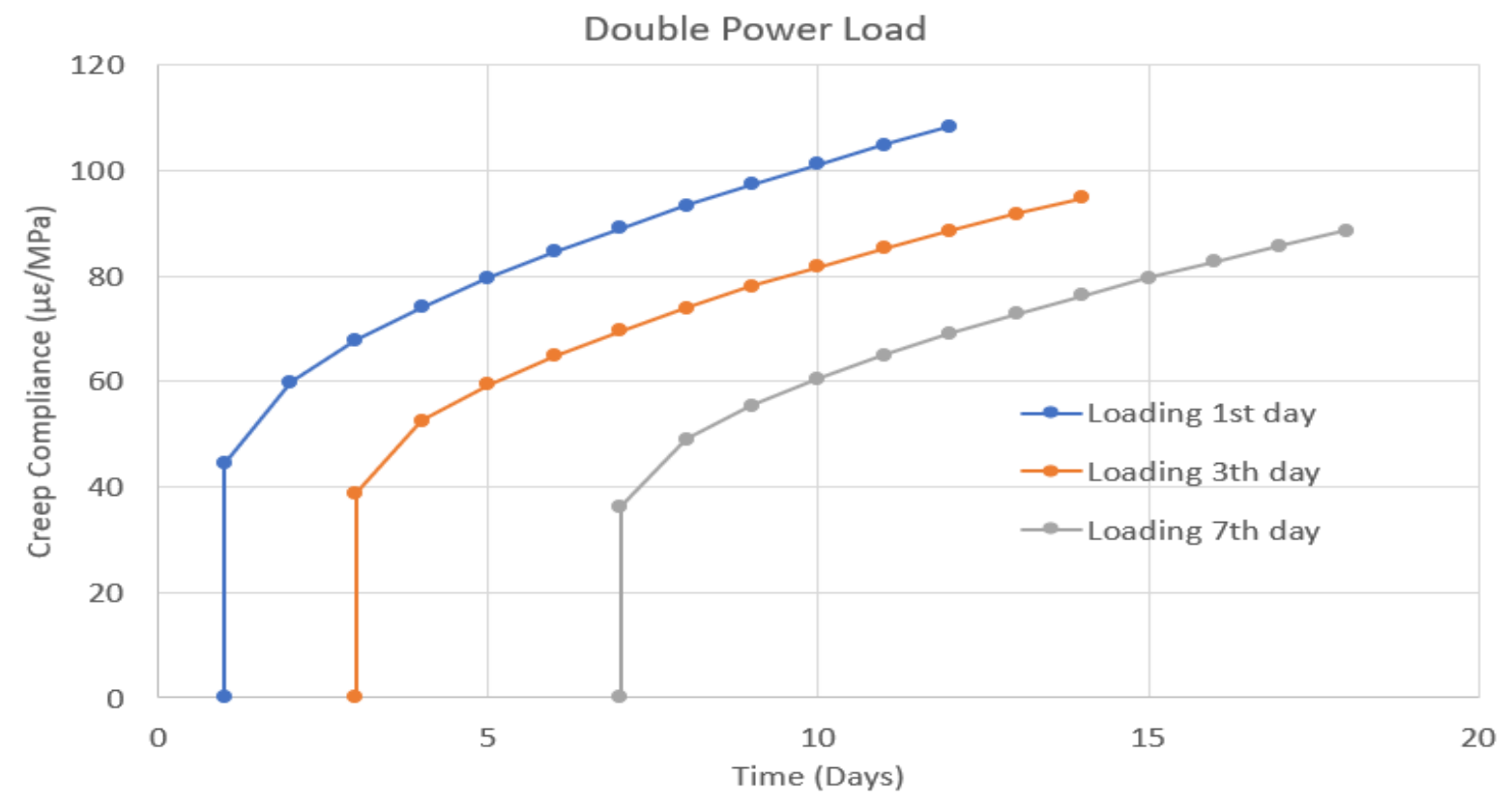

Figure $83 \mathrm{MDBL}$ at different loading age OPC 2

\section{3- OPC 3}

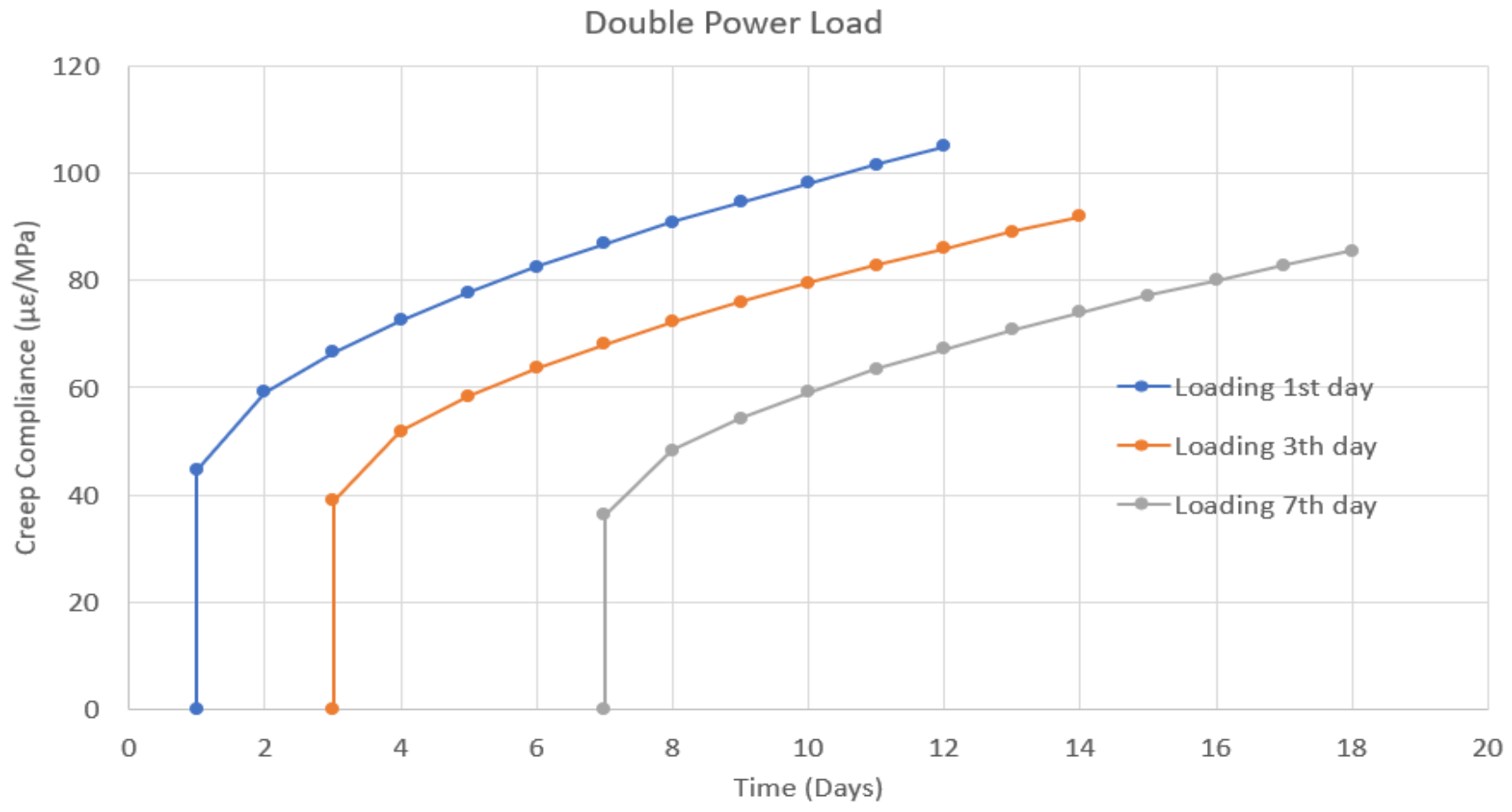

Figure $84 \mathrm{MDBL}$ at different loading age OPC 3 


\begin{tabular}{|c|c|c|c|}
\hline Concrete Mix & $\varphi 1$ & $\mathrm{~d}$ & $\mathrm{p}$ \\
\hline OPC 1 & 0.33 & 0.1 & 0.59 \\
\hline OPC 2 & 0.35 & 0.12 & 0.59 \\
\hline OPC 3 & 0.33 & 0.1 & 0.59 \\
\hline
\end{tabular}

Table 13 MDBL model parameters

To further verify the obtained creep parameters from the interfacial compressive stress calculation, the results were compared to the direct tensile creep test using Dog-Bone specimens with different loading ages.

At the very early age, the predictions were slightly lower than the experiments, but the elastic strain was correctly predicted. At the later age, the predictions matched perfectly with the experiments.

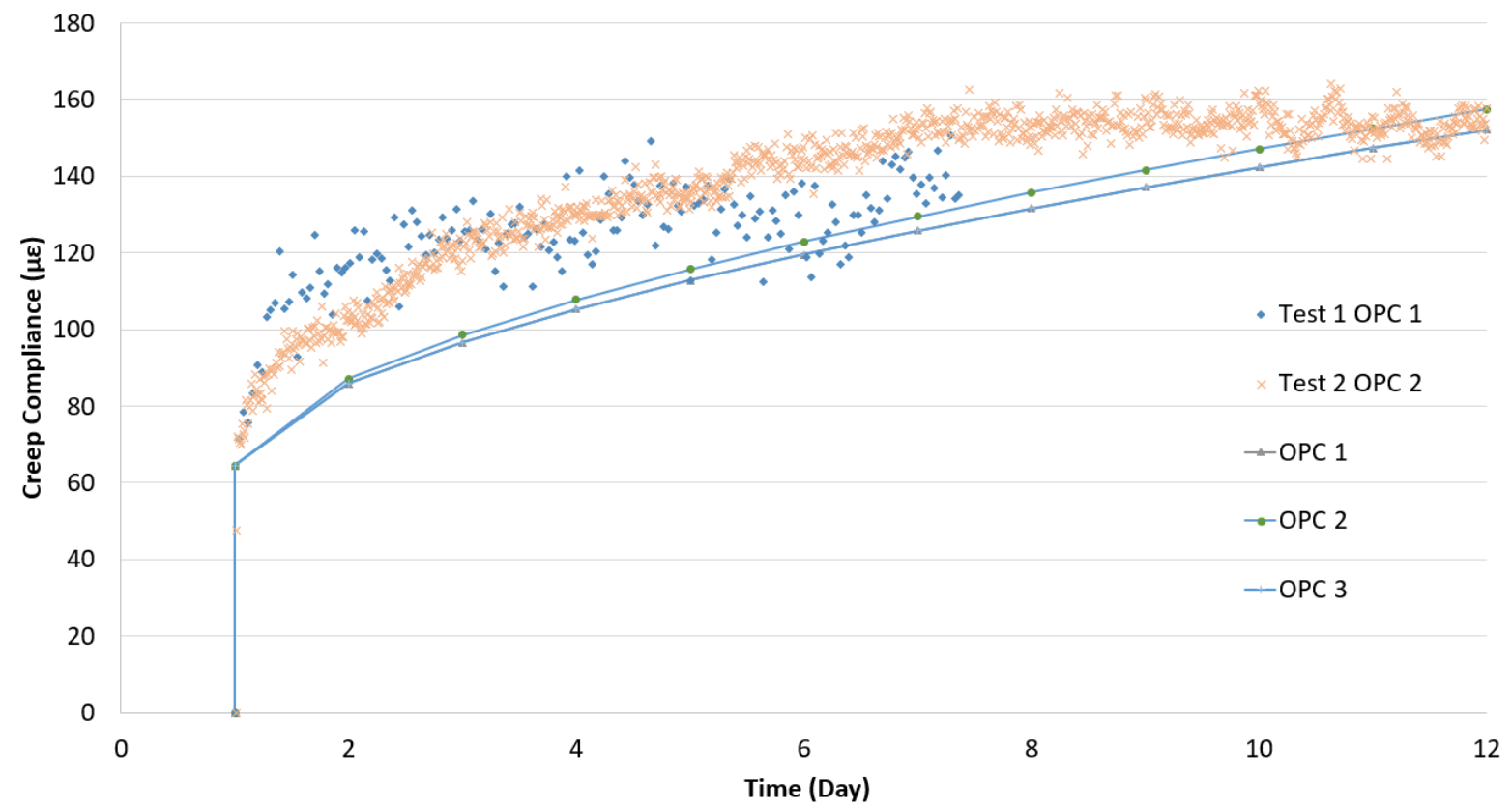

Figure 85 comparison between the Dog-bone and MDBL 


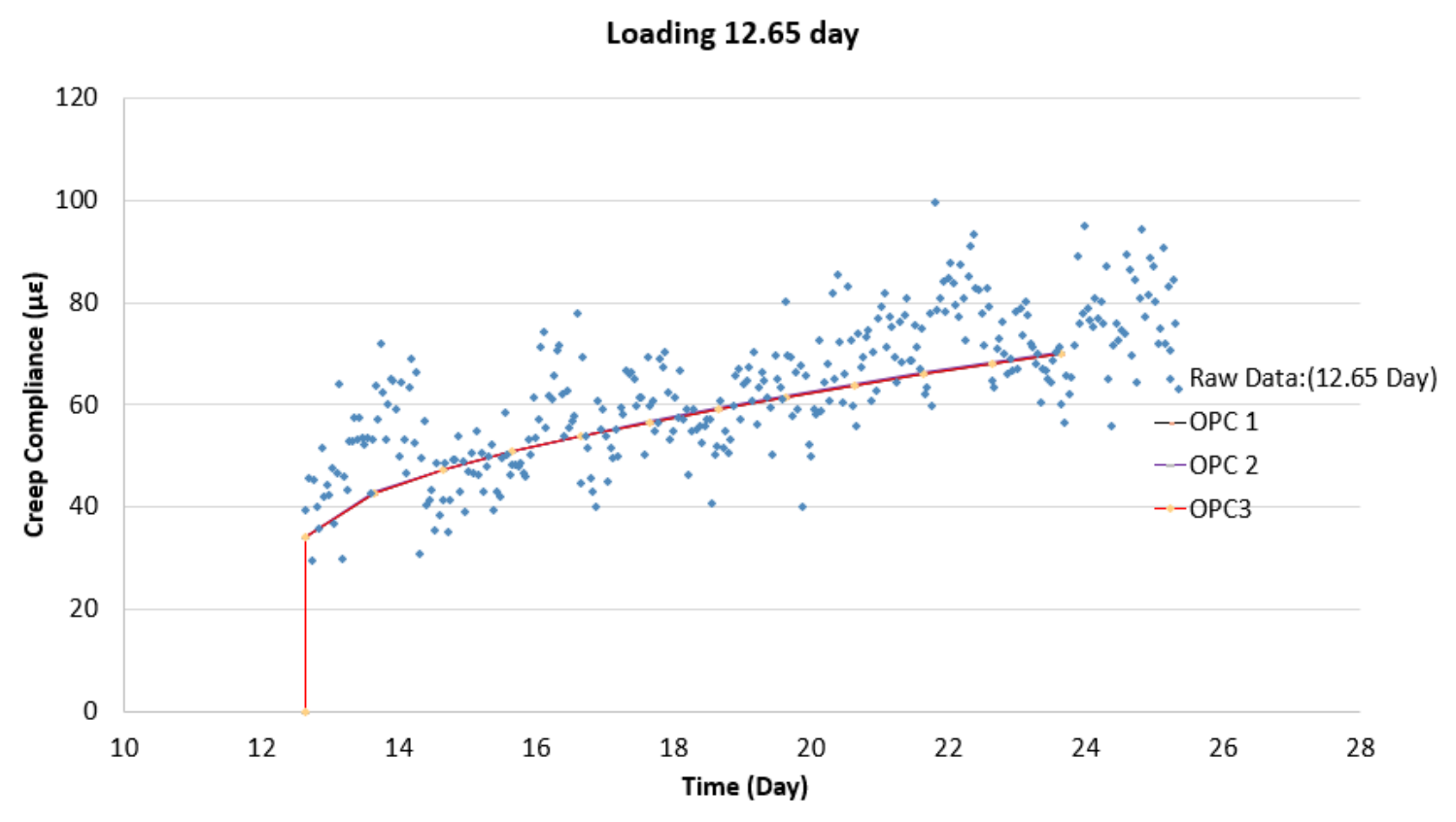

Figure 86 comparison between the Dog-bone OPC 1 and MDBL

The obtained MDBL parameters can predict the tensile creep of the concrete well as shown in Figure 85 for the loading at one-day and Figure 86 for the loading at 12.65 days for (OPC 1). This means that the obtained parameters can be used in FEM to further verify the tensile creep and the MDBL model.

It should be noted that MDBL parameters obtained assuming that the tensile creep along the depth of the concrete ring is constant by using the averaged shrinkage distribution. 


\section{Strength Analysis}

Effect of size of test specimen on the compressive and tensile strength of concrete.

For both compressive and tensile strength, using ( 4'x8') cylinders instead of (6"x12") results in higher strength.

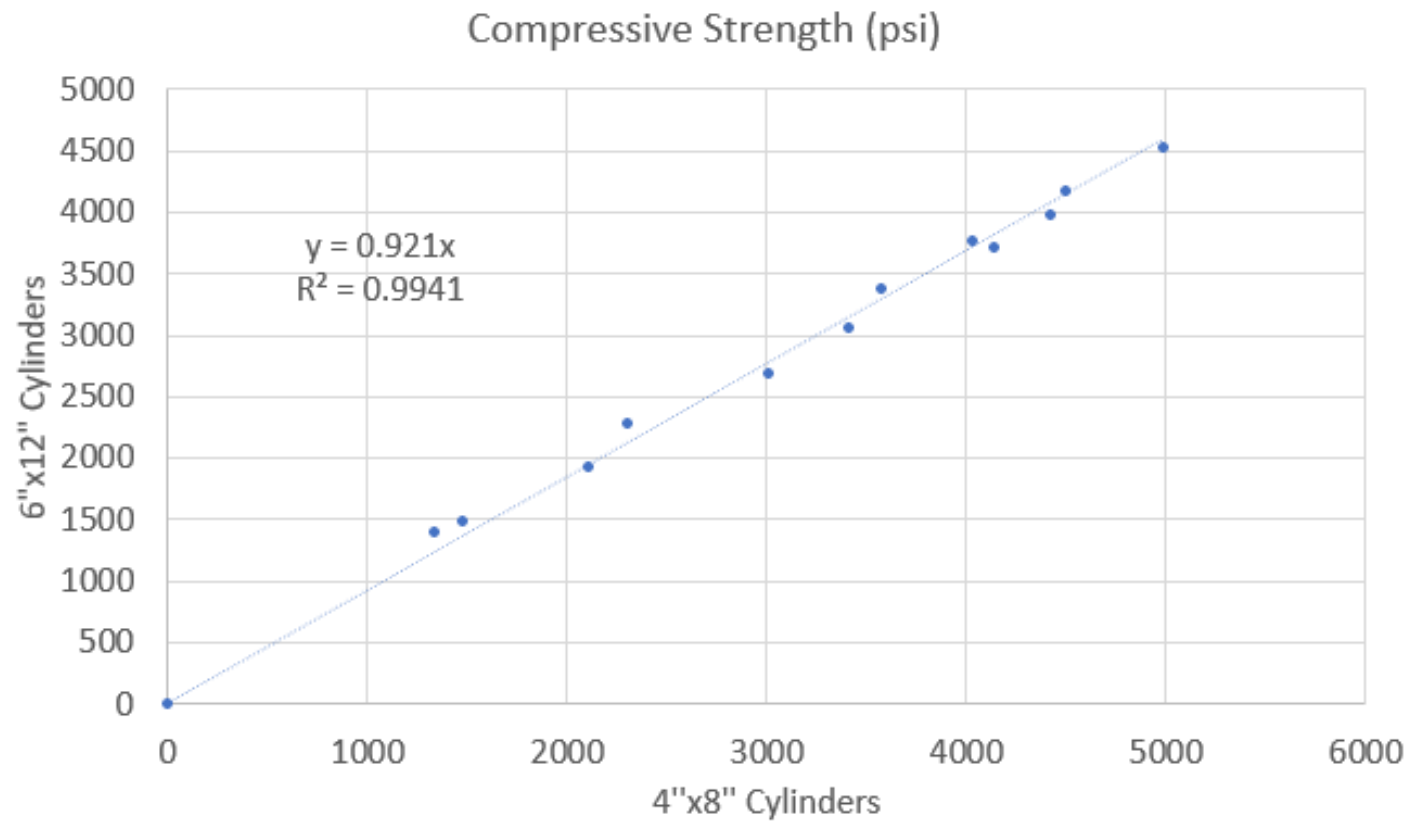

Figure 87 The relationship between using 4" 8 8" and 6"x12" cylinders for measuring the compressive strength

$$
f_{c}\left(6{ }^{\prime \prime} \times 12{ }^{\prime \prime}\right)=0.921 \times f c^{\prime}\left(4{ }^{\prime \prime} \times 88^{\prime \prime}\right) E q .71
$$

As shown in Figure 87 and Figure 88 For compressive strength the difference can be around $8 \%$, and for tensile strength, the difference can be around $6 \%$ to $7 \%$. 


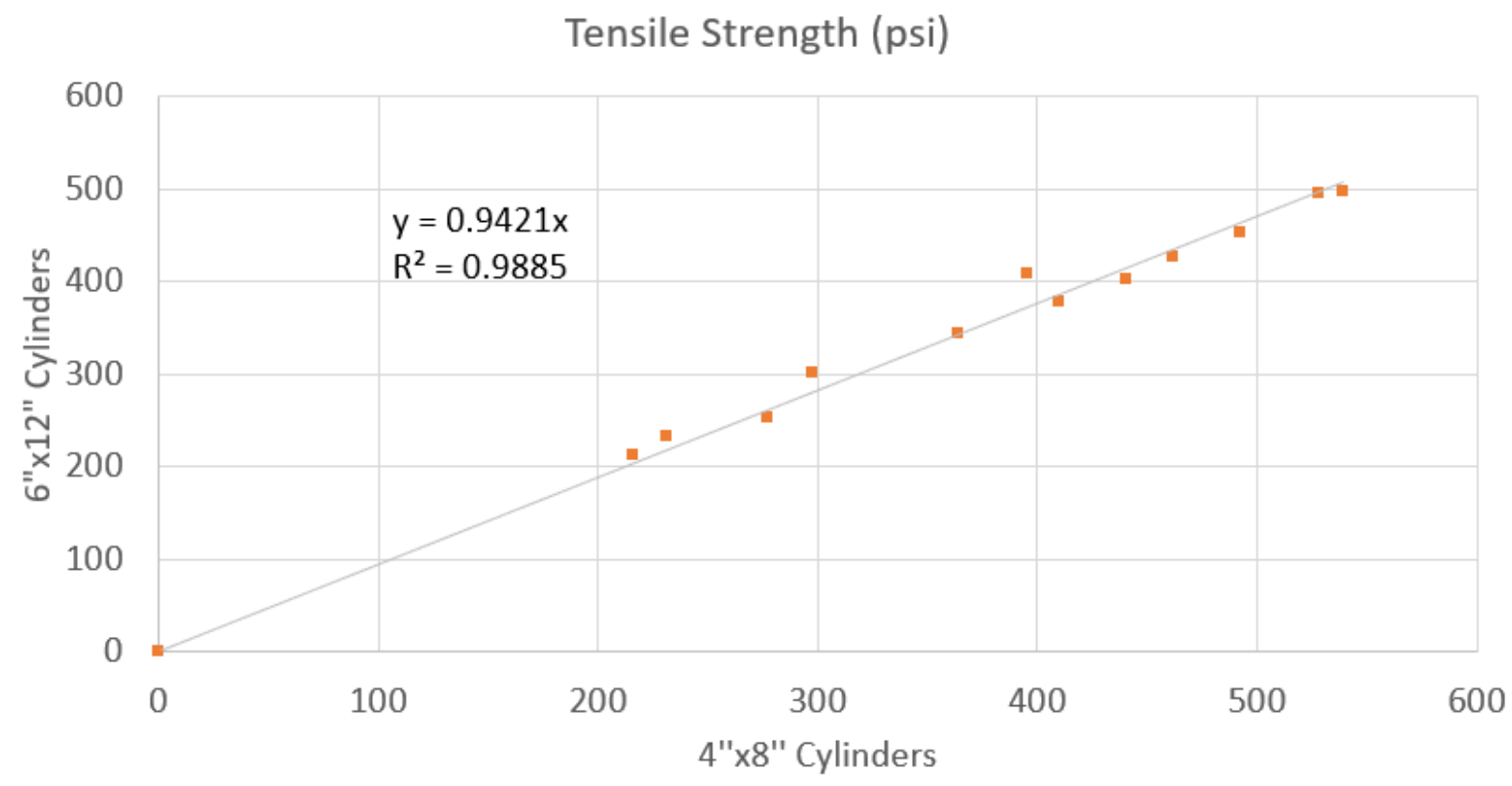

Figure 88 The relationship between using 4' $x 8$ "' and 6" 12 "' cylinders for measuring the Tensile Strength

$$
f t\left(6^{\prime \prime} \times 12^{\prime \prime}\right)=0.9421 \times f t\left(4 ' x 8^{\prime \prime}\right) . E q .72
$$

The above equations for both compressive and tensile strength can be very useful and can make an impact on deciding the volume of concrete that is needed to obtain their compressive and tensile strength tests. 


\section{$\underline{\text { Air Content Effects }}$}

Although the air content effects on the compressive strength are not the main purpose of this research, it's interesting to show the results obtained from testing the three OPC mixes since each of the mixes has different air percentages. The effects of $1 \%$ change in the air content can exceed the expectation. The results agree with many references in the literature that for a specific mix the higher the air content the lower the compressive strength of that mix.

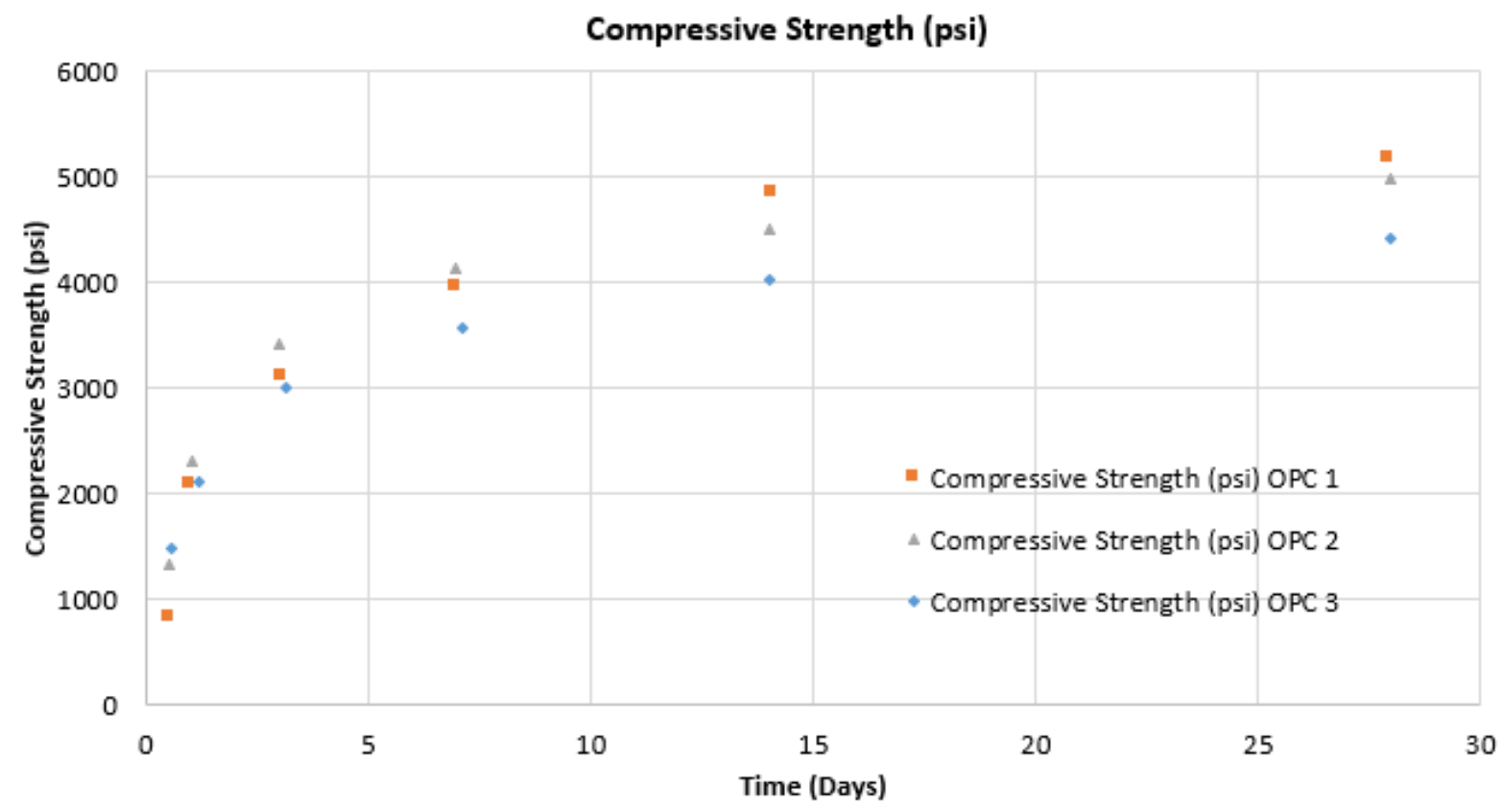

Figure 89 Compressive Strength development curves for concrete cylinders 4" 8 8" for three different mixes

The results are shown in Figure 89 that the increase of the air content by $1 \%$ can produce up to $10 \%$ reduction in the compressive strength. 


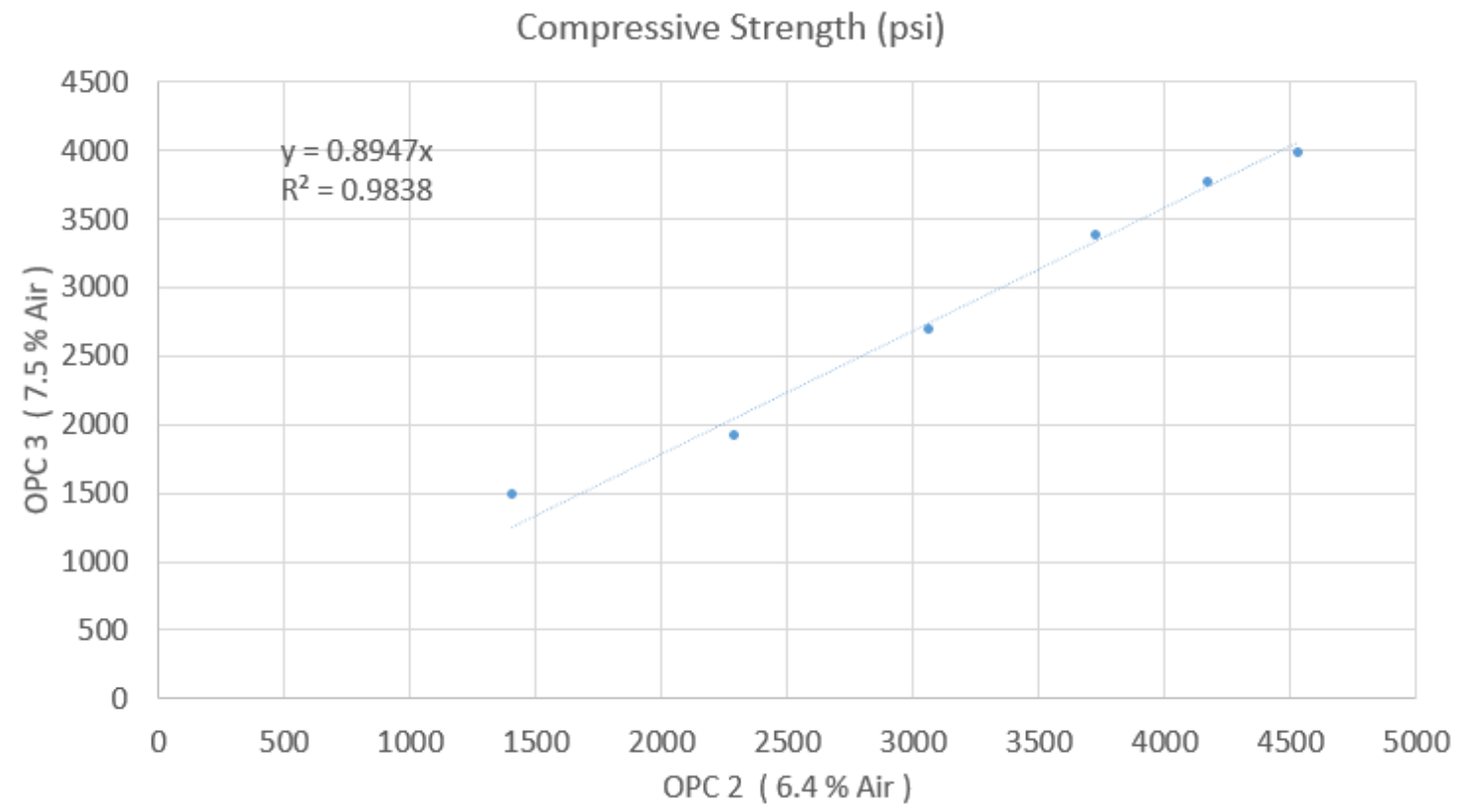

Figure 90 the relationship that represents the effect of the air content on the compressive strength at different ages

Tensile Stength (psi)

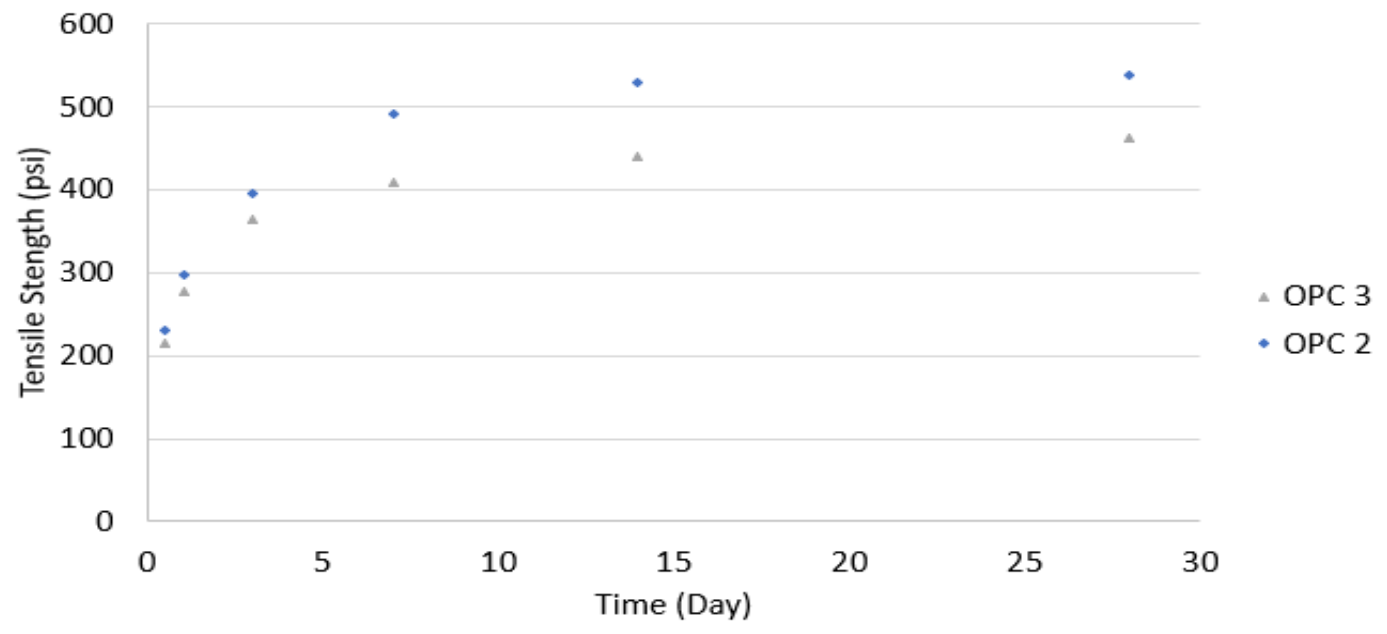

Figure 91 Tensile Strength development curves for concrete cylinders 4' x8', for different mixes 


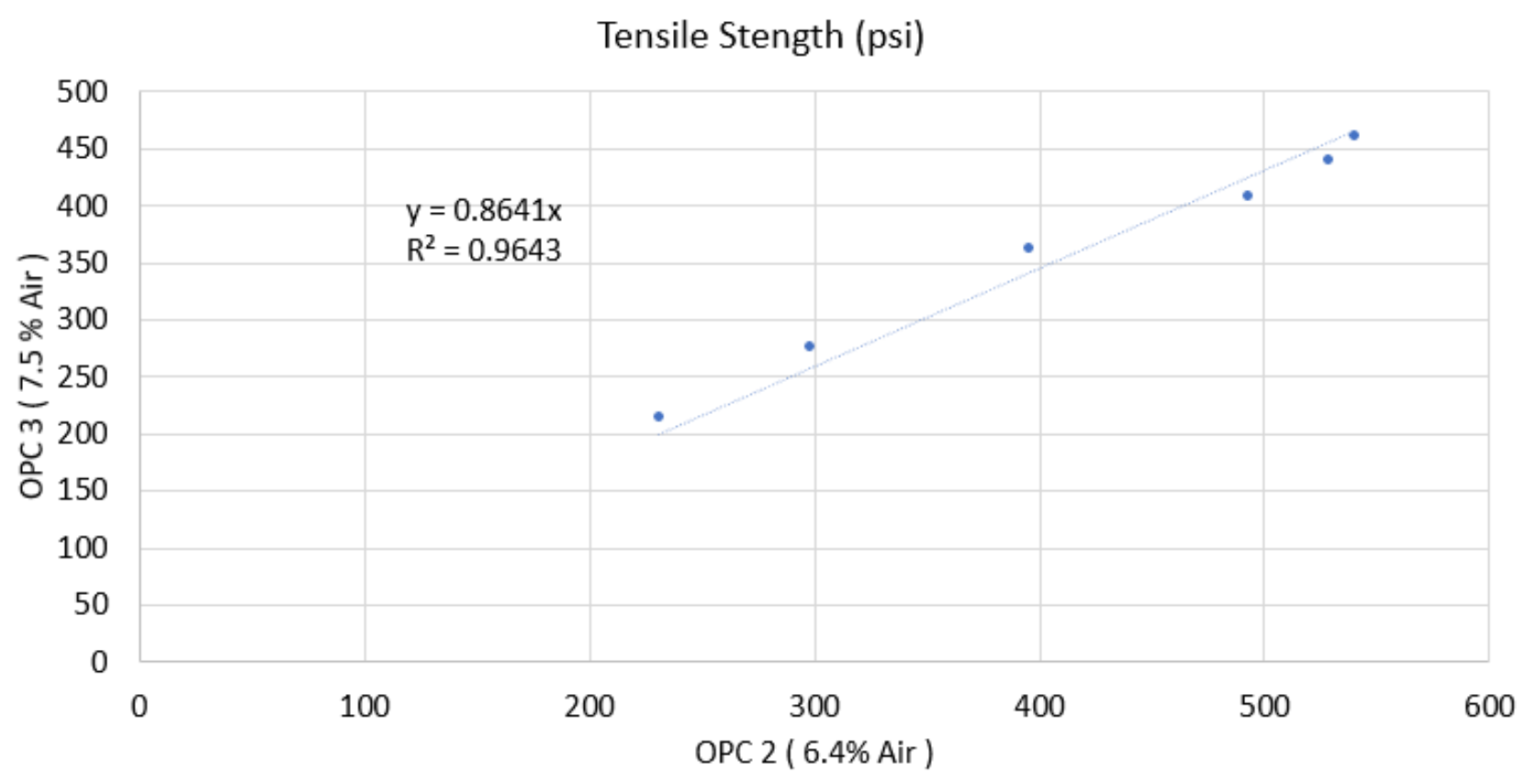

Figure 92 the relationship that represents the effect of the air content on the compressive strength at different ages

The test results show in Figure 91 and Figure 92 that the increase of the air content by $1.1 \%$ can produce up to $13 \%$ reduction in the tensile strength. The close relationship between the density and the air void volume in the concrete can explain the reduction of the compressive strength. However, more research and tests are needed to verify this result. 


\section{Finite Element Model}

The Finite Element Model (FEM) was developed using ABAQUS to simulate the restrained shrinkage ring test. The shrinkage and creep models were verified using the FEM supported by a user-defined subroutine to simulate the shrinkage and creep behavior in the concrete and to predict the critical time when the concrete is at risk of crack by Comparing the steel strain obtained from the experiment and the steel strain solved in the FEM.

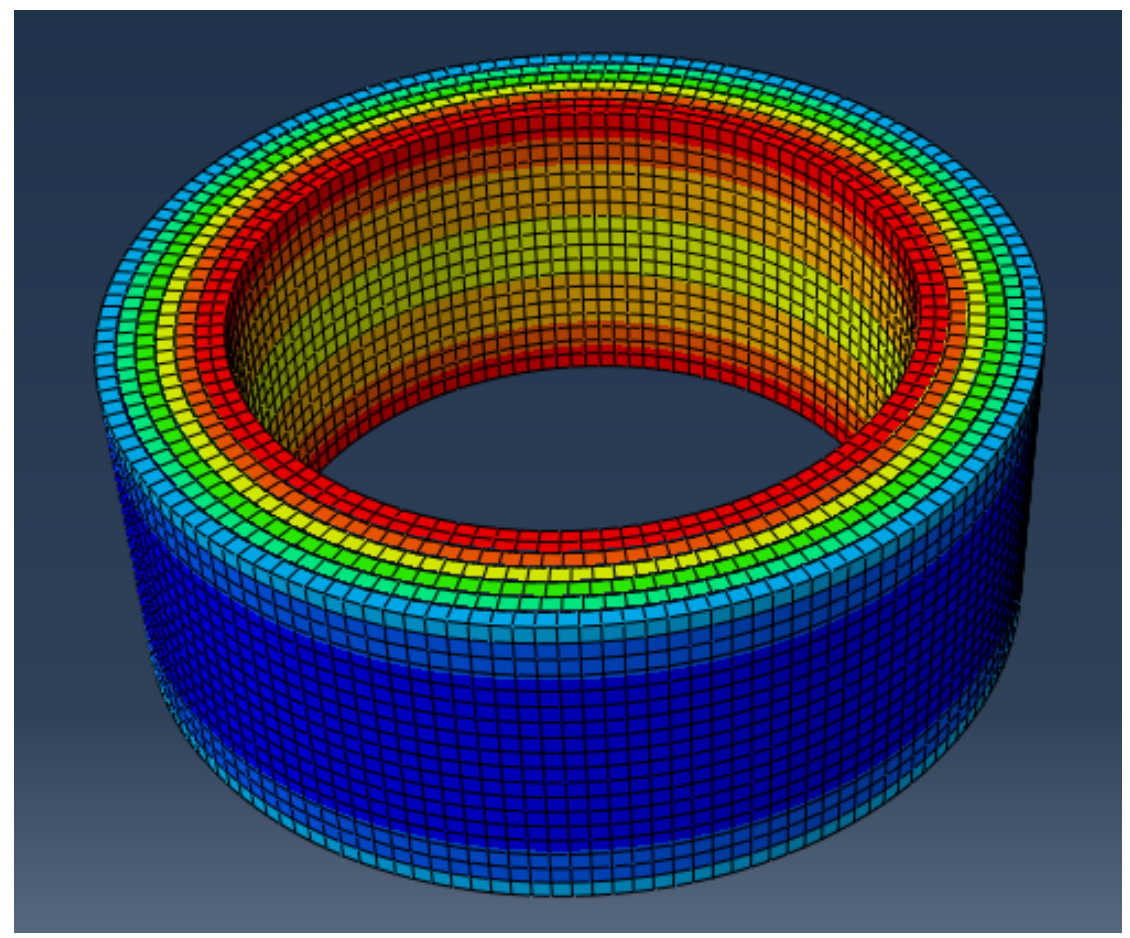

Figure 93 FEM model - Simulating the Ring Experiments

The model has 33630 nodes and 17010 elements using 3-D 8-node linear element (C3D8R) with 0.3-inch element size.

In order to have more accuracy, the model was designed with 5 layers of concrete each with 0.3 in thickness and 1 layer of steel with 0.5 in thickness. The drying shrinkage was 
calculated again in the subroutine for each layer, so each layer of the concrete has a different inelastic strain ( shrinkage ) which is the input as the load induce tensile stresses the drying in the model is in two directions only ( $\mathrm{r}$ and $\theta$ ). Figure 94 represents the developed strain for the OPC 1 case. And similarly, for OPC 2 and OPC 3, with different magnitude.

For the following figures:

R1: Represents the inner surface of the steel ring where the strain gages are attached.

R2: Represents the outer surface of the steel ring and the inner surface on the concrete where the concrete and the steel are bonded together.

R3: Represents the outer surface of the concrete ring where the concrete is exposed to the environment.

The change in concrete properties and viscoelastic behavior was simulated using a user subroutine "USDFLD" at every time increment. For each element, the program first calculates the equivalent age $\left(t_{e}\right)$ and degree of hydration $(\alpha)$ based on the temperature. The modified Double Power Law (MDPL) model was used to describe the tensile creep behavior.

The creep stress loading magnitude changes because of temperature variation. Load decomposition and superposition rules were used to calculate the overall creep coefficient. The effective modulus was then used to incorporate both elastic and viscoelastic deformations due to the creep behavior. At each time-step, the induced shrinkage stress was computed for each element, based on the shrinkage strain, current elastic modulus, and overall creep coefficient.

Finally, the equivalent age, degree of hydration and stresses in principle directions for each element were stored for the next time-step.

Poisson's ratio and coefficient of thermal expansion (CTE) of concrete were assumed constants, 0.2 and 4.73 micro-strains per ${ }^{\circ} \mathrm{F}$ respectively. Poisson's ratio and coefficient of 
thermal expansion (CTE) of steel were assumed constants, 0.3 and 7.2 micro-strains per ${ }^{\circ} \mathrm{F}$ respectively. The friction interaction between the concrete ring and the steel was ignored.

The current FEM model assumes a creep model that is linear to the applied stresses. The nonlinear creep behavior due to high stress/strength ratio is not considered in the current model.

\section{Modified Double Power Law}

\section{Steel Strain}

To further verify the developed tensile creep model, the developed MDBL was used in the FEM to calculate the steel strain during the concrete ring test.

\section{1- OPC 1}

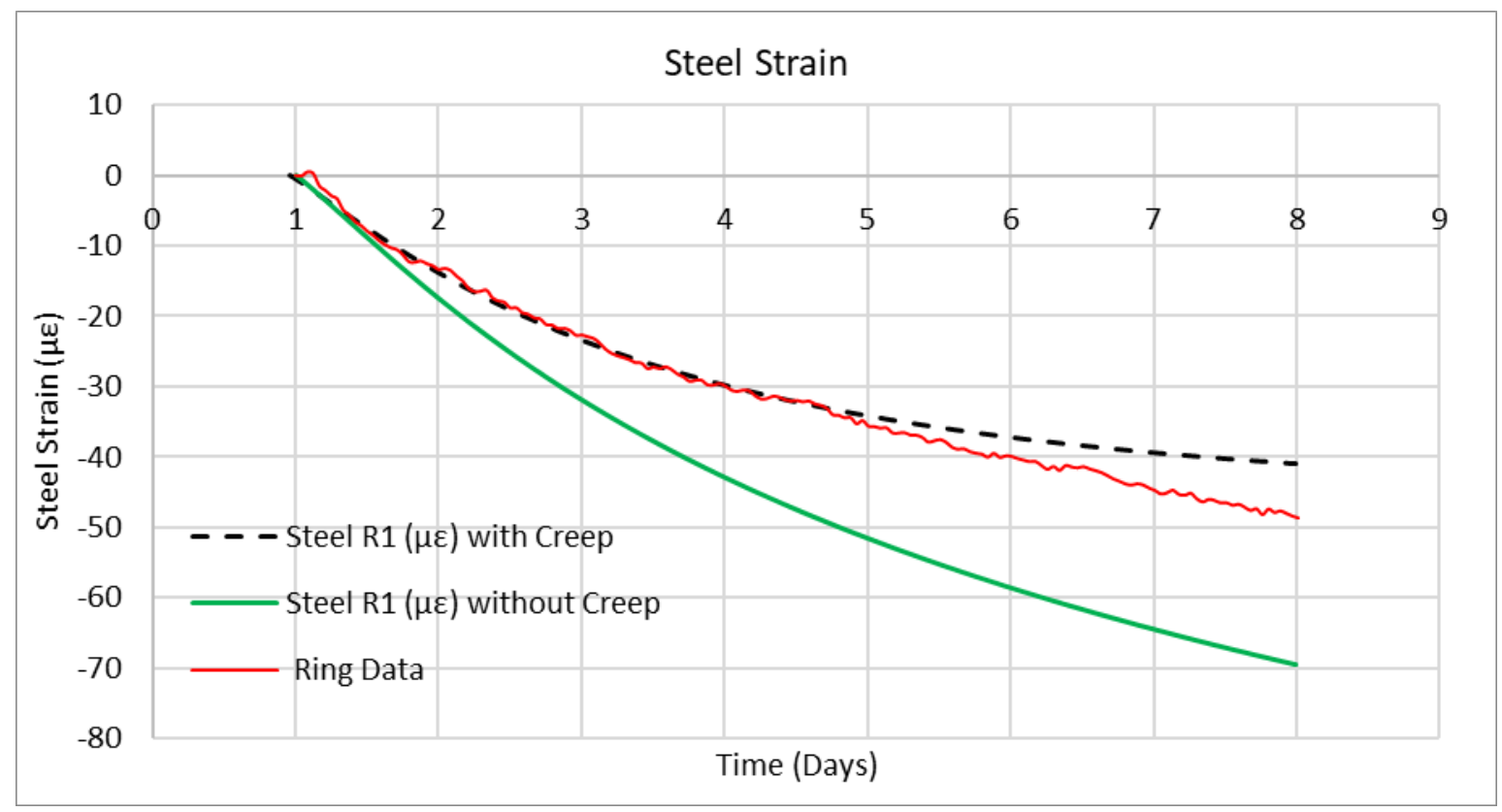

Figure 94 Comparison the strain between FEM and Ring test result OPC 1 


\section{2- OPC 2}

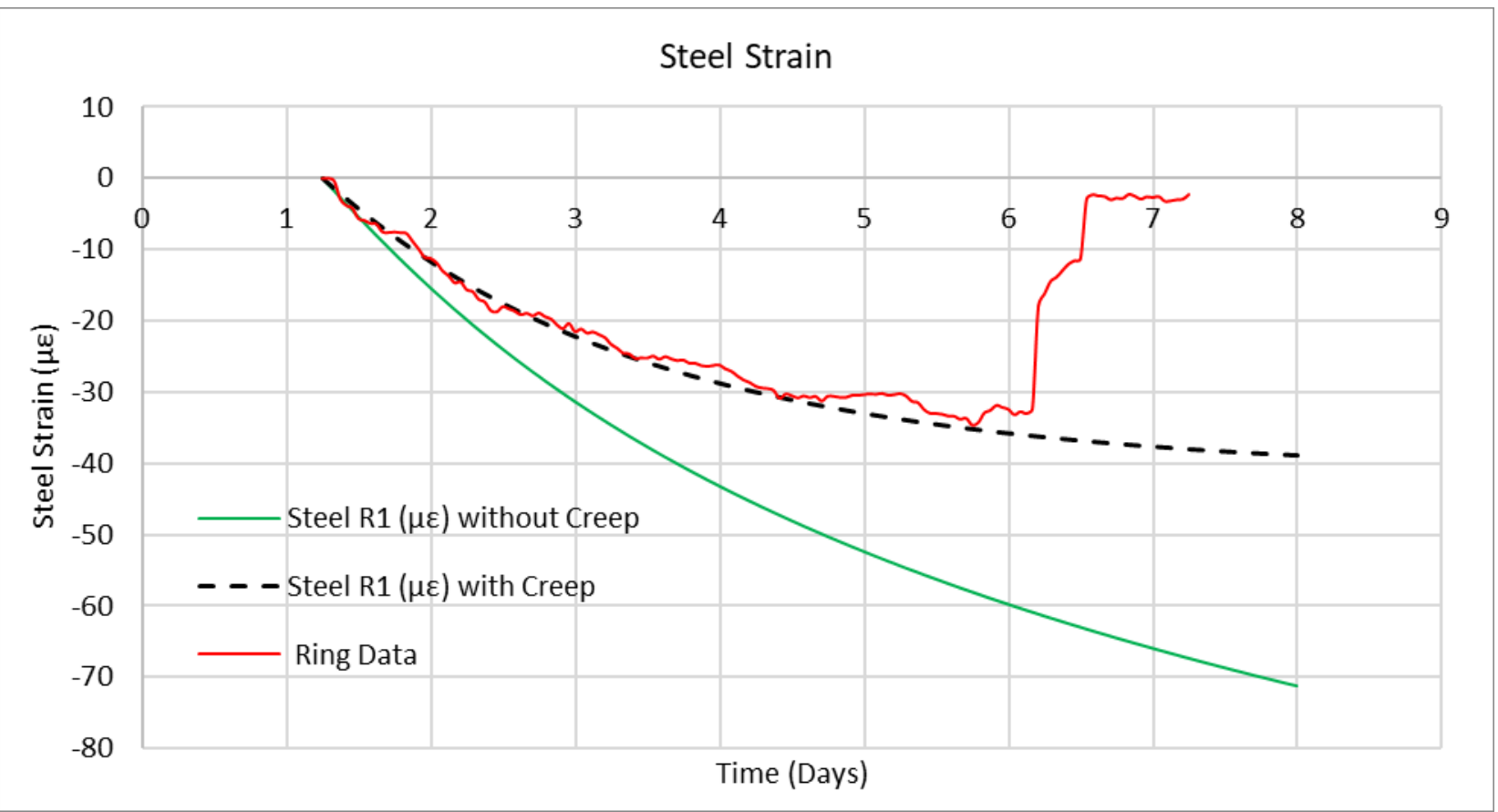

Figure 95 Comparison the strain between FEM and Ring test result OPC 2

\section{3- OPC 3}

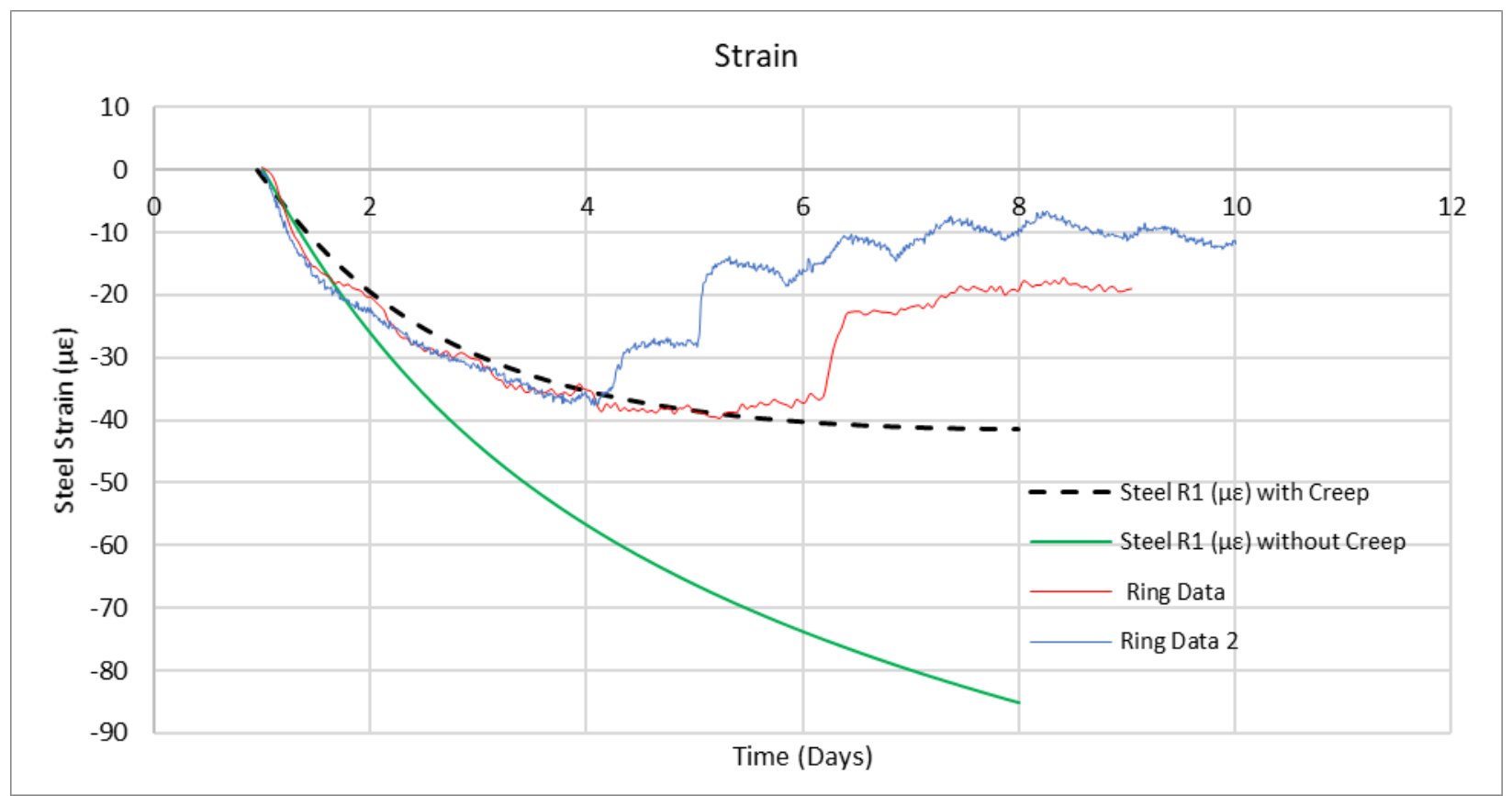

Figure 96 Comparison the strain between FEM and Ring test result OPC 3 
As shown in Figure 94, Figure 95 and Figure 96 by comparing both the experimentally measured steel strain and the strain solved by the FEM for all OPC mixes, the developed FEM can well predict the steel strain which indicates that the tensile creep parameters obtain previously are correct and have been verified.

\section{Stress Analysis}

After verifying the FEM, a stress analysis can be performed to predict the critical time when the concrete is at risk of cracking and to determine the stress distribution along the depth along the concrete ring. When these stresses exceed the allowable tensile strength of the concrete which was measured experimentally, cracks occur in the concrete.

As shown in Figure 97, Figure 98 and Figure 99 the FEM can well predict the critical time of cracking in the concrete. As the stress with the predicted creep at R3 exceed the tensile strength of the concrete the crack occurred and induced a sudden decrease in the measured steel strain.

The ring stress was calculated using the Linear Elastic Solution of the cylinder stressstrain relationship, so it is only an approximation just to locate the time of cracking.

Since the ring experiment data was collected one-day after casting, the calculated stress was still missing from the development of the stress during the first 24 hours. The advantage of using the FEM was that it allowed us to calculate the stress development starting from the casting time. As well as for the strain case. 


\section{1- OPC 1}

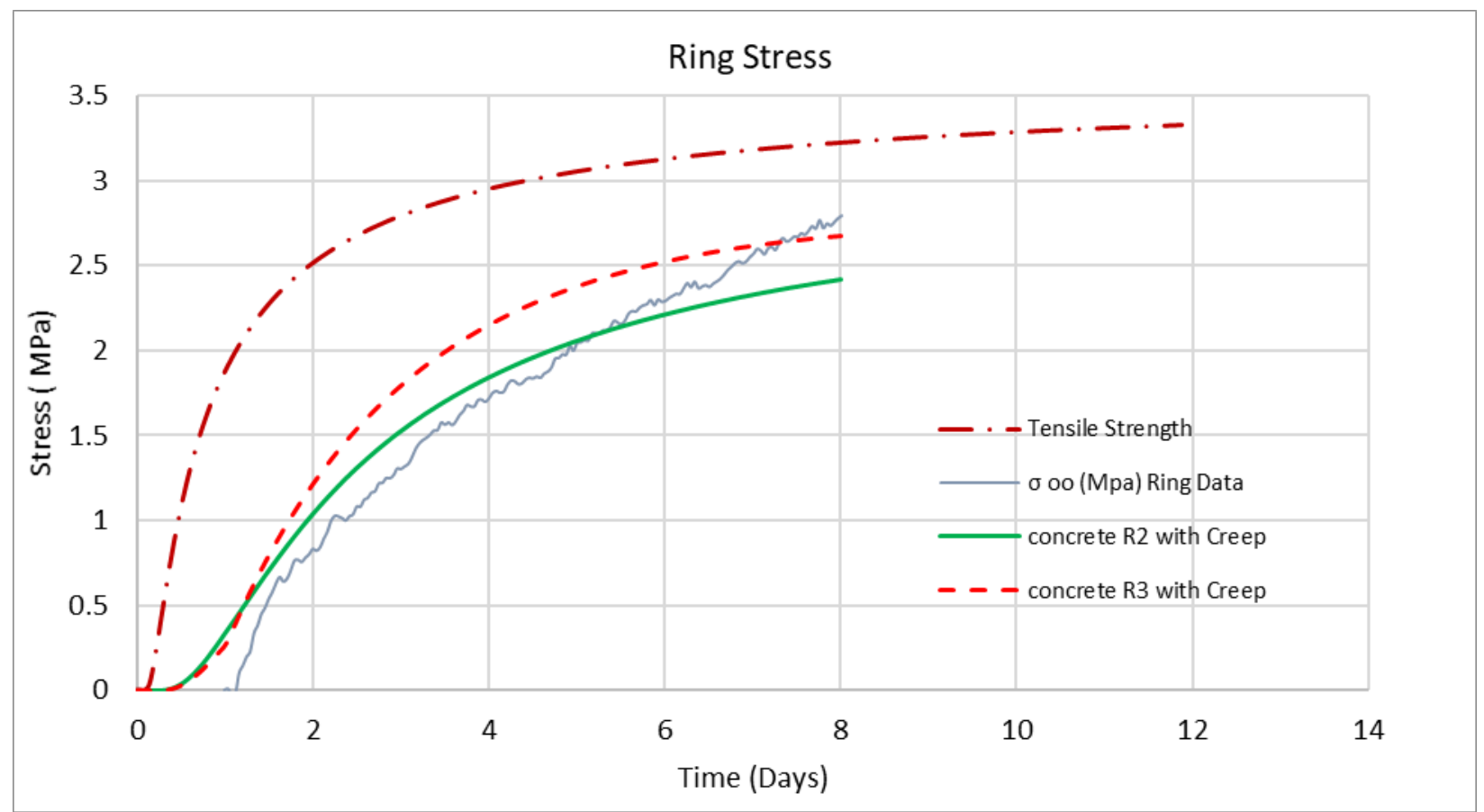

Figure 97 Comparison the stress between FEM and Tensile strength experiments result in OPC 1

\section{2- OPC 2}

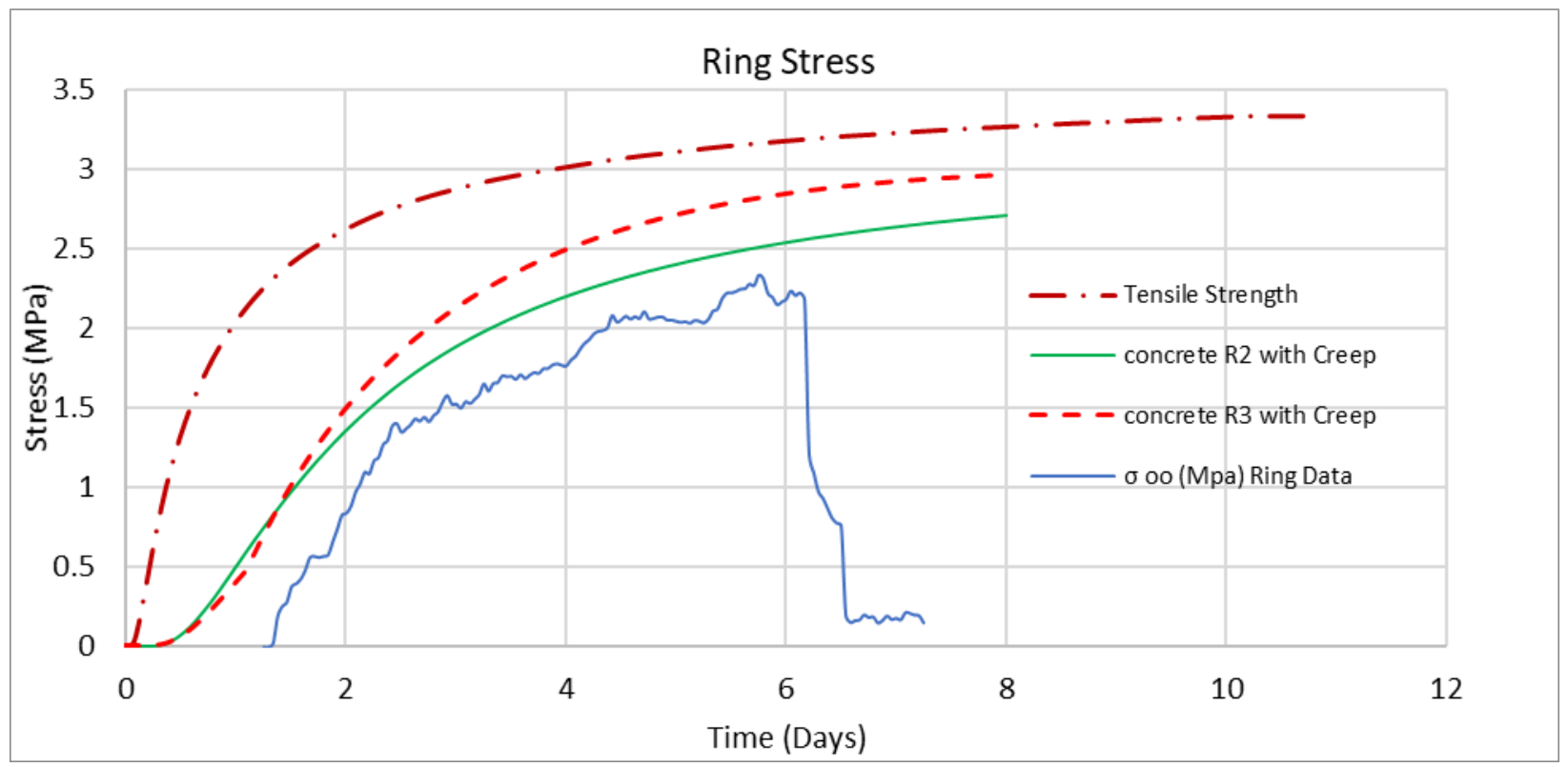

Figure 98 Comparison the stress between FEM and Tensile strength experiments result in OPC 2 


\section{3- OPC 3}

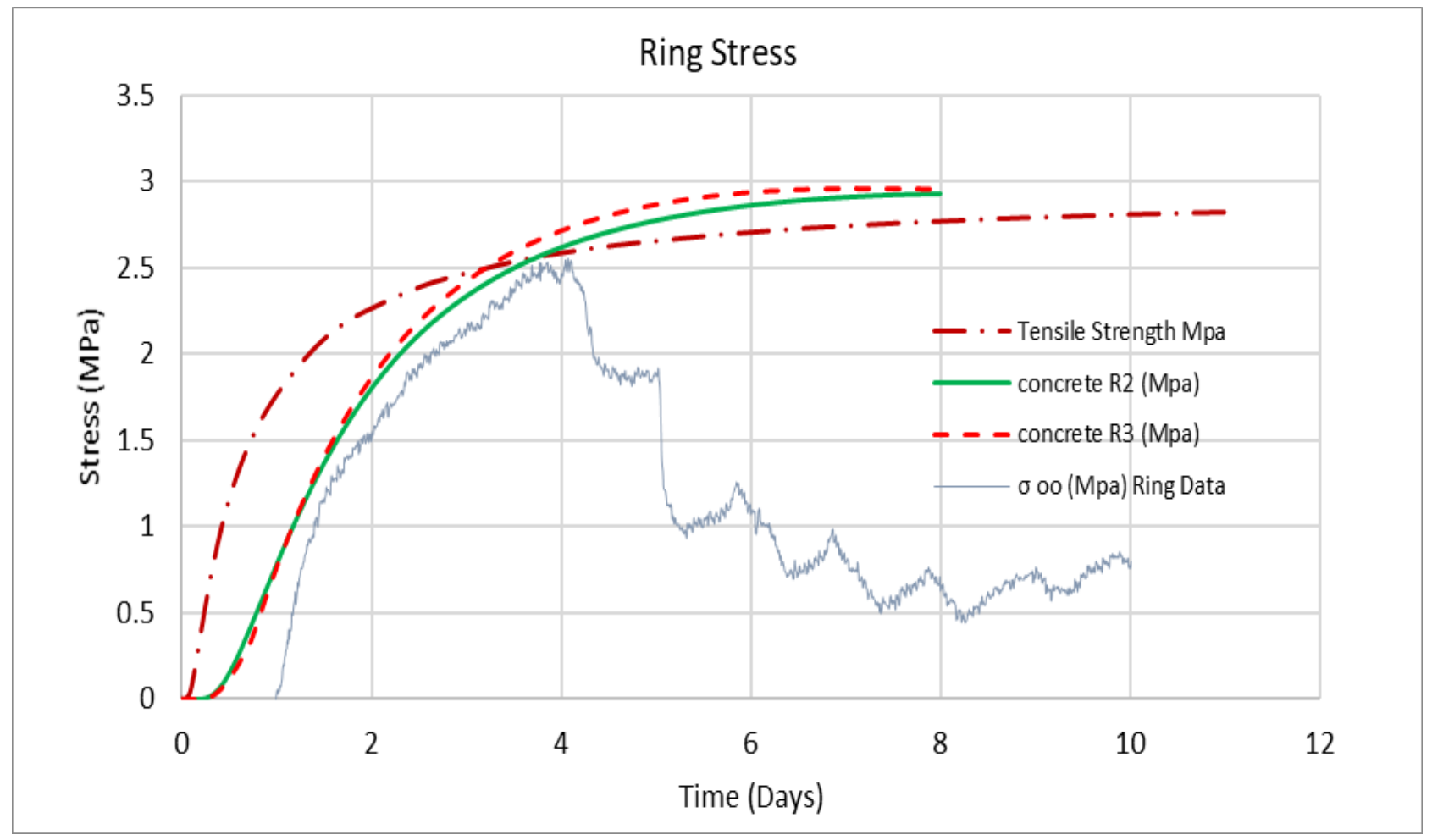

Figure 99 Comparison the stress between FEM and Tensile strength experiments result in OPC 3 


\section{B3 Model}

In order to further verify the MDBL tensile creep model, the B3 model was used to calculate the strain and compare it with the ring experiments. The B3 parameters $\mathrm{q} 1, \mathrm{q} 2, \mathrm{q} 3, \mathrm{q} 4, \mathrm{q} 5$ has been determined by curve fitting the determined creep compliance of the MDBL model as shown in figure 100. And the parameters are shown in Table 14.

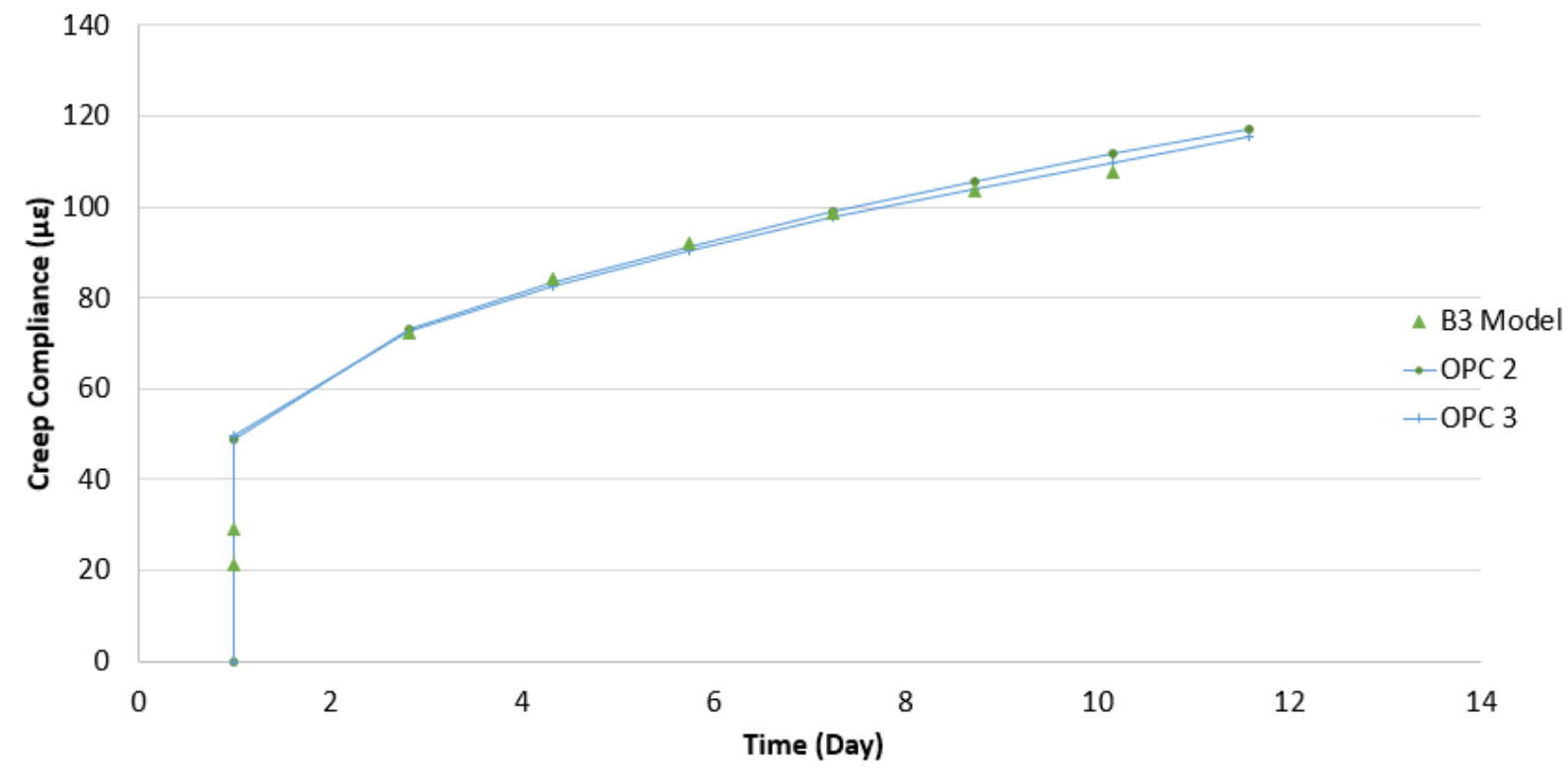

Figure 100, Fitted B3 Model using the original MDBL

\begin{tabular}{|c|c|c|c|c|}
\hline $\mathrm{q}_{1}$ & $\mathrm{q}_{2}$ & $\mathrm{q}_{3}$ & $\mathrm{q}_{4}$ & $\mathrm{q}_{5}$ \\
\hline 21.2 & 15 & 12 & 26 & 0.3 \\
\hline
\end{tabular}

Table 14 B3 model parameters

$\mathrm{q}_{1}=$ instantaneous compliance

$\mathrm{q}_{2}=$ aging viscoelastic compliance

$\mathrm{q}_{3}=$ non-aging viscoelastic compliance

$\mathrm{q}_{4}=$ flow compliance parameter 


\section{Steel Strain}

\section{1- OPC 1}

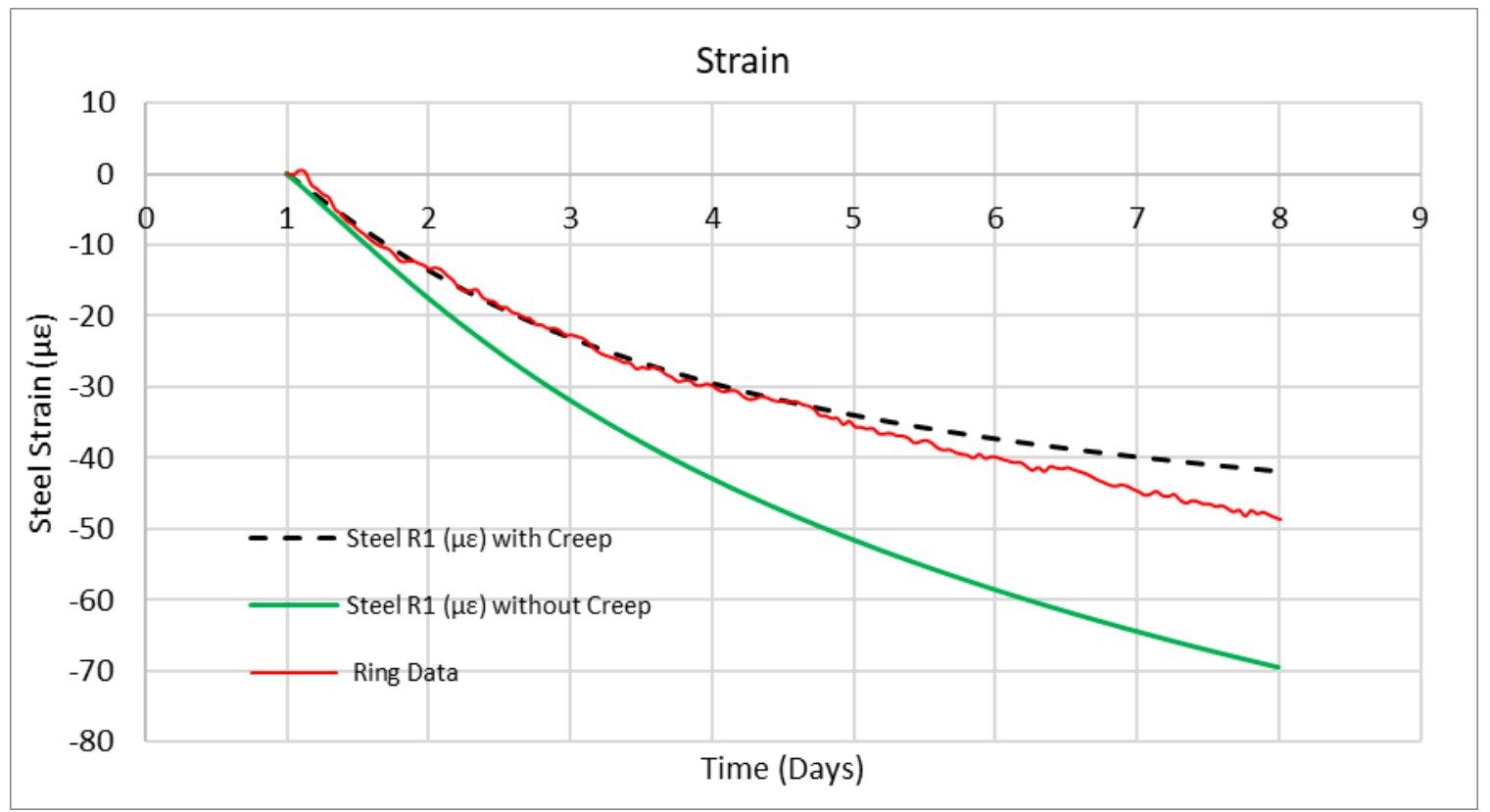

Figure 101 Comparison the strain between FEM and Ring test result OPC 1 using B3 Model

\section{2- OPC 2}

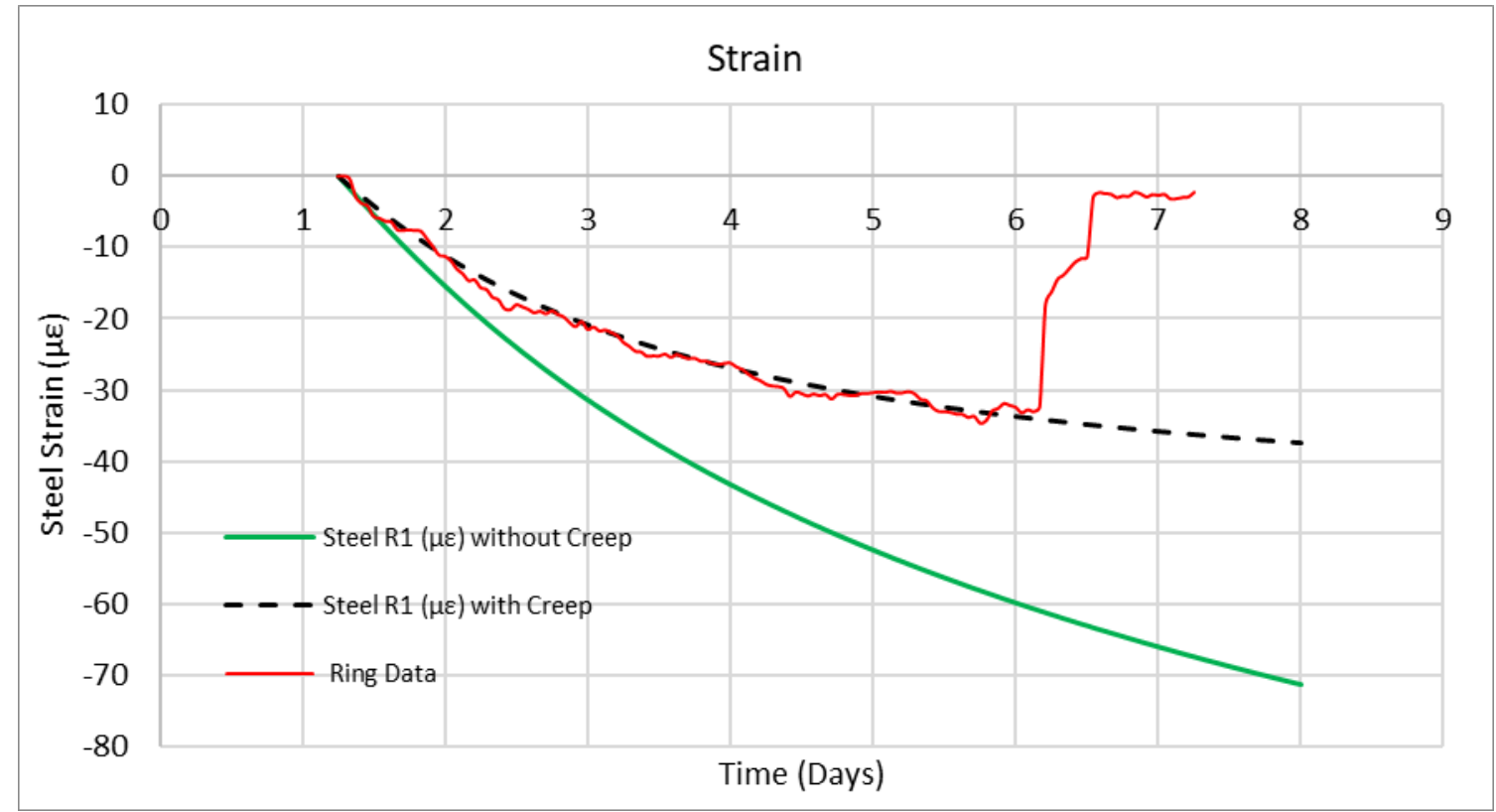

Figure 102 Comparison the strain between FEM and Ring test result OPC 2 using B3 Model 


\section{3- OPC 3}

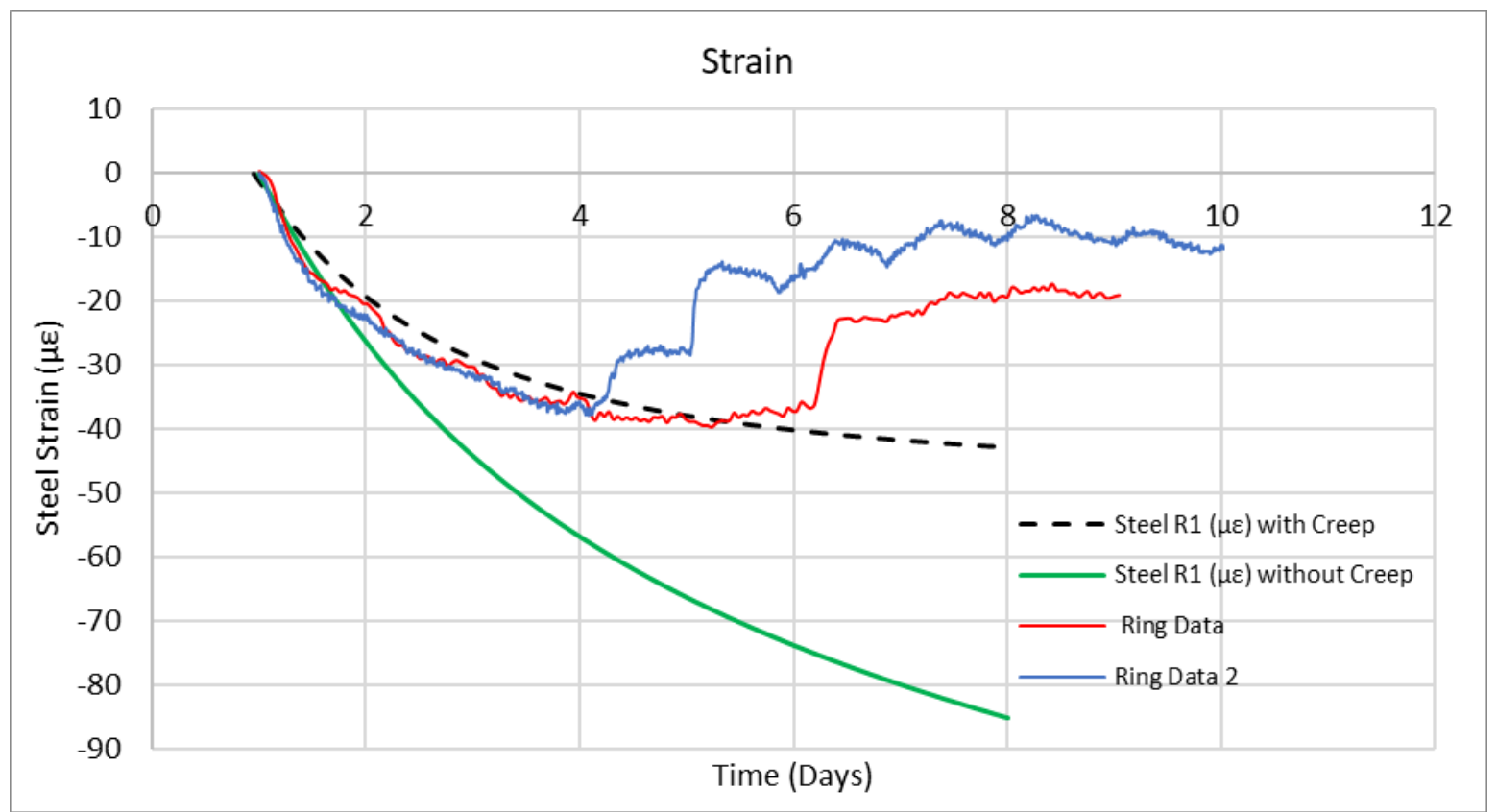

Figure 103 Comparison the strain between FEM and Ring test result OPC 3 using B3 Model

\section{Stress Analysis}

\section{1- OPC 1}

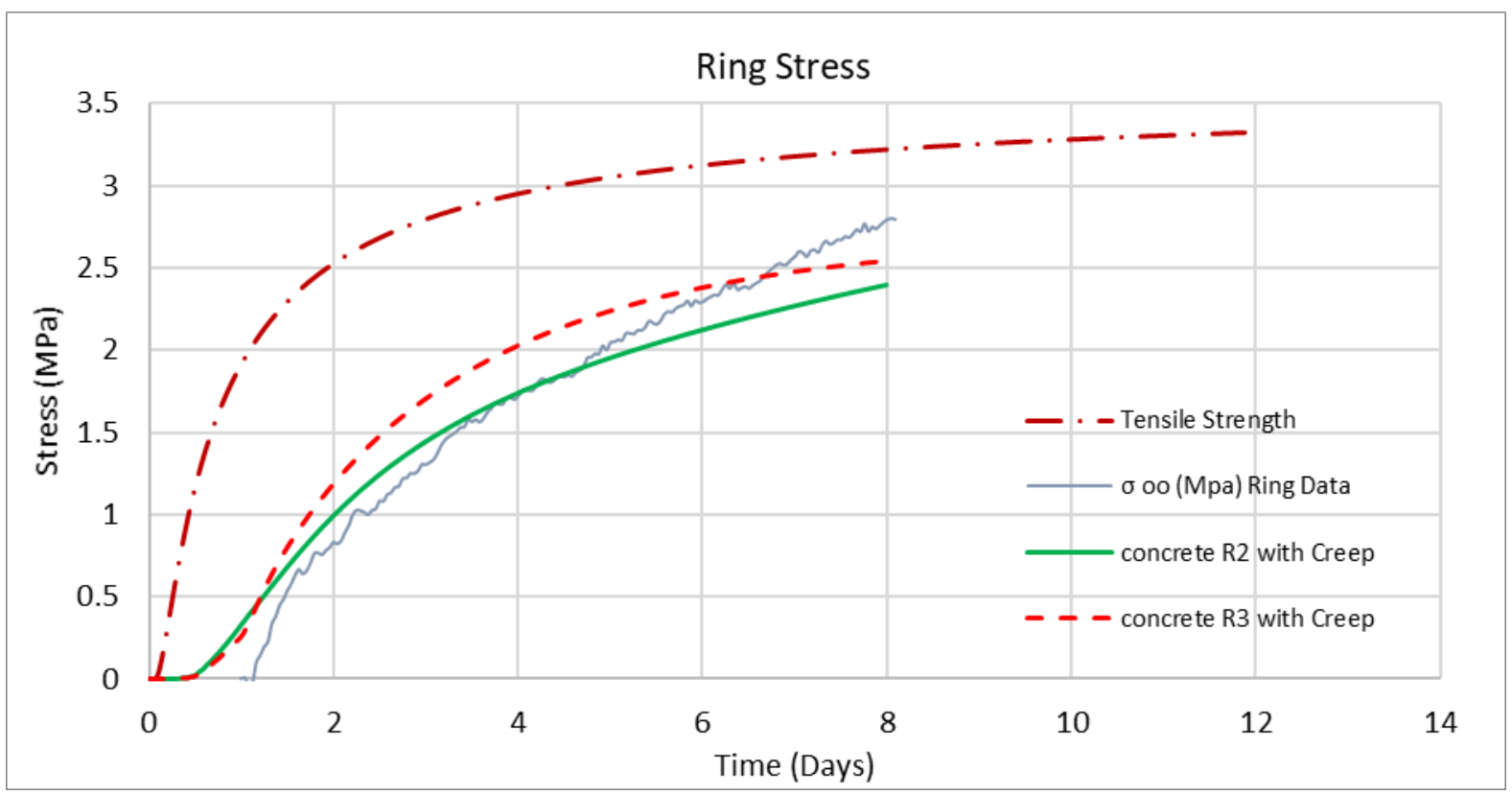

Figure 104 Comparison the stress between FEM and Tensile strength experiments result in OPC 1 using the B3 model 


\section{2- OPC 2}

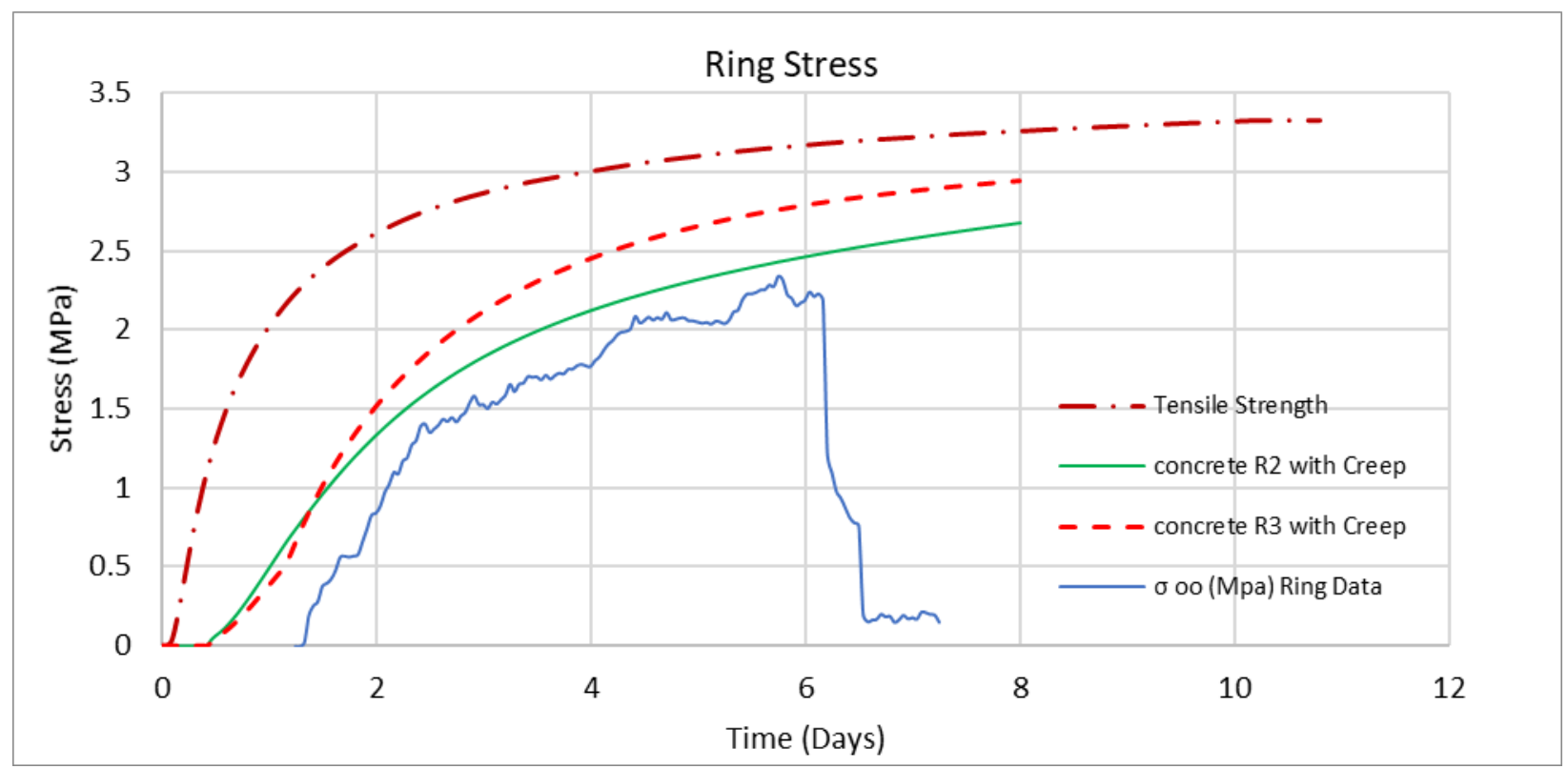

Figure 105 Comparison the stress between FEM and Tensile strength experiments result in OPC 2 using the B3 model

\section{3- OPC 3}

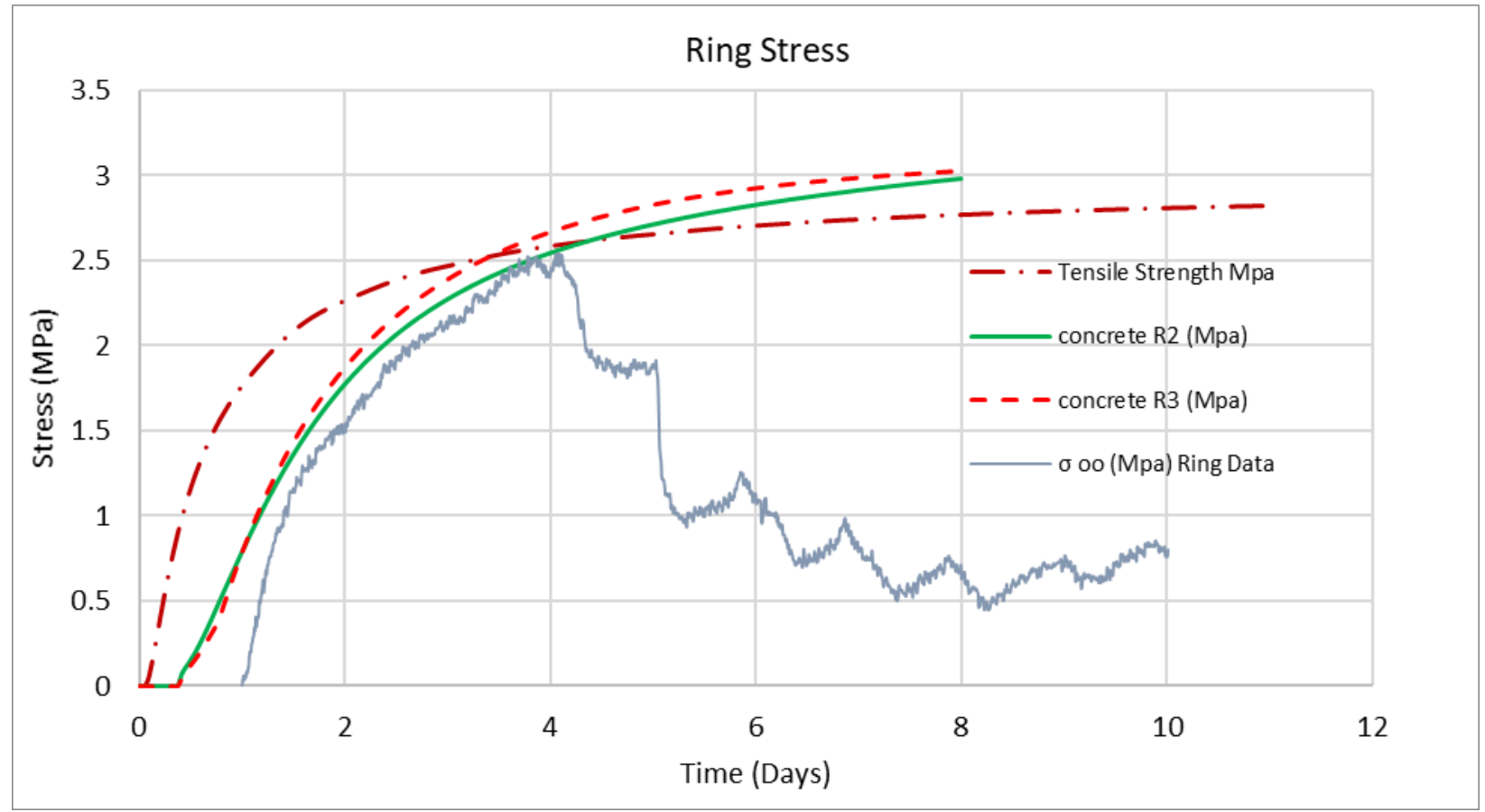

Figure 106 Comparison the stress between FEM and Tensile strength experiments result in OPC 3 using the B3 model 
Comparing both MDBL and B3 a small difference in the strain and that's due to the Userdefined subroutine, where MDBL is a stress-based model and B3 model is a strain-based model. Also, the curve fit may not be exact since each model behaves differently at later ages.

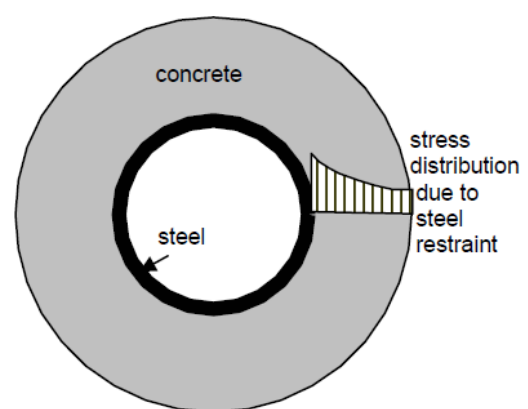

TopView

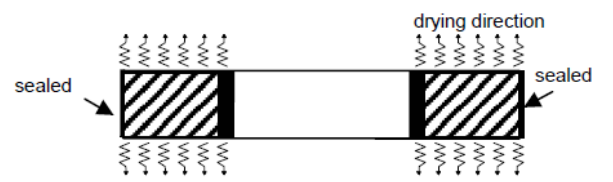

Front View

(a)

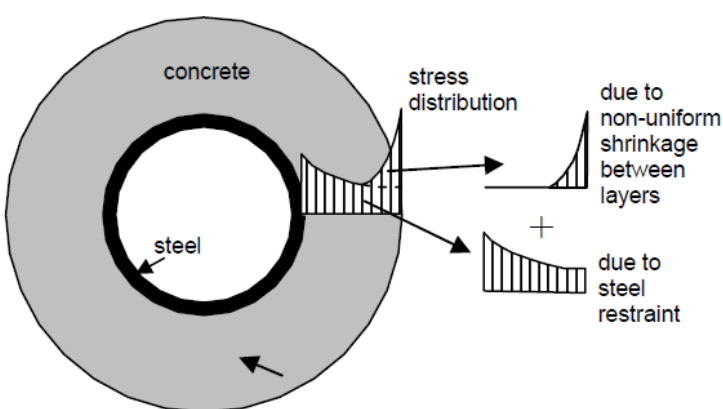

TopView

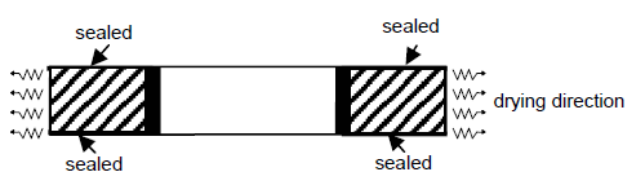

Front View

(b)

Figure 107 Stress distribution along the ring specimens Hossain, A.B.; Weiss (2006)

The non-uniform shrinkage and uniform shrinkage have a different effect on the stress development as shown in Figure 107, (a) when the concrete ring drying from the top and the bottom, the maximum stress occurs at the inner surface of the concrete ring with uniform shrinkage. On the other hand, (b) for the non-uniform shrinkage case, the maximum stress occurs at the outer surface of the concrete ring which is the drying condition of the ring in this study. This can also be verified by the FEM results in Figure 108 for OPC 2, and similarly for OPC 1 and OPC 3. 


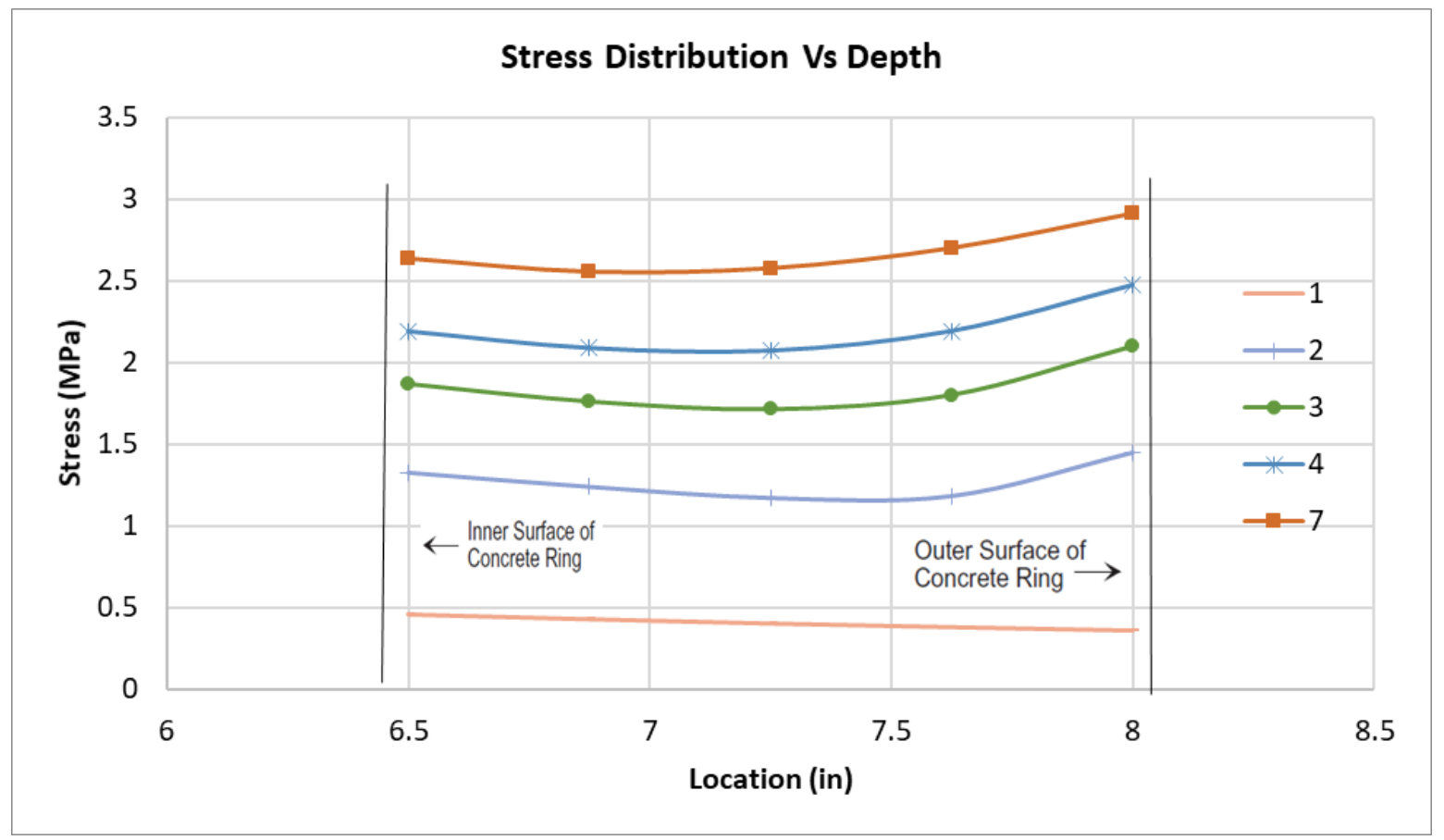

Figure 108 Stress distribution along the ring specimens OPC 2

Before the drying starts, the maximum stress occurs at the inner surface of the concrete, when the drying starts the maximum stress occurs at the inner surface of the concrete. The nonuniform shrinkage is very important in shrinkage related stress or cracking analysis.

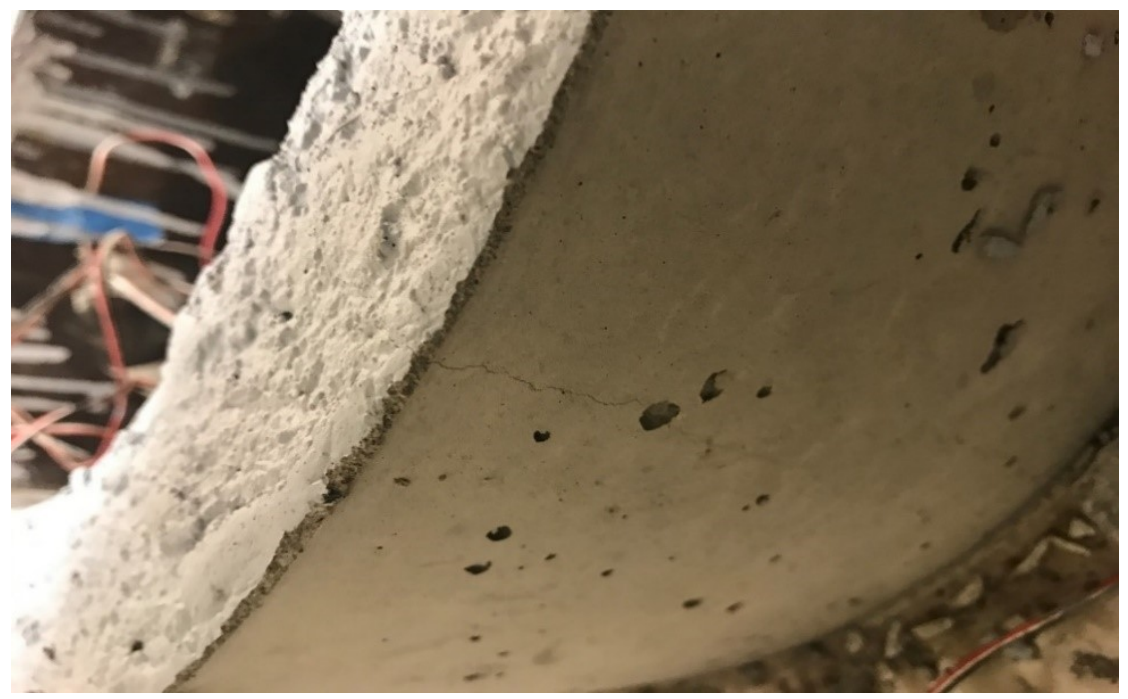

Figure 109 The location of the crack OPC 3 
As mention based on the FEM analysis, the crack of the concrete ring will be at the outer surface. We observed the crack location as shown in Figure 109, and as expected it did start at the outer surface of the concrete and then continued along the depth.

Using the stress analysis results, using the MDBL, the circumferential stress at the outer surface of the concrete ring are listed in the table below all values in (MPa) :

\begin{tabular}{|c|c|c|c|c|c|}
\hline Concrete Type & $\begin{array}{c}\text { Tensile Stress } \\
\text { at } 2 \text { days }\end{array}$ & $\begin{array}{c}\text { Tensile Stress } \\
\text { at } 8 \text { days }\end{array}$ & $\begin{array}{c}\text { Tensile Strength } \\
\text { at } 8 \text { days }\end{array}$ & Experiments & Predictions \\
\hline OPC 1 & 1.21 & 2.67 & 3.26 & No Crack & No Crack \\
\hline OPC 2 & 1.48 & 2.94 & 3.26 & Crack & No Crack \\
\hline OPC 3 & 1.86 & 2.96 & 2.77 & Crack & Crack \\
\hline
\end{tabular}

Table 15 Comparison between the predicted and the actual cracks

As shown in Table 15, the prediction of cracks was correct for both OPC 1 and OPC 3. However, for OPC 2, the prediction indicates that no crack will occur. Looking closer to OPC 2 case, first, the average ambient temperature of $\left(78^{\circ} \mathrm{F}\right)$ was used in the FEM analysis. Using the actual environmental temperature indicates that slightly higher circumferential stresses induced in the concrete ring but still no cracks are yet to happen. In the FEM analysis the Ring thickness is exactly 1.5 in, but in the actual ring experiment, the thickness of the ring might not be exactly 1.5 in at the crack location.

If the critical zone of cracking defined as (+/- $0.25 \mathrm{MPa})$ of the tensile strength of concrete, then the circumferential stress results indicates that OPC 2 reach the critical zone and the crack of the concrete ring is expected. the circumferential stress using actual environment temperature is shown in Figure 110: 


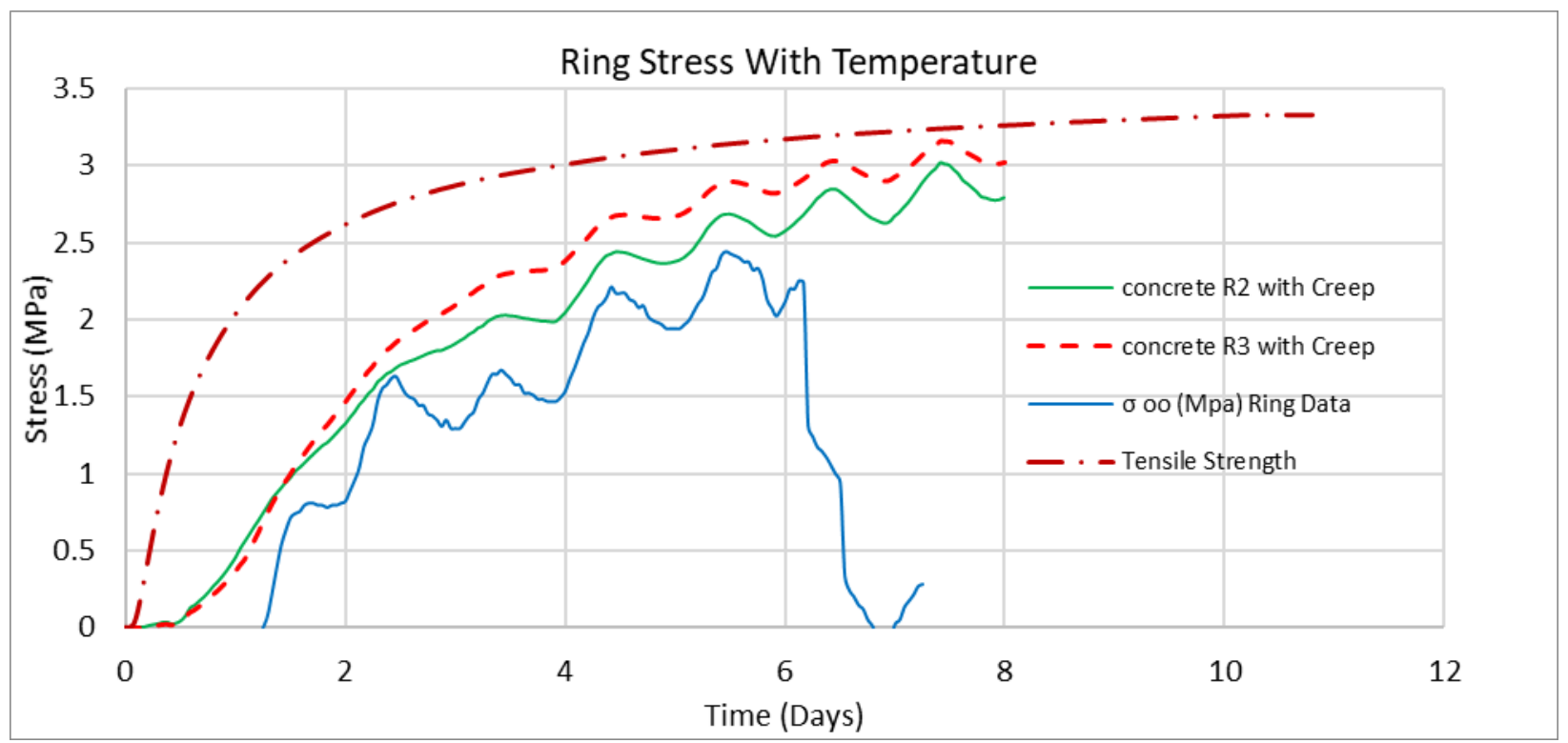

Figure 110 Comparison the stress between FEM and Tensile strength experiments result OPC 2 considering the actual environment temperature 


\section{Summary of Procedures}

A summary of the procedures is presented as a flow chart showing the steps in this research from the begging all the way to the end.

1. The first step starts with the concrete casting by choosing a concrete mix design.

2. Important Tests: Restrained Shrinkage Ring Test, and Shrinkage experiments ( Half-wrapped ), and other tests to find the mechanical properties of the concrete such as Hydration Degree, the Elastic Modulus, and Tensile Strength.

3. Next step is to find the moisture distribution inside the concrete. Theoretically and experimentally based on the proposed models.

4. From both the Shrinkage experiments and humidity analysis the shrinkage factor of concrete can be determined.

5. Calculate the interfacial compressive stress generated on the steel ring using the strain gauges measured during the restrained shrinkage ring testing

6. Calculating the theoretical value of the interfacial compressive stress generated on the steel ring by a giving model without considering the creep.

7. Find the tensile creep parameters by minimizing the difference between the theoretical value considering the creep, and the calculated value of the interfacial compressive stress from the ring Test. (Mat-Lab code recommended)

8. Verify the predicted tensile creep comparing it with a direct tensile creep test (Dog-Bone).

9. FEM can be used to verify the predicted tensile creep and stress analysis can be performed to predict the critical time when the concrete is at risk of cracking. 


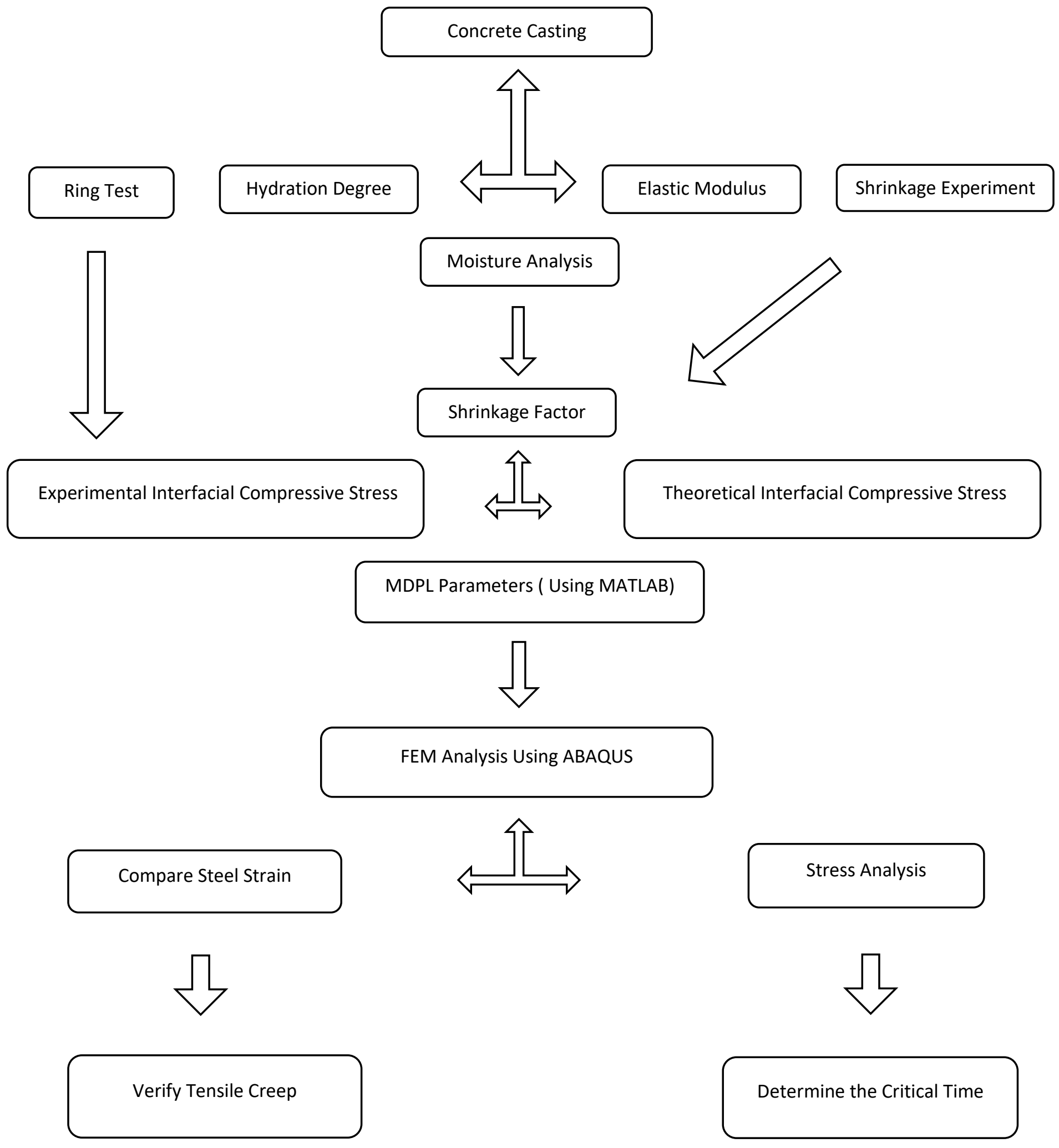

Figure 111 Summary of the procedures 


\section{Chapter 5 Conclusions and Recommendations}

Restrained shrinkage ring test is used to determine the tensile creep of the concrete at early-age. The concrete-steel interfacial compressive stress caused by the shrinkage of concrete is obtained through the Ring test. On the other hand, the theoretical value of the interfacial compressive stress at a given age is calculated by linear elastic analysis. The modified double power law (MDBL) was used to simulate the viscoelastic performance of concrete under tension. By minimizing the difference between the calculated and the tested interfacial compressive stress, the parameters for the tensile creep model for the concrete mix were generated.

Finite Element Model (FEM) simulation was performed using ABAQUS as a new method in order to analyze the shrinkage and creep behavior in the concrete under the Restrained Shrinkage Ring Test. The calculated humidity was used as an input in the FEM to calculate the shrinkage in concrete for a 5-layer concrete ring model through a user-defined subroutine. Concrete tensile creep was also calculated from the subroutine using the shrinkage induced stress. The predicted creep behavior was verified successfully by comparing the steel strain obtained from the experiment with what was solved using FEM. Furthermore, a stress analysis was performed to predict the critical time when the concrete is at risk of cracking in the concrete ring. It is noted that the current FEM model assumes a creep model that is linear to the applied stresses. The nonlinear creep behavior due to high stress/strength ratio is not considered in the current model. Poisson's ratio and coefficient of thermal expansion (CTE) of concrete were assumed constants, 0.2 and 4.73 micro-strains per ${ }^{\circ} \mathrm{F}$, respectively.

Using the restrained shrinkage ring test, creep relaxation parameters were obtained for the same mix concrete under different environment temperatures and humidity, thus, can be used 
to predict the concrete behavior under variable ambient environment. In this research, the temperatures range was between $\left(70-95^{\circ} \mathrm{F}\right)$ and the ambient relative humidity was between (30-80\%). The validation of this method under freezing temperature was not studied, further investigation to be done in the future.

The developed method in this research can also be used for the development of tensile creep models for concrete with other mix design and used for creep analysis of concrete at earlyage. The determined tensile creep, as a result, can be a useful tool in the prediction of shrinkage induced stress, and further, be used for cracking control of concrete structures at early age.

A relationship between both 4" x 8" and 6" x 12" cylinders was established. One of the benefits of this relationship can be saving materials and providing more specimens for "In Lab" casting because the drum mixer, which is only $3 \mathrm{ft}^{3}$, offers a limited volume. Using 4 ' ' $\mathrm{x} 8$ ', for both compressive and tensile strength is much more efficient.

For compressive strength

$$
f c{ }^{\prime}\left(6{ }^{\prime \prime} \times 12^{\prime \prime}\right)=0.921 \times f c{ }^{\prime}\left(4{ }^{\prime \prime} \times 8^{\prime \prime}\right) \quad E q .73
$$

For tensile strength

$$
f t\left(6^{\prime \prime} x 12^{\prime \prime}\right)=0.9421 \times f t\left(4{ }^{\prime \prime} x 8^{\prime \prime}\right) . \quad E q .74
$$

The developed equations above can only be used for similar OPC mixes with water/cement ratio of 0.49 , and the accuracy of the above equations is $99.4 \%$ for the compressive strength and $98.8 \%$ for the tensile strength of concrete.

The increase in air content can affect and decrease all the proportions of concrete by variable values. As previously seen, a relationship between the compressive strength and the air 
content was established. The higher the air content in the concrete the lower the compressive strength. However, the result shows that the increase of the air content by $1.1 \%$ can produce up to $10 \%$ reduction in the compressive strength, but these results don't agree with the literature and other research projects. The $10 \%$ reduction can be a result of many other factors- not only the air content itself.

Based on the literature the average reduction due to $1 \%$ air is only about $150-200$ psi. More research is needed, and more experimental data needs to be collected before setting a model to predict the effects of the air content. 


\section{Recommendations for Future Study}

For this research study, only three OPC concrete mixes were tested. Additional concrete mixes, such as replacing part of the cement with slag or fly-ash, where adding them can change concrete behaviors such as heat, degree of hydration, strength, and shrinkage, should be studied to acquire more accurate results and to validate the use of this method to determine the tensile creep for any kind of concrete.

During this study, the average environment humidity was used to find the moisture distribution inside the concrete. The actual and the change of environment humidity effects can be further studied to improve the existing model.

Additionally, the modified double power law MDBL was used. However, by using different creep models such as B3 and B4 and following the same procedure in this research, can be applied to verify the results to find the best model.

Additionally, during this study, only one type of ring was used with a thickness of 1.5 in, different concrete thicknesses can be used in order to find the effect of the ring thickness on the concrete behavior.

Also, fully-wrapped rings can be used to find the tensile creep of the concrete where only the autogenous shrinkage occurred; in that case, the shrinkage would only be due the selfdesiccation, and chemical shrinkage. 


\section{References}

1- Zhang ZB, Zhang J. Experimental study on the relationship between shrinkage strain and environmental humidity of concrete. J Build Mater 2006;6(6):720-3 (in Chinese).

2- Bissonnette B, Pierre P, Pigeon M. Influence of key parameters on drying shrinkage of cementitious materials. Cem Concr Res 1999;29(10):1655-62.

3- Baroghel-Bouny V, Mainguy M, Lassabatere T, Coussy O. Characterization and identification of equilibrium and transfer moisture properties for ordinary and highperformance cementitious materials. Cem Concr Res 1999;29(8): 1225-38.

4- Ayano T, Wittmann FH. Drying, moisture distribution, and shrinkage of cement-based materials. Mater Struct 2002;35(247):134-40.

5- Lee NP. 2007. 'Creep and Shrinkage of Inorganic Polymer Concrete'. BRANZ Study Report SR 175. BRANZ Ltd, Judgeford, New Zealand

6- Zhang J, Hou D, Han Y. Micromechanical modeling on autogenous and drying shrinkages of concrete. Constr Build Mater 2012;29(3):230-40.

7- Zhang J, Hou DW, Sun W. Experimental study on the relationship between shrinkage and interior humidity of concrete at early age. Mag Concr Res 2010;62(3):191-9.

8- Bazant, Z.P.; Najjar, L.J. Nonlinear water diffusion in nonsaturated concrete. Materials and Structures 1972, 5(25), 3-20.

9- Zhang, J.; Qi, K.; Huang, Y. Calculation of moisture distribution in early-age concrete. ASCE Journal of Engineering Mechanics 2009, 135(8), 871-880.

10- Bazant ZP, Panula L. Practical prediction of time-dependent deformation of concrete: II Basic creep. Mater Struct 1978;11(65):317-28. 
11- Powers TC, Brownyard TL. Studies of the physical properties of hardened Portland cement paste (nine parts). J Am Concr Inst October 1946-April 1947: 43, Bulletin 22, Research Laboratories of the Portland Cement Association, Chicago, 1948.

12- Jensen OM, Hansen PF. Water-entrained cement-based materials: I. Principles and theoretical background. Cem Concr Res 2001;31(5):647-54.

13-Zhu BF. Thermal stress and temperature control in mass concrete. Beijing: China Electric Power Publishing House; 1999 [in Chinese].

14- J. J. BROOKS, Influence of mix proportions, plasticizers and superplasticizers on creep and drying shrinkage of concrete, Mag. Concr. Res. 41, No. 148, pp. 145-54 (1989).

15- ASTM C403 / C403M-16, Standard Test Method for Time of Setting of Concrete Mixtures by Penetration Resistance, ASTM International, West Conshohocken, PA, 2016

16- ASTM C1581 / C1581M-16, Standard Test Method for Determining Age at Cracking and Induced Tensile Stress Characteristics of Mortar and Concrete under Restrained Shrinkage, ASTM International, West Conshohocken, PA, 2016

17- Neville, Adam M. Properties of concrete / A.M. Neville. -- 5th ed. 2011

18- Vandewalle L. Concrete creep and shrinkage at cyclic ambient conditions. Cem Concr Compos 2000;22(3):201-8.

19- Faria R, Azenha M, Figueiras JA. Modeling of concrete at early ages: application to an externally restrained slab. Cem Concr Compos 2006;28(6):572-85.

20-Garas Victor Y, Kahn Lawrence F, Kurtis Kimberly E. Short-term tensile creep and shrinkage of ultra-high-performance concrete. Cem Concr Compos 2009;31(3):147-52. 
21- Atrushi DS. Tensile and compressive creep of early age concrete: testing and modeling. Doctoral thesis. The Norwegian University of Science and Technology, Trondheim, Norway; 2003.

22- HIPERPAVIII: Moisture Transport and Sensitivity Analysis Enhancements. Qinwu Xu, J. Mauricio Ruiz, George K. Chang, Robert O. Rasmussen, and Dan K. Rozycki

23- Bentur A, Kovler K. Evaluation of early age cracking characteristics in cementitious systems. Mater Struct 2003;36(3):183-90.

24- Shah HR, Weiss J. Quantifying shrinkage cracking in fiber reinforced concrete using the ring test. Mater Struct 2006;39(9):887-99.

25- Bissonnette B. Tensile creep at early ages of ordinary, silica fume and fiber reinforced concretes. Cem Concr Res 1995;25(5):1075-85.

26- Kovler K, Igarashi S, Bentur A. Tensile creep behavior of high strength concretes at early ages. Mater Struct 1999;32(5):383-7.

27- Altoubat SA, Lange DA. Creep, shrinkage, and cracking of early age concrete. ACI Mater J 2001;98(4):323-31.

28- Atrushi DS. Tensile and compressive creep of early age concrete: testing and modeling. Doctoral thesis. The Norwegian University of Science and Technology, Trondheim, Norway; 2003.

29- Darquennes A, Staquet S, Delplancke-Ogletree M-P, Espion B. Effect of autogenous deformation on the cracking risk of slag cement concrete. Cem Concr Compos 2011;33(3):368-79.

30- Grzybowski M, Shah SP. Shrinkage cracking of fiber reinforced concrete. ACI Mater J 1990;87(2):138-48. 
31-Kjellsen K, Detwiler RJ. Later-age strength prediction by a modified maturity model. ACI Mater J 1993(May-June):220-7.

32-Chanvillard G, Daloia L. Concrete strength estimation at early age: modification of the method of equivalent age. ACI Mater J 1997;94(6):220-7.

33- Kim JK. Estimation of compressive strength by a new apparent activation energy function. Cem Concr Res 2001;31(2):217-25.

34- Pane I, Hansen W. Concrete hydration and mechanical properties under nonisothermal conditions. ACI Mater J 2002;99(6):534-42.

35- Akita H, Fujiwara T, Ozaka Y. A practical procedure for the analysis of moisture transfer within concrete due to drying. Mag Concr Res 1997;49(179):129-37.

36- Zhang J, Hou D, Gao Y, Sun W. Determination of moisture diffusion coefficient 37- of concrete at early-age from interior humidity measurements. Drying Technol 38-2011;29(6):689-96.

39- Lam, Jian-Ping, "Evaluation of concrete shrinkage and creep prediction models" (2002). Master's Theses. 2286. 